\title{
Natural Products Studies of
}

\author{
Marine Organisms
}

\section{of the South Pacific}

by

Bryan John Northover
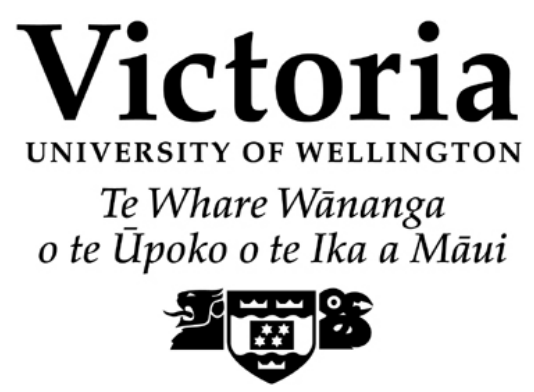

A thesis

submitted to Victoria University of Wellington

in fulfilment of the

requirements for the degree of

Master of Science

in Chemistry.

Victoria University of Wellington

2012 


\begin{abstract}
This thesis describes the NMR-guided isolation and structural elucidation of one novel and several known compounds from marine organisms collected from Tonga and New Zealand. In the process of this work, 11 Tongan algal specimens were subjected to preliminary NMR-guided investigation, as the study of Tongan marine algae is poorly represented. The HMBC spectra of crude fractions generated by the first chromatographic purification of the crude extracts were analysed for perceived structural novelty, providing three specimens that warranted further investigation.

Investigation of unknown algae PTN4_17G afforded substructure 76, observed in the known compound avrainvilloside, which included the rare 6-deoxy-6-aminoglucose moiety. This aminoglucose moiety has been reported from marine sources only twice in literature, both in algae specimens. An investigation of unknown brown algae PTN4_18E afforded substructure 83, a methacrylic acid containing moiety. Methacrylic acid moieties are also uncommon in marine organisms, with 27 reported structures containing the moiety, of which only two occur from algae. In each case suitable, mass spectrometry data was not obtainable therefore full structural elucidation of the compounds was not achieved. Further analysis of the unknown algae PTN3_38C afforded the known compound fistularin-3 86, although further studies revealed that a sponge contaminant was responsible for the presence of the compound. The results of this algae study provided interesting correlations between secondary metabolite concentrations of algae in temperate and sub-tropical environments, contrary to the observed correlations of marine sponges.
\end{abstract}

An investigation into an unknown New Zealand Raspailia sponge was conducted as previous studies had suggested the presence of novel resonances. Further analysis of the specimen yielded the known clerodane raspailodane A 126 and the unexpected novel steroidal glycoside raspailoside A 135 . Biological activity studies conducted on raspailoside $A$ showed inactivity towards the mammalian cell line HL-60 and Saccharomyces cerevisiae assays. 


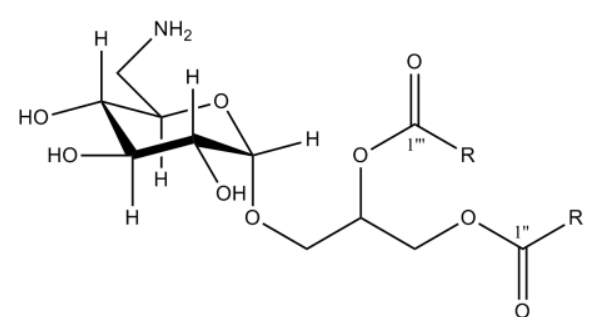

76<smiles>CCC(O)CNC(=O)C1=NO[C@]2(C=C(Br)C(OC)=C(Br)[C@@H]2O)C1</smiles>

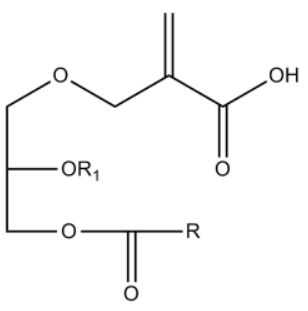

$83 \mathrm{R}=\mathrm{R}_{1}=$ unknown

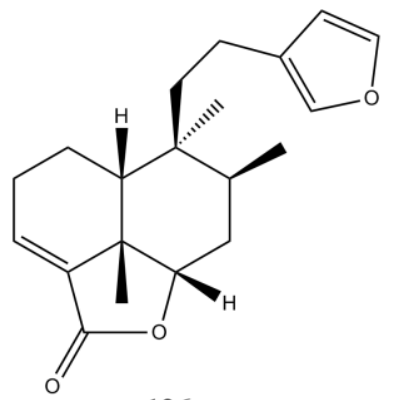

126

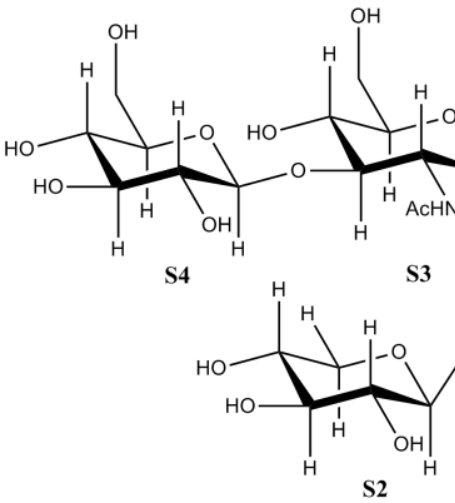




\section{Acknowledgements}

Throughout not only my master's study, but my undergraduate studies, I have been lucky to meet some great people in the School of Chemical and Physical Sciences at VUW and I would like to thank everyone for making SCPS an enjoyable place to be.

I would like to thank my supervisor Dr Peter Northcote and the members of the marine and aqua-vino natural product research groups that I worked with for all their help and guidance during my postgraduate studies. I would also like to thank Martin, Joe, Thomas, Cole and the rest of my fellow classmates during postgraduate study for all the help and good times we have had.

Finally I would like to thank my family for all the support they have given me while undertaking my university studies. 


\section{Table of Contents}

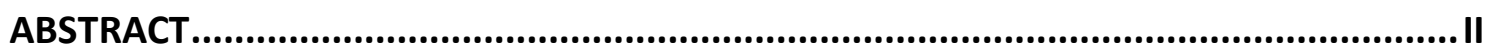

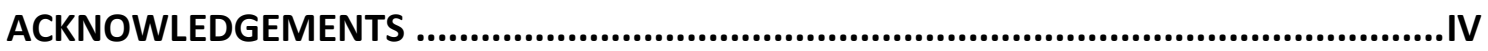

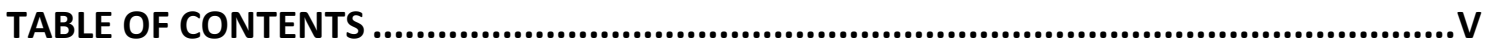

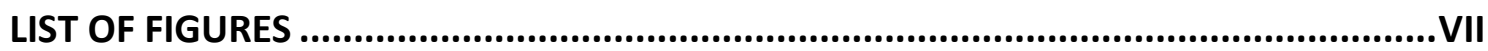

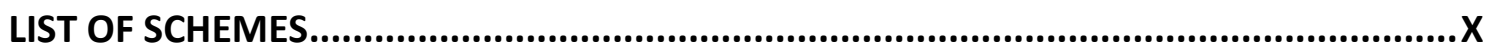

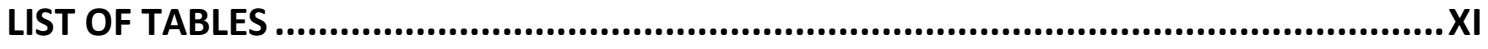

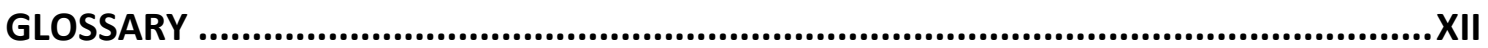

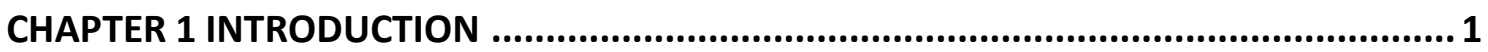

1.1. The Role of Natural Products in Traditional Medicine ......................................... 1

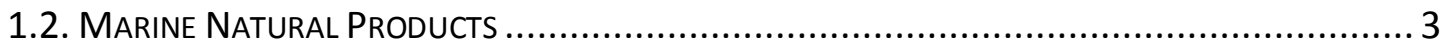

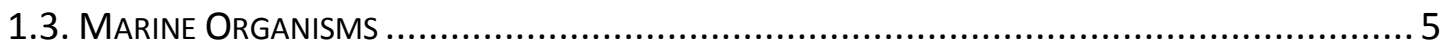

1.4. The New Zealand Marine ECo-Region.................................................................. 5

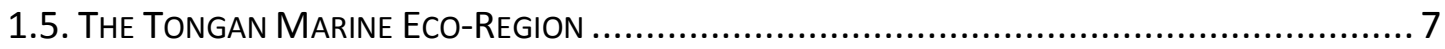

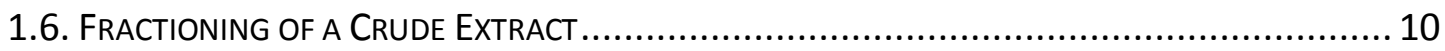

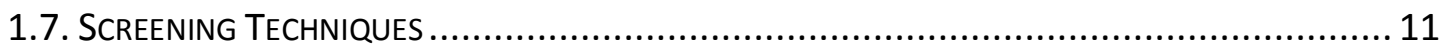

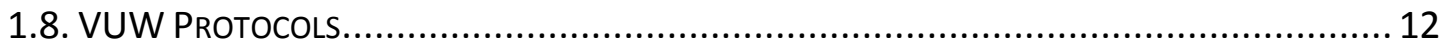

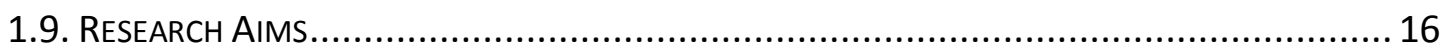

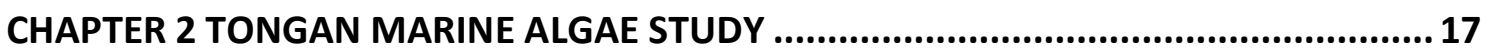

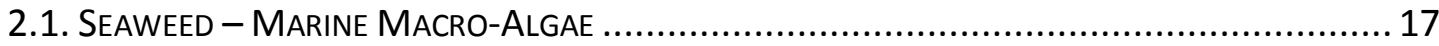

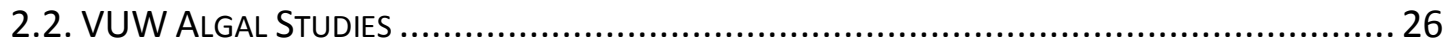

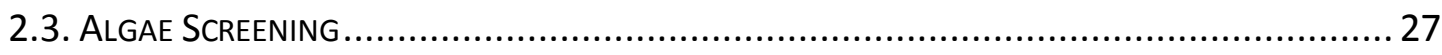

2.4. THE COMMON GLYCEROGLYCOLIPID - PTN4_17G............................................... 28

2.5. THE METHACRYLIC ACID MOIETY - PTN4_18E .................................................. 33

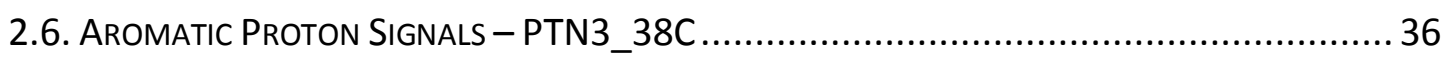

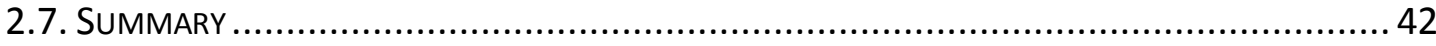

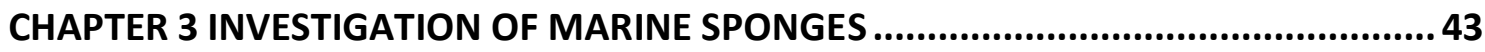

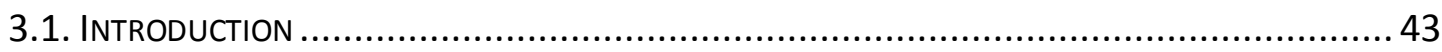

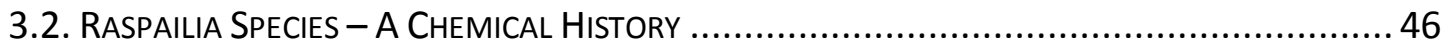


3.3. PTN2_45D 52

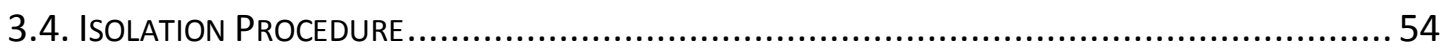

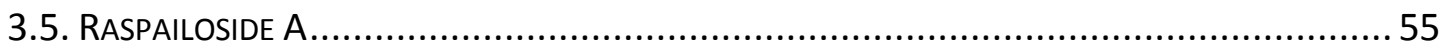

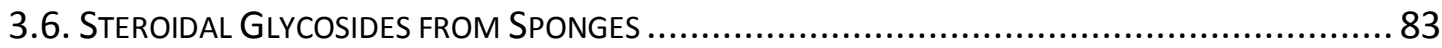

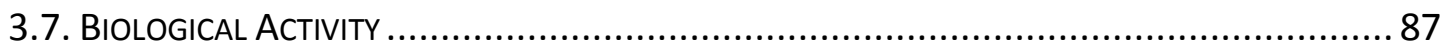

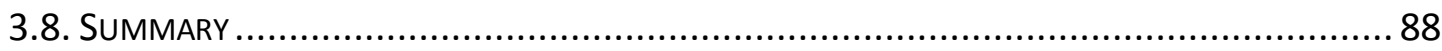

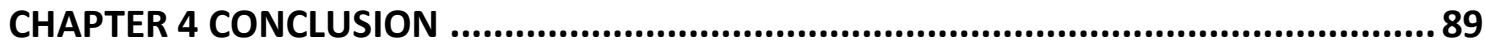

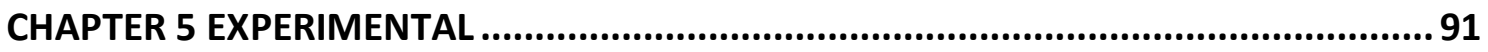

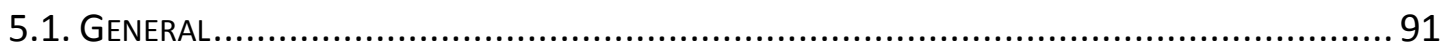

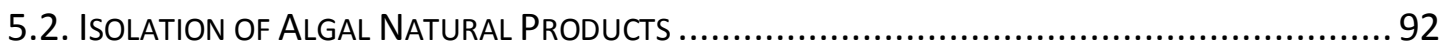

5.3. ISOLATION OF NATURAL PRODUCTS FROM RASPAILIA SP........................................... 95

APPENDIX A SPONGE SCREENING AND CYCLIC LOADING PROTOCOL ................99

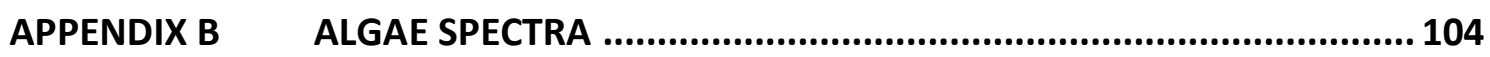

APPENDIX C NMR SPECTRA OF RASPAILOSIDE A (135) ................................... 120

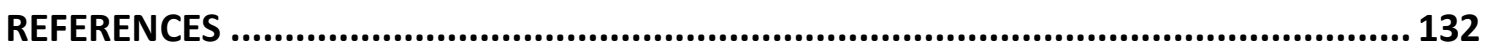




\section{List of Figures}

Figure 1.1 Map of NeW ZeALAND highlighting the EEZ boundary (oUtLined In BLACK). IMAGE COURTESY OF LAND INFORMATION NEW ZEALAND (LINZ). ${ }^{23}$ 6

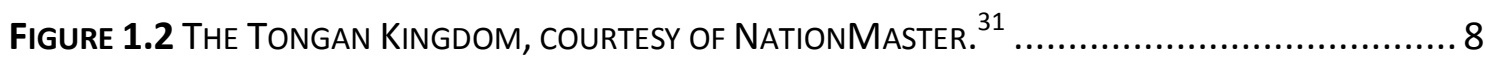

Figure 1.3 Diagram of THE MASS DISTRIBUTION OF A TYPICAL NEW ZEALAND MARINE ORGANISM EXTRACT OFF A REVERSED-PHASE SUPPORT. 10

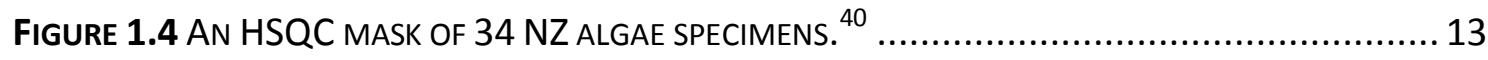

Figure 1.5 Common CORRELATIONS SEEN IN THE NZ ALGAL HSQC MASK. ${ }^{40}$............................. 14

Figure 2.1 A SELECTION OF BROWN, RED AND GREEN MARINE ALGAE AT LOW TIDE. ....................... 18

FIGURE 2.2 COSY CORRELATIONS ESTABLISHING A CARBON CHAIN CONSISTENT WITH A SUGAR MOIETY.29

FIGURE 2.3 COSY AND HMBC CORRELATIONS ESTABLISHING GLYCEROL FUNCTIONALITY ATTACHED AT C$1 '$ '....... 30

Figure 2.4 THE RELATIVE STEREOCHEMISTRY OF THE AMINOSUGAR MOIETY OF 76 DETERMINED BY COUPLING CONSTANTS.

FIGURE 2.5 COSY AND HMBC CORRELATIONS ESTABLISHING THE METHACRYLIC ACID MOIETY OF 83. . 34

FigURE 2.6 COSY AND HMBC CORRELATIONS ESTABLISHING THE GLYCEROL SUBUNIT OF 83. ........... 34

Figure 2.7 ElUCIDATED SUBSTRUCTURE 83 ALONG WITH KNOWN ANALOGUES............................... 35

FIGURE 2.8 COSY AND HMBC CORRELATIONS ESTABLISHING A SYMMETRICAL TETRA-SUBSTITUTED AROMATIC RING IN 86.

FiguRE 2.9 SELECTEd COSY AND HMBC CORRELATIONS ESTABLISHING SIDE CHAINS OFF THE AROMATIC RING IN 86. 38

FIGURE 2.10 COSY AND HMBC CORRELATIONS ESTABLISHING THE TERMINAL SUBSTRUCTURES OF $\mathbf{8 6 . 3 9}$

FIGURE 2.11 PhOTOS OF THE PTN3_38C ALGAE SAMPLE EXTRACTED, WITH HIGHLIGHTED CONTAMINANT. 40

Figure 3.1(A) SURFACE IMAGE OF PTN2_45D, ANALYSED IN THIS STUDY. (B) UNDERWATER PHOTOGRAPH OF RASPAILIA TOPSENTI (PHOTOGRAPH BY ALAN DUCKWORTH).

FIGURE 3.2 HMBC SCREEN OF 75\% $\mathrm{ME}_{2} \mathrm{CO}$ IN $\mathrm{H}_{2} \mathrm{O}$ SAMPLE OF PTN2_45D ( $\mathrm{CD}_{3} \mathrm{OD}$ ) PERFORMED BY SINGH. ${ }^{41}$

FIGURE 3.3 AN HSQC-TOCSY SPECTRUM WITH THE FOUR DISTINCT SUGAR SPIN SYSTEMS. GREEN FOR SUGAR ONE, BLUE FOR SUGAR TWO, BLACK FOR SUGAR THREE AND RED FOR SUGAR FOUR. 58

FIGURE 3.4 COSY AND 1D TOCSY DATA ESTABLISHING THE CONNECTIVITY OF THE CARBON CHAIN IN SUGAR ONE. 59 
Figure 3.5 SELECTED HMBC CORRELATIONS ESTABLISHING THE CYCLIC RING CONNECTIVITY OF SUGAR ONE.

FIGURE 3.6 NOE CORRELATIONS AND LARGE 1,2-DIAXIAL VICINAL COUPLING ESTABLISHING THE RELATIVE STEREOCHEMISTRY OF SUGAR ONE.

FIGURE 3.7 COSY AND 1D TOCSY DATA ESTABLISHING THE CARBON CHAIN CONNECTIVITY IN SUGAR TWO.

FIGURE 3.8 SELECTED HMBC CORRELATIONS ESTABLISHING THE CYCLIC RING CONNECTIVITY OF SUGAR TWO.

Figure 3.9 NOE CORRELATIONS AND LARGE 1,2-DIAXIAL VICINAL COUPLING ESTABLISHING THE RELATIVE STEREOCHEMISTRY OF SUGAR TWO.

FIGURE 3.10 DQF COSY AND 1D TOCSY DATA ESTABLISHING THE CARBON CHAIN CONNECTIVITY OF SUGAR THREE.

Figure 3.11 AN NOE CORRELATION AND LARGE 1,2-DIAXIAL VICINAL COUPLING ESTABLISHING THE RELATIVE STEREOCHEMISTRY OF SUGAR THREE.

FIGURE 3.12 COSY AND 1D TOCSY DATA ESTABLISHING THE CARBON CHAIN CONNECTIVITY OF SUGAR FOUR.......

FIGURE 3.13 NOE CORRELATIONS AND LARGE 1,2-DIAXIAL VICINAL COUPLING ESTABLISHING THE RELATIVE STEREOCHEMISTRY OF SUGAR FOUR.

FIGURE 3.14 NOE AND HMBC CORRELATIONS ESTABLISHING THE OLIGOSACCHARIDE CHAIN CONNECTIVITY OF 135 68

Figure 3.15 SELECTED COSY AND HMBC CORRELATIONS ESTABLISHING THE CONNECTIVITY OF SUBSTRUCTURE ONE.

Figure 3.16 SELECTED COSY AND HMBC CORRELATIONS ESTABLISHING THE CONNECTIVITY OF SUBSTRUCTURE TWO.

Figure 3.17 SELECTED COSY AND HMBC CORRELATIONS ESTABLISHING THE CONNECTIVITY OF SUBSTRUCTURE THREE.

FIGURE 3.18 COSY AND HMBC CORRELATIONS ESTABLISHING THE CONNECTIVITY OF SUBSTRUCTURE FOUR

FIGURE 3.19 COSY AND HMBC CORRELATIONS ESTABLISHING THE CONNECTIVITY OF SUBSTRUCTURE FIVE.

Figure 3.20 SelECTEd COSY AND HMBC CORRELATIONS ESTABLISHING THE CONNECTIVITY OF SUBSTRUCTURES ONE, TWO AND THREE. 
FiguRe 3.21 SeleCted COSY AND HMBC CORRELATIONS ESTABLISHING THE CONNECTIVITY OF THE SIDE CHAIN (SUBSTRUCTURES FOUR AND FIVE) TO THE TETRACYCLIC RING SYSTEM OF THE AGLYCON..... 75

Figure 3.22 SELECTEd NOE CORRELATIONS ESTABLISHING THE RELATIVE STEREOCHEMISTRY OF THE AGLYCON MOIETY IN 135. 


\section{List of Schemes}

SCHEME 3.1 The PROCEDURE LEADING TO THE ISOLATION OF RASPAILOSIDE A (135) FROM PTN2_45D. 


\section{List of Tables}

TABLE 2.1 SUMmARY OF THE SCREENING OF 11 ALGAE SAMPLES. ......................................... 27

TABLE $2.2{ }^{13} \mathrm{C}(150 \mathrm{MHz})$ AND ${ }^{1} \mathrm{H}(600 \mathrm{MHz})$ NMR DATA $\left(\mathrm{CD}_{3} \mathrm{OD}\right)$ FOR 76. 33

TABLE $2.3{ }^{13} \mathrm{C}(150 \mathrm{MHz})$ AND ${ }^{1} \mathrm{H}(600 \mathrm{MHz})$ NMR DATA $\left(\mathrm{CD}_{3} \mathrm{OD}\right)$ fOR FULVELLIC ACID ANALOGUE 83 35

TABLE $2.4{ }^{13} \mathrm{C}(150 \mathrm{MHz})$ AND ${ }^{1} \mathrm{H}(600 \mathrm{MHz})$ NMR DATA $\left(\mathrm{CD}_{3} \mathrm{OD}\right)$ FOR FISTULARIN-3 (86)...... 41

TABLE 3.1 TAXONOMIC CLASSIFICATION OF THE PHYLUM PORIFERA TO THE ORDER LEVEL. ${ }^{99} \ldots \ldots \ldots \ldots . . . . . . .44$

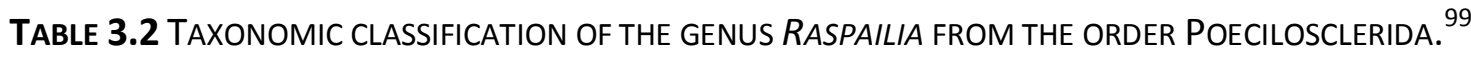
45

TABLE $3.3{ }^{13} \mathrm{C}(150 \mathrm{MHz})$ AND ${ }^{1} \mathrm{H}(600 \mathrm{MHz})$ NMR DATA $\left(\mathrm{CD}_{3} \mathrm{OD}\right)$ FOR THE OLIGOSACCHARIDE CHAIN OF RASPAILOSIDE A (135). 79

TABLE $3.4{ }^{13} \mathrm{C}(150 \mathrm{MHz})$ AND ${ }^{1} \mathrm{H}(600 \mathrm{MHz})$ NMR DATA $\left(\mathrm{CD}_{3} \mathrm{OD}\right)$ FOR THE AGLYCON MOIETY OF RASPAILOSIDE A (135) 81 


\section{Glossary}

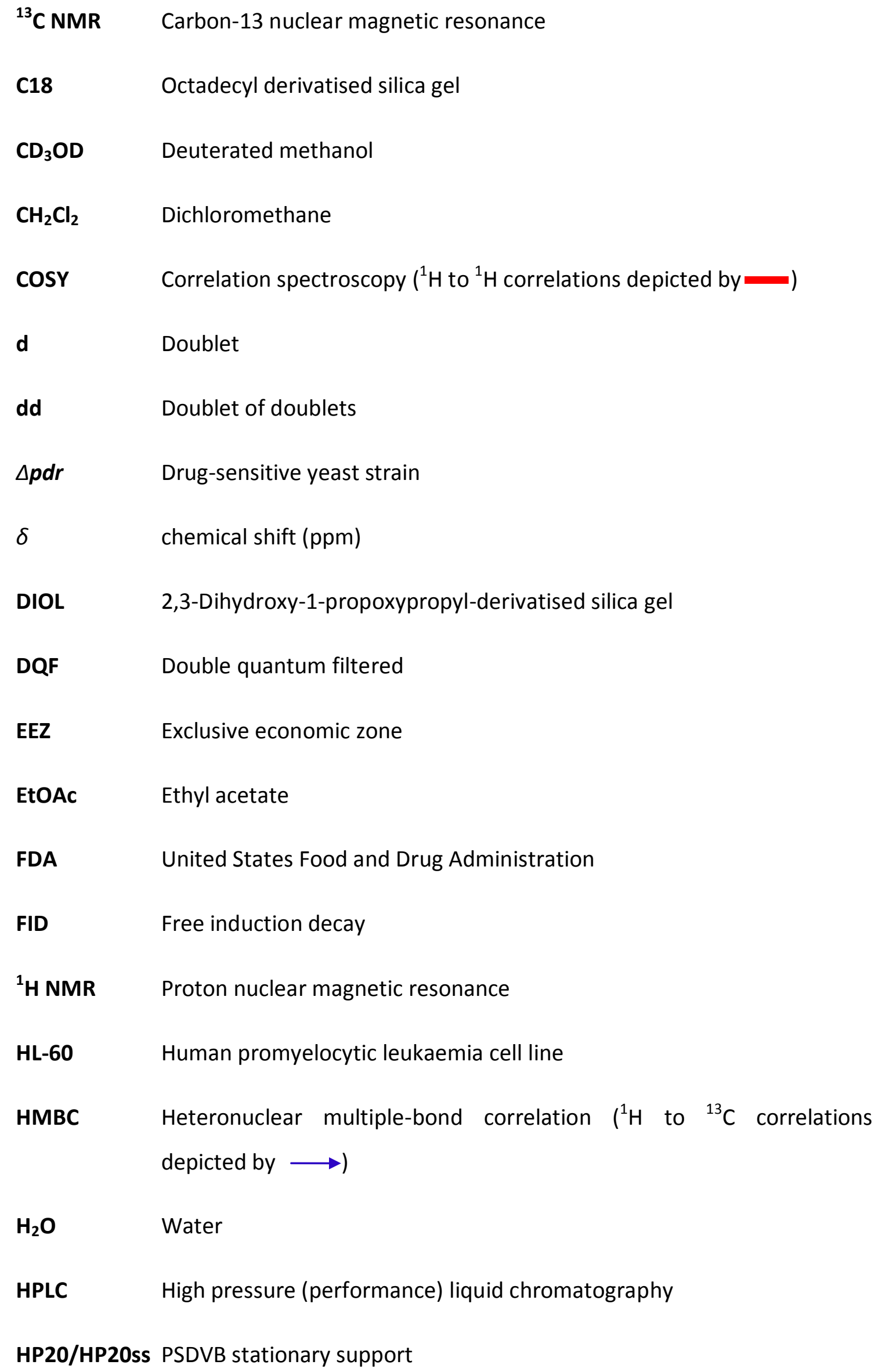




\begin{tabular}{|c|c|}
\hline HRESIMS & High resolution electrospray ionisation mass spectrometry \\
\hline HSQC & Heteronuclear single-quantum coherence \\
\hline $\mathrm{IC}_{50}$ & Inhibitory concentration in $50 \%$ of test subjects \\
\hline J & Scalar coupling constant $(\mathrm{Hz})$ \\
\hline LH-20 & Crosslinked dextran-based size exclusion resin \\
\hline m & Multiplet \\
\hline$m / z$ & Mass-to-charge ratio \\
\hline mult & Multiplicity \\
\hline $\mathrm{Me}_{2} \mathrm{CO}$ & Acetone \\
\hline $\mathrm{MeOH}$ & Methanol \\
\hline NMR & Nuclear magnetic resonance \\
\hline NOE & Nuclear Overhauser effect $\left({ }^{1} \mathrm{H}\right.$ to ${ }^{1} \mathrm{H}$ enhancements depicted by $\left.\longrightarrow\right)$ \\
\hline PDR & Pleiotropic drug resistance \\
\hline ppm & Parts per million \\
\hline PSDVB & Poly(styrene-divinylbenzene) \\
\hline ROESY & Rotating-frame nuclear Overhauser effect correlation spectroscopy \\
\hline $\mathbf{S}$ & Singlet \\
\hline SCUBA & Self contained underwater breathing apparatus \\
\hline t & Triplet \\
\hline TOCSY & Total correlation spectroscopy $\left({ }^{1} \mathrm{H}\right.$ to ${ }^{1} \mathrm{H}$ correlations depicted by $\left.\longrightarrow\right)$ \\
\hline VUW & Victoria University of Wellington \\
\hline
\end{tabular}




\section{Chapter 1}

\section{Introduction}

\subsection{The Role of Naturall Products in Traditionall Medicine}

Throughout the ages the natural environment, whether it be on-land or in the oceans, has provided human civilisations with resources for the production of foodstuffs, shelters, clothing and means of transport. ${ }^{1}$ History has also shown us how the use of terrestrial plants formed the basis for traditional medicines and herbal remedies with the earliest records dating back to $2600 \mathrm{BC}$, in Mesopotamia. ${ }^{2}$ Further evidence has been observed in records throughout history documenting the use of plants in traditional medicine systems. ${ }^{1-2}$ Biologically active secondary metabolites, present within the plant material, are considered to provide the therapeutic effect that these traditional medicines possessed. These secondary metabolites are naturally produced chemical substances that are not essential for sustaining the life of a given organism. The dedicated study of secondary metabolites (also known as natural products) from terrestrial plants only began in the $1800 \mathrm{~s}$, where scientists were able to utilise novel scientific techniques to isolate, purify, and define these active compounds. The efforts of scientists in these studies also laid the platform for modern-day synthetic organic chemistry.

Many important modern medicines used for treating a variety of diseases, and in other medicinal purposes, can be attributed to these biologically active secondary metabolites, isolated from terrestrial sources. In 1805 the narcotic analgesic morphine (1), was isolated from the opium poppy Papaver somniferum. ${ }^{3}$ Extensive structural studies eventually led to the elucidation of morphine's structure in $1925 .{ }^{4}$ In 1820 , quinine (2) was isolated from the bark of the Chinchona sp., a tree indigenous to certain regions of South America. ${ }^{1,4}$ Quinine has been described as the first effective anti-malarial compound found, paving the way for the synthesis of the commonly used anti-malarial drugs chloroquine (3) and mefloquine (4). ${ }^{5}$ 
From the bark of the willow tree (Cortex salicis) the main bioactive compound salicin (5) was discovered in the mid 1800's. However, it was the derivatives, salicylic acid (6) and acetylsalicylic acid (aspirin, 7) which showed improved medicinal properties. This led to the commercialisation of aspirin in $1899 .{ }^{6}$ Over 100 years later, aspirin features as the most successful drug worldwide to be derived from a bioactive secondary metabolite. ${ }^{6}$

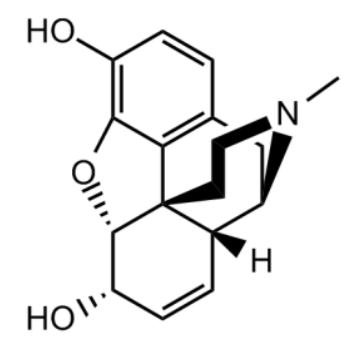

1<smiles>CCN(CC)CCCC(C)Nc1ccnc2cc(Cl)ccc12</smiles>

3

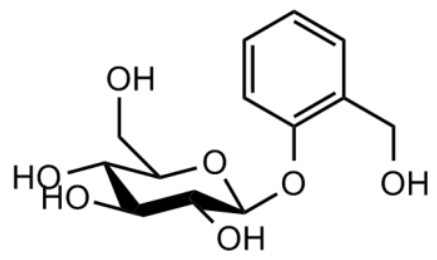<smiles>C=CC1CC2CCC1N2[C@H](O)c1ccnc2ccc(OC)cc12</smiles>

2<smiles>O[C@H](c1cc(C(F)(F)F)nc2c(C(F)(F)F)cccc12)[C@H]1CCCCN1</smiles>

4<smiles>[R]Oc1ccccc1C(=O)O</smiles>

$6 \mathrm{R}=\mathrm{H}$

$7 \mathrm{R}=\mathrm{COMe}$

The chance discovery of penicillin G (8) from the filamentous fungus Penicillium notatum by Alexander Fleming in 1929, and the realisation of its broad therapeutic uses in the 1940s, prompted intensive investigation of nature as a source of novel bioactive natural products. ${ }^{1-2,7}$ Since the 1940 s micro-organisms and, to a lesser degree, terrestrial plants have been excellent sources of antibiotics. ${ }^{8}$ Growing concerns in the medical field stemming from drug resistant bacteria and the discovery 
of new pathogens has meant that the search for novel bioactive products has expanded to encompass the marine natural environment.

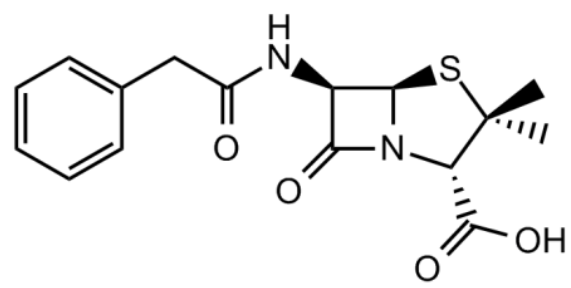

\subsection{Marine Natural Products}

More than $70 \%$ of the Earth's surface is covered by oceans and life itself has its origins in that marine environment. ${ }^{9}$ Furthermore, 34 of the 36 known phyla of living organisms come from an aquatic environment, which offers a greater biodiversity than that of the terrestrial environment. The large marine biodiversity has evolved to endure the harsh and extreme conditions in which it inhabits such as variable temperatures, currents, wave action, pressures and high salinity.

Throughout history, the use of marine organisms has played a very small part in the development of traditional medicines and is therefore not as heavily documented as its terrestrial counterparts. This was largely due to the accessibility issues of marine flora and fauna in all but the shallowest of waters. The scope and potential of marine natural products therefore remained unknown until the 1940s. The design and development of the first inexpensive and reliable SCUBA apparatus, by Jacques Cousteau in 1943, allowed for the routine collection of marine organisms at depths of down to $35 \mathrm{~m}^{10}$

The first marine-derived natural products to be isolated and identified were the biologically active nucleosides, spongothymidine (9) and spongouridine (10) from the Caribbean sponge Crypotethya crypta, in the early 1950s. ${ }^{11-13}$ After the discovery of 9 and $\mathbf{1 0}$ interest grew in the field and further research led to the development of the synthetic analogues Ara-C (cytosine arabinoside, 11), the first marine-derived anticancer agent, and the anti-viral agent AZT (azidothymidine, 12). ${ }^{14-15}$ However, it was not until the 1970s that marine natural products (MNP) emerged as a fully fledged discipline. ${ }^{16}$ 
Since then marine natural products chemists have sought novel biologically active secondary metabolites through the investigation of several types of marine organisms, including sponges, nudibranchs, soft corals and algae. As of 2010, marine natural products or derivatives thereof have provided four approved drugs, 13 in clinical trials and several at various stages of preclinical studies. ${ }^{17}$ More recently, as of early 2012, the MarinLit database has suggested that more than 24,000 marine natural products have been described. ${ }^{18}$

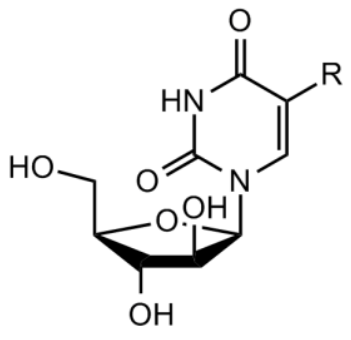

$9 \mathrm{R}=\mathrm{Me}$ $10 \mathrm{R}=\mathrm{H}$

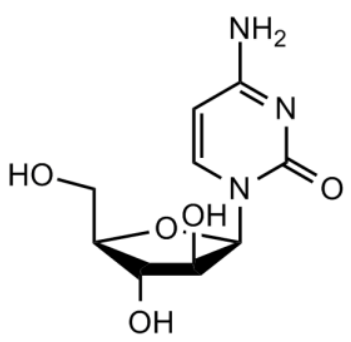

11<smiles>Cc1cn([C@H]2C[C@@H](C#N)[C@H](CO)O2)c(=O)[nH]c1=O</smiles>

12

Prialt (ziconotide, 13) was the first "direct from the sea" compound to be approved by the FDA and become a licensed pharmaceutical. Ziconotide was isolated from the venom ducts of the predatory cone snail of the genus Conus magus. ${ }^{19}$ The compound is the synthetic equivalent of the $\omega$-conopeptide MVIIA which is a 25 amino acid peptide chain. ${ }^{20}$ Ziconotide is a very potent and highly selective blocker of mammalian neuronal $\mathrm{N}$-type voltage-sensitive calcium channels inhibiting the activity of a subset of neurons including pain-sensing primary nociceptors. ${ }^{20}$ These properties make Prialt a potent non-opioid analgesic, currently in use for the management of severe chronic pain. ${ }^{20}$

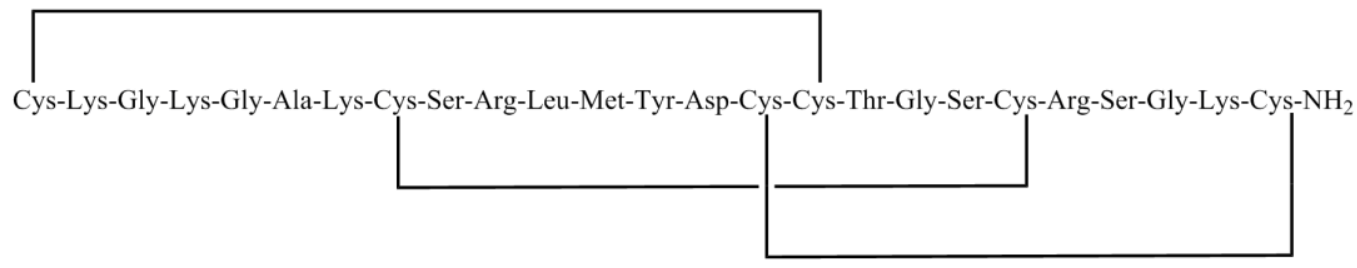




\subsection{Marine Organisms}

Marine organisms, that are typically soft-bodied and/or sessile, like macro-algae and sponges (discussed in more detail in Chapters 2 and 3 respectively) were, and still are of interest to marine natural product chemists. This interest comes from the potent chemical defence mechanism these organisms have attained, either through evolution or a symbiotic relationship. ${ }^{9} \quad$ This chemical defence mechanism consists of bioactive secondary metabolites that act as a deterrent when excreted by the organism. These natural products become immediately diluted as they are released into the ocean environment and therefore must be highly potent to have the desired effect. ${ }^{9}$

Sponges, in particular, are well known to form symbiotic relationships with large communities of micro-organisms. Symbiotic functions that have been attributed to this relationship include nutrient acquisition, stabilisation of sponge skeleton, processing of metabolic waste and secondary metabolite production. ${ }^{21}$ Some studies have been conducted demonstrating that symbiotic marine micro-organisms, harboured by sponges, are the original producers of some of the bioactive secondary metabolites isolated from sponge samples. ${ }^{22}$

\subsection{The New Zealland Marine Eco-region}

The marine natural products group at Victoria University of Wellington (VUW) has performed extensive studies on New Zealand marine organisms. New Zealand has an extremely biologically diverse marine environment, influenced by its geographical location, range and complexity of habitats, and the number of major ocean currents that pass within its Exclusive Economic Zone (EEZ), see Figure 1.1. ${ }^{23}$ New Zealand's EEZ has an area of 4.2 million $\mathrm{km}^{2}$ spanning over $30^{\circ}$ of latitude from subtropical to subAntarctic waters, and extending from shallow waters to the deep sea. ${ }^{24}$ New Zealand's marine environment is home to an estimated 23,000 species of which approximately 12,000 have been identified. ${ }^{24}$ 


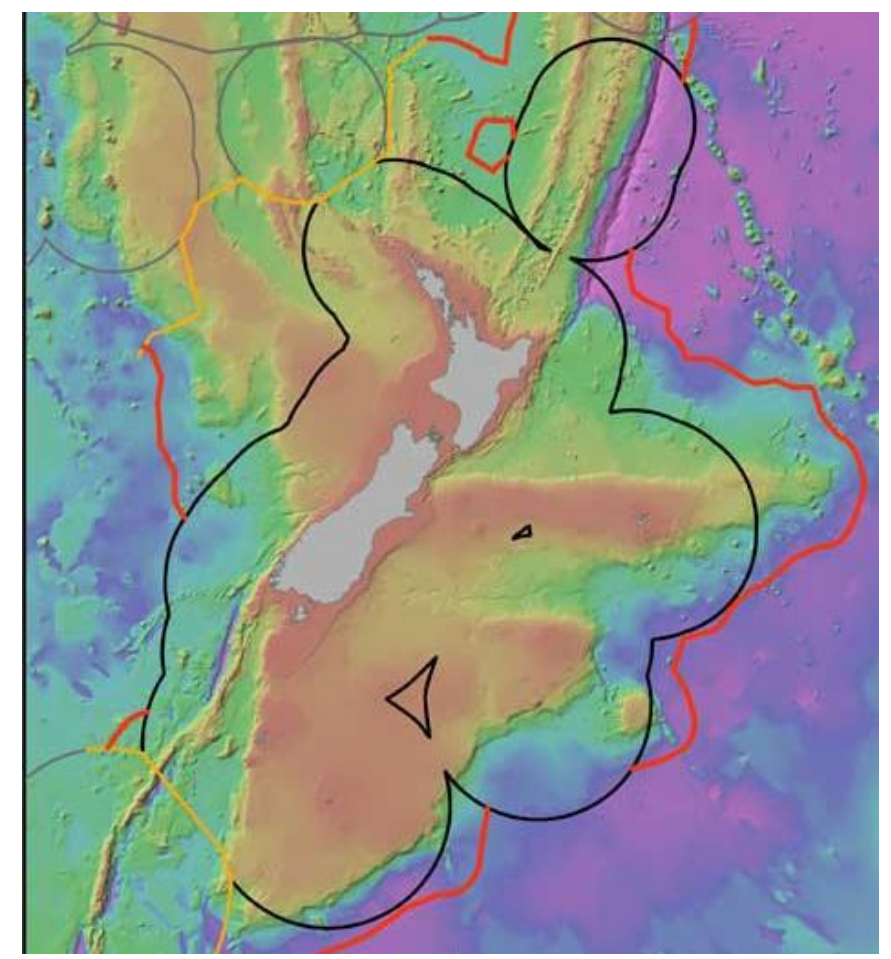

Figure 1.1 Map of New Zealand highlighting the EEZ boundary (outlined in black). Image courtesy of Land Information New Zealand (LINZ). ${ }^{23}$

Between 1979 and August 2012 the MarinLit database accumulated records on 410 natural products isolated from New Zealand marine organisms. ${ }^{18}$ One such study of the New Zealand sponge Mycale hentscheli provided the isolation of the polyketide derived compounds, mycalamides (14-16) and pelorusides (17-18). ${ }^{25-29}$ Studies of Raspailia sponge species have also led to the isolation of several novel compounds, discussed in Chapter 3. New Zealand red algae studies have led to the isolation of novel compounds, across several classes, including the acetogenins (19-21) and sesquiterpenes (22-23). ${ }^{30}$ Further red algae natural products have been reported with some mentioned in Chapter 2.

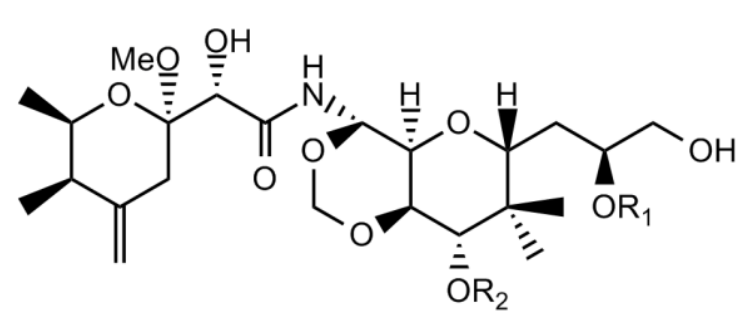

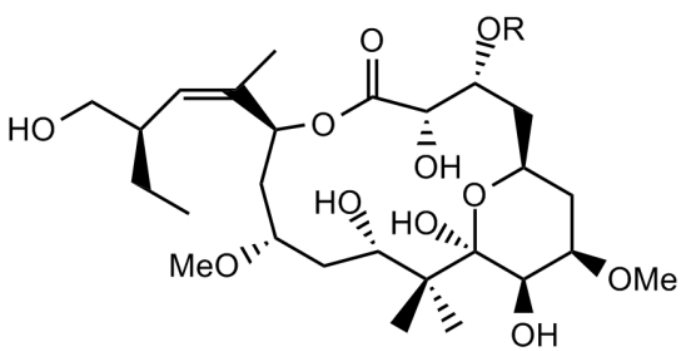

$14 \mathrm{R}_{1}=\mathrm{H}, \quad \mathrm{R}_{2}=\mathrm{Me}$

$17 \mathrm{R}=\mathrm{Me}$

$15 \mathrm{R}_{1}=\mathrm{Me}, \mathrm{R}_{2}=\mathrm{Me}$

$18 \mathrm{R}=\mathrm{H}$

$16 \mathrm{R}_{1}=\mathrm{H}, \quad \mathrm{R}_{2}=\mathrm{H}$ 


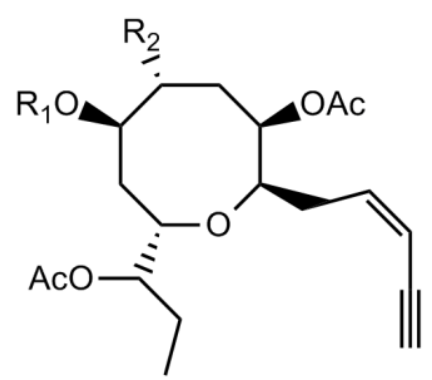

$19 \mathrm{R}_{1}=\mathrm{Ac}, \mathrm{R}_{2}=\mathrm{Cl}$

$20 \mathrm{R}_{1}=\mathrm{H}, \mathrm{R}_{2}=\mathrm{OAc}$

$21 \mathrm{R}_{1}=\mathrm{Ac}, \mathrm{R}_{2}=\mathrm{OH}$

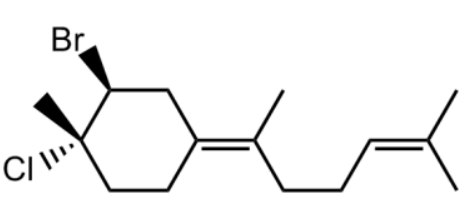

22

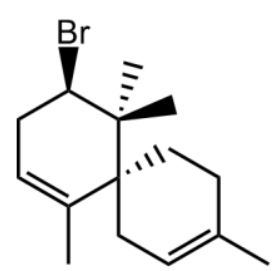

23

\subsection{The Tongan Marine Eco-Region}

Recently the group has changed direction and is now focussed on studies of marine organisms from the Kingdom of Tonga as opposed to New Zealand. The Kingdom of Tonga is located $2000 \mathrm{~km}$ northeast of New Zealand and consists of 171 islands of which 36 are inhabited, see Figure 1.2. ${ }^{31}$ Tonga is located between $18^{\circ}$ and $22^{\circ} \mathrm{S}$ latitude and $173^{\circ}$ and $176^{\circ} \mathrm{W}$ longitude, and is divided into three main island groups; Vava'u in the north, Tongatapu and 'Eua in the south with Ha'apai in between. Tonga has a total land area of $688 \mathrm{~km}^{2}$ with an EEZ over 1000 times larger at 700,000 km which provides a large diverse marine environment in which studies could be undertaken. Tonga was of interest to the VUW marine chemistry group as the tropical conditions gave rise to different species of marine organisms which could be found in a variety of habitats, including coral reefs, which are not found in the colder waters of New Zealand. The Tongan islands were also chosen as, until recently, access had been limited and as such, there had been very few reports of secondary metabolites isolated from Tongan marine organisms. Two dives were conducted in different regions, to collect and study various marine organisms. One particular dive collection was performed around the southern coastline of the island of 'Eua, where several sponge species were found. 


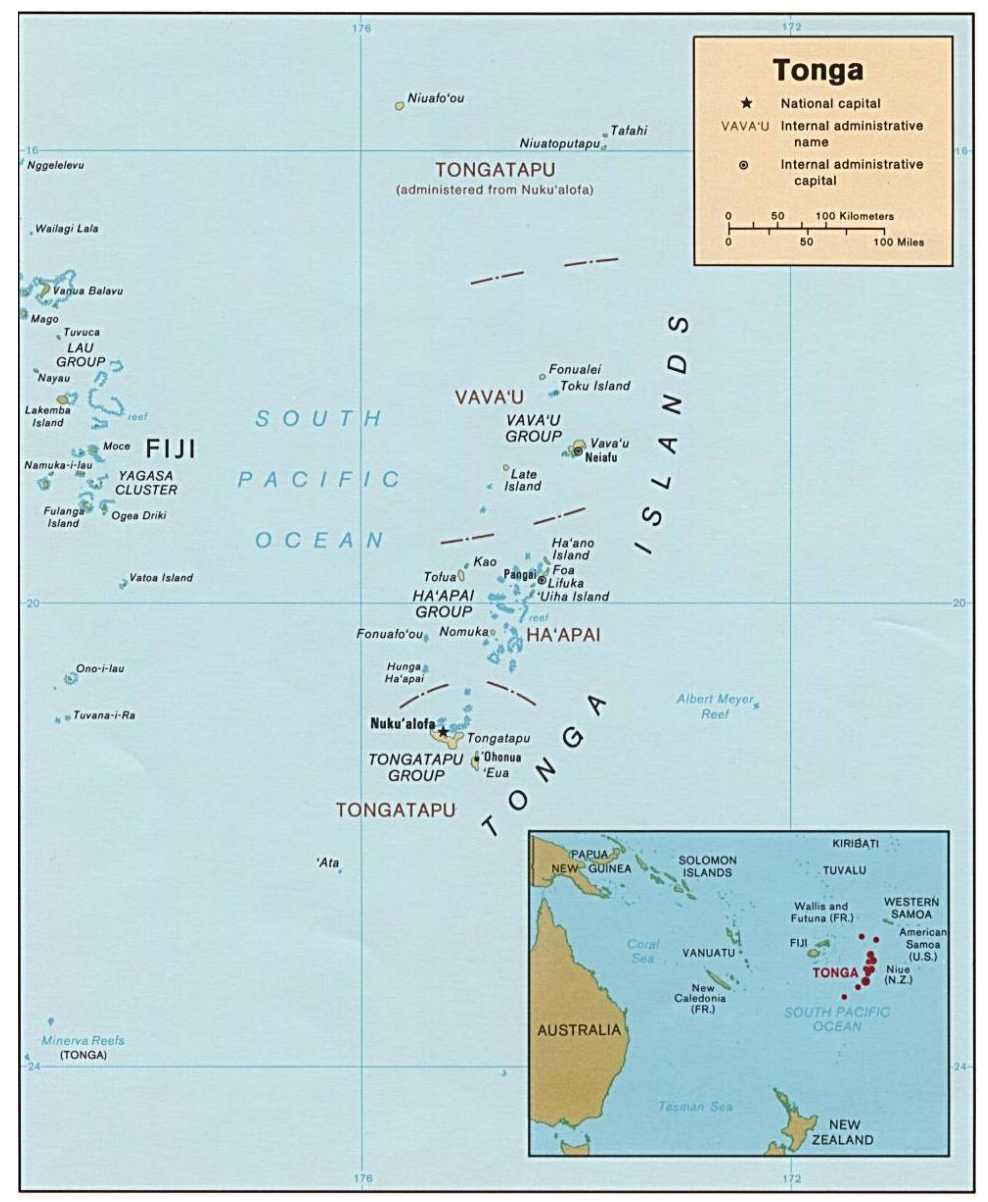

Figure 1.2 The Tongan Kingdom, courtesy of NationMaster. ${ }^{31}$

A study by Taufa, on sponges of the order Dictyoceratida, saw the isolation of the novel sesterterpenes, isoluffariellolide (24) and 1-O-methylisoluffariellolide (25) from a Fascaplysinopsis sp., and the compound secothorectolide (26) from an undescribed species. $^{32}$ Biological testing showed that $\mathbf{2 4 - 2 5}$ exhibited micromolar cytotoxicity against the human promyelocytic leukaemia (HL-60) cell line while 26 displayed micromolar cytotoxicity towards ovarian cancer cells. ${ }^{32}$ A study by Barber saw the isolation and identification of seven novel metabolites of polyketide origin, lehualides E-K (27-33) from a Plakortis sponge specimen. ${ }^{33}$ Biological testing showed that 28-31 displayed micromolar cytotoxicity against the HL-60 cell line. ${ }^{33}$ The isolation of compounds 24-33 and subsequent biological activity studies indicate that Tongan sponges contain numerous new and structurally diverse bioactive secondary metabolites and as such, research into tropical marine organisms has become commonplace at VUW. There have however, been limited studies into Tongan marine red algae suggesting the potential for further novel compound isolation. 


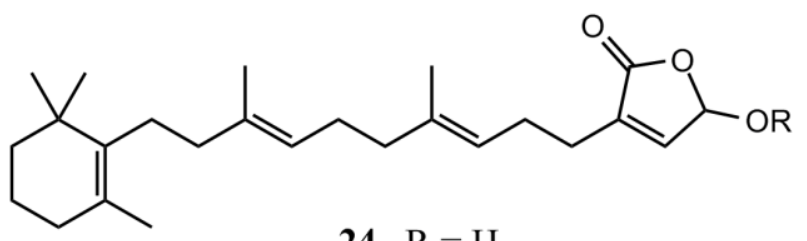

$24 \mathrm{R}=\mathrm{H}$

$25 \mathrm{R}=\mathrm{Me}$<smiles>CC(C)=CCC/C(C)=C/CC/C(C)=C/CC/C(C=O)=C\CC(O)C1=CC(=O)OC1O</smiles><smiles>[R]Oc1c(C)c(C/C=C(\C)CCCCCCc2ccccc2)oc(=O)c1OC</smiles>

$27 \mathrm{R}=\mathrm{Me}$

$28 \mathrm{R}=\mathrm{H}$<smiles>COc1c(O)c(C)c(C/C=C(\C)CCCCCCCCc2ccccc2)oc1=O</smiles>

29<smiles>[R]SCCCCCCCCCCc1oc(=O)c(OC)c(OC)c1C</smiles><smiles>[R][X]=C([R])C</smiles><smiles>COc1c(C)c(C)oc(=O)c1OC</smiles> 


\subsection{Fractioning of a Crude Extract}

Crude extracts, concentrated solvent solutions (typically methanol or ethanol) obtained from the extraction and subsequent filtration of an organism, have proven to be difficult to analyse and handle due to wide polarity and solubility ranges. Initial purification of a crude extract has over the years seen changes in methodology from, the straightforward technique of liquid/liquid partitioning to column chromatography. A reversed-phase chromatography procedure was developed by Blunt and Munro utilising a solid support of octadecyl-derivatised silica (C18) and a low pressure chromatographic technique which was found to overcome problems associated with using standard flash chromatography (normal phase). ${ }^{34}$ Figure 1.3 is a hypothetical graph showing the mass distribution of a typical New Zealand marine organism crude extract eluted off a reversed-phase solid support. The target secondary metabolites are typically found at intermediate polarities as they often have complex structures that contain both polar and non-polar entities (amphiphilic).

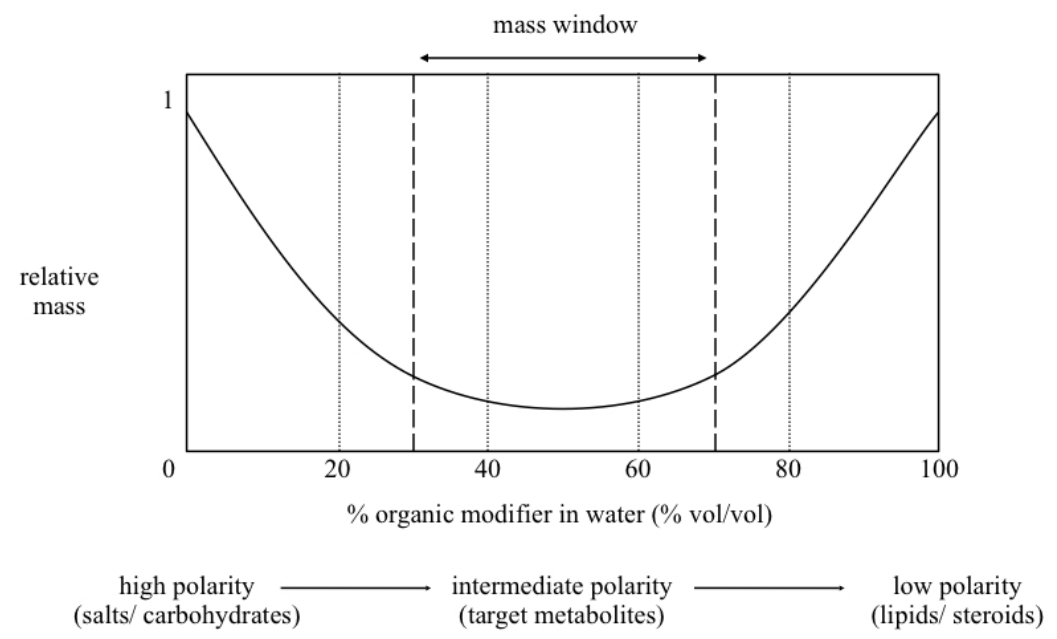

Figure 1.3 Diagram of the mass distribution of a typical New Zealand marine organism extract off a reversed-phase support.

However, Blunt and Munro's procedure did encounter some difficulties as the procedure could not be performed on a large scale and significant amounts of extract were difficult to concentrate onto a solid support of finite size. Additionally the C18 solid support is not reusable as continued elution with highly aqueous solvents strips the beads of the octadecyl chains exposing uncapped silanol groups, making it a potentially costly procedure while also compromising reproducibility. ${ }^{35}$ 
At VUW, West and Northcote developed a variation of the Blunt/Munro method for fractioning a crude sample, cyclic loading, which was done on poly(styrenedivinylbenzene) (PSDVB). ${ }^{36}$ PSDVB is a rigid and macroporous highly cross linked polymer that was used as the stationary reversed-phase support in favour of C18. PSDVB was found to have the advantages of being relatively inexpensive and unlike C18 reusable due to being chemically inert with no surface ligands that could be stripped off the column during use. ${ }^{35}$ See Appendix A for the cyclic loading process.

\subsection{Screening Techniques}

The most commonly used method for screening crude extracts for new natural products is bioassay-directed isolation which involves testing fractions of an extract for a specific activity. An extract that provides positive biological activity is iteratively fractionated, with the collected fractions being tested against the same assay, tracking the activity until a pure compound is isolated. In the 1990s, a bioassay-directed approach to isolation and identification of a biologically active compound was often challenging, expensive and slow. One of the major reasons for this was that the investigator had total dependence on a suitable bioassay that will show some effect when screening crude extracts and subsequently guiding the isolation and separation procedure. $^{35}$ Bioassay-directed isolation remains the dominant paradigm in the field of natural products isolation, backed strongly by the pharmaceutical industries desire for novel compounds that contain targeted bioactivity against certain diseases.

During the 1990s, NMR-based screening methods were developed, on the back of many advances in spectroscopic techniques and in particular, high-resolution NMR techniques. This revolutionised the determination of compounds re structural complexity, for example secondary metabolites. ${ }^{37}$ The important NMR advances related to natural product structure determination fell into two categories; multidimensional pulse methods and sensitivity improvements. ${ }^{37}$ An array of experimental methods have become available through continuous development and expansion of high-resolution two-dimensional NMR spectroscopy. Multidimensional experiments, such as correlation spectroscopy (COSY), heteronuclear single-quantum coherence spectroscopy (HSQC) and heteronuclear multiple-bond correlation spectroscopy $(\mathrm{HMBC})$, provide through-bond correlations affording a wealth of 
molecular connectivity data utilised in defining the structure of interest. Sensitivity improvements have also been vital in the continual development of NMR-based screening. The advances in cryogenic electronics and micro-probe technologies has aided in increasing the resolution, and reducing the amount of material required to run a successful NMR spectrum, to less than a milligram. ${ }^{37}$

NMR-based screening also answers a few of the problems associated with bioassaydirected screening. The NMR method is not looking at bioactivity and is therefore, not prone to being narrowly focussed, as several novel structures can be highlighted concurrently. Each structure can have their own distinct biological activity tested separately. Structural novelty can be known early on in the purification process allowing more thought-out purification steps to be conducted, with full structural elucidation being achieved earlier than in the bioassay method. Finally, an NMR method is not destructive as most of the material can be recovered from the purification process which is significant when dealing with small samples. It should be noted however, that an NMR guided isolation procedure is relatively insensitive compared to bioassay-directed isolation and the activity of the compound isolated is not known until after purification.

\subsection{VUW Protocols}

Marine natural products chemistry has been an on-going area of research at VUW since the mid-1990s with an NMR-guided isolation procedure being used to identify and isolate secondary metabolites from marine sources. Over the years the screening protocol has seen advancements that have made early determination of interesting marine organisms easier to achieve. The first in-house screening procedure was introduced in the late 1990s with the structure and novelty of a compounds functionality becoming the primary interest. Initial work utilised $1 \mathrm{D}^{1} \mathrm{H} N \mathrm{NR}$ spectra to guide the isolation of novel compounds from a crude sample which led to the isolation of several novel compounds including $17 .{ }^{28,36}$

There were, however, limitations associated with the ${ }^{1} \mathrm{H}$ NMR experiment that affected its widespread application. The spectral crowding of crude extracts in the ${ }^{1} \mathrm{H}$ NMR spectrum, at shifts below $5.5 \mathrm{ppm}$, due to overlapping primary metabolite resonances, meant that secondary metabolites with no deshielded proton shifts would 
not appear in the ${ }^{1} \mathrm{H}$ NMR protocol. A new screening protocol was developed using the 2D HSQC NMR experiments to more widely identify secondary metabolites from semi-purified extracts. The introduction of a second dimension allowed better separation of the primary metabolite resonances from upfield secondary metabolite resonances while also providing extra chemical information about the compound. Using West's pre-screen semi-purification step, the revised screening protocol was analysed using the three NMR experiments $\left({ }^{1} \mathrm{H}\right.$ NMR, COSY and HSQC). ${ }^{35}$

Utilising 2D HSQC NMR it became possible to collate a number of generated screens to produce a mask, which showed the positions of correlations related to primary metabolites. This was first observed with the use of a paper mask where a subsequent screen was overlaid on the relevant mask with any unusual correlations noted. ${ }^{35}$ Digital HSQC compiling software was later developed, allowing for an increased number of screen spectra to be incorporated into the mask while also eliminating most of the human error and time required superimposing the spectra in a paper mask. ${ }^{38-39}$ The HSQC spectral masks generated for New Zealand sponges and red algae proved highly useful in organism selection and subsequently led to the isolation of several novel biologically active secondary metabolites (Wojnar and Singh PhD theses and. ${ }^{40-42}$ Figures 1.4 and 1.5 illustrate the HSQC mask of 34 New Zealand algae samples (Popplewell study) with frequent correlations seen in white and less frequent correlations seen in blue. ${ }^{40}$ By masking out the common white correlations it becomes easier to assess the degree of structural novelty present in a given spectrum.

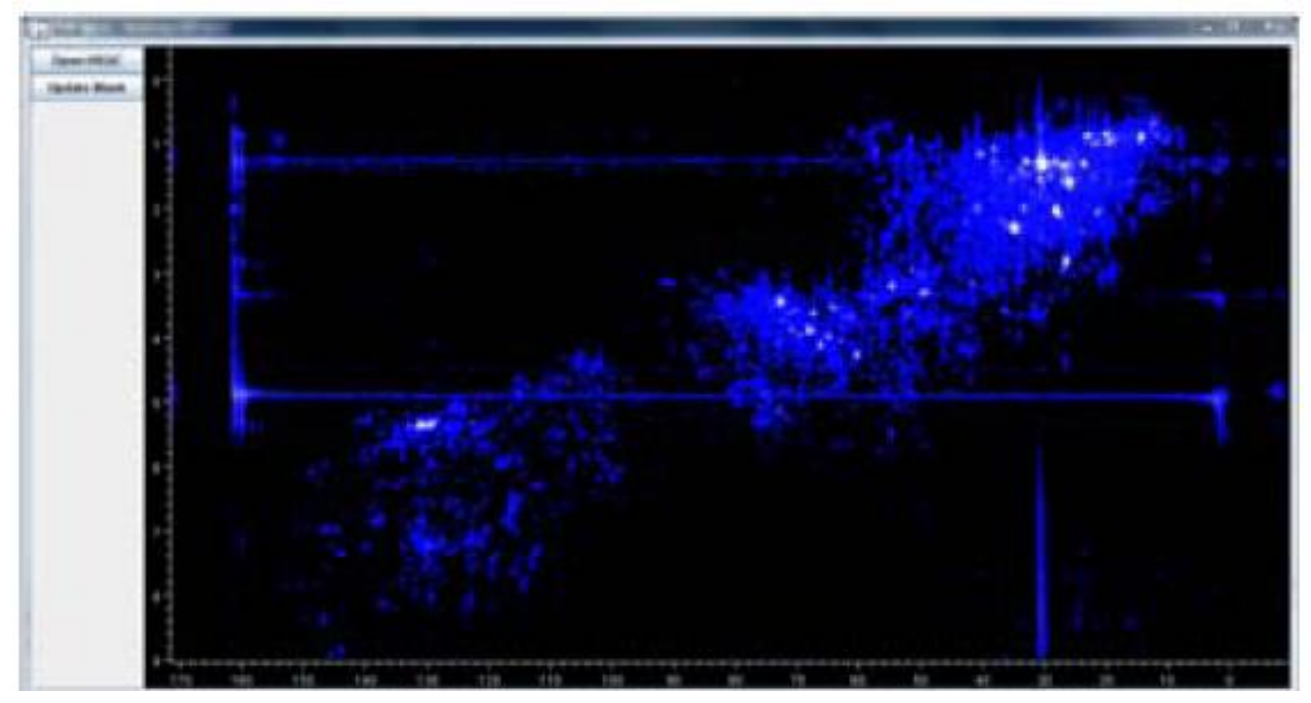

Figure 1.4 An HSQC mask of $34 \mathrm{NZ}$ algae specimens. ${ }^{40}$ 


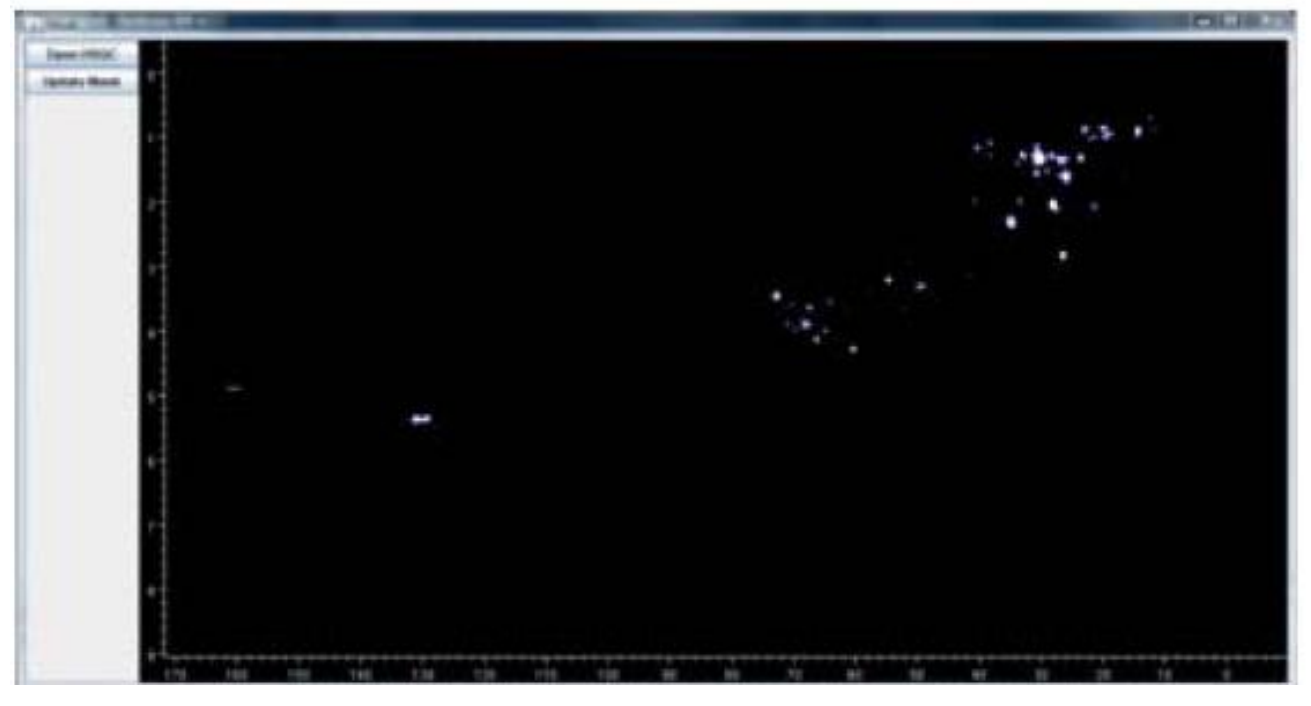

Figure 1.5 Common correlations seen in the NZ algal HSQC mask. ${ }^{40}$

From several sponge collections around New Zealand the HSQC mask began to show that a given screen exhibited correlations only consistent with compounds already isolated in the lab. This suggested that the same sponge organisms were being collected. At this point a decision was made that led to three different pathways being undertaken in-house; the collection and study of sponge organisms from Tonga (mentioned previously), the study of New Zealand red algae and an HMBC digital mask was considered.

\section{New Zealand Red Algae Studies}

At the same time as Tongan sponge studies were going on, New Zealand marine red algae were being looked at, as an alternative source of interesting and novel secondary metabolites. A study by Popplewell found that the standard protocol for the screening of sponge extracts through 2D experiments, discussed previously, was easily adapted to New Zealand macro-algae. ${ }^{40}$ Red algal fractions were, on average, slightly richer compared to those of the New Zealand sponge extracts studied (comparison between equal $100 \mathrm{~g}$ wet weight extractions) which meant less initial sample was required. ${ }^{40} \mathrm{~A}$ number of samples were screened and a digital HSQC mask was generated (Figure 1.4) which afforded easier determination of samples to be studied in further detail. Further mention of this study is given in Chapter two. 


\section{The HMBC Screen}

The third development that was taken by the VUW marine natural products group was the advancement in the screening protocol used to determine whether prospective organisms contain potentially novel secondary metabolites. While the HSQC screen has been a tool successfully used in the lab at VUW for the use in isolating novel secondary metabolites with diverse structures it does have its limitations. It does not inherently detect non-protonated functional groups, for example nitriles and nonprotonated olefinic carbons and no direct evidence is provided that indicates that any of the correlations observed, belong to a single molecular entity.

A further advancement implemented in-house involved the screening for substructures within the crude extract. The HMBC experiment, first proposed in 1986, provided multiple-bond correlations between ${ }^{1} \mathrm{H}$ and ${ }^{13} \mathrm{C}$ nuclei. ${ }^{43}$ The $\mathrm{HMBC}$ experiment is a less sensitive experiment than the HSQC, however it is a more powerful experiment due to the wealth of structural information it provides. Substructure screening can be achieved using the quicker COSY experiment however this only shows correlations of protonated carbons in a sequence but generally does not allow for non-protonated carbon linkages in the sequence. Additionally the COSY provides less spectral dispersion as the second dimension is derived from the same ${ }^{1} \mathrm{H}$ nucleus.

The identification of families of compounds at an early stage of purification could be possible with a functional $\mathrm{HMBC}$ screen which would be very useful after just a single fractionation. ${ }^{41}$ This would allow early determination, in the isolation process, of whether the organism has potential and is worthy of further study or whether it should be disregarded. The running of an HMBC screen concurrently with an HSQC screen can provide a wealth of information, allowing interesting one-bond correlations, observed in an HSQC, to be extended to multiple-bond correlations through an HMBC screen further leading to a possible substructure determination. An HMBC experiment does however, require a longer acquisition time to generate high resolution data as it is looking at ${ }^{n} J_{C H}$ coupling (where $n=2,3,4$ or 5 ) which is considerably weaker than the ${ }^{1} J_{\mathrm{CH}}$ coupling observed in HSQC experiments. 


\subsection{Research Aims}

This study will analyse Tongan algae with specimens screened and purified for novel secondary metabolites. The concentration and structural diversity of Tongan algae will be compared with that of the previously studied temperate NZ algae, to ascertain whether the same results are seen as was observed in sponges (discussed in Chapter 2). NMR guided isolation will be applied to lead the chromatographic process and the $\mathrm{HMBC}$ screen will be used to identify molecular substructures early in the purification process. A study of a New Zealand Raspailia sponge sample will be performed to determine whether the $\mathrm{HMBC}$ screening protocol of previously disregarded sponge samples brings about the isolation and structural elucidation of novel compounds. Novel samples will be submitted for biological activity studies with the aim of identifying compounds with interesting biological activity. 


\section{Chapter 2}

\section{Tongan Marine Algae Study}

\subsection{Seaweed - Marine Macro-Algae}

Seaweed, or marine macro-algae, are ancient organisms that make up a large proportion of the world's marine flora. Global utilisation of macro-algae is a multibillion dollar industry, based on the farming of edible seaweed and its uses in the production of agar, carrageenan and alginate. ${ }^{44}$ The form of the algae plant body varies, from the relative simplicity of a single cell, $1.5 \mu \mathrm{m}$ in size, to kelps, some of which may reach lengths of up to $60 \mathrm{~m} .{ }^{45}$ Algae are very abundant organisms found in either aquatic or intertidal habitats with aquatic species growing in both fresh and salt water. Some algae have been found in locations where the salinity reaches high levels in the dry seasons, whereas other algae that live on the hulls of ships, are remarkably tolerant to both fresh and saline water. ${ }^{45}$

Marine macro-algae are traditionally split into the three phyla Chlorophyta (green), Phaeophyta (brown) and Rhodophyta (red) based on colour which is affected by the composition and amount of photosynthetic pigments, see Figure 2.1. ${ }^{40,45}$ Algae are polyphyletic - they do not fall within a single group linked by a common ancestor. Red and green algae are classified under the kingdom Plantae, while brown algae are classified under the kingdom Chromista. Typically, macro-algae are sessile and as a consequence have developed, through evolution, a chemical defence mechanism using bioactive secondary metabolites.

As seaweeds are typically found close to shore in shallow waters, the ease of accessibility meant they were among the first group of marine organisms to be investigated by marine natural products chemists. Prior to early work on marine algae, the medicinal properties of seaweeds had been demonstrated in traditional and folk medicines. However, it was not until the 1970s that algae, along with other marine organisms, were looked at as a vast resource for the discovery of potentially useful 
secondary metabolite natural products. Between 1977 and 1987 algae was believed to be the source of $35 \%$ of the newly discovered chemicals over that time span. ${ }^{46}$

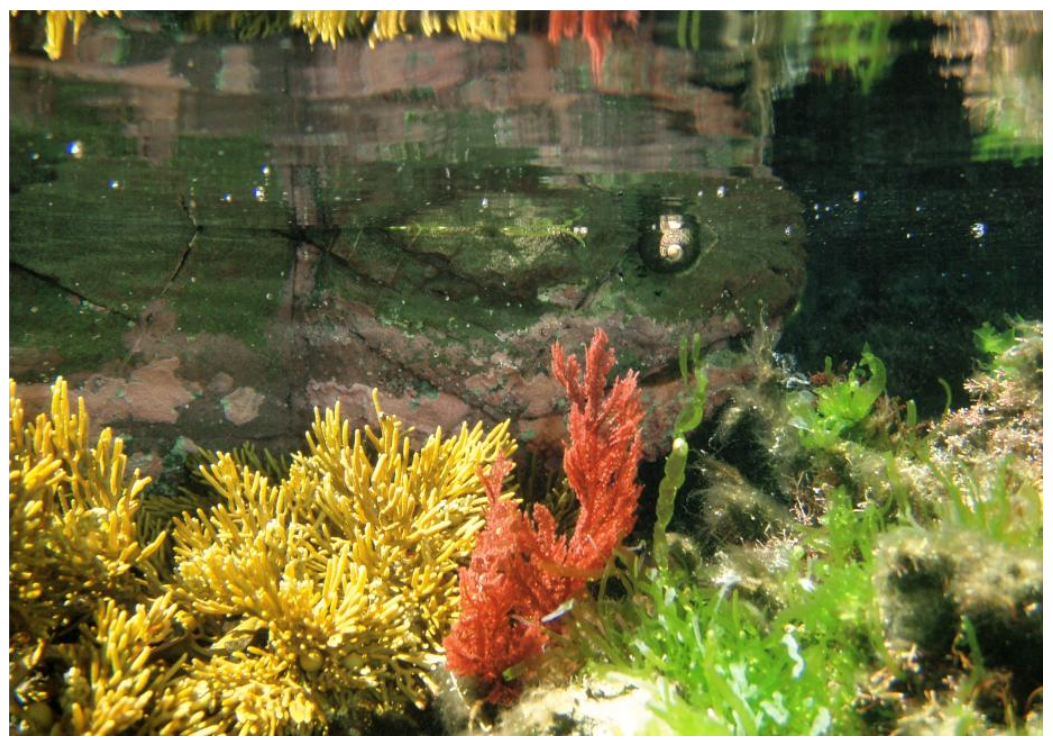

Figure 2.1 A selection of brown, red and green marine algae at low tide.

Early studies found tropical green algae (Chlorophyta), along with a few temperate relatives contained a number of biologically active secondary metabolites. An early characteristic feature of green algal metabolites was the 1,4-diacetoxybutadiene moiety reported in more than half of the compounds isolated before $1984 .{ }^{47}$ Numerous research groups around the world undertook much of the early work on Chlorophyta samples, isolating a number of these 1,4-diacetoxybutadiene containing compounds. ${ }^{47-54}$ The simplest of these was flexilin (34), isolated from Caulerpa flexilis in $1978 .^{48}$ Two closely related 1,4-diacetoxybutadienes, caulerpenyne (35) and rhipocephalin (36), were subsequently isolated from Caulerpa prolifera and Rhipocephalus phoenix, respectively. ${ }^{49-50}$ Other functionalities observed in early green algae metabolites included a trialdehyde compound halimedatrial (37), produced by several species of the genus Halimeda. ${ }^{55-56}$ Halimedatrial showed diverse and potent biological effects, including inhibiting growth of marine fungi and bacteria. Caulerpa prolifera was also found to contain several linear triterpenoid squalene derivatives including 38-40. ${ }^{57}$ Cymopol (41) and Cyclocymopol (42), along with their monomethyl ethers (43-44), were early examples of brominated hydroquinones isolated from Cymopolia barbata. ${ }^{58-59}$ 
<smiles>CC(=O)O/C=C(\C=C\OC(C)=O)CC/C=C(\C)CCC=C(C)C</smiles>

34

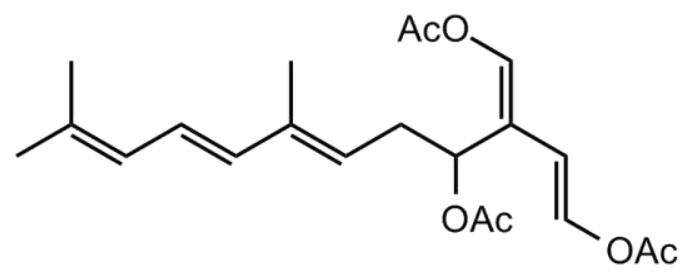

36

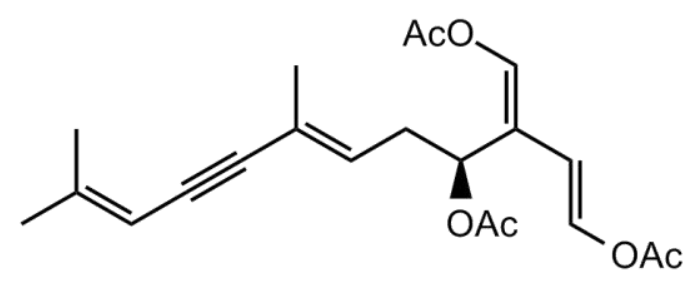

35

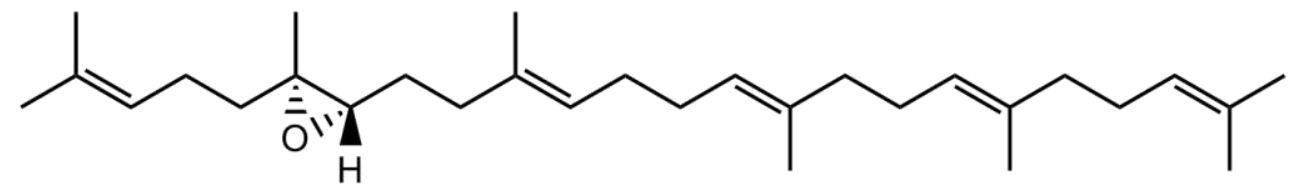

38<smiles>CC(C)=CCC/C(C)=C/CC/C(C)=C/CC[C@H]([C@H](C)O)C(C)(C)CC/C=C(\C)CCC=C(C)C</smiles><smiles>C=C(CO)CC/C(C)=C/CC/C(C)=C/CC/C=C(\C)CC/C=C(\C)CCC=C(C)C</smiles>

40<smiles>[R20]c1cc(C/C=C(\C)CCC=C(C)C)c(O)cc1Br</smiles><smiles>[R7]Oc1cc(C[C@H]2C(=C)CC[C@@H](Br)C2(C)C)c(O)cc1Br</smiles>

$41 \mathrm{R}=\mathrm{H}$

$43 \mathrm{R}=\mathrm{Me}$

$42 \mathrm{R}=\mathrm{H}$

$44 \mathrm{R}=\mathrm{Me}$ 
Natural product chemists conducted extensive early studies into brown algae (Phaeophyta) and the many classes of metabolites they contained. These classes ranged from simple lipids to more complex polymeric phenolics, called phlorotannins. Glombitza and co-workers performed extensive research into isolating phlorotannins (isolated and purified in their peracetylated form) from brown algae. ${ }^{60-66}$ This included undecafuhalol octacosa-acetate (45), the largest of the polymeric phenols to be defined during their research at the time, isolated from Bifurcaria bifurcate. ${ }^{64}$ The tropical brown alga Stypopodium zonale was found to excrete a rust-coloured substance that rendered seawater toxic to fish. The excretion turned out to be the orthoquinone stypoldione (46), the aerial oxidation product of stypotriol (47), which is the more toxic of the two compounds. ${ }^{67}$ The algae specimen was found to also contain stypodiol (48), epistypodiol (49). ${ }^{67-68}$ The order Dictyotales was also studied with isolated compounds typified by the presence of diterpenes and, to a lesser extent, sesquiterpenes. One family of diterpenes are 'spatanes', which contain a diterpene analogue of the bourbonene skeleton. Spatol (50), obtained from Spatoglossum schmittii, was the first metabolite of the spatane series to be described. ${ }^{69}$ Spatol showed potent cytotoxicity in the urchin egg assay, which was believed to be associated with the 1,3-diepoxide moiety in the side chain. ${ }^{69}$ Several more studies in the early 1980s found more diterpenoid spatanes from other brown algae sources. ${ }^{47}$

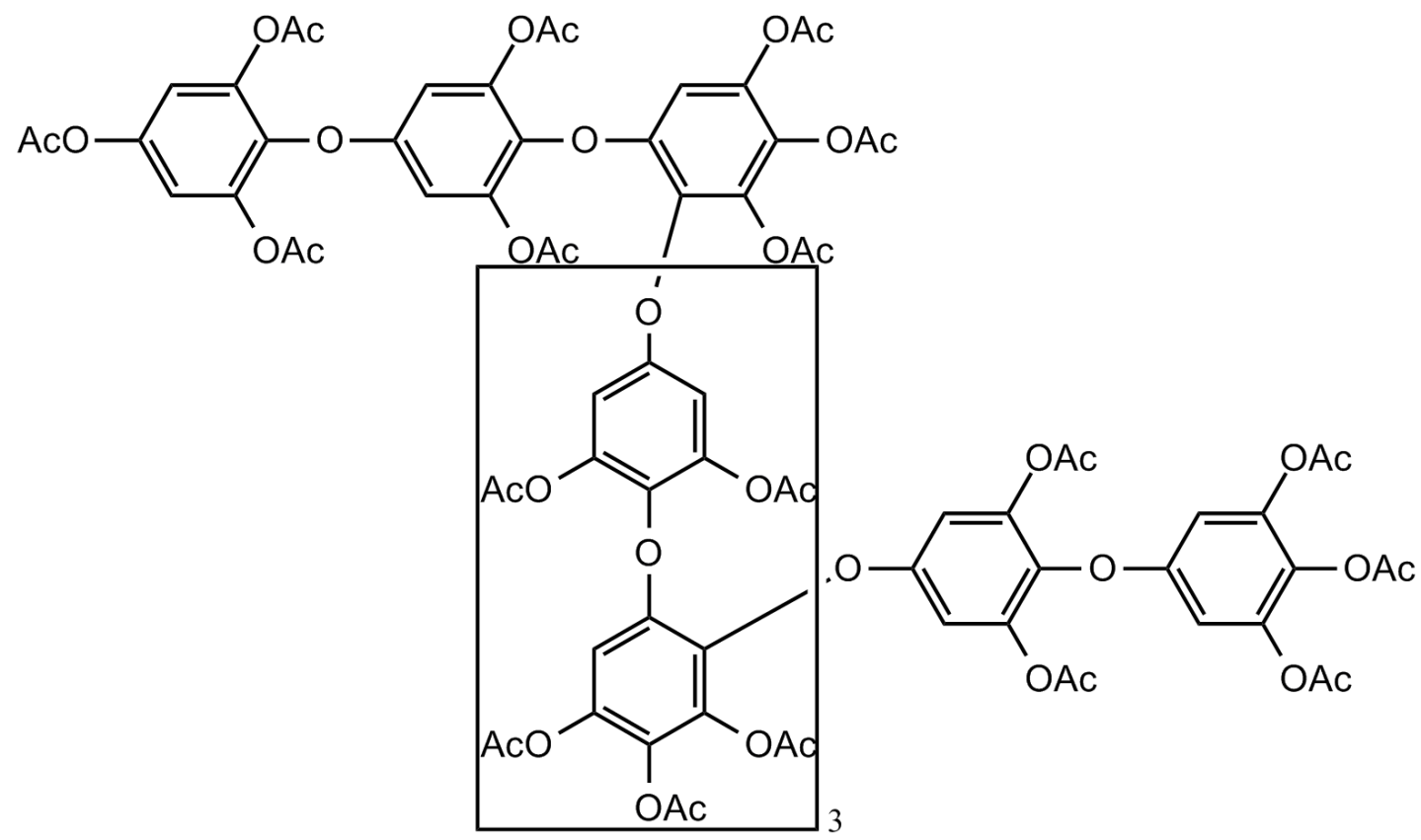


<smiles>CC1=CC(=O)C(=O)C2=C1O[C@]1(C2)[C@@H](C)CC[C@@H]2[C@@H]1CC[C@]1(C)C(C)(C)[C@@H](O)CC[C@]21C</smiles>

46<smiles>Cc1cc(O)c(O)c2c1O[C@]1(C2)[C@@H](C)CC[C@H]2[C@]3(C)CC[C@H](O)C(C)(C)[C@@]3(C)CC[C@@]21C</smiles>

47

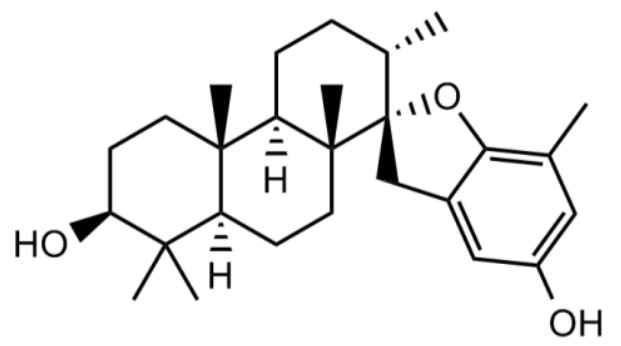

48

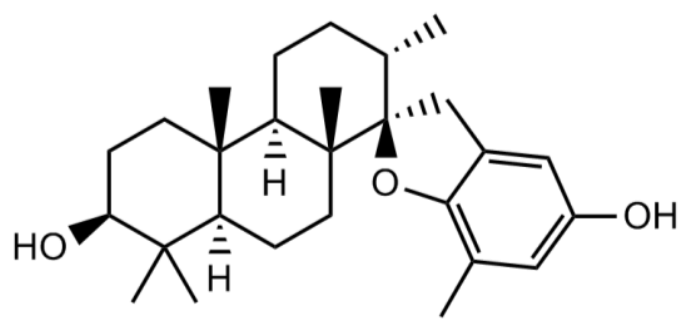

49

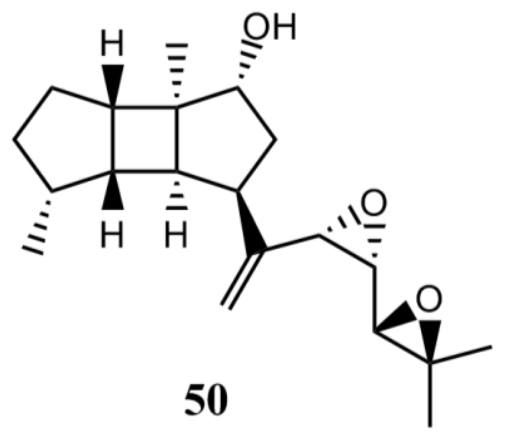

Early studies into red algae (Rhodophyta) found that they contained a vast array of halogenated lipids, monoterpenes, sesquiterpenes and diterpenes. Halogenated monoterpene isolates included two antimicrobial metabolites from Plocamium cruciferum discovered by Blunt, Munro and co-workers. ${ }^{70-71}$ They were shown to be a polyhalogenated monoterpene (51) and a bisnormonoterpenoid (52). Halogenated sesquiterpenes, such as the chamigrenes, were discovered frequently in early red algae analysed. Such chamigrenes included glanduliferol (53), isolated from Laurencia glandulifera. ${ }^{72-73}$ The halogenated selinanes represented a more distinct group of compounds from the genus Laurencia. The compound $(1 S, 4 R, 7 R)-1$-bromo-4-hydroxy7-chloroselinane (54) was found in an undescribed Australian Laurencia species. ${ }^{74}$ Along with the work on halogenated monoterpenes, Blunt, Munro and co-workers discovered the unusual squalene derived metabolite thyrsiferol (55) from the red alga Laurencia thyrsifera. ${ }^{75}$ Thyrsiferol was subsequently found to exhibit inhibition in human breast tumour cell lines. ${ }^{76}$ Some non-halogenated metabolites were found in early studies including macrocyclic lipids such as (56), which was isolated from 
Phacelocarpus labilladieri. ${ }^{77}$ The $y$-pyrone was found to have a macrocyclic acetylenecontaining ring cyclised through an enol ether linkage.<smiles>C/C(=C\C[C@@H](Cl)[C@](C)(Br)CCl)[C@@H](Cl)C(Br)Br</smiles>

51

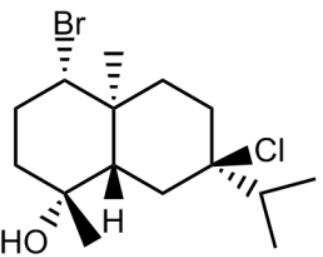

54<smiles>CC(Cl)=CCC(O)C(C)=CCl</smiles>

52

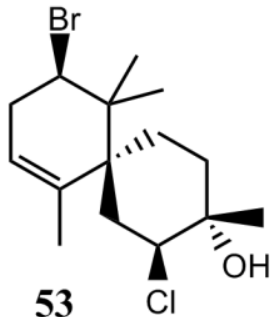

53<smiles>CC(C)(O)[C@@H]1CC[C@@](C)([C@H](O)CC[C@H](O)[C@H]2CC[C@H]3O[C@](C)([C@H]4CC[C@@H](Br)C(C)(C)O4)CC[C@]3(C)O2)O1</smiles>

55<smiles>CCNC1=CC/C=C\C/C=C\CC#CCCCCc2cc(=O)cc(o2)O1</smiles>

56

In the mid 1980's, marine natural products chemistry became more bioassay driven with a particular emphasis on mammalian cell cytotoxicity in the hope of finding anticancer compounds. The study of algae diminished in favour of marine sponges and tunicates, the extracts of which showed higher cytotoxicity in these bioassays. Recently, as structurally driven marine natural products have become more widely utilised, macro-algae studies have been rejuvenated by several natural products groups leading to the discovery of further novel compounds, with interesting bioactivity. Algal collections from tropical, temperate and polar regions ${ }^{78}$ have proven to be a good source of novel compounds with much structural diversity. Annual reviews from the last 10 years have stated that the number of secondary metabolites reported from green algae have been in decline each year while brown algae secondary metabolite numbers reported have been in decline since 2009. However, 
the number of compounds from red algae, which saw a decline in 2008 , has picked up again in recent years. ${ }^{79-80}$

Novel green algae secondary metabolites reported in recent years have largely been from a single family of compounds, the kahalides, isolated entirely from Bryopsis pennata. The two most recent kahalides reported were two cyclic depsipeptides 5OHKF (57) and norKA (58). ${ }^{81}$ One member of the kahalide family, kahalide $F(59)$ has been under active development as an anti-cancer drug and has reached phase two clinical studies. $^{81}$

Terpenes and polyphenols are the dominant classes of secondary metabolites isolated from brown algae. Novel phlorotannins also continue to be isolated, including diphlorethohydroxycarmalol (60) from Ishige okamurae. ${ }^{82}$ Compound 60 was found to possess radical-scavenging activity in addition to potent inhibition of $\alpha$-glucosidase and $\alpha$-amylase, with possible potential as a functional food or nutraceutical for diabetes.

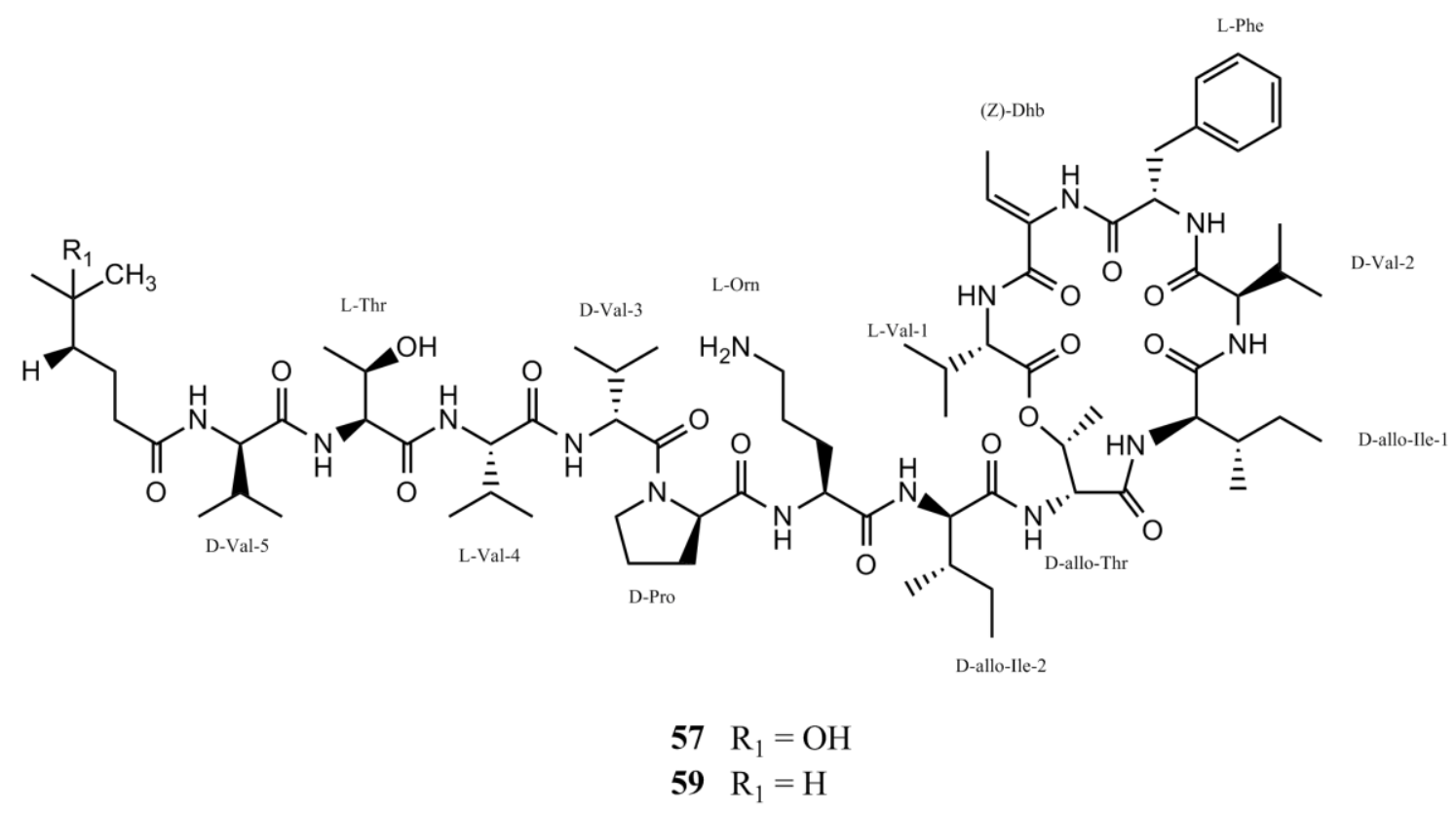




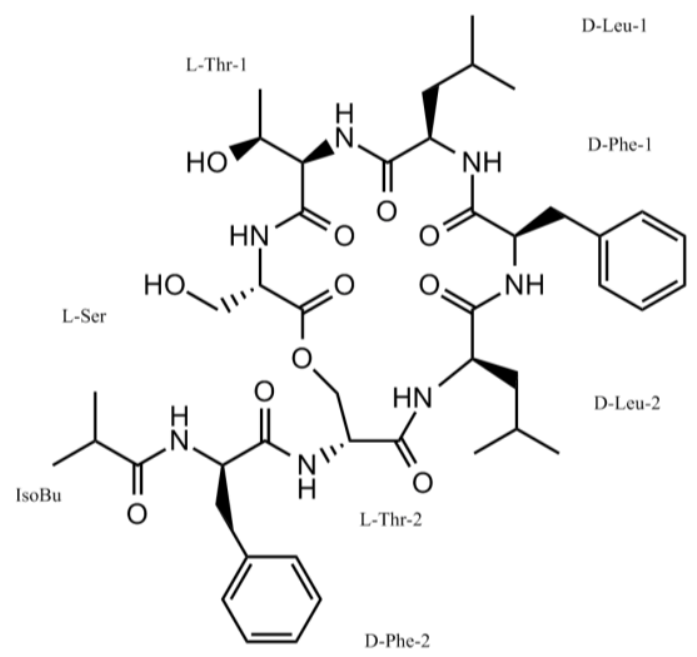

58<smiles>Oc1cc(O)cc(Oc2c(O)cc3c(c2O)Oc2cc(Oc4c(O)cc(O)cc4O)c(O)c(O)c2O3)c1</smiles>

60

Red algae continue to be a prolific source of polyhalogenated secondary metabolites, while more recently, other classes have been reported including oxylipins and bromophenols. Oxylipins (or eicosanoids), such as 61 and 62 isolated from Rhodymenia pertusa, and labillarides A-K (63-73) isolated from Phacelocarpus labilladieri, have been found. ${ }^{40,83}$ Compounds of this nature are derived from fatty acids by pathways involving at least one step of dioxygen-dependent oxidation. ${ }^{83}$ Biosynthesis of oxylipins is initiated by lipoxygenase enzymes. ${ }^{84}$ Products of the lipoxygenase pathway, in mammalian tissues, are pivotal signalling molecules in many physiological and pathophysiological conditions including asthma. ${ }^{85}$ Bromophenol compounds, such as $\mathbf{7 4}$ from Symphyocladia latiuscula have also been isolated recently. ${ }^{86}$ These compounds are of interest as they show nitrite scavenging, $\alpha$ glucosidase inhibition, antioxidant, feeding-deterrent, anti-inflammatory and aldose reductase inhibitory activities. 
<smiles>CCC#CCC=CC=C[C@H](O)[C@@H](O)CCCC(=O)O</smiles>

\section{1}

$62 \triangle$ saturated<smiles></smiles>

64

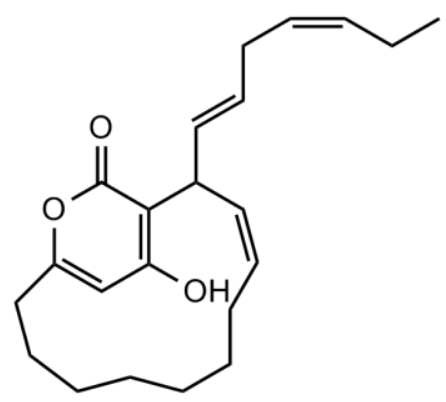

66<smiles></smiles>

71<smiles>CC/C=C/C/C=C/C=C/CCCCCCCCC1=CC(=O)CO1</smiles><smiles>CC/C=C\CC(/C=C\C=C/CCCCCCCc1cc(CC2C=CC2=O)cc(=O)o1)CC</smiles>

63

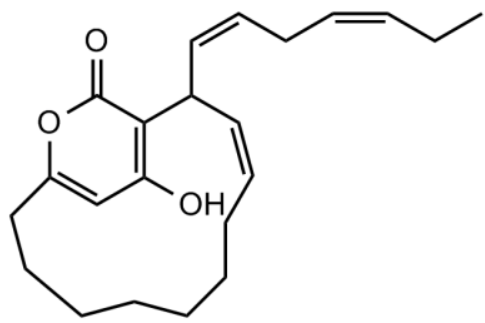

65

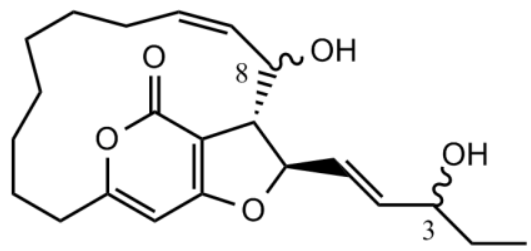

67

68 3,8-epi

69 8-epi

70 3-epi<smiles></smiles>

72<smiles>Oc1c(O)c(Br)c(Cc2c(Br)c(O)c(O)c(Br)c2Br)c(Br)c1Br</smiles> 


\subsection{VUW Algall Studies}

Popplewell's previous study was undertaken in the marine natural products group at VUW, examining 34 temperate New Zealand red algae for the presence of novel secondary metabolites. Across the 34 samples, examined with the VUW HSQC screening protocol, four showed interesting signals that were studied in further detail. From two of these samples, distinctive signals were observed consistent with known monoterpene and indole-containing compounds. Purification of the other two samples led to the isolation of the aforementioned novel macrolides, labillarides A-K (63-73) from Phacelocarpus labilladieri and the novel nitrogenous bromophenol, colensolide A (75) from Osmundaria colensoi. ${ }^{40,87}$ Biological testing of the labillarides showed that $\mathbf{6 3}, \mathbf{6 4}$ and 71 showed moderate cytotoxicity while 65 showed moderate antibacterial activity. The successful study showed the prominence of novel secondary metabolites in New Zealand algal samples.<smiles>CO[C@]12CCN(Cc3cc(O)c(O)c(Br)c3Br)[C@H]1NC(=O)N2</smiles>

75

The marine natural products laboratory at VUW has, over the last few years, expanded its marine organism collection sites, from the temperate waters of New Zealand to the tropical waters of Tonga. Tropical algae that had been collected across two dive trips to Tonga had not yet been studied, however, work conducted in house with tropical sponges had found that they possess a higher concentration of secondary metabolites along with more structural diversity than their temperate counterparts. During this study a variety of red, brown and green algae, from Tongan sources, were assessed. 


\subsection{Algae Screening}

In this study, a total of 11 algae were screened using the HSQC screening protocol. Additional HMBC spectral data was obtained for each sample and a computer based mask was generated using software developed in the marine natural products group at VUW. ${ }^{39}$ The mask initially revealed similarities between several samples indicating similar compounds within multiple samples. The results of the 11 screens, of the medium polarity crude extracts ( $75 \% \mathrm{Me}_{2} \mathrm{CO}$ in $\mathrm{H}_{2} \mathrm{O}$ sample) are summarised in Table 2.1. Additional discussion is provided for samples PTN4_17G, PTN4_18E and PTN3_38C, which contained the most interesting NMR resonances.

Table 2.1 Summary of the screening of 11 algae samples.

\begin{tabular}{|c|c|c|c|c|}
\hline Algal Sample & Collection Site & $\begin{array}{c}\text { Algae Type } \\
\text { (Colour) }\end{array}$ & $\begin{array}{l}\text { Presence of a Common } \\
\text { Glyceroglycolipid } \\
\text { (Oxymethine and } s p^{2} \\
\text { resonances) }\end{array}$ & Additional Strong Signals \\
\hline PTN4_17G & Houma Blowholes, Tongatapu & green & yes & - \\
\hline PTN4_05H & Hunga Magic, Vava'u & red & yes & - \\
\hline PTN4_13F & Ledges, Vava'u & red & yes & - \\
\hline PTN3_33A & Ano Beach, Vava'u & brown & yes & - \\
\hline PTN3_33B & Ano Beach, Vava'u & brown & yes & - \\
\hline PTN4_18E & Houma Blowholes, Tongatapu & brown & yes & methylidene functionality \\
\hline PTN4_17D & Houma Blowholes, Tongatapu & red & yes & $\begin{array}{l}\text { Downfield carbonyl } \\
\text { functionality }\end{array}$ \\
\hline
\end{tabular}




\subsection{The Common Glyceroglycolipid - PTN4_17G}

As seen from Table 2.1, all 11 of the algae specimens screened showed oxymethine and $s p^{2}$ resonances characteristic of glycolipid compounds. Upon comparison with other screens in this study, it was apparent that most of the characteristic glycolipid signals were identical between species. Interestingly these common resonances were not prominent in any of the previously screened New Zealand algae, so an investigation of these signals was initiated. PTN4_17G was the first algae sample screened in this study that showed these glycolipid characteristics. The sample was subjected to further purification steps in order to determine the structure of the common metabolite.

PTN4_17G, an unidentified green alga, was collected from the Houma blowholes on the Tongan island of Tongatapu. Analysis of the 1D and 2D data of the crude sample showed the presence of resonances attributable to a number of oxymethine protons $\left(\delta_{C} 60-80, \delta_{H} 3-5\right)$, carbonyl carbons $\left(\delta_{C} 160-180\right)$ and $s p^{2}$ carbons. Further purification involved firstly stepwise elution from $\mathrm{H}_{2} \mathrm{O}$ through to $\mathrm{MeOH}$ on a $2 \mathrm{ml} \mathrm{HP2Oss} \mathrm{column}$ and secondly, stepwise elution from $\mathrm{CH}_{2} \mathrm{Cl}_{2}$ through EtOAc to $\mathrm{MeOH}$ on a $2 \mathrm{ml} \mathrm{DIOL}$ column. The sample came off the HP20ss column in $100 \% \mathrm{MeOH}$ and also came off the DIOL column in $\mathrm{MeOH}$. The full molecular formula for the compound was not possible as mass spectrometry did not provide a relevant $[\mathrm{M}+\mathrm{H}]^{+}$pseudomolecular ion peak. Therefore full determination of the molecular formula and structure was unable to be attained.

Analysis of the spectra revealed that the unknown glycolipid compound contained a single sugar moiety. Six signals were observed in the HSQC consisting of one anomeric $\left(\mathrm{CH}-1^{\prime} \delta_{\mathrm{C}} 99.8, \delta_{\mathrm{H}} 4.76\right)$, four oxymethines $\left(\mathrm{CH}-2^{\prime} \delta_{\mathrm{C}} 73.3, \delta_{\mathrm{H}} 3.40, \mathrm{CH}-3^{\prime} \delta_{\mathrm{C}} 74.7, \delta_{\mathrm{H}}\right.$ 3.63, $\left.\mathrm{CH}-4^{\prime} \delta_{\mathrm{C}} 74.8, \delta_{\mathrm{H}} 3.08, \mathrm{CH}-5^{\prime} \delta_{\mathrm{C}} 69.7, \delta_{\mathrm{H}} 4.07\right)$ and one deshielded methylene $\left(\mathrm{CH}_{2}-6^{\prime} \delta_{\mathrm{C}} 54.0, \delta_{\text {На }} 3.35, \delta_{\text {нь }} 2.92\right)$.

A series of COSY correlations observed $\left(\mathrm{H}-\mathrm{1}^{\prime}\right.$ to $\mathrm{H}-2^{\prime}, \mathrm{H}-2^{\prime}$ to $\mathrm{H}-3^{\prime}, \mathrm{H}-3^{\prime}$ to $\mathrm{H}-4^{\prime}, \mathrm{H}-4^{\prime}$ to $H-5^{\prime}, H-5^{\prime}$ to $H-6^{\prime} a, H-5^{\prime}$ to $H-6^{\prime} b$ and $H-6^{\prime}$ a to $H-6^{\prime} b$ ), revealed a linear carbon chain typical of a sugar moiety, represented in Figure 2.2. The unusual carbon and proton shifts of $\mathrm{CH}_{2}-6^{\prime}\left(\delta_{\mathrm{C}} 54.0, \delta_{\mathrm{Ha}} 3.35, \delta_{\mathrm{Hb}} 2.92\right)$ revealed that this position was not a standard pyrano-hexose oxymethylene. The upfield shift in the carbon dimension 
indicated the presence of an amino functionality attached to position six, as shown in Figure 2.2. This aminomethylene six position signal was observed in all the sample screens and showed no further correlations suggestive of amide functionality at the position. Tabulated NMR of PTN4_17G is provided in Table 2.2.

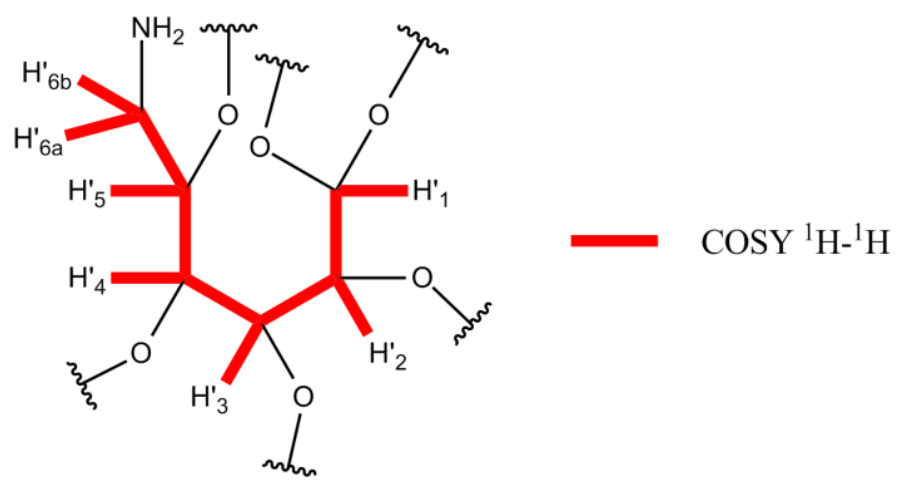

Figure 2.2 COSY correlations establishing a carbon chain consistent with a sugar moiety.

Correlations observed in the HMBC experiment $\left(\mathrm{H}-1^{\prime}\right.$ to $\mathrm{C}-2^{\prime}, \mathrm{C}-3^{\prime}$ and $\mathrm{C}-5^{\prime} ; \mathrm{H}-2^{\prime}$ to $\mathrm{C}-3^{\prime}$; $\mathrm{H}-3^{\prime}$ to $\mathrm{C}-2^{\prime}$ and $\mathrm{C}-4^{\prime} ; \mathrm{H}-4^{\prime}$ to $\mathrm{C}-3^{\prime}, \mathrm{C}-5^{\prime}$ and $\mathrm{C}-6^{\prime} ; \mathrm{H}-5^{\prime}$ to $\mathrm{C}-4^{\prime}$ and $\mathrm{C}-6^{\prime}$; and finally $\mathrm{H}-6^{\prime} \mathrm{b}$ to $\mathrm{C}^{\left.-5^{\prime}\right)}$ confirmed the COSY assignments. The $\mathrm{HMBC}$ correlation observed from $\mathrm{H}-1^{\prime}$ to $C-5^{\prime}$ revealed an ether linkage between $C-1^{\prime}$ and $C-5^{\prime}$ which established a 6-deoxy-6amino sugar moiety ring system seen in Figure 2.3.

Further analysis of the 2D spectra revealed a second spin system that contained two oxymethylenes $\left(\mathrm{CH}_{2}-1 \delta_{\mathrm{C}} 64.0, \delta_{\mathrm{Ha}} 4.51, \delta_{\mathrm{Hb}} 4.18\right.$ and $\left.\mathrm{CH}_{2}-3 \delta_{\mathrm{C}} 66.9, \delta_{\mathrm{Ha}} 4.11, \delta_{\mathrm{Hb}} 3.57\right)$ and an oxymethine $\mathrm{CH}-2\left(\delta_{\mathrm{C}} 71.5, \delta_{\mathrm{H}}\right.$ 5.31). In the HSQC experiment $\mathrm{CH}_{2}-1$ was discerned due to its deshielded proton shifts. COSY correlations were observed from $\mathrm{H}-1 \mathrm{a}, \mathrm{b}$ to $\mathrm{H}-2$ an oxymethine, which established a bond between $\mathrm{C}-1$ and $\mathrm{C}-2$. The bond between C- 2 and C-3 was determined by COSY correlations observed between $\mathrm{H}$ 2 and $\mathrm{H}-3 \mathrm{a}, \mathrm{b}$. No further COSY correlations were observed which indicated that $\mathrm{C}-1, \mathrm{C}-$ 2 and C-3 made up a glycerol subunit. Analysis of the HMBC spectrum revealed correlations from $\mathrm{H}-1^{\prime}$ to $\mathrm{C}-3$ and $\mathrm{H}-3 \mathrm{a}, \mathrm{b}$ to $\mathrm{C}-1^{\prime}$ which indicated that the glycerol subunit was attached to the sugar moiety through $C-1^{\prime}$, as shown in Figure 2.3. This indicated that the common compound seen across most of the algal screens was a glyceroglycolipid. The coupling constants of $\mathrm{H}-1^{\prime}(3.7 \mathrm{~Hz})$ and $\mathrm{H}-2^{\prime}(9.7$ and $3.8 \mathrm{~Hz}$ ) could be determined which provided evidence that $\mathrm{H}-\mathrm{I}^{\prime}$ was equatorial therefore the linkage between the sugar moiety and the glycerol moiety was determined to be an $\alpha$ linkage. 


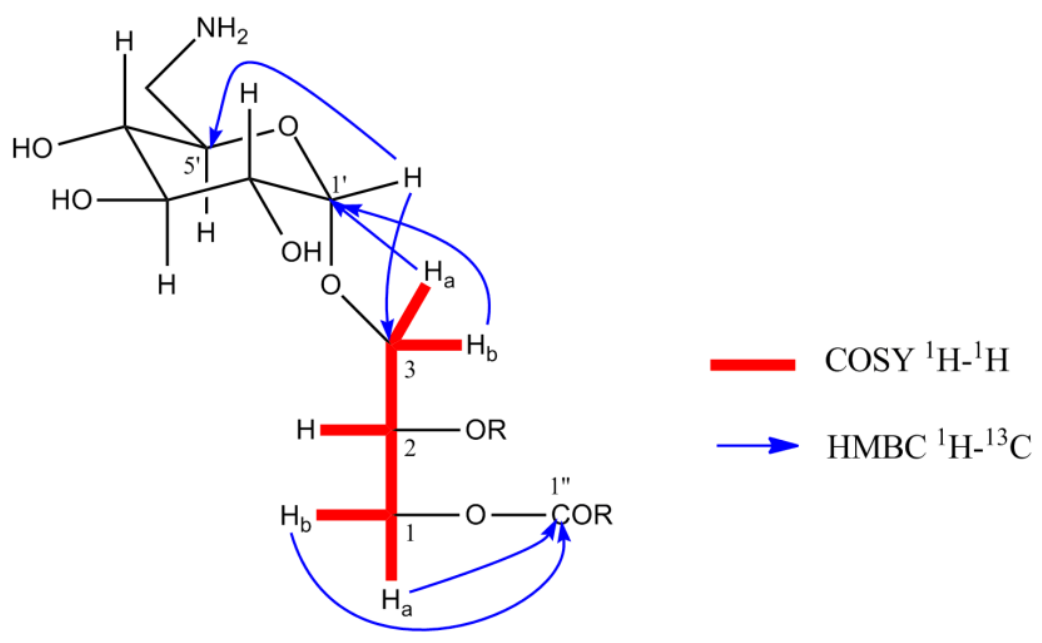

Figure 2.3 COSY and HMBC correlations establishing glycerol functionality attached at C-1'.

HMBC correlations were observed from $\mathrm{H}-1 \mathrm{a}$, b to a carbonyl C- $1^{\prime \prime}\left(\delta_{C} 174.9\right)$ which confirmed the presence of an ester functionality, illustrated in Figure 2.3. Although it was not observed, the chemical shift of $\mathrm{H}-2\left(\delta_{\mathrm{H}} 5.31\right)$ was consistent with the attachment of an acyl unit (approximate $1 \mathrm{ppm}$ downfield shift from expected if the functional group was a hydroxyl). Due to inconclusive mass spectrometry data the fatty acid chain lengths could not be determined.

The full relative stereochemistry of the sugar moiety was determined using the coupling constants of the protons around the ring system. The anomeric proton $\mathrm{H}-1^{\prime}$ was observed to be a doublet with a coupling constant of $3.7 \mathrm{~Hz}$ which is indicative of an axial-equatorial relationship with $\mathrm{H}-2^{\prime}$. Proton $\mathrm{H}-2^{\prime}$ was determined to be axial on the $\alpha$ face of the ring (therefore an $\alpha$ configuration at $C-1^{\prime}$ ) as it was revealed to be a doublet of doublets with a large coupling constant of $9.7 \mathrm{~Hz}$ to $\mathrm{H}-3^{\prime}$, indicative of a 1,2trans diaxial relationship. Proton $\mathrm{H}-4$ ' was observed to be a triplet with a coupling constant of $9.3 \mathrm{~Hz}$ which indicated a 1,2-diaxial relationship with $\mathrm{H}-3^{\prime}$, confirming that $\mathrm{H}-3^{\prime}$ was in an axial position on the $\beta$ face. A large coupling constant of $9.5 \mathrm{~Hz}$ was observed for the broad triplet $\mathrm{H}-5^{\prime}$ signal which confirmed that $\mathrm{H}-4^{\prime}$ was axial on the $\alpha$ face and therefore $\mathrm{H}-5^{\prime}$ was axial on the $\beta$ face. This confirmed that the sugar moiety contained $\alpha$-D-glucose stereochemistry, with the structure provided in Figure 2.4. 


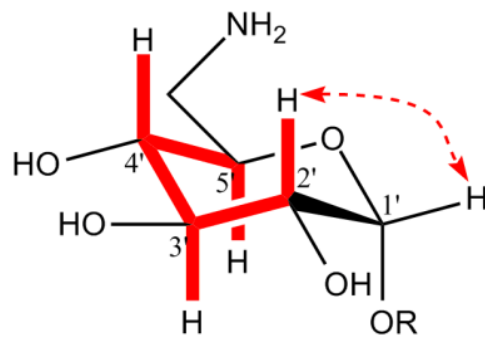

OR
Small ${ }^{1} \mathrm{H}-{ }^{1} \mathrm{H}$ coupling

Large 1,2 diaxial

vicinal coupling

$\mathrm{R}=$ glycerolipid

Figure 2.4 The relative stereochemistry of the aminosugar moiety of $\mathbf{7 6}$ determined by coupling constants.

In general, glyceroglycolipids are common compounds isolated from higher plants and macro-algae. Amination of sugar analogues is most commonly observed at the two position, in the form of 2-deoxy-2-amino (or 2-acetamido) sugar moieties, with such moieties seen in compounds distributed amongst different marine organisms. Glyceroglycolipid compounds containing the 6-deoxy-6-amino glucose moiety are considered to be extremely rare with isolation of such compounds sparsely reported.

The first reported isolation of glyceroglycolipids containing the rare sugar moiety were strangulatosides (77-78), isolated in 2001 from rhizomes of the terrestrial Chinese herbaceous plant Serratula strangulata. ${ }^{88}$ The linolenoyl group is a polyunsaturated fatty acid containing 18 carbons and three double bonds. The compound avrainvilloside (79) was isolated from the green alga Avrainvillea nigricans in 2005, collected in Prince Rupert Bay of Portsmouth (Dominica). ${ }^{89}$ In this particular study, avrainvilloside was found to be inactive in murine fibrosarcoma studies. ${ }^{89}$ Two separate studies of the terrestrial plants Desmodium gangeticum, 2005 and Ocimum sanctum, 2007 led to the isolation of an aminoglucosyl glycerolipid (80) and ocimumoside $A(\mathbf{8 1})$ respectively. ${ }^{90-91}$ Compound $\mathbf{8 0}$ was found to exhibit in vitro antileishmanial and immunomodulatory activity..$^{90}$ Most recently, a study of the brown algae Ishige okamurae led to the isolation of ishigoside (82) a potential free-radical scavenger against hydroxyl and alkyl radicals. ${ }^{92}$

The main difference between compounds 79-82, apart from the differing fatty acid chain length, is that $\mathbf{8 0}$ contains a $\beta$-linkage between the glucose and glycerol moieties whereas 79, 81 and 82 contain an $\alpha$-link at the same position. As demonstrated by structures 77-82, these glyceroglycolipids only differ in their fatty acid chain lengths, although additional functionality off the amino centre is possible, as seen in $\mathbf{7 8}$. The spectral data in this study confirms that the unknown glyceroglycolipid is similar to the 
previously isolated compounds $\mathbf{7 9 , 8 1}$ and $\mathbf{8 2}$, however the length and presence of $s p^{2}$ carbons in the purported fatty acid chains of $\mathbf{7 6}$ were unknown in this study.

The presence of the glyceroglycolipid in most Tongan (sub-tropical) and seeming absence in New Zealand (temperate) algae is of interest as it poses questions about whether environmental factors play a role in primary metabolite production in algae specimens. Detection of this metabolite in such high levels across red, brown and green tropical algae was another interesting outcome from this study that could not be explained without further investigation.

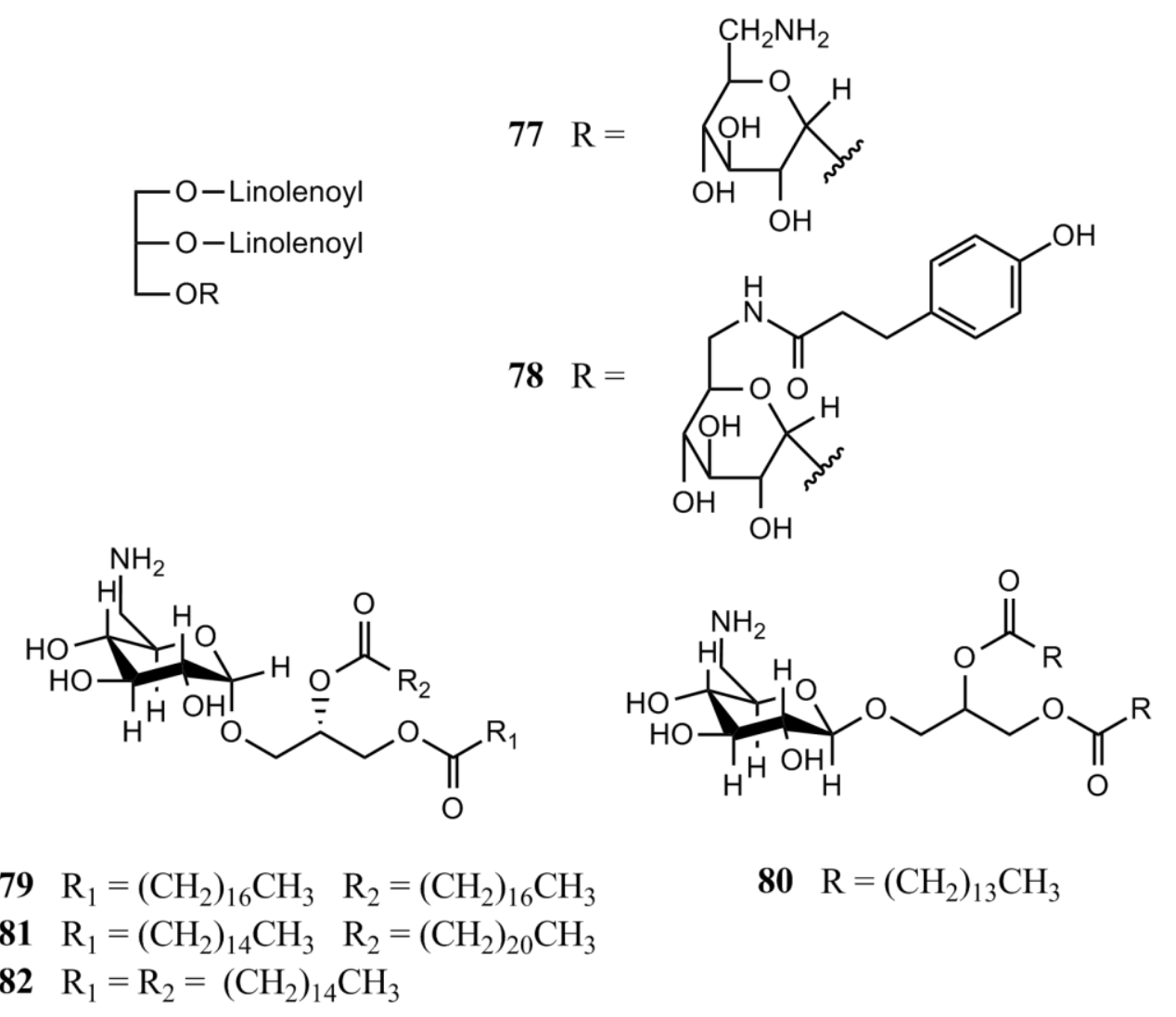


Table $2.2{ }^{13} \mathrm{C}(150 \mathrm{MHz})$ and ${ }^{1} \mathrm{H}(600 \mathrm{MHz}) \mathrm{NMR}$ data $\left(\mathrm{CD}_{3} \mathrm{OD}\right)$ for $\mathbf{7 6}$.

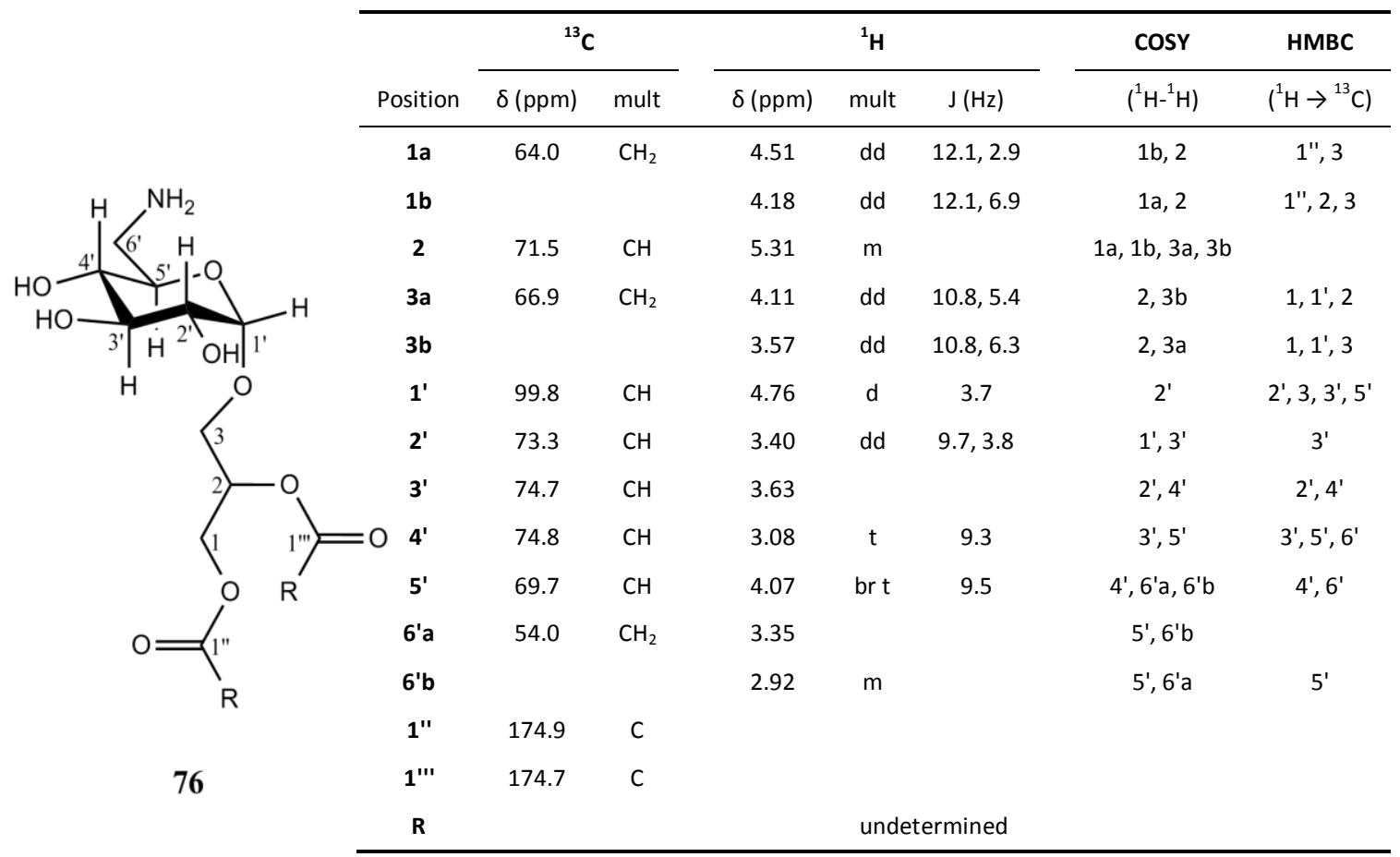

\subsection{The Methacrylic Acid Moiety - PTN4_18E}

PTN4_18E, an unidentified brown alga, was collected at the Houma Blowholes on the Tongan island of Tongatapu. A number of oxymethine resonances and $s p^{2}$ carbon resonances were present in the $1 D$ and $2 D$ experiments run, matching resonances seen across most of the algal specimens. Some additional peaks were of interest in the HMBC screen while the HSQC screen revealed the presence of a methylidene group which warranted further investigation.

Two DIOL column purifications were performed allowing for structural elucidation of the compound to be achieved. The first column involved stepwise elution from $\mathrm{CH}_{2} \mathrm{Cl}_{2}$ to $\mathrm{MeOH}$ through EtOAc, while the second column was eluted stepwise from hexanes to $\mathrm{MeOH}$ through $\mathrm{CH}_{2} \mathrm{Cl}_{2}$. From the $50 \% \mathrm{CH}_{2} \mathrm{Cl}_{2}$ in hexanes fraction, spectral analysis was performed, elucidating 83. The sample was submitted for mass spectrometry analysis, however, no relevant $[\mathrm{M}+\mathrm{H}]^{+}$was attained which left an unknown molecular formula. Analysis of the HSQC experiment revealed that the terminal methylene group $\mathrm{CH}_{2}-4\left(\delta_{\mathrm{C}} 124.4, \delta_{\mathrm{Ha}} 6.24, \delta_{\mathrm{Hb}} 5.82\right)$ observed an allylic COSY correlation from $\mathrm{H}-4 \mathrm{a}, \mathrm{b}$ to an oxymethylene group $\mathrm{CH}_{2}-3\left(\delta_{C} 69.4, \delta_{H} 4.21,2 \mathrm{H}\right)$. HMBC correlations were observed from H-4a,b to $\mathrm{C}-3$ and $\mathrm{C}-1$, a carbonyl carbon $\left(\delta_{c} 169.2\right)$; with the shift of this centre consistent with an $\alpha, \beta$-unsaturated carboxylic acid. Weak HMBC 
correlations were observed from $\mathrm{H}-3 \mathrm{a}, \mathrm{b}$ to a non-protonated olefinic carbon $\mathrm{C}-2\left(\delta_{\mathrm{C}}\right.$ 139.4). This spectral data established the double bond between C-4 and C-2, and the single bonds from $\mathrm{C}-1$ to $\mathrm{C}-2$ and $\mathrm{C}-2$ to $\mathrm{C}-3$. This confirmed the isolated substructure seen in Figure 2.5.

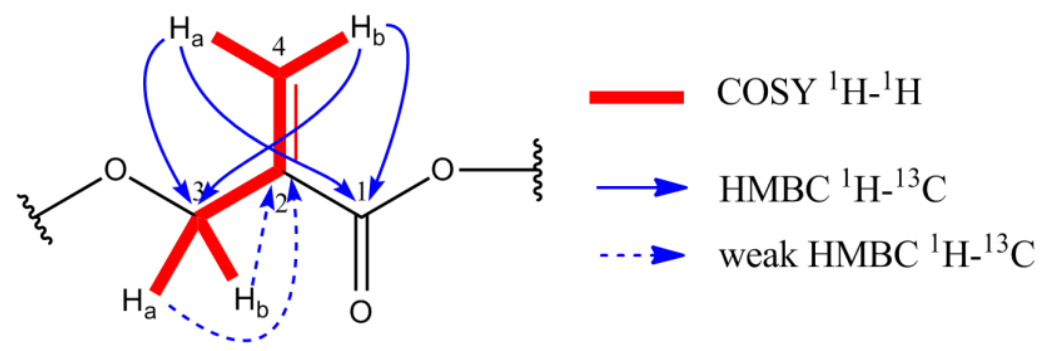

Figure 2.5 COSY and HMBC correlations establishing the methacrylic acid moiety of $\mathbf{8 3}$.

The assignment of a carboxylic acid functional group was confirmed with no additional $\mathrm{HMBC}$ correlations observed to $\mathrm{C}-1$, apart from $\mathrm{H}-3 \mathrm{a}, \mathrm{b}$ which suggested no ester functionality. A spin system containing two oxymethylenes $\left(\mathrm{CH}_{2}-5 \delta_{\mathrm{C}} 69.9, \delta_{\mathrm{H}} 3.65,2 \mathrm{H}\right.$ and $\left.\mathrm{CH}_{2}-7 \delta_{\mathrm{C}} 63.7, \delta_{\mathrm{Ha}} 4.38, \delta_{\mathrm{Hb}} 4.15\right)$ and an oxymethine $\mathrm{CH}-6\left(\delta_{\mathrm{C}} 71.5, \delta_{\mathrm{H}} 5.24\right)$ was observed with COSY correlations ( $\mathrm{H}-5 \mathrm{a}, \mathrm{b}$ to $\mathrm{H}-6$ and $\mathrm{H}-6$ to $\mathrm{H}-7 \mathrm{a}, \mathrm{b})$ establishing $\mathrm{a}$ familiar glycerol subunit C-7 to C-6 to C-5. HMBC correlations were observed from $\mathrm{H}$ $5 a, b$ to $C-3$, which established the link to the methacrylic acid moiety with additional HMBC correlations observed confirming the glycerol assignment, shown in Figure 2.6. An $\mathrm{HMBC}$ correlation was observed from $\mathrm{H}-7 \mathrm{~b}$ to a carbonyl carbon $\mathrm{C}-8\left(\delta_{c} 174.7\right)$, which established ester functionality at that position. The $\mathrm{HMBC}$ revealed methylene protons between $\delta_{\mathrm{H}}$ 2-3 ppm and several methylene carbon resonances (consistent with a fatty acid chain) correlating into the same carbonyl indicating the possible presence of a fatty acid chain. NMR data for $\mathbf{8 3}$ is provided in Table 2.3.

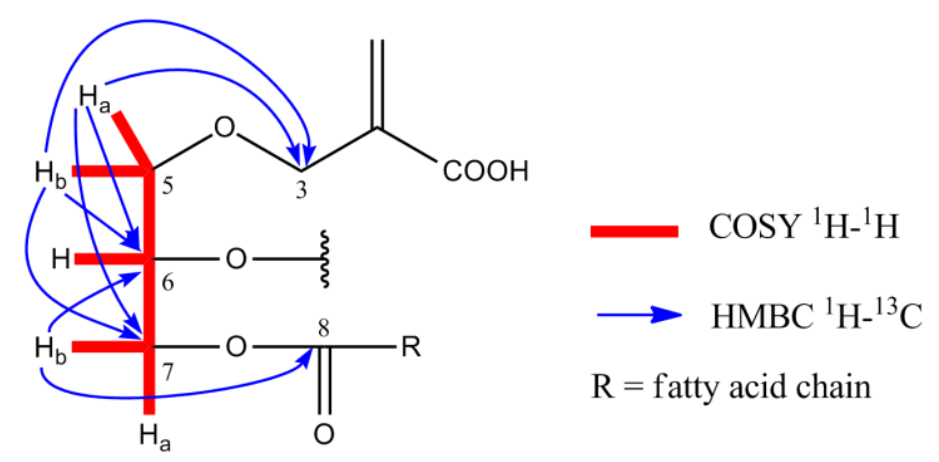

Figure 2.6 COSY and HMBC correlations establishing the glycerol subunit of $\mathbf{8 3}$. 
A study in 1981 of the brown alga, Sargassum fulvellum, isolated from Chiba, Japan described the isolation of novel types of glycerides bearing a methacrylic acid moiety (84-85), shown in Figure $2.7 . .^{93}$ On comparison with structural data of $\mathbf{8 4 - 8 5}$, the spectral data and structural elucidation of the compound isolated in this study was found to coincide (accounting for solvent differences).

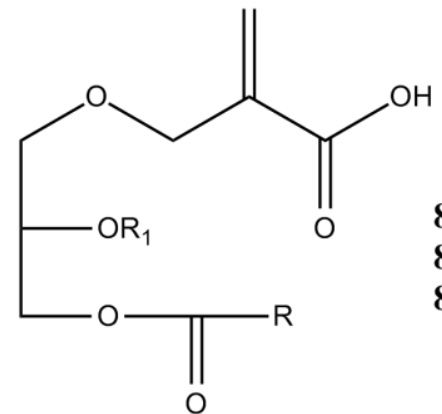

$83 \mathrm{R}=\mathrm{R}_{1}=$ unknown

$84 \mathrm{R}=\mathrm{C}_{19} \mathrm{H}_{31} \quad \mathrm{R}_{1}=\mathrm{H}$

$85 \mathrm{R}=\mathrm{C}_{19} \mathrm{H}_{35} \quad \mathrm{R}_{1}=\mathrm{H}$

Figure $\mathbf{2 . 7}$ Elucidated substructure $\mathbf{8 3}$ along with known analogues.

One significant difference from the literature suggested that two fatty acid chains may be present in $\mathbf{8 3}$ as a downfield shift of proton six was observed. Given no suitable mass spectrometry data was obtained, NMR analysis alone could not confirm the presence of a second chain. It was therefore not known whether the compound isolated in this study was compound $\mathbf{8 4}$ or $\mathbf{8 5}$, or indeed another fulvellic acid analogue. The morphology of the Tongan brown algae sample in this study was consistent with algae of the species Sargassum.

Table $2 .{ }^{13} \mathrm{C}(150 \mathrm{MHz})$ and ${ }^{1} \mathrm{H}(600 \mathrm{MHz})$ NMR data $\left(\mathrm{CD}_{3} \mathrm{OD}\right)$ for fulvellic acid analogue $8 \mathbf{3}$

\begin{tabular}{|c|c|c|c|c|c|}
\hline \multirow[b]{2}{*}{ Position } & \multicolumn{2}{|c|}{${ }^{13} \mathrm{C}$} & \multirow{2}{*}{$\frac{{ }^{1} \mathbf{H}}{\delta(\mathrm{ppm})}$} & \multirow{2}{*}{$\frac{\cos Y}{\left({ }^{1} \mathrm{H}-{ }^{1} \mathrm{H}\right)}$} & \multirow{2}{*}{$\begin{array}{c}\text { HMBC } \\
\left({ }^{1} \mathrm{H} \rightarrow{ }^{13} \mathrm{C}\right)\end{array}$} \\
\hline & $\delta(\mathrm{ppm})$ & mult & & & \\
\hline 1 & 169.2 & C & & & \\
\hline 2 & 139.4 & C & & & \\
\hline $3 a$ & 70.7 & $\mathrm{CH}_{2}$ & 4.21 & $4 a, 4 b$ & $2(w)^{*}, 4(w)$ \\
\hline $3 b$ & & & 4.21 & $4 a, 4 b$ & $2(w), 4(w)$ \\
\hline $4 a$ & 125.7 & $\mathrm{CH}_{2}$ & 6.23 & $3 a, 3 b, 4 b$ & 1,3 \\
\hline $4 b$ & & & 5.82 & $3 a, 3 b, 4 a$ & 1,3 \\
\hline $5 a$ & 69.9 & $\mathrm{CH}_{2}$ & 3.65 & 6 & $3,6,7$ \\
\hline $5 b$ & & & 3.65 & 6 & $3,6,7$ \\
\hline 6 & 71.5 & $\mathrm{CH}$ & 5.24 & $5 a, 5 b, 7 a, 7 b$ & \\
\hline $7 a$ & 63.7 & $\mathrm{CH}_{2}$ & 4.38 & $6,7 b$ & \\
\hline $7 b$ & & & 4.15 & $6,7 a$ & 6,8 \\
\hline 8 & 174.7 & C & & & \\
\hline$R$ and $R_{1}$ & & & unde & ined & \\
\hline
\end{tabular}

* $(w)$ indicates weak signals 


\subsection{Aromatic Proton Signalls - PTN3_38C}

PTN3_38C, an unidentified red alga, was collected from Split Rock, in the island group of Vava'u, Tonga. Analysis of the 1D and 2D screen spectra revealed resonances consistent with aromatic protons, $s p^{2}$ carbons and oxymethines. The presence of aromatic signals justified further purification as no previous algal sample investigated in this study had exhibited such resonances.

Given the strong resonances in the screen spectra structural elucidation could be achieved from a sample semi-purified after one DIOL column with stepwise elution from $\mathrm{CH}_{2} \mathrm{Cl}_{2}$ to $\mathrm{MeOH}$ through EtOAc. The molecular formula of $\mathbf{8 6}$ was determined to be $\mathrm{C}_{31} \mathrm{H}_{30} \mathrm{O}_{11} \mathrm{~N}_{4} \mathrm{Br}_{6}$ from a positive ion mode HRESIMS measurement of the $[\mathrm{M}+\mathrm{Na}]^{+}$ pseudomolecular ion peak at $m / z 1130.6895$ ( $\Delta-1.2 \mathrm{ppm})$. The relative abundance of an isotope cluster from $[\mathrm{M}]^{+}$to $[\mathrm{M}+12]^{+}$provided evidence consistent with six bromines present in the compound. The molecular formula required the structure to contain 16 double bond equivalents.

Given the presence of distinguishable aromatic signals, structural elucidation originated at $\mathrm{CH}-15, \mathrm{CH}-15^{\prime}\left(\delta_{\mathrm{C}} 131.6, \delta_{\mathrm{H}} 7.62\right)$, a single aromatic proton. COSY data revealed a single correlation from $\mathrm{H}-15$ to $\mathrm{H}-17$, an oxymethine $\mathrm{CH}-17\left(\delta_{\mathrm{C}} 71.4, \delta_{\mathrm{H}}\right.$ 4.76), a signal consistent with allylic coupling, illustrated in Figure 2.8. Correlations were observed in the $\mathrm{HMBC}$ spectrum from $\mathrm{H}-15$ to three non-protonated aromatic carbons $C-13\left(\delta_{C} 153.1\right), C-14$ and $C-14^{\prime}\left(\delta_{C} 118.7\right)$, and C-16 $\left(\delta_{C} 143.1\right)$ while also correlating to $\mathrm{C}-17$. An additional $\mathrm{HMBC}$ correlation indicated the presence of a carbon atom magnetically equivalent to C-15 within two to three bonds, C-15'. This suggested the presence of a symmetrical tetra-substituted aromatic benzene ring, shown in Figure 2.8. Substituent assignment around the ring was achieved by assessing the carbon shifts of $\mathrm{C}-13, \mathrm{C}-14$ and $\mathrm{C}-16$ while also accounting for the determined symmetry. Carbon 13 observed the largest downfield shift consistent with the high electronegativity of a bound oxygen functionality while carbon 16 observed a smaller downfield shift due to the lower electronegativity of a bound carbon functionality. Carbons 14 and 14' exhibited an upfield shift which suggested possible bromine attachment at these positions. 


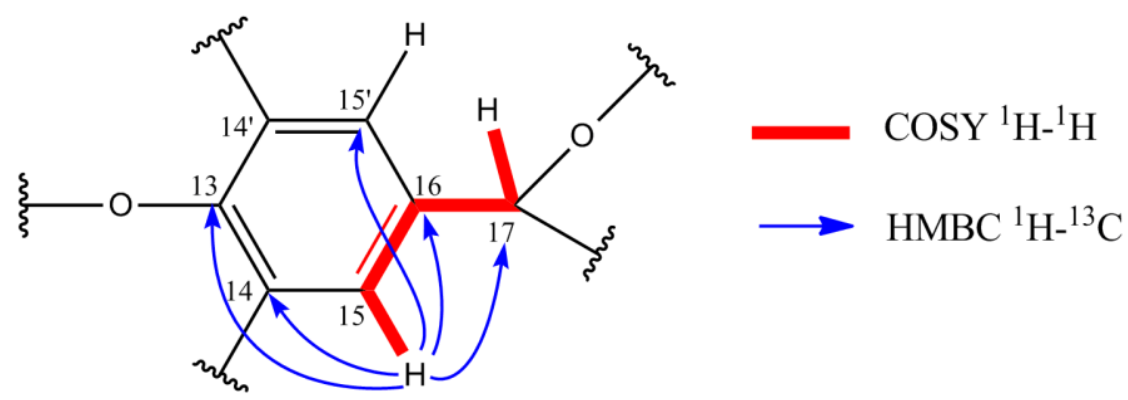

Figure 2.8 COSY and HMBC correlations establishing a symmetrical tetra-substituted aromatic ring in $\mathbf{8 6}$.

Further COSY correlations from $\mathrm{H}-17$ to $\mathrm{H}-18 \mathrm{a}$, b revealed a methylene group, $\mathrm{CH}_{2}-18$ $\left(\delta_{\mathrm{C}} 47.5, \delta_{\mathrm{Ha}} 3.49, \delta_{\mathrm{Hb}} 3.40\right)$. An HMBC correlation was observed from $\mathrm{H}-17$ to $\mathrm{C}-18$ confirming a bond between $\mathrm{C}-17$ and $\mathrm{C}-18$. Amide functionality was determined to be present, bound to $\mathrm{C}-18$, due to $\mathrm{HMBC}$ correlations observed from $\mathrm{H}-18 \mathrm{a}, \mathrm{b}$ to $\mathrm{a}$ carbonyl carbon C-9' $\left(\delta_{c} 161.5\right)$ with a resonance consistent with an amide. Protons $\mathrm{H}-$ $18 \mathrm{a}, \mathrm{b}$ are characteristically downfield, indicating that the amide functionality is bound to C-18 through the nitrogen, as shown in Figure 2.9 (typically between 2-3 ppm if bound through carbonyl).

A series of COSY correlations revealed a spin system containing an oxymethylene group $\mathrm{CH}_{2}-12\left(\delta_{\mathrm{C}} 75.7, \delta_{\mathrm{Ha}} 4.04, \delta_{\mathrm{Hb}} 3.99\right)$ bound to an oxymethine group $\mathrm{CH}-11\left(\delta_{\mathrm{C}}\right.$ $\left.69.8, \delta_{H} 4.22\right)$ with $\mathrm{CH}-11$ bound to a second methylene group, $\mathrm{CH}_{2}-10\left(\delta_{\mathrm{C}} 43.6, \delta_{\mathrm{Ha}}\right.$ $\left.3.72, \delta_{\mathrm{Hb}} 3.50\right)$, establishing a carbon chain of $\mathrm{C} 10-\mathrm{C} 11-\mathrm{C} 12$. HMBC correlations were observed confirming the carbon chain, with selected correlations shown in Figure 2.9. $\mathrm{HMBC}$ correlations from $\mathrm{H}-12 \mathrm{a}, \mathrm{b}$ to $\mathrm{C}-13$ revealed that the carbon chain was bound to the aromatic ring through an ether linkage. This confirmed the symmetrical assignment of C-14/C-14' and C-15/C-15'. Further correlations were observed in the HMBC experiment from $\mathrm{H}-10 \mathrm{a}, \mathrm{b}$ to $\mathrm{C}-9\left(\delta_{C} 161.6\right)$ a carbonyl carbon with a resonance consistent with an amide functionality. The ${ }^{13} \mathrm{C}$ and ${ }^{1} \mathrm{H}$ shifts of $\mathrm{CH}_{2}-10$ were similar to $\mathrm{CH}_{2}-18$ which established that $\mathrm{C}-10$ was bound through the amide nitrogen, illustrated in Figure 2.9. 


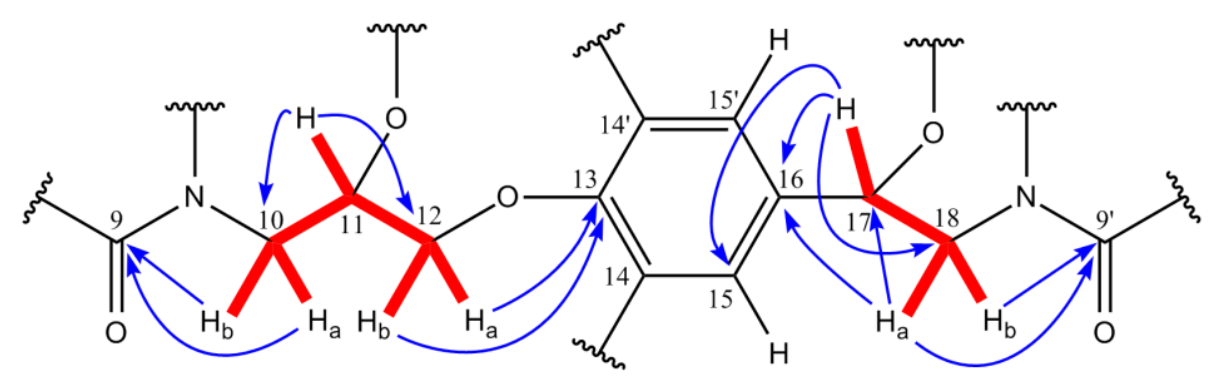

$\operatorname{COSY}{ }^{1} \mathrm{H}-{ }^{1} \mathrm{H}$

$\longrightarrow \mathrm{HMBC}{ }^{1} \mathrm{H}^{-13} \mathrm{C}$

Figure 2.9 Selected COSY and HMBC correlations establishing side chains off the aromatic ring in 86

A similar substructure is observed in fistularin-3 (86) previously reported in $1979 .{ }^{94}$ Fistularin-3 is a bromo tyrosine derived metabolite which has been found to be a distinct marker for the marine sponges belonging to the order Verongida. ${ }^{95}$ Compound $\mathbf{8 6}$ was previously isolated by Taufa in the marine natural products group at VUW from an unidentified Tongan sponge sample. ${ }^{32}$ The spectral data collected during Taufa's study was compared to the data from this study with several similarities observed suggesting that the isolated compound in this study was fistularin-3. ${ }^{32}$<smiles>CCC(O)CNC(=O)C1=NO[C@]2(C=C(Br)C(OC)=C(Br)[C@@H]2O)C1</smiles><smiles>COC1=C(Br)[C@H](O)[C@@]2(C=C1Br)CC(C(=O)NCC(O)c1cc(Br)c(OC)c(Br)c1)=NO2</smiles>

86

Confirmation of the presence of fistularin-3 was achieved by elucidating the substructure at one end of the compound. From the molecular formula it was determined that $\mathrm{C}_{18} \mathrm{H}_{8} \mathrm{O}_{6} \mathrm{~N}_{2} \mathrm{Br}_{4}$ remained, accounting for the previously assigned aromatic containing substructure. Further analysis of the spectral data revealed key COSY and $\mathrm{HMBC}$ correlations, which established the substructure shown in Figure 2.10 comprised of carbons C-1 through C-8 and C-19. These correlations revealed a 
substructure of fistularin-3 with an observed connection to the aromatic containing substructure, through an $\mathrm{HMBC}$ correlation from $\mathrm{H}-7$ a to the amide carbonyl $\mathrm{C}-9$, further confirming its presence. The presence of a second identical substructure at the other end of $\mathbf{8 6}$ was confirmed by molecular formula determination and further spectral analysis. The molecular formula of the substructure, $\mathrm{C}_{9} \mathrm{H}_{4} \mathrm{O}_{3} \mathrm{NBr}_{2}$ (excluding position nine), indicated that the remaining mass of the compound contained the identical $\mathrm{C}_{9} \mathrm{H}_{4} \mathrm{O}_{3} \mathrm{NBr}_{2}$ formula. The resonances and correlations of the second substructure were very similar to the first, as shown in Table 2.4. The ${ }^{1} \mathrm{H}$ NMR revealed shoulders on the peaks of $\mathrm{H}-1, \mathrm{H}-5, \mathrm{H}-7 \mathrm{a}$ and $\mathrm{H}-7 \mathrm{~b}$ suggestive of signal overlap which confirmed the presence of two symmetrical substructures.

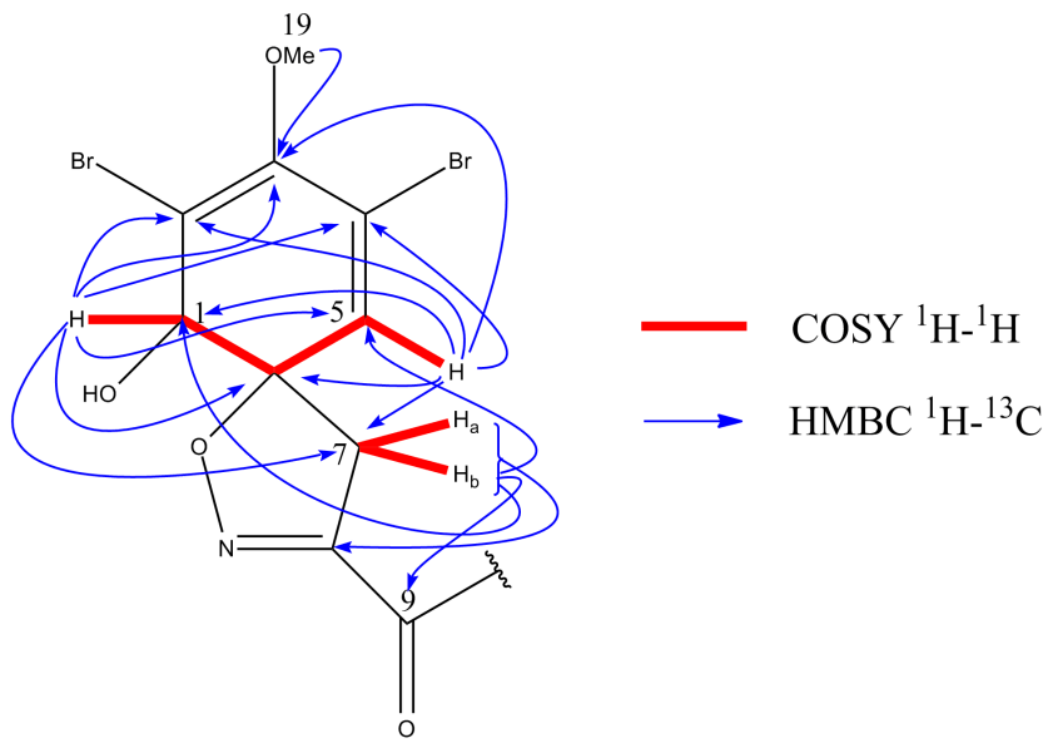

Figure 2.10 COSY and HMBC correlations establishing the terminal substructures of $\mathbf{8 6}$

The appearance of fistularin-3, a common sponge secondary metabolite, in the algal sample suggested that the initial sample extracted may have contained a sponge contaminant. Upon further investigation, it was confirmed that a small sample of an unidentified black sponge had contaminated the original extraction (see Figure 2.11). The sponge contaminant was approximately $2 \times 1 \mathrm{~cm}$, and weighed $0.22 \mathrm{~g}$. The appearance of fistularin-3 in the sample, given the mass of sponge compared to algae present, indicated that Tongan sponges contain much higher concentrations of secondary metabolites than their algae counterparts. 
A second extraction of PTN3_38C was performed, ensuring there was no sponge contamination. The screen spectra revealed several resonances in the oxymethine region, consistent with the commonly observed glyceroglycolipid, however, no aromatic resonances attributable to fistularin-3 were observed. This confirmed that the sponge accounted for the interesting signals observed after the first extraction.
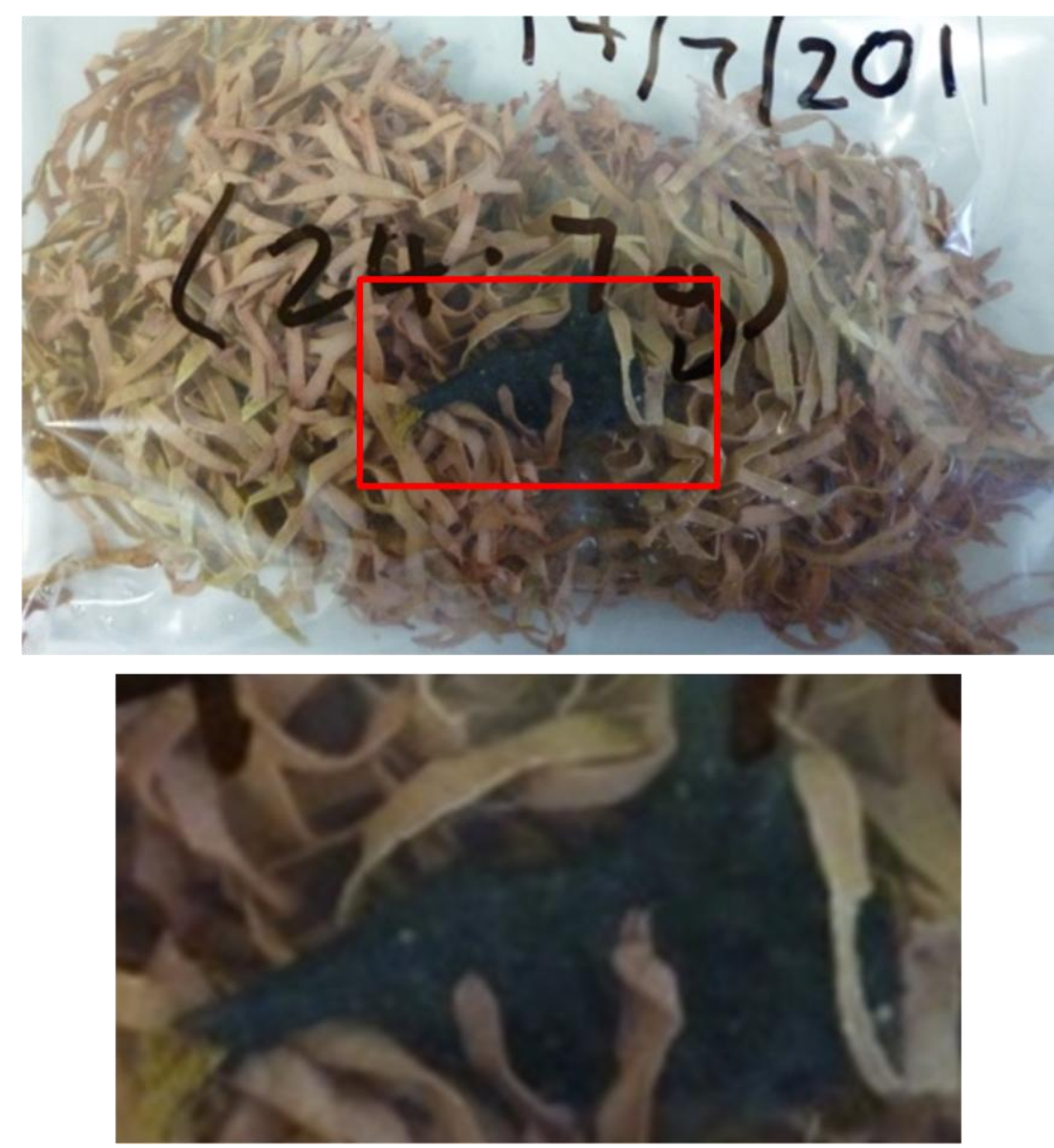

Figure 2.11 Photos of the PTN3_38C algae sample extracted, with highlighted contaminant. 
Table $2 .{ }^{13} \mathrm{C}(150 \mathrm{MHz})$ and ${ }^{1} \mathrm{H}(600 \mathrm{MHz})$ NMR data $\left(\mathrm{CD}_{3} \mathrm{OD}\right)$ for fistularin-3

(86)

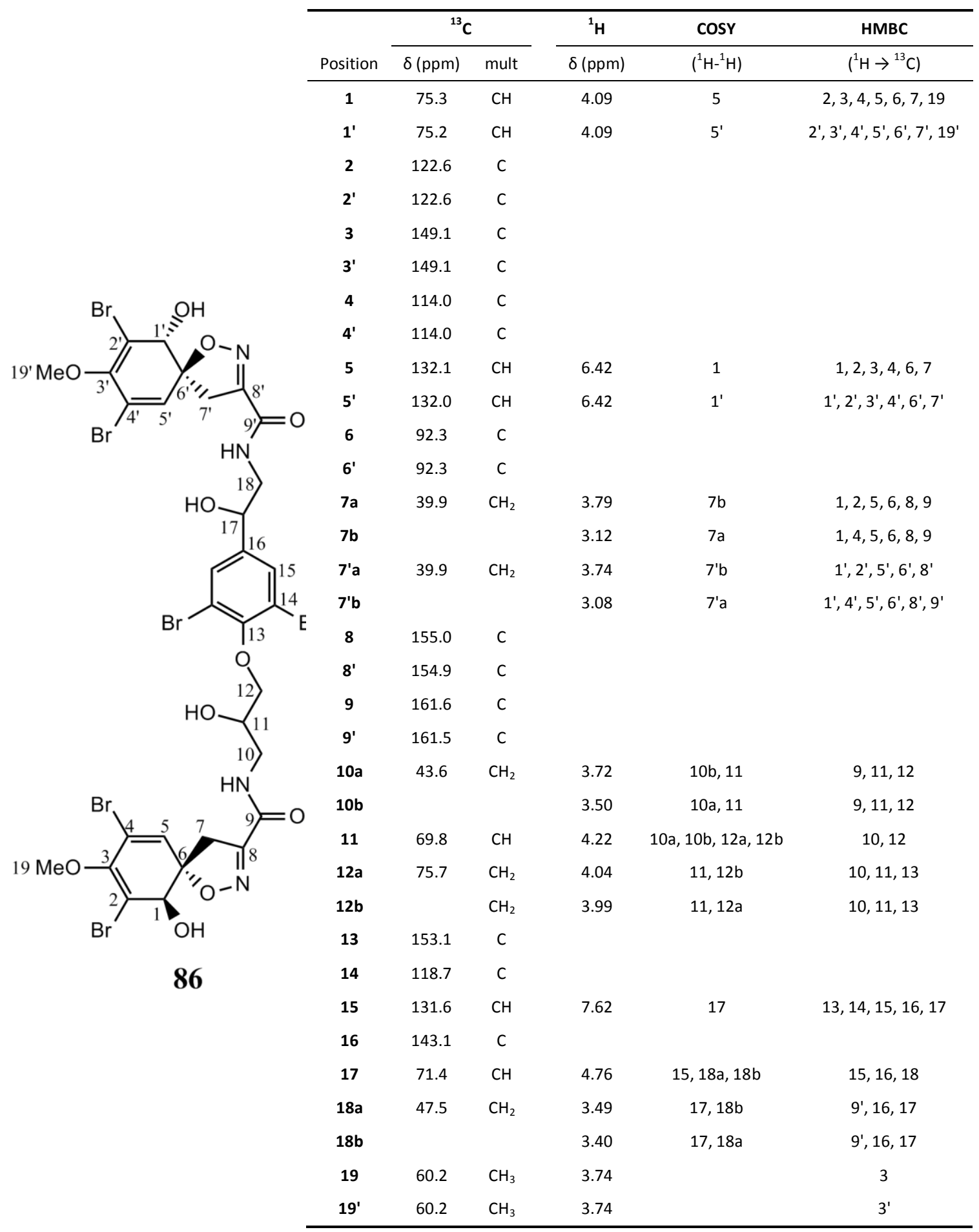




\subsection{Summary}

This study of marine algae was conducted with a sample size of 11 algal specimens collected from various regions around the island of Vava'u, Tonga. The study was undertaken to answer whether the structural diversity of secondary metabolites found in Tongan algae, compared with New Zealand algae, rivalled the concentration and increased structural diversity observed in Tongan sponges compared to New Zealand sponges. The sample size of 11 algae was used to compare with the previous study of temperate red algae collected in New Zealand waters which had revealed the isolation of several novel oxylipins and a nitrogenous bromophenol compound along with other diverse known compounds.

Although 11 specimens was a small sample size, the results from the screening spectra highlighted that the $75 \% \mathrm{Me}_{2} \mathrm{CO}$ in $\mathrm{H}_{2} \mathrm{O}$ samples of Tongan algae exhibited lower concentrations of secondary metabolites across all samples, compared to temperate New Zealand red algae. The structural diversity of Tongan algae appeared to be less diverse than that of New Zealand algae as there was a large presence of glyceroglycolipid and other fatty acid containing compounds. The 6-amino-6deoxyglucose glyceroglycolipid isolated from PTN4_17G appeared to be present in green, red and brown algae samples, perhaps indicating it was a common tropical algal primary metabolite rather than a secondary metabolite.

The results of this study suggested that the increase in concentrations and structural diversity of secondary metabolites isolated from tropical sponges, compared to temperate sponges is reversed in macro-algae. The lower concentration of secondary metabolites was confirmed during isolation of fistularin-3, where a small sponge contaminant overshadowed a larger algae sample in the extract screen. A larger sample size of tropical algae would be required to fully confirm the findings from this study. No biological testing was performed during this study as full purification was not achieved. 


\section{Chapter 3}

\section{Investigation of Marine Sponges}

\subsection{Introduction}

Sponges, phylum Porifera, are considered to be the most primitive metazoans (multicellular animals) with fossil evidence dating back to Cambrian times, approximately 500 million years ago, providing evidence that sponges were widespread inhabitants of the ocean reefs. ${ }^{96}$ Sponges show few of the features ordinarily associated with commonly recognised animals, including the lack of a nervous, circulatory or digestive system meaning a low level of cellular organisation. ${ }^{97}$ The animal nature of sponges was therefore not recognised until the late $18^{\text {th }}$ century due to their basic structure and primitive characteristics. ${ }^{97}$ However, for all their primitive characteristics, sponges account for a large proportion of the epifaunal biomass. In 1994, there was a conservative estimate of 15,000 species of sponges worldwide which has since grown to in excess of 20,000 recorded species in $2012 .{ }^{98-99}$

The taxonomy within Porifera is not certain and continues to be revisited as the physical and morphological characteristics, normally used to resolve species, are restricted. A given sponge's colour, size and shape can be affected by the environment in which the sponge is found. Species are therefore primarily classified based on their skeletal framework (spicules). Using spicule characterisation the phylum Porifera was originally divided into three classes: Calcarea (sponges with a mineral skeleton composed entirely of calcium carbonate), Demospongiae (sponges with siliceous spicules and with a skeleton of organic fibres or fibrillar collagen) and Hexactinellida (sponges with siliceous spicules), shown in Table 3.1. ${ }^{100}$ Highlighted in red in Tables 3.1 and 3.2, adapted from Hooper and van Soest ${ }^{99}$ is the taxonomic classification from the phylum porifera of the sponge species analysed in this study.

Demospongiae is the largest and most diverse class of Porifera. It is divided into 13 orders, of which Poecilosclerida is one of the largest. The order Poecilosclerida 
contains several families of sponges, including Raspailiidae, which contains the genus Raspailia (Table 3.2). ${ }^{99}$

Table 3.1 Taxonomic classification of the phylum porifera to the order level. ${ }^{99}$

\begin{tabular}{|c|c|c|c|}
\hline Phylum & Class & Sub-class & Order \\
\hline \multirow{24}{*}{ Porifera } & \multirow{5}{*}{ Calcarea } & \multirow{3}{*}{ Calacaronea } & Baerida \\
\hline & & & Leucosolenida \\
\hline & & & Lithonida \\
\hline & & \multirow{2}{*}{ Calcinea } & Clathrinida \\
\hline & & & Murrayonida \\
\hline & \multirow{14}{*}{ Demospongiae } & \multirow{9}{*}{ Ceractinomorpha } & Agelasida \\
\hline & & & Dendroceratida \\
\hline & & & Dictyoceratida \\
\hline & & & Halichondrida \\
\hline & & & Halisarcida \\
\hline & & & Haplosclerida \\
\hline & & & Poecilosclerida \\
\hline & & & Verongida \\
\hline & & & Verticillitida \\
\hline & & \multirow{4}{*}{ Tetractinomorpha } & Astrophorida \\
\hline & & & Chondrasida \\
\hline & & & Hadromerida \\
\hline & & & Spirophorida \\
\hline & & Homoscleromorpha & Homosclerophida \\
\hline & \multirow{5}{*}{ Hexactinellida } & Amphodiscophora & Amphodiscosida \\
\hline & & \multirow{4}{*}{ Hexasterophora } & Aulocalycoida \\
\hline & & & Hexactinosida \\
\hline & & & Lychnicosida \\
\hline & & & Lyssacinosida \\
\hline
\end{tabular}


Table 3.2 Taxonomic classification of the genus Raspailia from the order Poecilosclerida. ${ }^{99}$

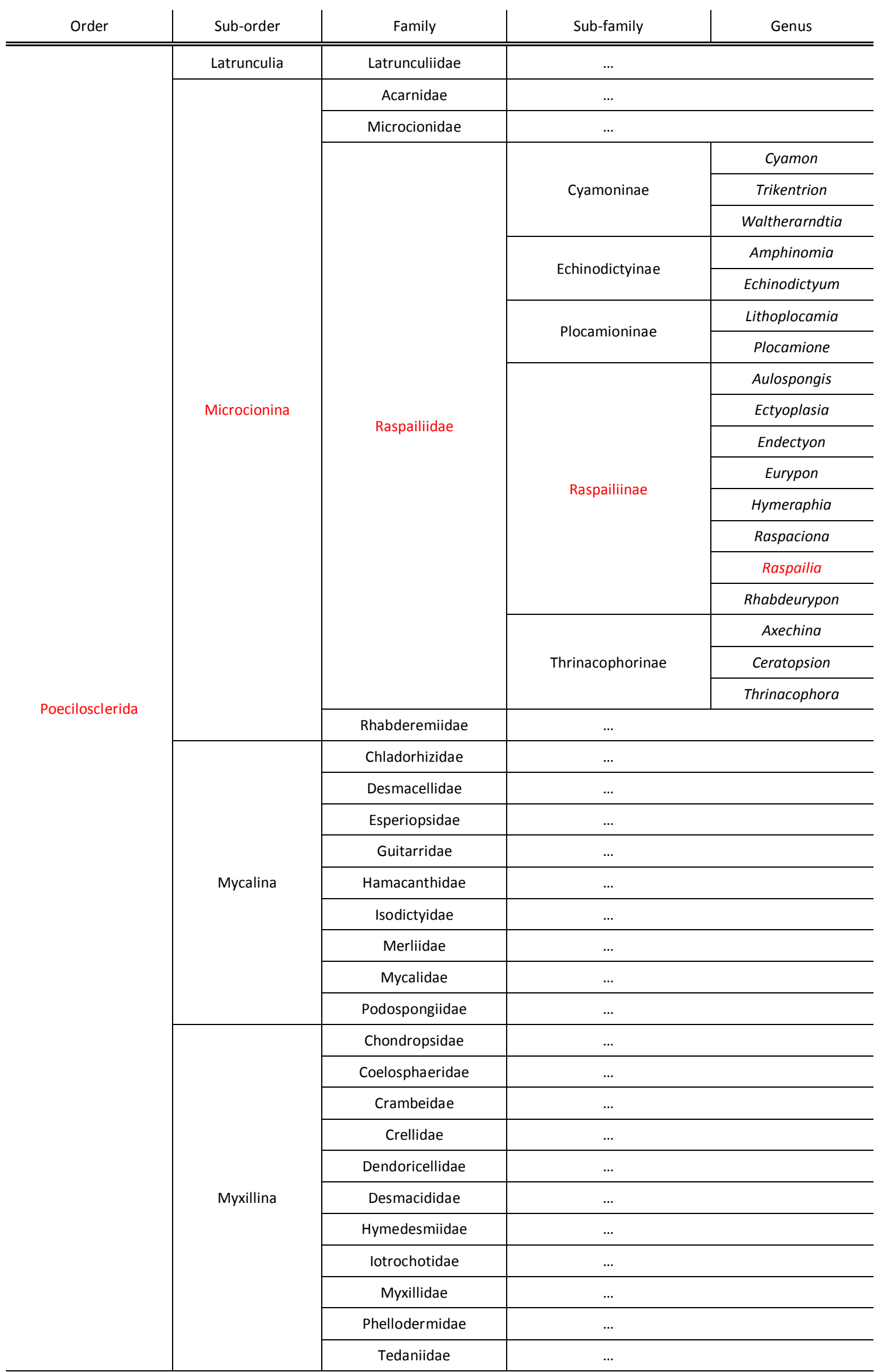




\subsection{Raspaillia Species - A Chemicall History}

The genus Raspailia is characterised by the absence of microscleres and contains more than 100 described species. These species are distributed world-wide, mainly in shallow waters, and have been studied with some success due to the ease of accessibility. ${ }^{99}$ As of 2011 , over forty different secondary metabolites have been reported from Raspailia sponges belonging to five main families of compounds: raspailynes, raspailols, asmarines, agminosides and clerodane diterpenes.

The first reports of isolated secondary metabolites were from the sponges $R$. pumila and $R$. ramosa collected from the North-East Atlantic. They were found to contain a series of novel long-chain enol ethers of glycerol. The generic structure contains a conjugated system, made up of an enol ether, an acetylenic bond, and a 1,2disubstituted olefinic bond. ${ }^{101-102}$ The family of raspailynes was categorised by the configuration of the two double bonds in the compound. Three such configurations have been found with the most common being the $(1 Z, 5 Z)$ configuration observed in raspailynes A, A1, B, B1, B2 (87-91) and isoraspailynes A, B and B1 (92-94). ${ }^{101-102}$ The $(1 Z, 5 E)$ configuration was observed in isoraspailyne Ba and B1a (95-96) with the final $(1 E, 5 Z)$ configuration, present in isoraspailyne B1b (97). ${ }^{102}$ There have been no reports of raspailynes containing an $(1 E, 5 E)$ configuration.

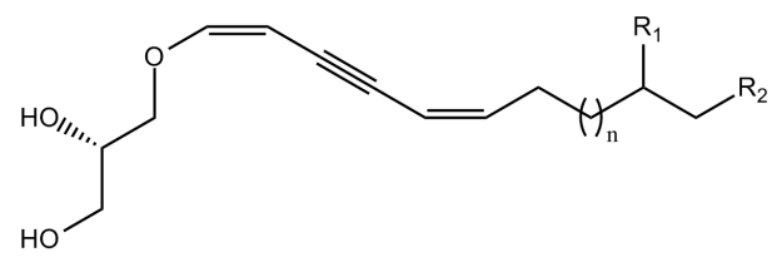

$$
\begin{aligned}
& 87 \mathrm{n}=9 \quad \mathrm{R}_{1}=\mathrm{H} \quad \mathrm{R}_{2}=\mathrm{OH} \\
& 88 \mathrm{n}=7 \quad \mathrm{R}_{1}=\mathrm{H} \quad \mathrm{R}_{2}=\mathrm{OH} \\
& 89 \mathrm{n}=4 \quad \mathrm{R}_{1}=\mathrm{H} \quad \mathrm{R}_{2}=\mathrm{H} \\
& 90 \mathrm{n}=3 \quad \mathrm{R}_{1}=\mathrm{H} \quad \mathrm{R}_{2}=\mathrm{H} \\
& 91 \mathrm{n}=2 \quad \mathrm{R}_{1}=\mathrm{H} \quad \mathrm{R}_{2}=\mathrm{H} \\
& 92 \mathrm{n}=9 \quad \mathrm{R}_{1}=\mathrm{OH} \quad \mathrm{R}_{2}=\mathrm{H} \\
& 93 \mathrm{n}=3 \quad \mathrm{R}_{1}=\mathrm{Me} \quad \mathrm{R}_{2}=\mathrm{H} \\
& 94 \mathrm{n}=2 \mathrm{R}_{1}=\mathrm{Me} \mathrm{R} \mathrm{R}_{2}=\mathrm{H}
\end{aligned}
$$
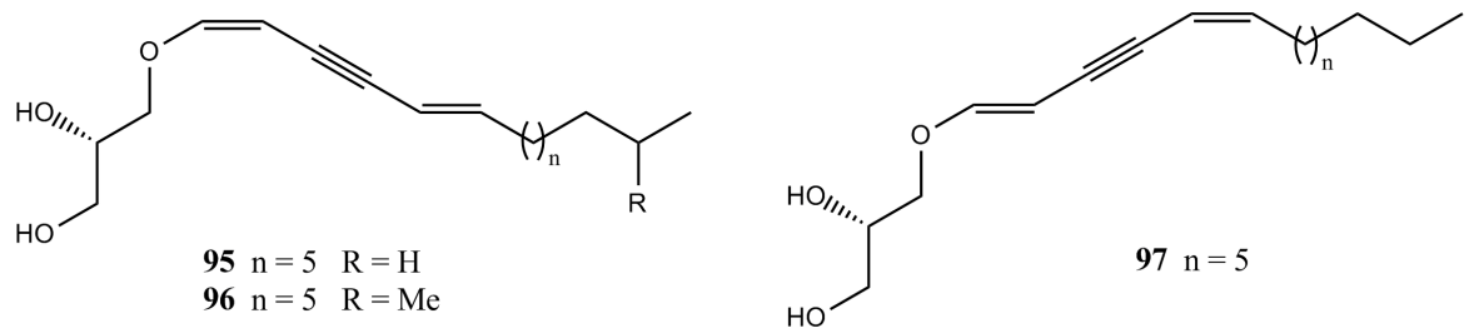
In the mid 1990s, two cyclic hemi-acetals, raspailol A and B (98-99), were isolated from an unknown Palauan Raspailia sponge species. ${ }^{103}$ The absolute configuration of the ring was determined by Mosher's method, however, full stereochemical assignment was not obtained until total synthesis of raspailol A and B was achieved. ${ }^{104}$ At the time, the chemotaxonomy of 97-98 was unknown, however, they appeared to be a unique class of the polyketide family.

Asmarines A-K (100-110) are a family of nitrogen-containing metabolites that were found to be of mixed biogenesis: clerodane diterpene and adenine. The compounds were collected, each from unidentified Raspailia sponge species, from three separate locations. Compounds 100-105 were collected from the Red Sea with 100 and 101 showing micromolar cytotoxic activity against murine leukaemia, human lung carcinoma, human colon carcinoma and human melanoma cell lines. ${ }^{105-106}$ Compounds 106-107 were collected from Wasini Island, off the coast of Kenya, while 108-110 were collected from Nosy Be, an Island off the coast of Madagascar. ${ }^{107-108}$ Compounds 102-110 still possessed some cytotoxicity but at levels less potent than $\mathbf{1 0 0}$ and 101. ${ }^{106-108}$ Two new diterpenes, barekol $(\mathbf{1 1 1})^{107}$ and nosyberkol $(\mathbf{1 1 2})^{108}$ were also isolated along with three known diterpenes.

In addition to the novel compounds isolated from Raspailia, there have been reported isolations of some known compounds of interest. Esmodil (113), an acetylcholine mimetic, and phorboxazoles $A$ and $B$ (114-115), known antifungal and cytostatic macrolides, were isolated from an unknown Raspailia species off the coast of Western Australia. ${ }^{109}$ The isolation of $\mathbf{1 1 3}$ was of particular interest as it was a known synthetic drug that had been investigated during the 1930s. The compound 1,4-dideoxy-1,4imino-D-arabinitol (116) was also isolated from an unknown Raspailia species from the coast of Western Australia. ${ }^{110}$ This compound was previously isolated from terrestrial plants and has since been synthetically produced as it possesses $\alpha$-glucosidase inhibitory properties. ${ }^{110}$ 

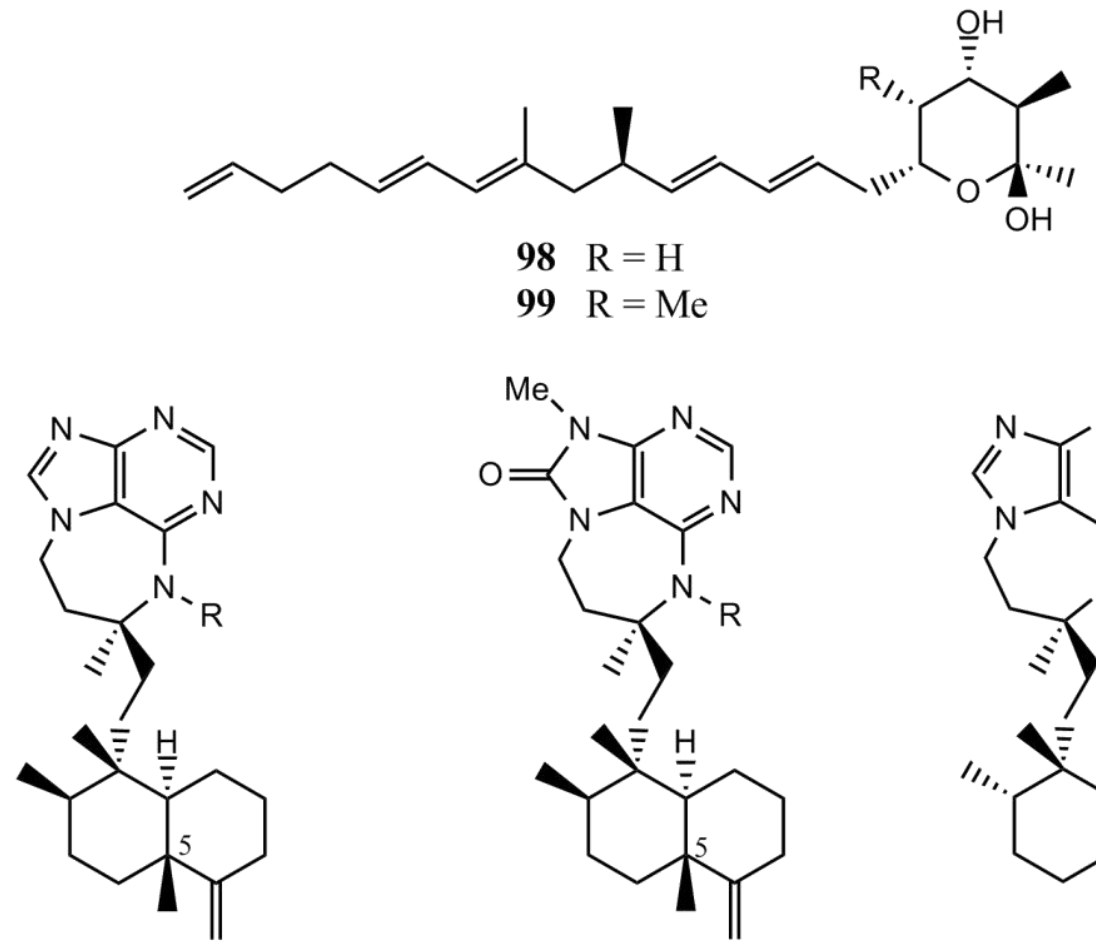

$100 \mathrm{R}=\mathrm{OH}$

$102 \mathrm{R}=\mathrm{H}, 5$ - epi

$101 \mathrm{R}=\mathrm{OH}, 5$ - epi

$106 \mathrm{R}=\mathrm{OMe}$

$103 \mathrm{R}=\mathrm{H}$<smiles>[R]N1c2ncnc3ncn(c23)CC[C@]1(C)CC</smiles>

$107 \mathrm{R}=\mathrm{H}$

$104 \mathrm{R}=\mathrm{OMe}$

$110 \mathrm{R}=\mathrm{H}, 5$ - epi

$105 \mathrm{R}=$ OMe, 5- epi

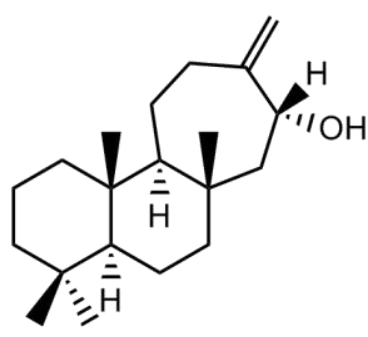

111
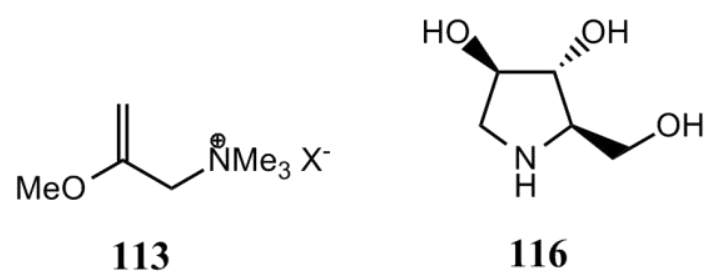

116<smiles>[R][R](=O)C=[R]([R2])[H]</smiles> 
The marine natural products group at VUW has investigated two New Zealand species of Raspailia with several novel compounds isolated in each case. Raspailia agminata, collected from Taheke Reef in the Cavalli Islands, Northland, was found to contain the agminosides, a novel family of glycolipids. Agminosides A-E (117-121) contained up to six partially acetylated glucose residues bound to the same length aglycon methyl ester. $^{42,111}$ Despite their novel structures, the agminosides did not exhibit strong biological activity.

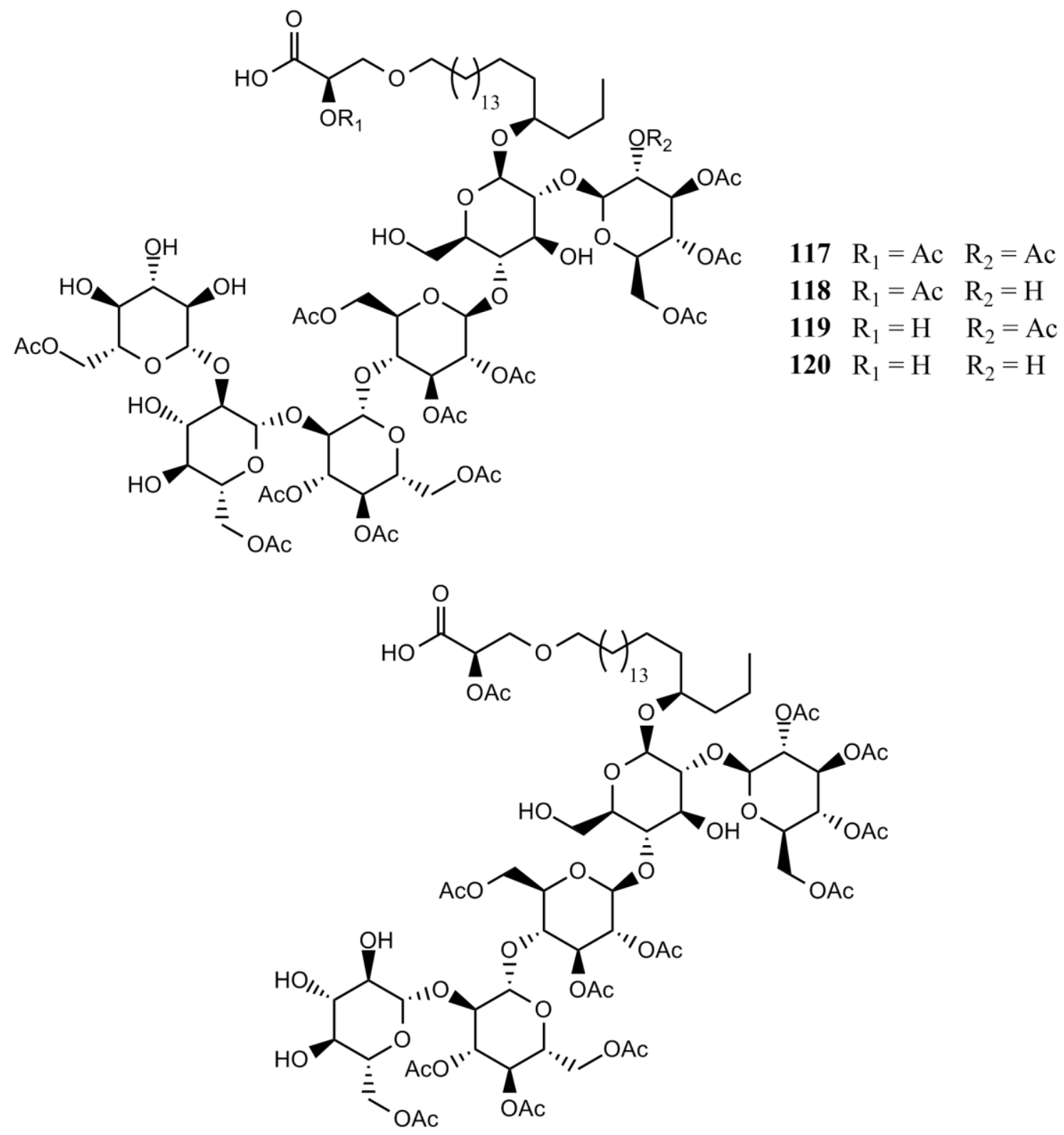


The New Zealand marine sponge Raspailia topsenti, (Dendy ${ }^{112}$ ), has also proven to be a rich source of secondary metabolites. It has been studied in much detail affording numerous novel secondary metabolites. Several collections have been made from different sites around New Zealand with the original source being from Doubtful Sound, Fiordland.

From the first collection, the clerodane diterpenoids raspailol (122), raspailenone $A$ (123) and raspailodanes $C(\mathbf{1 2 4})$ and $D(\mathbf{1 2 5})$ were isolated. ${ }^{36,113}$ Additional collections of $R$. topsenti have been made from at least four other locations around New Zealand - D'Urville Island, Marlborough Sounds; off the coast of New Plymouth; Three Kings Islands, north of Cape Reinga; and Elizabeth reef, Tutukaka, Northland. Further work on $R$. topsenti collected from D'Urville Island and off the coast of New Plymouth resulted in the isolation of three further clerodanes, raspailodanes $A(\mathbf{1 2 6}), B(\mathbf{1 2 7})$ and $E(\mathbf{1 2 8}) .^{38}$

Investigation of the Three Kings Islands collection afforded the novel clerodanes topsentane A and B (129-130) and raspailenone B (131). ${ }^{114}$ This was followed by the isolation of the novel, raspailodane $F$ and $G(\mathbf{1 3 2}-133)$ alongside (122) and (127). ${ }^{38}$ One final compound isolated by the VUW research group, was the $\beta$-substituted- $\gamma$-hydroxybutenolide analogue of 122 , compound $134 .^{115}$ Due to insufficient material the stereochemistry of $\mathbf{1 3 4}$ could not be assigned, however, it is most likely analogous to 122. It is important to acknowledge that the profile of compounds was different in each geographical variant. ${ }^{38}$ Biological testing was performed across the novel clerodanes isolated with $\mathbf{1 2 2}$ and $\mathbf{1 2 9 - 1 3 0}$ having shown to possess anti-inflammatory activity in vitro. ${ }^{36,114}$ 


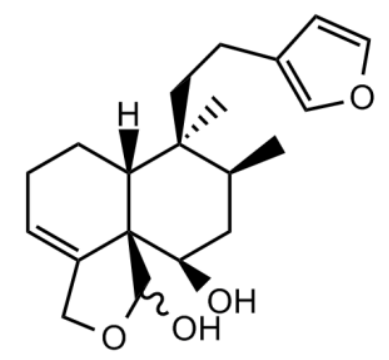

122

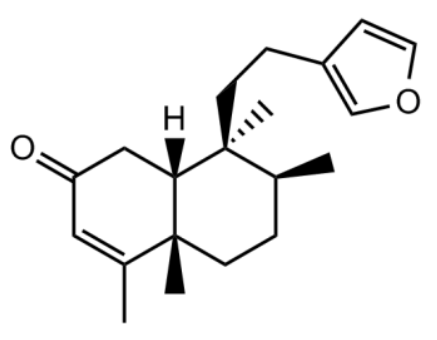

123

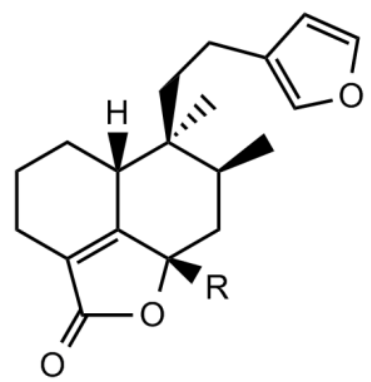

$124 \mathrm{R}=\mathrm{OMe}$ $125 \mathrm{R}=\mathrm{H}$

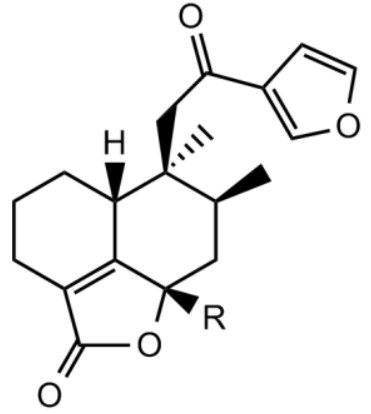

$128 \mathrm{R}=\mathrm{H}$

$133 \mathrm{R}=\mathrm{OMe}$

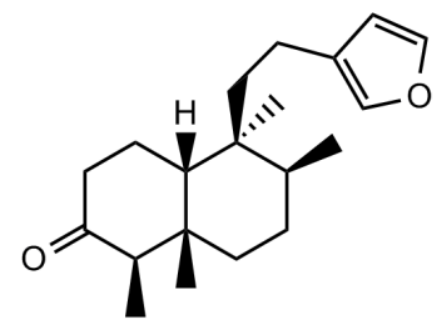

131

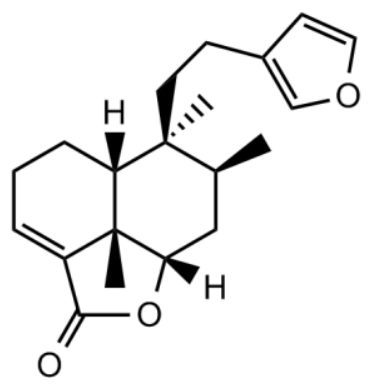

126

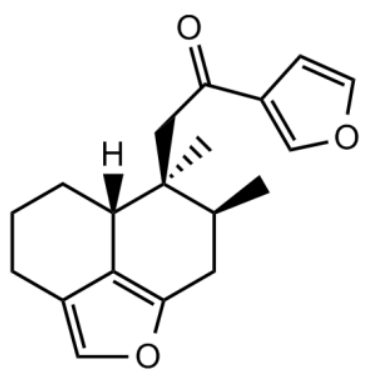

129

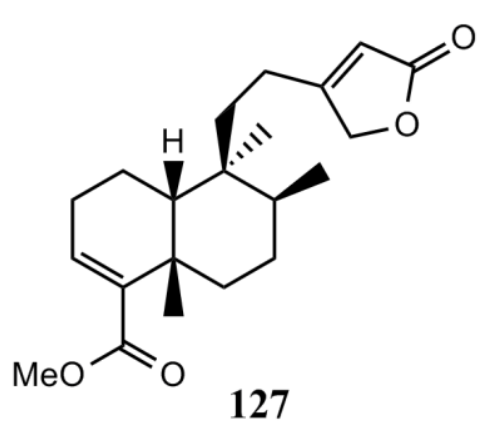

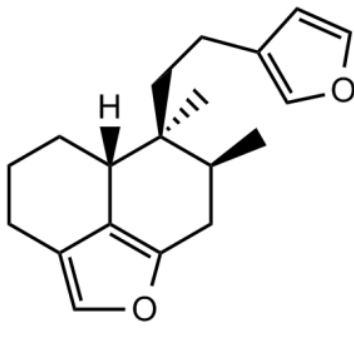

130
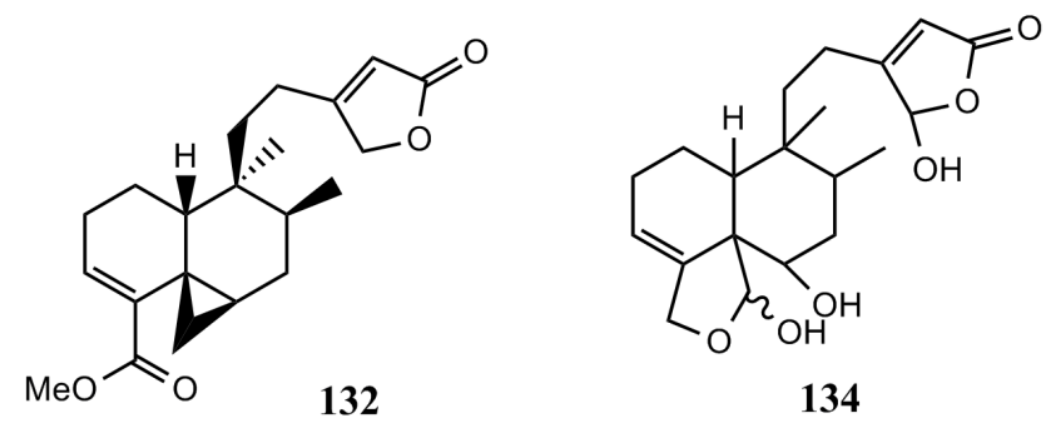


\subsection{PTN2_4.5D}

PTN2_45D, an orange-finger sponge (Figure 3.1) of the genus Raspailia was collected off Elizabeth reef, Tutukaka, Northland in November 2003. This particular sponge was subjected to the standard HSQC screening protocol, however was not studied in any further detail. Singh's subsequent HMBC study highlighted prominent features in the screen, shown in Figure 3.2, which included correlations to functionalised carbons such as ketone, alkene and acetal centres. ${ }^{41}$ From the screen, characteristic clerodane diterpene correlations were observed that were consistent with compounds previously mentioned in this chapter. However, Singh indicated that there were a number of correlations across the spectrum that were not associated with the furan and acetal regions of known clerodane diterpenes, therefore suggesting that the sponge sample warranted further investigation. The sponge bore similarities to $R$. topsenti including the bright orange colour, however, the morphology was slightly different. Figure 3.1 illustrates the morphological differences observed between a known $R$. topsenti sample and the Raspailia sample that was investigated during this study.

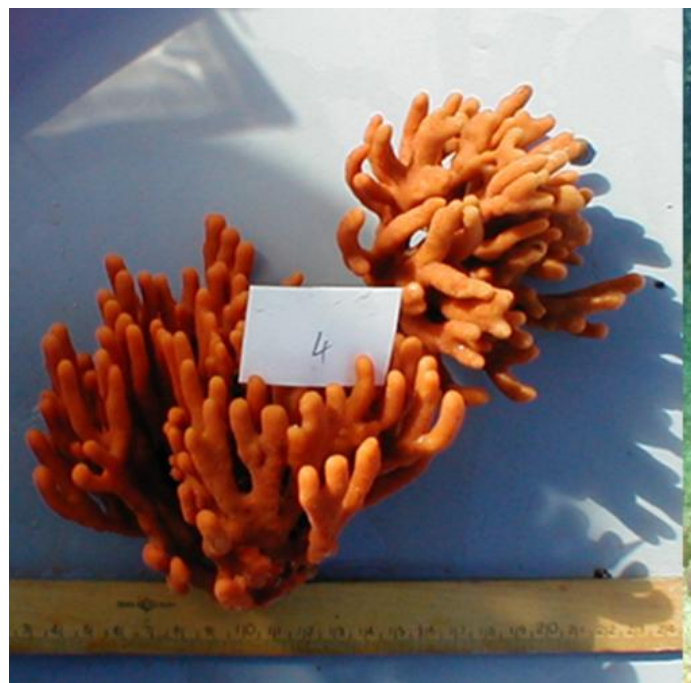

(a)

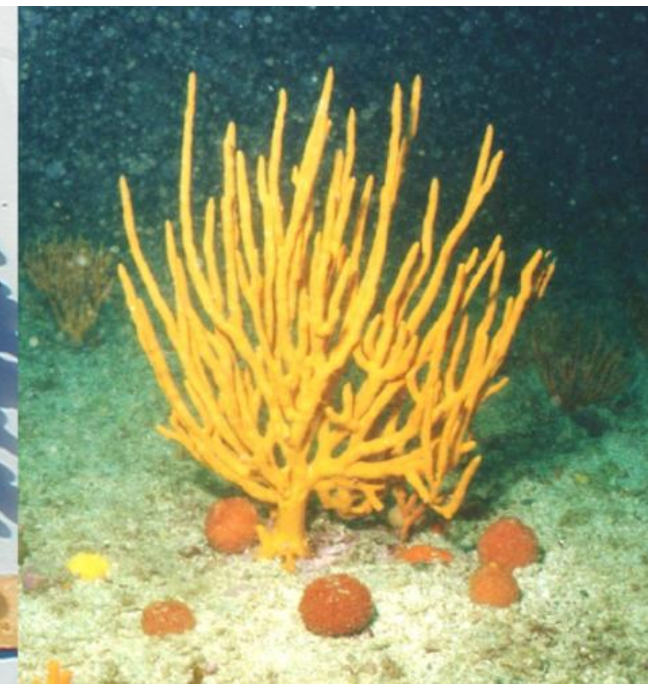

(b)

Figure 3.1(a) Surface image of PTN2_45D, analysed in this study. (b) Underwater photograph of Raspailia topsenti (photograph by Alan Duckworth). 


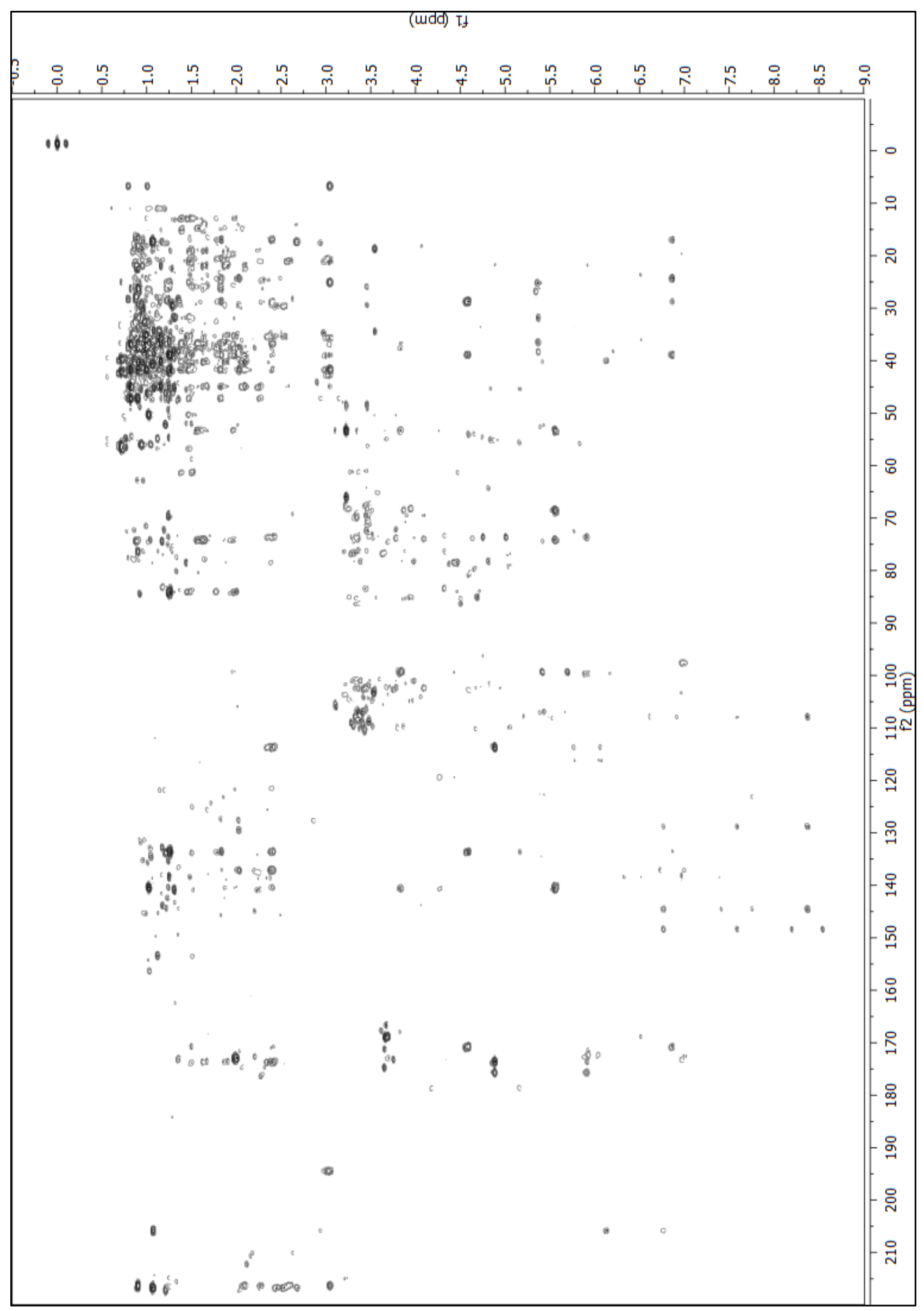

Figure 3.2 $\mathrm{HMBC}$ screen of $75 \% \mathrm{Me}_{2} \mathrm{CO}$ in $\mathrm{H}_{2} \mathrm{O}$ sample of PTN2_45D $\left(\mathrm{CD}_{3} \mathrm{OD}\right)$ performed by Singh. ${ }^{41}$ 


\section{4: Isolation Procedure}

In this study, an extraction of $100 \mathrm{~g}$ of an unknown Raspailia sponge species collected from Elizabeth reef, Northland, was performed. The sponge was extracted twice with $\mathrm{MeOH}$ and the extracts were cyclic loaded onto reversed-phase HP20 beads. The column was then eluted with increasing concentrations of $\mathrm{Me}_{2} \mathrm{CO}$ in $\mathrm{H}_{2} \mathrm{O}$. Previous studies used eluting concentrations of $20,40,75,85 \mathrm{Me}_{2} \mathrm{CO}$ in $\mathrm{H}_{2} \mathrm{O}$ and $100 \%$ $\mathrm{Me}_{2} \mathrm{CO}^{36,38,114}$ whereas in this study the five eluting fractions 20, 40, 60, $80 \mathrm{Me}_{2} \mathrm{CO}$ in $\mathrm{H}_{2} \mathrm{O}$ and $100 \% \mathrm{Me}_{2} \mathrm{CO}$ were used.

As mentioned previously, a number of clerodanes have been isolated from a known $R$. topsenti species, all possessing a $\beta$-substituted furan ring, which have diagnostic proton signals in the aromatic region (6-8 ppm) of a ${ }^{1} \mathrm{H}$ NMR. These allowed for early detection of samples containing possible clerodane compounds. The 40,60 and $80 \%$ samples from the initial HP20 separation all showed the presence of furan signals in their respective ${ }^{1} \mathrm{H}$ NMR spectra. With one additional stage of purification, the $80 \%$ sample bore the known raspailodane A (126).

Early studies of $R$. topsenti, in the laboratory at VUW using 1D ${ }^{1} \mathrm{H}$ NMR, suffered from the inability to easily detect functionality below $5 \mathrm{ppm}$, without purification, due to NMR signal overlap (outlined in Chapter 1). Backed by a more sensitive instrument and a modified isolation protocol, interesting signals were observed in the oxymethine region (3-5 ppm) of the $60 \%$ and $80 \%$ fractions. These oxymethine correlations combined with the presence of several $s p^{3}$ carbon signals was suggestive of a saponin. These molecules are often large in size, and therefore size exclusion chromatography was employed using LH-20, a hydroxypropylated bead-formed dextran medium. Further purification involved the use of normal-phase chromatography (DIOL) and reversed-phase HPLC (C18).

Full purification was made difficult as a minor compound presumed to be related, appeared to behave similarly during purification. NMR studies suggested that the minor compound only differed in the side chain of the aglycon. Scheme 3.1 shows the isolation procedure, where the sample is split in half with one half purified using HPLC and the other through repeated LH-20 columns with mixed solvent systems implemented to afford polar separations. It was found through reversed-phase HPLC 
that the aglycon moiety appeared to be purified (major: minor approximately 15:1) while purification of the polar sugar moiety was minimal. Through repeated LH-20 columns it was found that the polar sugar moiety was purified while purification of the non-polar moiety was not achieved as well as seen with HPLC. Each pathway provided a sample that was found to be primarily the same single compound with differing impurities. Spectral data from each purification pathway was used in elucidating the structure as full pure isolation of the major compound could not be unequivocally obtained (ratio 15:1). The purification scheme led to the isolation and structural elucidation of the major compound raspailoside $A(\mathbf{1 3 5})$, a novel steroidal glycoside.

\subsection{Raspailoside A}

The molecular formula of raspailoside $A$ (135) was determined to be $\mathrm{C}_{51} \mathrm{H}_{83} \mathrm{O}_{20} \mathrm{~N}$ from a positive ion mode HRESIMS measurement of the $[\mathrm{M}+\mathrm{H}]^{+}$pseudomolecular ion peak at $\mathrm{m} / z 1030.5573(\Delta-0.91 \mathrm{ppm})$. The molecular formula indicated the presence of 11 double bond equivalents in the molecule. Detailed ${ }^{1} \mathrm{H}$ NMR, COSY, HSQC and HMBC data was obtained for structural elucidation, however ${ }^{13} \mathrm{C}$ NMR data obtained was weak and difficult to analyze and therefore not used during characterisation. All carbon shifts were obtained from HSQC and HMBC spectra run. From the HSQC experiment 46 carbons were confirmed to be present, consisting of six methyls, 10 methylenes, four oxymethylenes, seven methines, 18 oxymethines and one aminomethine, accounting for 72 hydrogens. The remaining five non-protonated carbons were observed through correlations in the $\mathrm{HMBC}$ to consist of two carbonyls $\left(\delta_{c} 174.2\right.$ and 217.9$)$, one olefinic $\left(\delta_{c} 141.4\right)$ and two $s p^{3}$ quaternary centres $\left(\delta_{c} 37.5\right.$ and 43.2). HSQC correlations showed only one signal present in the olefinic region ( $\delta_{C}$ 122.5) indicating the presence of one double bond, which revealed that the compound was an octacyclic structure. 


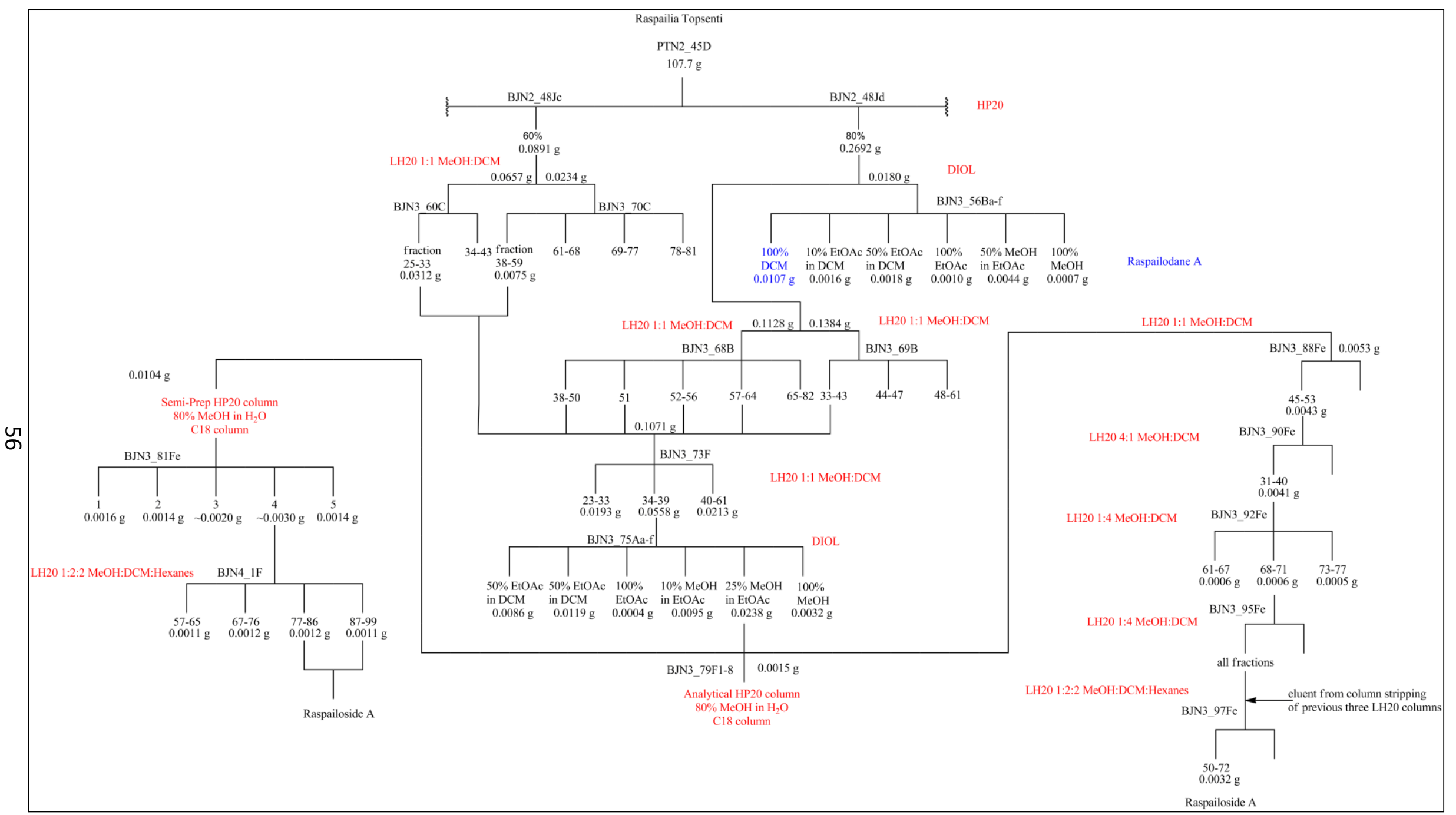

Scheme 3.1 The procedure leading to the isolation of raspailoside A (135) from PTN2_45D. 


\section{Oligosaccharide Chain of $\mathbf{1 3 5}$}

Using a combination of COSY, HSQC, HMBC, HSQC-TOCSY, 1D TOCSY and ROESY experiments the structures of each monosaccharide unit was determined along with the relative stereochemistry in each unit. Additionally, the nature of the glycosidic linkages could be ascertained using these experiments.

The HSQC experiment showed the presence of four anomeric methines $\mathrm{S} 1-\mathrm{CH}-1\left(\delta_{\mathrm{C}}\right.$ $\left.102.0, \delta_{H} 4.47\right), \mathrm{S} 2-\mathrm{CH}-1\left(\delta_{C} 103.5, \delta_{H} 4.81\right), \mathrm{S} 3-\mathrm{CH}-1\left(\delta_{C} 100.0, \delta_{H} 4.63\right)$ and $\mathrm{S} 4-\mathrm{CH}-1\left(\delta_{C}\right.$ $\left.104.7, \delta_{H} 4.32\right)$, which, along with the large number of oxymethines present, indicated the presence of four sugar subunits. Due to the presence of these similar subunits, the oxymethine region of the HSQC was quite complicated. COSY spectra, which could normally be used to elucidate the structure of a sugar residue by following coupled proton shifts around the sugar ring, proved difficult to analyse due to severe signal overlap. This overlap can lead to the unintentional combination of different sugar systems during structural elucidation. The HSQC-TOCSY sequence was a very useful experiment in the identification of distinct sugar spin systems. The experiment is an extension of the HSQC in which a TOCSY transfer between protons is added prior to data acquisition thus relaying the original proton-carbon correlation peak onto neighbouring protons within the same spin system, producing a ${ }^{13} \mathrm{C}$-dispersed TOCSY spectrum. ${ }^{116}$ The carbon dimension allowed for unambiguous assignment of ${ }^{1} \mathrm{H}$ signals to each subunit. This dispersion of the proton spin system in the carbon dimension, gave a distinct pattern of signals for each sugar ring. The HSQC-TOCSY was used to separate the signals into four distinct spin systems relating to each sugar moiety, illustrated in Figure 3.3.

The ROESY experiment (rotating frame NOE) was chosen to detect through space proximity, after weak correlations of varying phase were observed in 1D and 2D NOESY experiments. The weak NOESY results are consistent with a molecule having a molecular mass of 1000-1500 atomic mass units (amu) where Z-axis or transient NOEs are weak and of alternate sign for molecules of this size. ${ }^{116}$ As stated, raspailoside $A$ has a molecular mass of 1029.55 amu which fell in the range where NOESY experiments were less effective. 


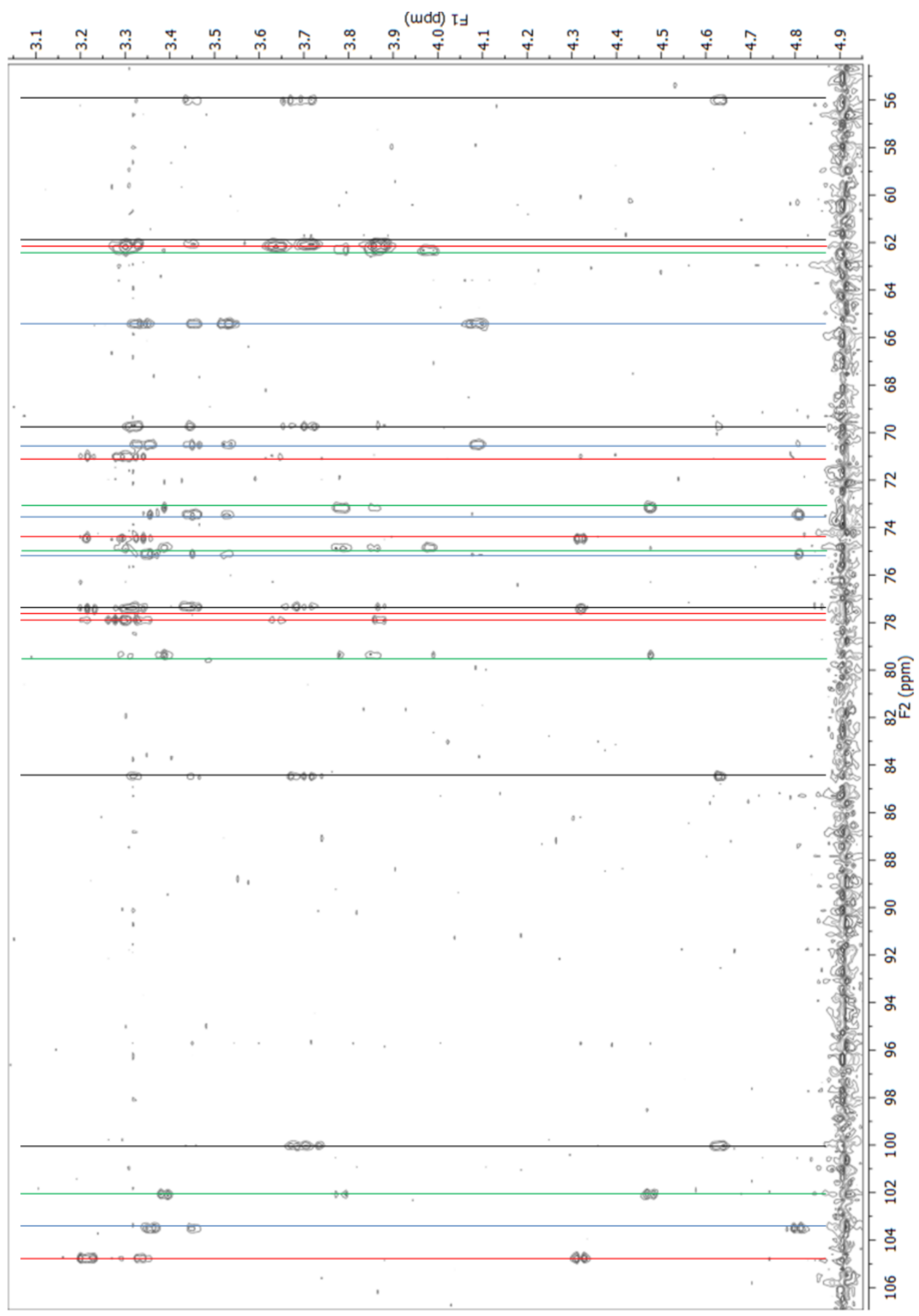

Figure 3.3 An HSQC-TOCSY spectrum with the four distinct sugar spin systems. Green for sugar one, blue for sugar two, black for sugar three and red for sugar four. 


\section{Sugar One}

Figure 3.3 revealed a spin system (shown in green) that was comprised of one anomeric (acetal) $\left(\mathrm{CH}-1 \delta_{\mathrm{C}} 102.0, \delta_{H} 4.47\right)$, three oxymethines $\left(\mathrm{CH}-2 \delta_{\mathrm{C}} 73.2, \delta_{H} 3.39\right.$, $\left.\mathrm{CH}-3 \delta_{\mathrm{C}} 79.4, \delta_{\mathrm{H}} 3.78, \mathrm{CH}-4 \delta_{\mathrm{C}} 74.9, \delta_{\mathrm{H}} 3.86\right)$ and one oxymethylene $\left(\mathrm{CH}_{2}-5 \delta_{\mathrm{C}} 62.4, \delta_{\mathrm{Ha}}\right.$ $\left.3.98, \delta_{\mathrm{Hb}} 3.30\right)$.

A series of COSY correlations that were observed $(\mathrm{H}-1$ to $\mathrm{H}-2, \mathrm{H}-2$ to $\mathrm{H}-3, \mathrm{H}-3$ to $\mathrm{H}-4$, $\mathrm{H}-4$ to $\mathrm{H}-5 \mathrm{a}, \mathrm{H}-4$ to $\mathrm{H}-5 \mathrm{~b}$ and $\mathrm{H}-5$ a to $\mathrm{H}-5 \mathrm{~b}$ ), revealed a linear carbon chain typical of a sugar moiety, represented in Figure 3.4. The sequence of oxymethines in the sugar ring was confirmed using 1D TOCSY experiments. By selectively exciting the anomeric proton, and then progressively increasing the spin lock mixing time, from 15 to $150 \mathrm{~ms}$ in $15 \mathrm{~ms}$ increments (each increment providing a separate FID), excitation is progressively transferred to other neighbouring spins exciting the protons providing spectral signals. As the mixing time increased, the signals further from the anomeric centre were revealed in the order observed from the COSY data. Proton $\mathrm{H}-2$ was revealed at $30 \mathrm{~ms}, \mathrm{H}-3$ at $45 \mathrm{~ms}, \mathrm{H}-4$ at $75 \mathrm{~ms}$, until the methylene protons $\mathrm{H}-5 \mathrm{a}$ and $\mathrm{H}-5 \mathrm{~b}$ were revealed at a mixing time of $105 \mathrm{~ms}$. A second 1D TOCSY experiment was performed by selectively exciting proton $\mathrm{H}-5 \mathrm{a}$ under the same conditions. The protons were revealed in the correct reverse order, beginning with proton $\mathrm{H}-5 \mathrm{~b}$ at $15 \mathrm{~ms}$ and ending with proton $\mathrm{H}-1$ at 90 ms. Both 1D TOCSY experiments are illustrated in Figure 3.4 .

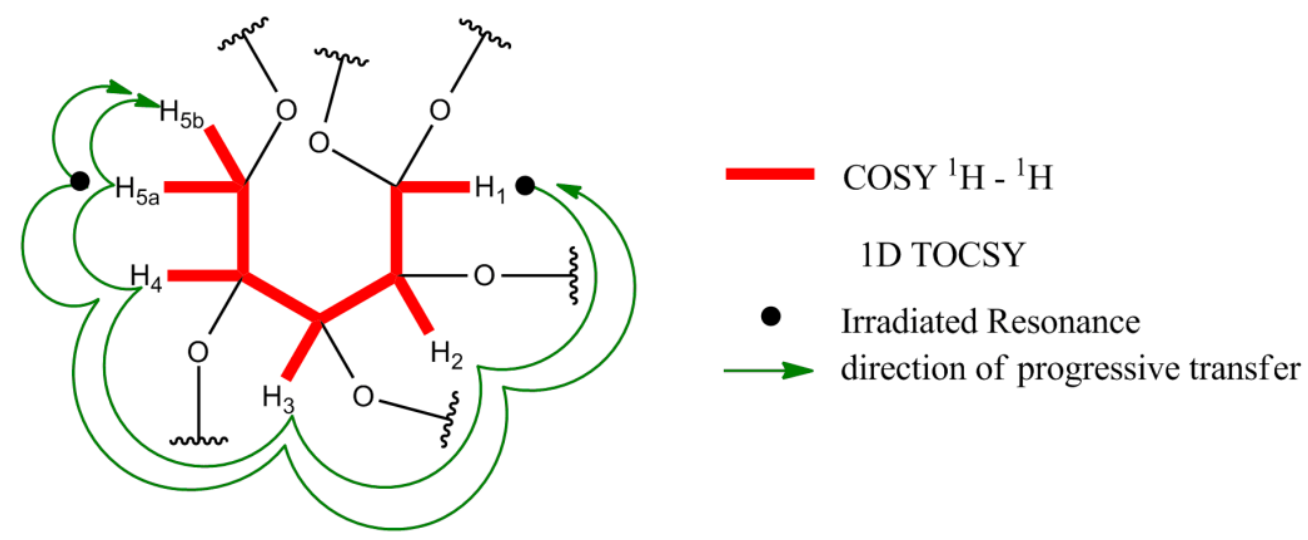

Figure 3.4 COSY and 1D TOCSY data establishing the connectivity of the carbon chain in sugar one. 
$\mathrm{HMBC}$ correlations were observed from $\mathrm{H}-1$ to $\mathrm{C}-5$ and $\mathrm{H}-5 \mathrm{a}, \mathrm{b}$ to $\mathrm{C}-1$, as shown in Figure 3.5. This revealed an ether linkage from C-1 to C-5 which established a pyranopentose ring system. Further $\mathrm{HMBC}$ correlations were observed, including $\mathrm{H}-2$ to $\mathrm{C}-1$, $\mathrm{H}-2$ to $\mathrm{C}-3, \mathrm{H}-3$ to $\mathrm{C}-2, \mathrm{H}-3$ to $\mathrm{H}-4$, and between $\mathrm{H}-5$ a and $\mathrm{C}-3$, all consistent with the established sequence.

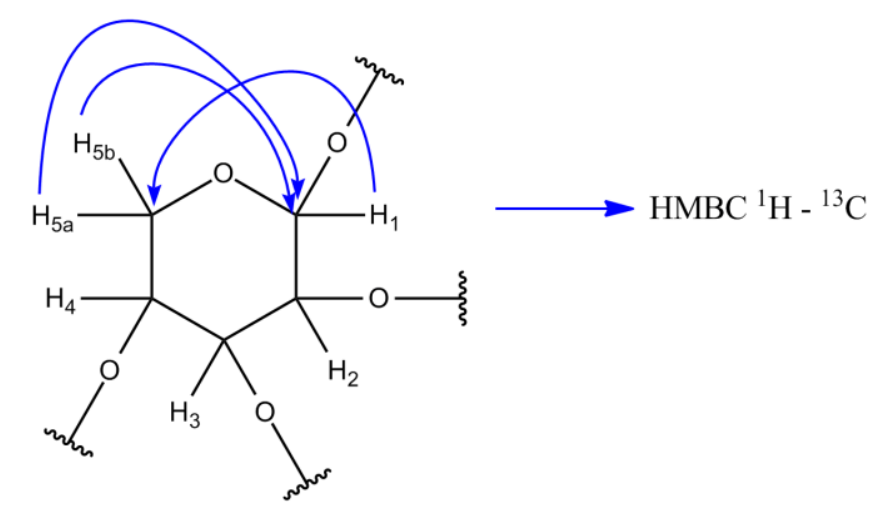

Figure 3.5 Selected HMBC correlations establishing the cyclic ring connectivity of sugar one.

The relative stereochemistry of the protons around the ring was established by using a combination of ${ }^{1} \mathrm{H}-{ }^{1} \mathrm{H}$ coupling constants, observed in ${ }^{1} \mathrm{H}$ NMR and $1 \mathrm{D}$ TOCSY experiments, and through space NOE correlations (observed via a series of 1D ROESY experiments). From the ${ }^{1} \mathrm{H}$ NMR, $\mathrm{H}-1$ was observed to be doublet with a coupling constant of $6.2 \mathrm{~Hz}$. The large coupling constant indicated a 1,2-trans diaxial relationship between $\mathrm{H}-1$ and $\mathrm{H}-2$, establishing a $\beta$ configuration at the $\mathrm{C}-1$ position $(\mathrm{H}-$ 1 axial, $\beta$ face) and $\mathrm{H}-2$ axial, on the $\alpha$ face of the ring system. From the 1D TOCSY experiment, the multiplicities of all the protons in the spin system were clearly resolved and the coupling constants could be determined for protons $\mathrm{H}-2, \mathrm{H}-3, \mathrm{H}-4, \mathrm{H}-$ $5 \mathrm{a}$ and $\mathrm{H}-5 \mathrm{~b}$. Proton $\mathrm{H}-2$ was observed to be a triplet with a coupling constant of 6.8 $\mathrm{Hz}$ which indicated a 1,2-trans diaxial relationship with $\mathrm{H}-3$, confirming the $\mathrm{H}-2$ assignment and, indicating that $\mathrm{H}-3$ was axial on the $\beta$ face. Proton $\mathrm{H}-3$ was revealed to be a triplet with a coupling constant of $7.7 \mathrm{~Hz}$ which indicated a 1,2-trans diaxial relationship with $\mathrm{H}-4$, confirming the $\mathrm{H}-3$ assignment while indicating that $\mathrm{H}-4$ was axial on the $\alpha$ face. Proton $\mathrm{H}-4$ was observed to be a multiplet and therefore coupling constants to protons $\mathrm{H}-5 \mathrm{a}$ and $\mathrm{H}-5 \mathrm{~b}$ could not be determined. Protons $\mathrm{H}-5$ a and $\mathrm{H}-5 \mathrm{~b}$ were clearly observed as doublet of doublets in the ${ }^{1} \mathrm{H}$ NMR and $1 D$ TOCSY. The coupling constant between $\mathrm{H}-5 \mathrm{a}$ and $\mathrm{H}-4$ was observed to be $4.3 \mathrm{~Hz}$ whereas between $\mathrm{H}-5 \mathrm{~b}$ and $\mathrm{H}-4$ a larger coupling of $8.5 \mathrm{~Hz}$ was observed. The coupling indicated there 
was a 1,2-trans diaxial relationship between $\mathrm{H}-5 \mathrm{~b}$ and $\mathrm{H}-4$, which suggested $\mathrm{H}-5 \mathrm{~b}$ was axial on the $\beta$ face of the ring while $\mathrm{H}-5 \mathrm{a}$ was equatorial on the $\alpha$ face. Given the coupling and multiplicity that was observed it was determined that sugar one was a $\beta$ xylopyranose subunit, illustrated in Figure 3.6.

The proposed relative stereochemistry was confirmed by relevant cross peaks seen in ROESY experiments. NOE correlations between $\mathrm{H}-1$ and $\mathrm{H}-3$ (seen both from $\mathrm{H}-1$ to $\mathrm{H}-$ 3 and $\mathrm{H}-3$ to $\mathrm{H}-1$ ) and also from $\mathrm{H}-1$ to $\mathrm{H}-5 \mathrm{~b}$ indicated 1,3-diaxial relationships. This confirmed that $\mathrm{H}-1, \mathrm{H}-3$ and $\mathrm{H}-5 \mathrm{~b}$ were all on the same face of the ring, shown in Figure 3.6. An NOE correlation was also observed from $\mathrm{H}-5$ a to $\mathrm{H}-4$ which confirmed that they were on the same face of the ring. Given the confirmed sequence of carbons, the oxacyclic ring structure and the stereochemical relationship of the protons around the ring, the data was consistent with a $\beta$-xylopyranose structure.

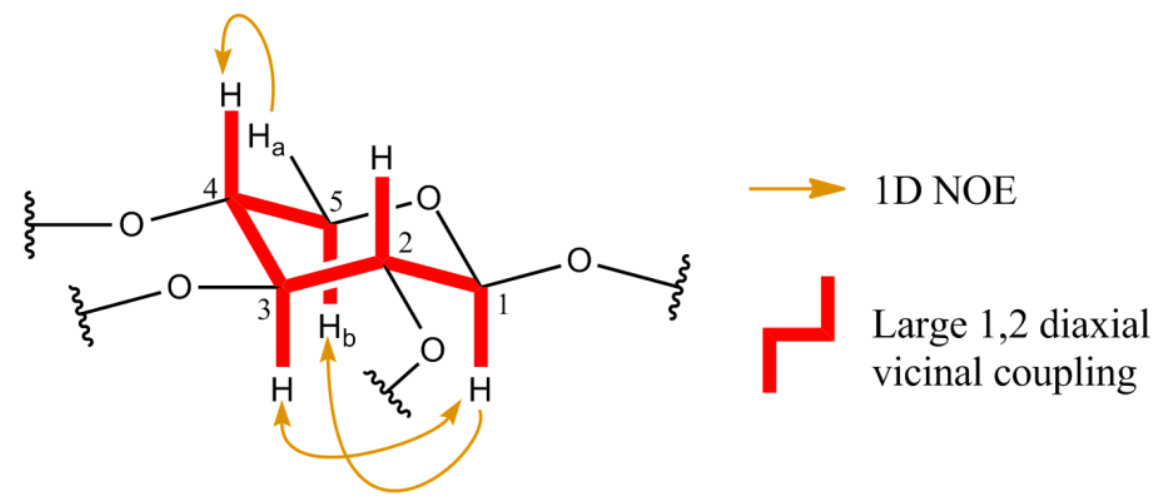

Figure 3.6 NOE correlations and large 1,2-diaxial vicinal coupling establishing the relative stereochemistry of sugar one.

\section{Sugar Two}

Full characterisation of sugar two was provided although it bore close resemblance to the previously elucidated sugar one. The HSQC-TOCSY experiment revealed a spin system (shown in blue in Figure 3.3) that was comprised of one anomeric (acetal) ( $\mathrm{CH}$ $\left.1 \delta_{\mathrm{C}} 103.5, \delta_{H} 4.81\right)$, three oxymethines $\left(\mathrm{CH}-2 \delta_{\mathrm{C}} 73.5, \delta_{H} 3.36, \mathrm{CH}-3 \delta_{\mathrm{C}} 75.1, \delta_{H} 3.45\right.$, $\left.\mathrm{CH}-4 \delta_{\mathrm{C}} 70.6, \delta_{\mathrm{H}} 3.53\right)$ and one oxymethylene $\left(\mathrm{CH}_{2}-5 \delta_{\mathrm{C}} 65.5, \delta_{\mathrm{Ha}} 4.09, \delta_{\mathrm{Hb}} 3.34\right)$.

A series of COSY correlations observed $(\mathrm{H}-1$ to $\mathrm{H}-2, \mathrm{H}-2$ to $\mathrm{H}-3, \mathrm{H}-3$ to $\mathrm{H}-4, \mathrm{H}-4$ to $\mathrm{H}-5 \mathrm{a}$, $\mathrm{H}-4$ to $\mathrm{H}-5 \mathrm{~b}$ and $\mathrm{H}-5$ a to $\mathrm{H}-5 \mathrm{~b}$ ), revealed a linear carbon chain typical of a sugar moiety, identical to sugar one, shown in Figure 3.7. The sequence of oxymethines in the chain was confirmed using 1D TOCSY experiments, illustrated in Figure 3.7. Selective 
excitation of the anomeric proton $\mathrm{H}-1$ was performed, with the progressive increase in the spin lock mixing time revealing the proton shifts in the order observed from the COSY data. Similarly, the correct reverse order was observed in a 1D TOCSY series where $\mathrm{H}-5 \mathrm{a}$ was irradiated.

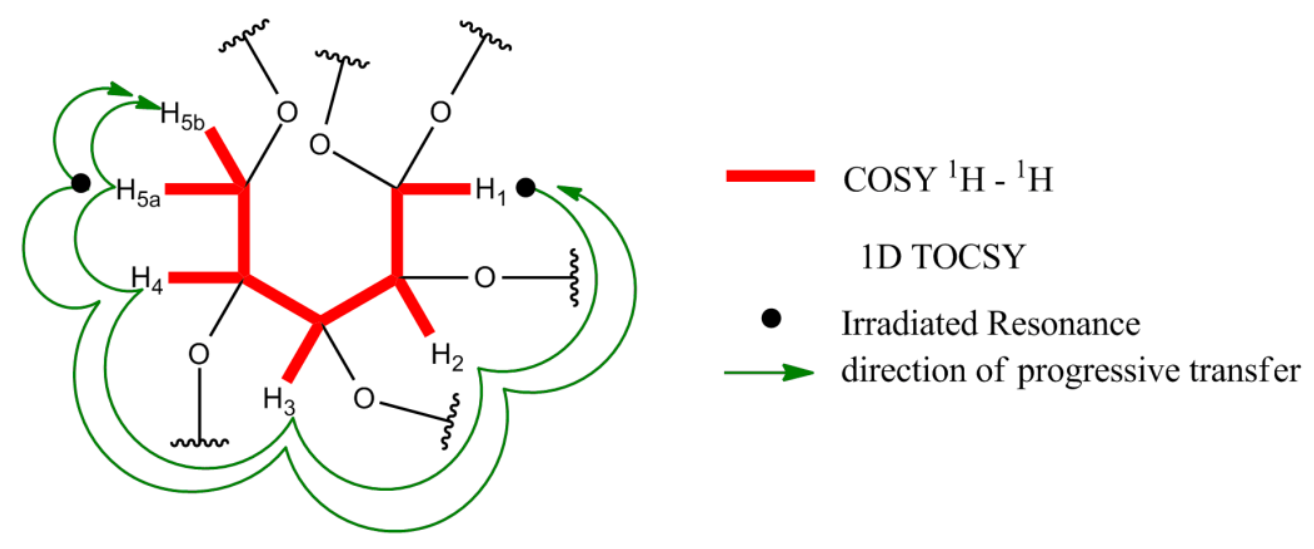

Figure 3.7 COSY and 1D TOCSY data establishing the carbon chain connectivity in sugar two.

HMBC correlations were observed from $\mathrm{H}-1$ to $\mathrm{C}-5, \mathrm{H}-5$ a to $\mathrm{C}-1$ and $\mathrm{H}-5 \mathrm{~b}$ to $\mathrm{C}-1$, shown in Figure 3.8. This revealed an ether linkage from C-1 to C-5 which established a second pyrano-pentose ring system.

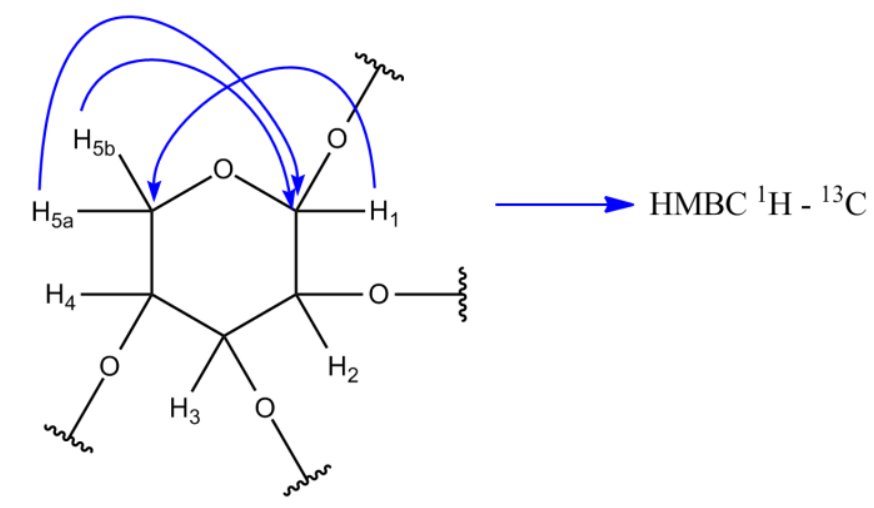

Figure 3.8 Selected HMBC correlations establishing the cyclic ring connectivity of sugar two.

The relative stereochemistry of the protons around the ring of sugar two was established by using a combination of ${ }^{1} \mathrm{H}-{ }^{1} \mathrm{H}$ coupling constants and through space NOE correlations. From the ${ }^{1} \mathrm{H}$ NMR, $\mathrm{H}-1$ was observed to be a doublet with a coupling constant of $6.1 \mathrm{~Hz}$. The large coupling constant indicated a 1,2-trans diaxial relationship between $\mathrm{H}-1$ and $\mathrm{H}-2$ and established a $\beta$ configuration of the $\mathrm{C}-1$ position ( $\mathrm{H}-1$ axial, $\beta$ face) and assigning $\mathrm{H}-2$ axial, on the $\alpha$ face of the ring system. From the 1D TOCSY experiment, the multiplicities of the protons were clearly resolved and the coupling constants were determined for protons $\mathrm{H}-2(\mathrm{t}, 6.8 \mathrm{~Hz}), \mathrm{H}-3(\mathrm{t}, 7.5 \mathrm{~Hz}), \mathrm{H}-4$ 
(multiplet), $\mathrm{H}-5 \mathrm{a}$ (dd, 11.8, $4.5 \mathrm{~Hz}$ to $\mathrm{H}-4$ ) and $\mathrm{H}-5 \mathrm{~b}$ (dd, 12.0, 8.2 $\mathrm{Hz}$ to $\mathrm{H}-4)$. The large coupling constants observed in sugar two were similar to those observed in sugar one, therefore indicating the axial positions of the methine protons, shown in Figure 3.9. These similarities led to the assignment of sugar two as a second $\beta$-xylopyranose ring system.

The proposed relative stereochemistry was confirmed by relevant NOE correlations seen in ROESY experiments, also shown in Figure 3.9. NOE correlations between $\mathrm{H}-1$ and $\mathrm{H}-3$, and $\mathrm{H}-1$ and $\mathrm{H}-5 \mathrm{~b}$ indicated the presence of 1,3-diaxial relationships. This confirmed that $\mathrm{H}-1, \mathrm{H}-3$ and $\mathrm{H}-5 \mathrm{~b}$ were all on the same face of the ring. An NOE correlation was also observed from $\mathrm{H}-5 \mathrm{a}$ to $\mathrm{H}-4$ which confirmed that they were on the same face of the ring. Given the confirmed sequence of carbons, the oxacyclic ring structure and the stereochemical relationship of the protons around the ring the data was consistent with an established $\beta$-xylopyranose structure.

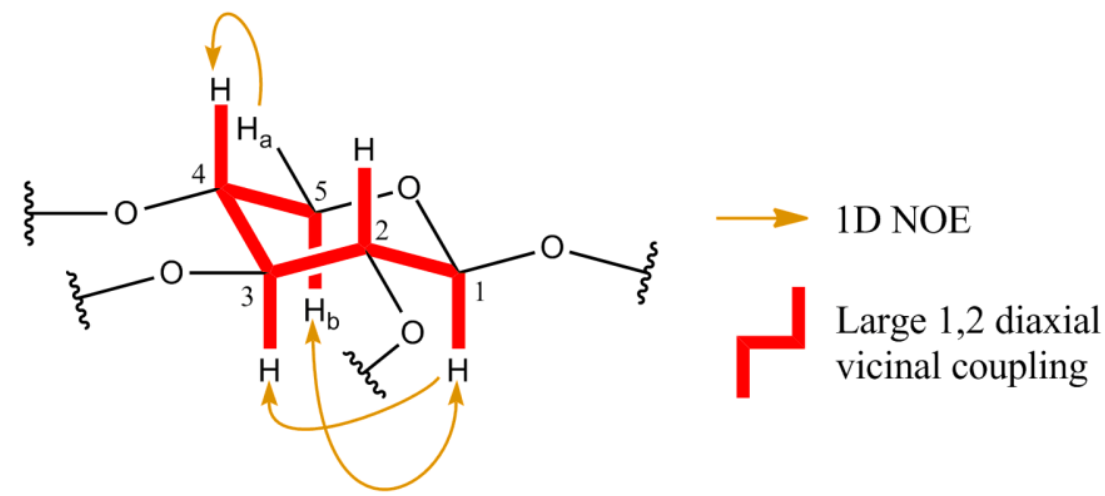

Figure 3.9 NOE correlations and large 1,2-diaxial vicinal coupling establishing the relative stereochemistry of sugar two.

\section{Sugar three}

From the HSQC-TOCSY experiment a third spin system was observed, shown in black in Figure 3.3, that was comprised of one anomeric (acetal) $\left(\mathrm{CH}-1 \delta_{C} 100.0, \delta_{H} 4.63\right)$, one aminomethine $\left(\mathrm{CH}-2 \delta_{\mathrm{C}} 56.1, \delta_{\mathrm{H}} 3.71\right)$, three oxymethines $\left(\mathrm{CH}-3 \delta_{\mathrm{C}} 84.5, \delta_{\mathrm{H}} 3.67, \mathrm{CH}-4\right.$ $\left.\delta_{\mathrm{C}} 69.8, \delta_{\mathrm{H}} 3.45, \mathrm{CH}-5 \delta_{\mathrm{C}} 77.4, \delta_{\mathrm{H}} 3.32\right)$ and one oxymethylene $\left(\mathrm{CH}_{2}-6 \delta_{\mathrm{C}} 62.1, \delta_{\mathrm{Ha}} 3.87\right.$, $\delta_{\mathrm{Hb}}$ 3.71). An unusual upfield heteromethine was observed at $\delta_{\mathrm{C}} 56.1$ and $\delta_{\mathrm{H}} 3.71$ with a ${ }^{1} J_{\mathrm{CH}}$ value of $142 \mathrm{~Hz}$, which was determined to be consistent with a nitrogen bound functionality, typically either an amino or amido group. Correlations were observed in the HMBC between a methyl $\left(\delta_{C} 22.8, \delta_{H} 1.98\right)$ and a carbonyl carbon $\left(\delta_{C} 174.2\right)$ and from $\mathrm{H}-2$ to the carbonyl carbon. The carbon shift of $\delta_{c} 174.2$ is consistent with an 
amido carbonyl carbon which suggested that the nitrogen group was a NHAc group, attached at position two, shown in Figure 3.10.

In the previously described sugar subunits, COSY correlations were clearly discernible around the linear chain. In sugar three however, the ${ }^{1} \mathrm{H}$ resonances of $\mathrm{H}-2$ and $\mathrm{H}-6 \mathrm{~b}$ $\left(\delta_{\mathrm{H}} 3.71\right.$ and 3.71$)$ overlapped each other, while $\mathrm{H}-3$ was also in close spectral proximity $\left(\delta_{H} 3.67\right)$, made analysis of the COSY spectra difficult. Close examination of a double quantum filtered (DQF) COSY experiment provided evidence of $\mathrm{H}-2$ to $\mathrm{H}-3, \mathrm{H}-3$ to $\mathrm{H}-4, \mathrm{H} 4$ to $\mathrm{H}-5, \mathrm{H}-5$ to $\mathrm{H}-6 \mathrm{a}, \mathrm{H}-5$ to $\mathrm{H}-6 \mathrm{~b}$ and $\mathrm{H}-6$ a to $\mathrm{H}-6 \mathrm{~b}$ correlations which established a linear chain from C1 through to C6, illustrated in Figure 3.10.

A series of 1D TOCSY experiments, with selective excitation of the anomeric centre $\mathrm{H}-1$ and progressive spin lock mixing times, afforded information confirming the sequence of the chain, shown in Figure 3.10. At 30 ms both $\mathrm{H}-2$ and $\mathrm{H}-3$ were revealed, proton $\mathrm{H}-4$ was observed at $45 \mathrm{~ms}, \mathrm{H}-5$ at $75 \mathrm{~ms}$ and $\mathrm{H}-6 \mathrm{a}$ at $120 \mathrm{~ms}$. Proton $\mathrm{H}-6 \mathrm{~b}$ could not be easily revealed during the 1D TOCSY experiment due to overlap with $\mathrm{H}-2$, however a shoulder was seen on the original H-2 triplet peaks which may indicate the presence of $\mathrm{H}-6 \mathrm{~b}$ after $120 \mathrm{~ms}$. The HMBC experiment showed correlations that confirmed the established carbon chain sequence. The correlations observed were from $\mathrm{H}-2$ to $\mathrm{C}-1$ and $\mathrm{C}-3 ; \mathrm{H}-3$ to $\mathrm{C}-1, \mathrm{C}-2, \mathrm{C}-4$ and $\mathrm{C}-5 ; \mathrm{H}-4$ to $\mathrm{C}-3$ and $\mathrm{C}-5 ; \mathrm{H}-5$ to $\mathrm{C}-6$; H-6a to $\mathrm{C}-1$ and $\mathrm{C}-$ 4 and $\mathrm{H}-6 \mathrm{~b}$ to $\mathrm{C}-1$ and $\mathrm{C}-5$. The $\mathrm{HMBC}$ experiment did not reveal any correlations between positions $\mathrm{CH}-1$ and $\mathrm{CH}-5$ that indicated an ether linked sugar ring.

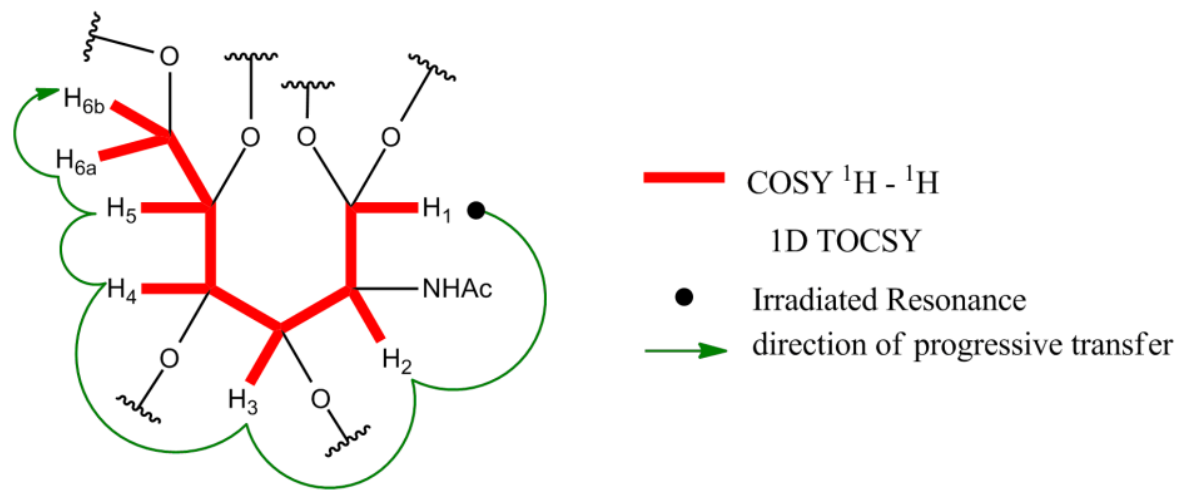

Figure 3.10 DQF COSY and 1D TOCSY data establishing the carbon chain connectivity of sugar three. 
Again, the relative stereochemistry of sugar three was determined using ${ }^{1} \mathrm{H}-{ }^{1} \mathrm{H}$ coupling constants, multiplicity and 1D NOE correlations. H-1 was observed in a doublet environment with a coupling constant of $7.8 \mathrm{~Hz}$. The large coupling constant indicated a 1,2-trans diaxial relationship between $\mathrm{CH}-1$ and $\mathrm{CH}-2$, which established a $\beta$ configuration of the anomeric position ( $\mathrm{H}-1$ axial, $\beta$ face) and $\mathrm{H}-2$ 's position, axial on the $\alpha$ face. The series of 1D TOCSY experiments from $\mathrm{H}-1$, described earlier, clearly resolved $\mathrm{H}-2, \mathrm{H}-3, \mathrm{H}-4$ and $\mathrm{H}-6$ a from the overall proton spectrum. Proton $\mathrm{H}-2$ was seen to be a triplet with a large coupling constant of $9.5 \mathrm{~Hz}$ which indicated a diaxial relationship with $\mathrm{H}-3$, confirming the assignment of $\mathrm{H}-2$, and indicating that $\mathrm{H}-3$ was axial on the $\beta$ face. Proton $\mathrm{H}-3$ was revealed as a triplet with a large coupling constant of $9.2 \mathrm{~Hz}$ which suggested a diaxial relationship with $\mathrm{H}-4$, reaffirming the $\mathrm{H}-3$ assignment, while $\mathrm{H}-4$ was established as axial on the $\alpha$ face. Proton $\mathrm{H}-4$ was observed to be a triplet with a large coupling constant of $8.9 \mathrm{~Hz}$ which indicated a diaxial relationship with $\mathrm{H}-5$, supporting the assignment of $\mathrm{H}-4$, and indicating that $\mathrm{H}-5$ was axial on the $\beta$ face. Proton $\mathrm{H}-6 \mathrm{a}$ was revealed as being a doublet of doublets with a small coupling of $2.1 \mathrm{~Hz}$ to $\mathrm{H}-5$ which suggested $\mathrm{H}-6$ a was equatorial to the ring. Proton $\mathrm{H}-6 \mathrm{~b}$ was shielded by signal overlap and therefore multiplicity and coupling could not be determined. Irradiation of H-1 in a 1D ROESY experiment revealed an NOE correlation between $\mathrm{H}-1$ and $\mathrm{H}-3$ indicating a 1,3-cis diaxial relationship. The large couplings, NOE and established axial positions of protons $\mathrm{H}-1, \mathrm{H}-2, \mathrm{H}-3, \mathrm{H}-4$ and $\mathrm{H}-5$ are consistent with a glucose configuration of a pyranohexose subunit, illustrated in Figure 3.11. This established the structure of the subunit as 2-(acetylamino)-2deoxy-D-glucose or $\mathrm{N}$-acetylglucosamine.

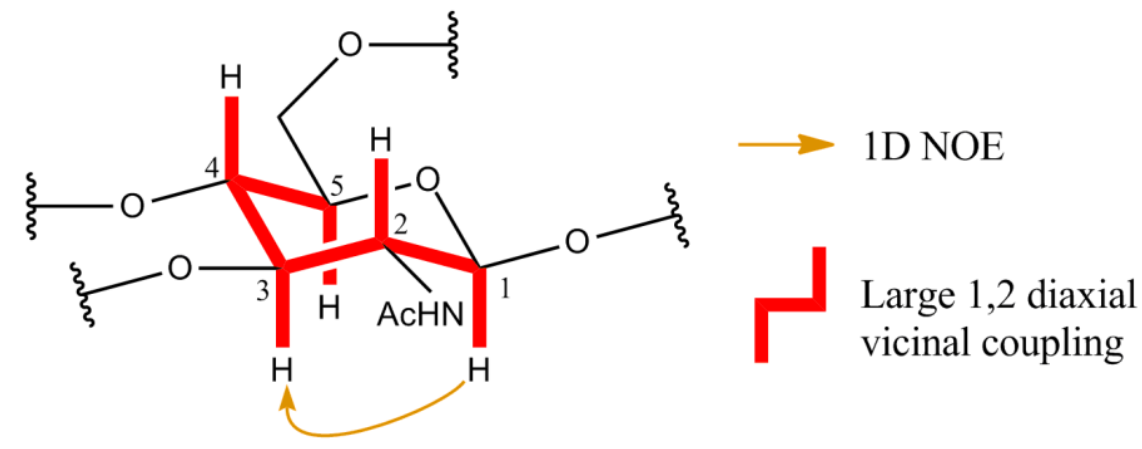

Figure 3.11 An NOE correlation and large 1,2-diaxial vicinal coupling establishing the relative stereochemistry of sugar three. 


\section{Sugar Four}

The fourth sugar-like spin system from the HSQC-TOCSY experiment, shown in red in Figure 3.3, was comprised of the remaining one anomeric (acetal) $\left(\mathrm{CH}-1 \delta_{\mathrm{C}} 104.7, \delta_{\mathrm{H}}\right.$ 4.32), four oxymethines $\left(\mathrm{CH}-2 \delta_{\mathrm{C}} 74.5, \delta_{\mathrm{H}} 3.22, \mathrm{CH}-3 \delta_{\mathrm{C}} 77.4, \delta_{\mathrm{H}} 3.34, \mathrm{CH}-4 \delta_{\mathrm{C}} 71.1, \delta_{\mathrm{H}}\right.$ 3.29, $\left.\mathrm{CH}-5 \delta_{\mathrm{C}} 77.9, \delta_{\mathrm{H}} 3.30\right)$ and one oxymethylene $\left(\mathrm{CH}_{2}-6 \delta_{\mathrm{C}} 62.2, \delta_{\mathrm{Ha}} 3.87, \delta_{\mathrm{Hb}} 3.63\right)$.

The spectral data of sugar four was difficult to analyse as the overlap of signals in the subunit ( $\mathrm{H}-3, \mathrm{H}-4$ and $\mathrm{H}-5$ separated by $0.05 \mathrm{ppm}$ ) were more severe than in the case of sugar three. COSY correlations were observed from $\mathrm{H}-1$ to $\mathrm{H}-2, \mathrm{H}-2$ to $\mathrm{H}-3$ and $\mathrm{H}-6 \mathrm{a}$ to $\mathrm{H}-6 \mathrm{~b}$. COSY correlations were also observed from $\mathrm{H}-3, \mathrm{H}-6 \mathrm{a}$ and $\mathrm{H}-6 \mathrm{~b}$ into an unresolved proton environment at approximately $\delta_{H} 3.30$, illustrated in Figure 3.12. A series of 1D TOCSY experiments, selectively exciting the anomeric centre $\mathrm{H}-1$ and then progressively increasing the spin lock mixing time provided evidence of a contiguous system from $\mathrm{H}-1$ through to $\mathrm{H}-6 \mathrm{a}$ and $\mathrm{H}-6 \mathrm{~b}$ which indicated that there was two oxymethines present, in the unresolved section of the chain, shown in Figure 3.12. $\mathrm{HMBC}$ correlations within sugar four were only useful in reaffirming positions $\mathrm{H}-1, \mathrm{H}-2$ and $\mathrm{H}-3$. Although correlations confirming the sugar ring system were not observed in the HMBC experiment the resonances from the spectra analysed $\left({ }^{1} \mathrm{H}, \mathrm{COSY}, \mathrm{HSQC}\right.$, HMBC, 1D TOCSY and 1D ROESY) were diagnostic of a sugar moiety.

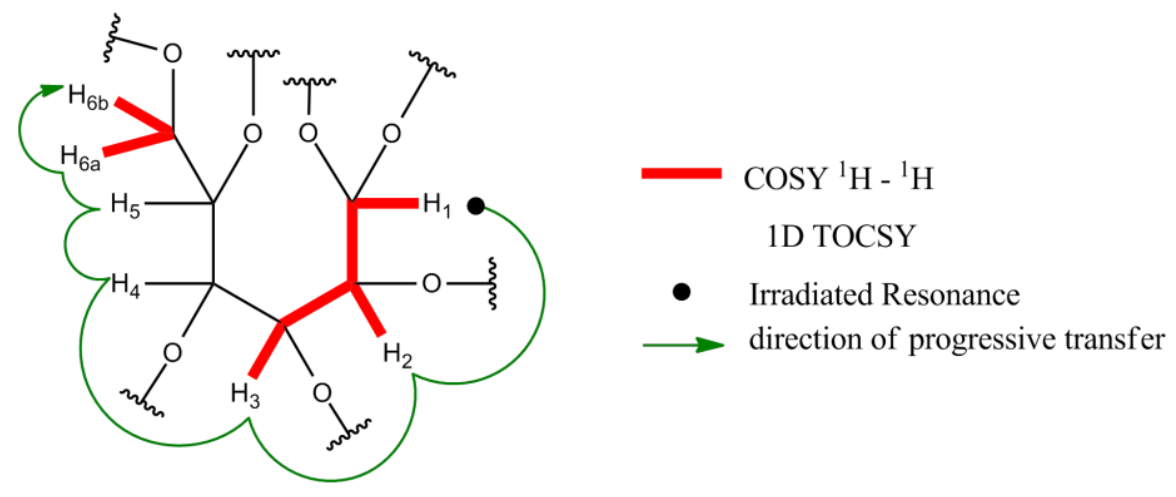

Figure 3.12 COSY and 1D TOCSY data establishing the carbon chain connectivity of sugar four.

The relative stereochemistry of sugar four was determined using ${ }^{1} \mathrm{H}-{ }^{1} \mathrm{H}$ coupling constants, multiplicity and 1D NOE correlations. H-1 was observed in a doublet environment with a coupling constant of $7.8 \mathrm{~Hz}$. The large coupling constant indicated a 1,2-trans diaxial relationship between $\mathrm{H}-1$ and $\mathrm{H}-2$, which established a $\beta$ configuration of the anomeric position ( $\mathrm{H}-1$ axial, $\beta$ face) and $\mathrm{H}-2$ 's position, axial on 
the $\alpha$ face. Protons $\mathrm{H}-2$ and $\mathrm{H}-3$ were observed to be triplets with large coupling constants similar to sugar three, indicating similar proton stereochemistry $(\mathrm{H}-2,8.5 \mathrm{~Hz}$, axial, $\alpha$ face) and $(\mathrm{H}-3,8.6 \mathrm{~Hz}$, axial, $\beta$ face). The large coupling constant of $\mathrm{H}-3$ revealed that proton $\mathrm{H}-4$ was in a 1,2-trans diaxial relationship with $\mathrm{H}-3$, in an axial position on the $\alpha$ face. Proton $\mathrm{H}-6 \mathrm{a}(\mathrm{dd}, 11.9,1.9 \mathrm{~Hz})$ and $\mathrm{H}-6 \mathrm{~b}(\mathrm{dd}, 11.9,5.9 \mathrm{~Hz}$ ) possessed small and large coupling constants to $\mathrm{H}-5$ respectively which indicated that $\mathrm{H}-6$ a was equatorial to $\mathrm{H}-5$ and $\mathrm{H}-6 \mathrm{~b}$ was axial. This suggested that $\mathrm{H}-5$ was in an axial position on the $\beta$ face of the ring. Irradiation of $\mathrm{H}-1$ in a 1D ROESY experiment revealed NOE correlations from $\mathrm{H}-1$ to $\mathrm{H}-3$ and $\mathrm{H}-1$ to $\mathrm{H}-5$ indicating 1,3-cis diaxial relationships which suggested a glucose stereochemistry of the sugar moiety, illustrated in Figure 3.13.

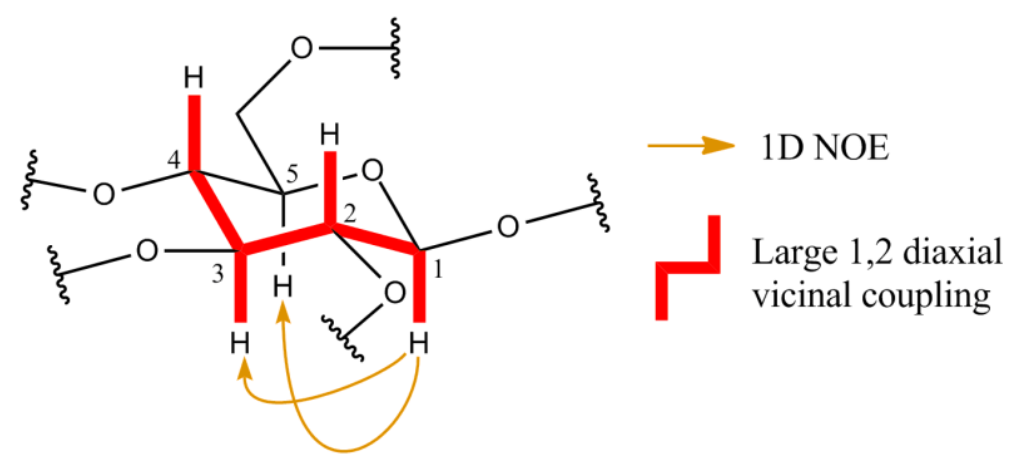

Figure 3.13 NOE correlations and large 1,2-diaxial vicinal coupling establishing the relative stereochemistry of sugar four.

Full positional assignment was performed by comparing the ${ }^{13} \mathrm{C}$ shifts of positions four and five to literature sources of glucose NMR, acquired in MeOD. ${ }^{111,117-120}$ Sources showed that the lower carbon shift is assigned position four of the ring $\left(\delta_{C} 71.1\right)$ and the higher shift, position five $\left(\delta_{C}\right.$ 77.9). Comparison of the carbon shifts of glucose with that of sugar four confirmed the NOE correlations observed, therefore sugar four was a $\beta$-D-glucopyranose moiety.

\section{Oligosaccharide Chain Connectivity}

The glycosidic linkages between the four sugar subunits and to the aglycon moiety were established through $\mathrm{HMBC}$ and NOE correlations. All linkages were determined to be $\beta$-glycosidic linkages as the anomeric proton doublets possessed large coupling constants as mentioned previously. Additionally, ${ }^{1} J_{\mathrm{CH}}$ coupling constants of 
approximately $160 \mathrm{~Hz}$ were observed which support the axial positioning of the anomeric protons (a $\beta{ }^{1} J_{\mathrm{CH}}$ coupling constant is approximately $170 \mathrm{~Hz}$ ). ${ }^{121}$ The HMBC experiment revealed a correlation between $\mathrm{S} 1-\mathrm{H} 1$ and the oxymethine carbon of the aglycon, the only oxymethine unaccounted for by the four sugars. This three-bond correlation firmly established a glycosidic linkage between S1 and the aglycon. This linkage was confirmed by reciprocal NOE correlations observed between S1-H1 and the oxymethine proton of the aglycon. An HMBC correlation was observed from S2-H1 to S1-C3 which indicated that S2 was linked to S1 through a $1 \rightarrow 3$ glycosidic linkage. This three-bond correlation was confirmed by reciprocal NOE correlations between S2$\mathrm{H} 1$ and S1-H3. HMBC correlations from S3-H1 to S1-C4 and S1-H4 to S3-C1 revealed a $1 \rightarrow 4$ glycosidic linkage between S1 and S3. The $1 \rightarrow 4$ linkage was confirmed by an NOE correlation observed from S3-H1 to S1-H4 which established a branched oligosaccharide chain. Reciprocal HMBC correlations observed from S4-H1 to S3-C3 and $\mathrm{S} 3-\mathrm{H} 3$ to $\mathrm{S} 4-\mathrm{C} 1$ revealed a $1 \rightarrow 3$ linkage between S4 and S3, confirmed by an NOE between the centres. Additionally, the oxymethine centres were determined to be hydroxyl groups as all relevant proton and carbon shifts were consistent with this functionality. Therefore the oligosaccharide chain was described as $\beta$ - $D$-Glc $p$ - $(1 \rightarrow 3)-\beta$ $D$-GlcpNHAc- $(1 \rightarrow 4)-[\beta-D-X y \mid p-(1 \rightarrow 3)]-\beta-D-X y \mid p$, shown in Figure 3.14.

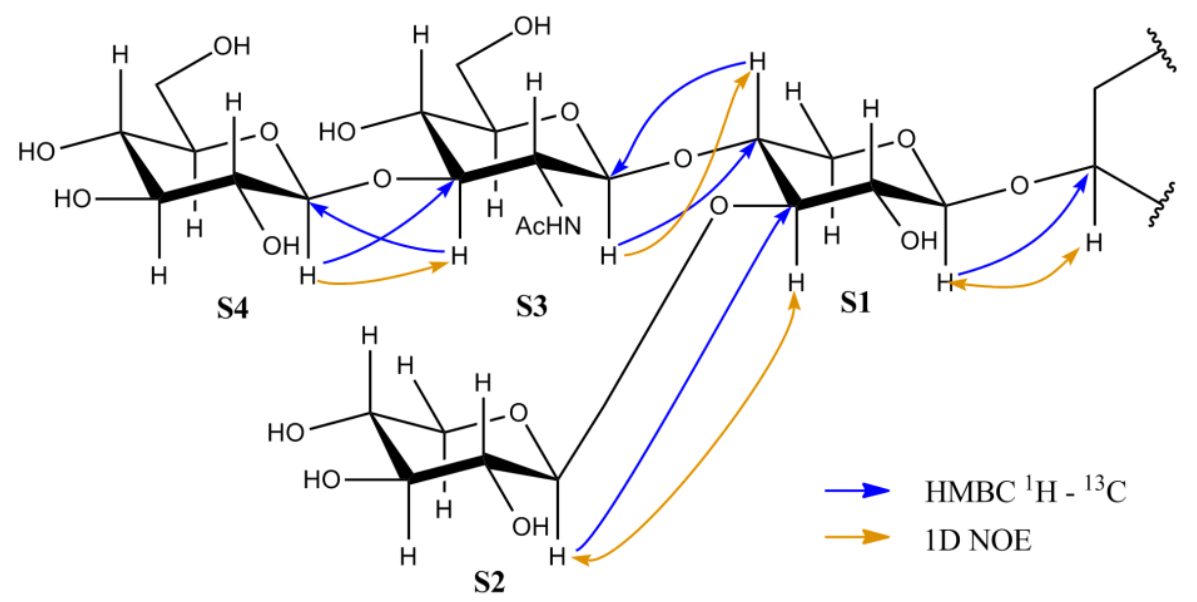

Figure 3.14 NOE and HMBC correlations establishing the oligosaccharide chain connectivity of 135. 


\section{The Aglycon}

The oligosaccharide chain accounts for 25 carbons, 40 hydrogens, 19 oxygens and one nitrogen from the original formula $\mathrm{C}_{51} \mathrm{H}_{83} \mathrm{O}_{20} \mathrm{~N}$. This indicated that the aglycon contained 27 carbons, 43 hydrogens and one oxygen atom. The 27 carbons left included an oxymethine, a saturated ketone carbonyl, a tri-substituted double bond, and two quaternary centres while the ${ }^{1} \mathrm{H}$ revealed two clearly discernible methyl singlets and a methyl doublet. The oligosaccharide chain accounted for five double bond equivalents therefore six double bond equivalents were present in the aglycon structure. This indicated that the aglycon was tetracyclic as four double bond equivalents remained after accounting for the ketone and double bond functionality. Using COSY, HSQC, HMBC and 1D TOCSY experiments, five proton spin systems were fully identified, which led to five substructure determinations accounting for most of the non-oxygenated carbons of the aglycon. Full assembly of the aglycon was then achieved by COSY and HMBC correlations observed between the sub-structures.

\section{Substructure One}

A methylene $\left(\mathrm{CH}_{2}-4, \delta_{\mathrm{C}} 39.3, \delta_{\mathrm{Ha}} 2.40, \delta_{\mathrm{Hb}} 2.24\right)$ was easily discernible in HSQC and COSY experiments. A series of COSY correlations were observed from $\mathrm{CH}_{2}-4$ to an oxymethine $\mathrm{CH}-3\left(\delta_{\mathrm{C}} 79.6, \delta_{\mathrm{H}} 3.49\right)$, from $\mathrm{CH}-3$ to methylene $\mathrm{CH}_{2}-2\left(\delta_{\mathrm{C}} 30.5, \delta_{\mathrm{Ha}} 1.87\right.$, $\left.\delta_{\mathrm{Hb}} 1.60\right)$ and from $\mathrm{CH}_{2}-2$ to another methylene $\mathrm{CH}_{2}-1\left(\delta_{\mathrm{C}} 38.3, \delta_{\mathrm{Ha}} 1.88, \delta_{\mathrm{Hb}} 1.07\right)$. These ${ }^{1} \mathrm{H}-{ }^{1} \mathrm{H}$ couplings established the order of the carbon linkages and revealed a linear carbon chain C1-C2-C3-C4. The order of this chain was confirmed by a series of 1D TOCSY experiments, selectively exciting $\mathrm{H}-4 \mathrm{a}$ and $\mathrm{H}-4 \mathrm{~b}$, in separate experiments, observing through the increase in spin lock mixing time, first, the geminal partner followed by $\mathrm{H}-3, \mathrm{H}-2 \mathrm{a}, \mathrm{b}$ and finally $\mathrm{H}-1 \mathrm{a}, \mathrm{b}$. $\mathrm{HMBC}$ correlations observed from $\mathrm{H}-4 \mathrm{a}$ to C-2 and C-3 and from H-1a,b to C-2 confirmed the established structure, illustrated in Figure 3.15. The observed ${ }^{13} \mathrm{C}$ and ${ }^{1} \mathrm{H}$ shifts of $\mathrm{CH}-3$ were consistent with an oxymethine position, which was identified previously as the attachment point for the oligosaccharide chain to the aglycon moiety. 


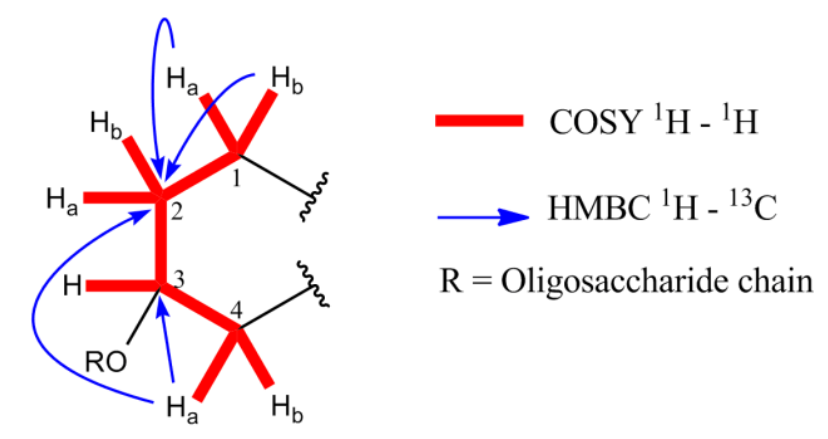

Figure 3.15 Selected COSY and HMBC correlations establishing the connectivity of substructure one.

\section{Substructure Two}

Analysis of the HSQC data for 135 revealed a single downfield methine proton $\mathrm{CH}-6\left(\delta_{\mathrm{C}}\right.$ $\left.122.5, \delta_{H} 5.38\right)$, indicative of an olefinic methine. A bond was established between C- 6 and a slightly downfield methylene $\mathrm{CH}_{2}-7\left(\delta_{\mathrm{C}} 32.7, \delta_{\mathrm{Ha}} 1.99, \delta_{\mathrm{Hb}} 1.53\right)$, through observed COSY correlations from $\mathrm{H}-6$ to $\mathrm{H}-7 \mathrm{a}, \mathrm{b}$. A COSY correlation was then revealed from $\mathrm{CH}-7$ a to a methine proton, $\mathrm{CH}-8\left(\delta_{\mathrm{C}} 32.9, \delta_{\mathrm{H}} 1.49\right)$, while the COSY correlation from $\mathrm{H}-7 \mathrm{~b}$ to $\mathrm{CH}-8$ was not clearly observed due to overlap of the two signals in the COSY spectrum. The correlation between $\mathrm{H}-7 \mathrm{a}$ and $\mathrm{H}-8$ confirmed a $\mathrm{C} 7-\mathrm{C} 8$ bond. A COSY correlation was then observed between $\mathrm{CH}-8$ and a second methine $\mathrm{CH}-9\left(\delta_{\mathrm{C}}\right.$ $51.4, \delta_{H}$ 0.95). From this methine, a single COSY correlation was observed to methylene $\mathrm{CH}_{2}-11\left(\delta_{\mathrm{C}} 21.8, \delta_{\mathrm{H}} 1.54,2 \mathrm{H}\right)$. A single correlation was observed as the HSQC showed the methylene's two proton resonances overlapped at $1.54 \mathrm{ppm}$. A final COSY correlation was observed in this substructure from $11 a, b$ to the methylene $\mathrm{CH}_{2}-$ $12 \mathrm{a}, \mathrm{b}\left(\delta_{\mathrm{C}} 40.8, \delta_{\mathrm{Ha}} 2.04, \delta_{\mathrm{Hb}} 1.20\right)$, which established the carbon connectivity illustrated in Figure 3.16.

A series of 1D TOCSY experiments were performed starting from different signals along the substructure. Selectively exciting $\mathrm{H}-6$ resulted in the progressive appearance of protons $\mathrm{H}-7 \mathrm{a}, \mathrm{b}, \mathrm{H}-8$ and $\mathrm{H}-9$ (weakly) as the spin lock mixing time was increased. Selective excitation of $\mathrm{H}-9$ revealed protons $\mathrm{H}-11 \mathrm{a}, \mathrm{b}$, followed by $\mathrm{H}-12 \mathrm{a}, \mathrm{b}$ as the mixing time increased. Protons $\mathrm{H}-8$ through to $\mathrm{H}-6$ were also observed with excitation of $\mathrm{H}-9$ which reaffirmed the carbon sequence in the substructure. Additionally, along the substructure chain $\mathrm{HMBC}$ correlations were observed which confirmed the assignment of the sequence, shown in Figure 3.16. 


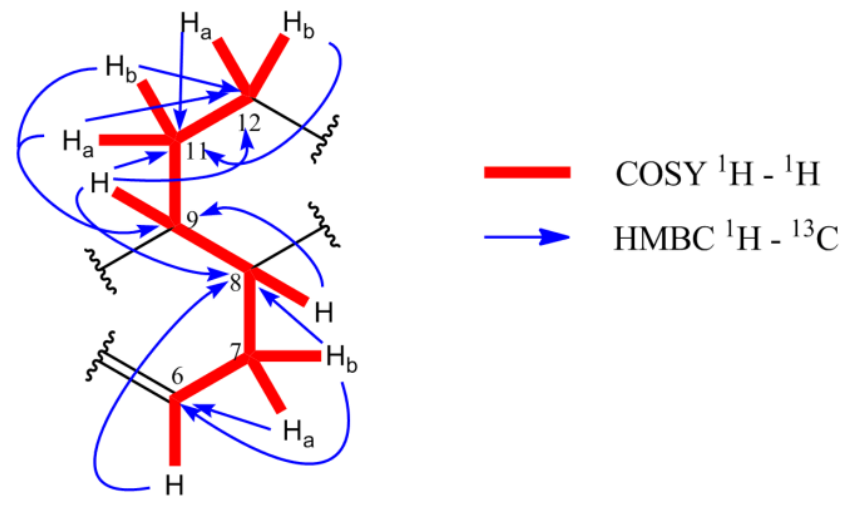

Figure 3.16 Selected COSY and HMBC correlations establishing the connectivity of substructure two.

\section{Substructure Three}

Further analysis of the HSQC experiment revealed a methine proton $\mathrm{CH}-17\left(\delta_{\mathrm{C}} 57.1, \delta_{\mathrm{H}}\right.$ 1.13) that was distinctive due to its downfield carbon shift. A COSY correlation observed from $\mathrm{H}-17$ to the methylene $\mathrm{CH}_{2}-16\left(\delta_{\mathrm{C}} 28.9, \delta_{\mathrm{Ha}} 1.88, \delta_{\mathrm{Hb}} 1.34\right)$ established a $\mathrm{C}-17$ to $\mathrm{C}-16$ bond. COSY correlations were observed from $\mathrm{H}-16 \mathrm{a}, \mathrm{b}$ to a second methylene $\mathrm{CH}_{2}-15\left(\delta_{\mathrm{C}} 25.0, \delta_{\mathrm{Ha}} 1.63, \delta_{\mathrm{Hb}} 1.12\right)$ which revealed a bond between $\mathrm{C}-16$ and $\mathrm{C}-15$. COSY correlations were then observed from $\mathrm{H}-15 \mathrm{a}, \mathrm{b}$ to $\mathrm{CH}-14\left(\delta_{\mathrm{C}} 57.8, \delta_{\mathrm{H}}\right.$ 1.03) a methine group with a similar downfield ${ }^{13} \mathrm{C}$ NMR shift as $\mathrm{C}-17$, which indicated that C-17 and C-14 were in similar environments. Substructure three was confirmed as a C17-C16-C15-C14 carbon chain by a series of HMBC correlations as illustrated in Figure 3.17 .

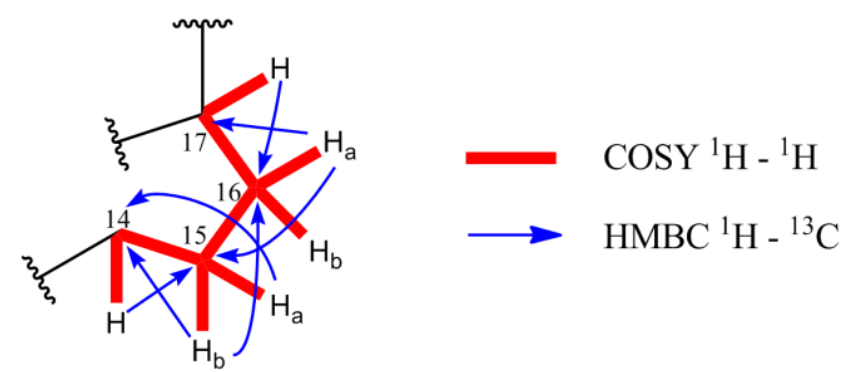

Figure 3.17 Selected COSY and HMBC correlations establishing the connectivity of substructure three. 


\section{Substructure Four}

A deshielded methylene group $\mathrm{CH}_{2}-23\left(\delta_{\mathrm{C}} 38.0, \delta_{\mathrm{Ha}} 2.54, \delta_{\mathrm{Hb}} 2.46\right)$ was clearly observed in the HSQC spectrum. COSY correlations observed from $\mathrm{H}-23 \mathrm{a}, \mathrm{b}$ to methylene $\mathrm{CH}_{2}-22$ $\left(\delta_{\mathrm{C}} 30.7, \delta_{\mathrm{Ha}} 1.73, \delta_{\mathrm{Hb}}\right.$ 1.23) revealed a bond between $\mathrm{C}-23$ and $\mathrm{C}-22$. COSY correlations observed from $\mathrm{H}-22 \mathrm{a}, \mathrm{b}$ to a methine, $\mathrm{CH}-20\left(\delta_{\mathrm{C}} 36.4, \delta_{\mathrm{H}} 1.42\right)$, established a C-22 to $\mathrm{C}-20$ bond. COSY correlations between $\mathrm{H}-20$ and methyl $\mathrm{CH}_{3}-21\left(\delta_{\mathrm{C}} 18.7, \delta_{\mathrm{H}}\right.$ 0.95) then revealed a bond between C-20 and C-21 off one branch of the C-20 methine, which established the connectivity of substructure four, shown in Figure 3.18 .

A series of 1D TOCSY experiments were run selectively exciting $\mathrm{H}-23 \mathrm{a}$ and $\mathrm{H}-21$ and then increasing the spin lock mixing time to observe the neighbouring protons. Exciting $\mathrm{H}-23 \mathrm{a}$ saw the progressive excitation of $\mathrm{H}-23 \mathrm{~b}$ followed by $\mathrm{H}-22 \mathrm{a}, \mathrm{b}, \mathrm{H}-20$ and finally $\mathrm{H}-21$ while excitation of $\mathrm{H}-21$ first resulted in the appearance of $\mathrm{H}-20$, followed by $\mathrm{H}-22 \mathrm{a}, \mathrm{b}$ followed by $23 \mathrm{a}, \mathrm{b}$. The $1 \mathrm{D}$ TOCSY data confirmed the order that was observed from the COSY data which established the substructure as the linear chain C23-C22-C20-C21. Additionally, HMBC correlations confirming the substructure were observed, illustrated in Figure 3.18.

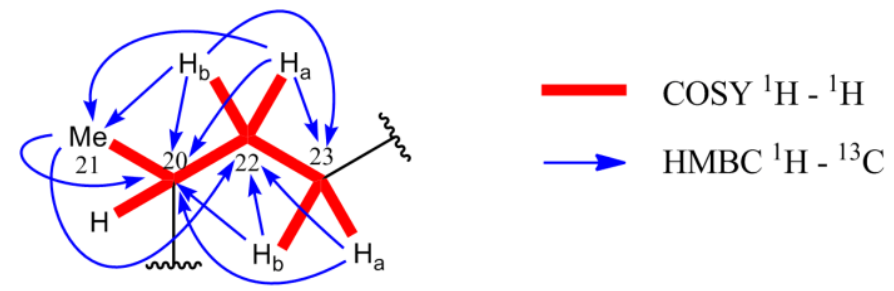

Figure 3.18 COSY and HMBC correlations establishing the connectivity of substructure four.

\section{Substructure Five}

Analysis of the ${ }^{1} \mathrm{H}$ NMR and HSQC revealed a deshielded septet methine, $\mathrm{CH}-25\left(\delta_{\mathrm{C}}\right.$ 41.6, $\left.\delta_{H} 2.68\right)$, that was clearly resolved in both spectra. The septet environment of $\mathrm{H}$ 25 , together with only one observed COSY correlation suggested that C-25 was the central carbon in a spin system made up of an isolated isopropyl group terminus. A COSY correlation observed from $\mathrm{H}-25$ to methyls $\mathrm{CH}_{3}-26\left(\delta_{\mathrm{C}} 18.4, \delta_{\mathrm{H}} 1.07\right)$ and $\mathrm{CH}_{3}-27$ $\left(\delta_{C} 18.4, \delta_{H} 1.07\right)$, established bonds between C25-C26 and C25-C27. HMBC 
correlations, shown in Figure 3.19, were observed which confirmed the isolated isopropyl structure of substructure five.

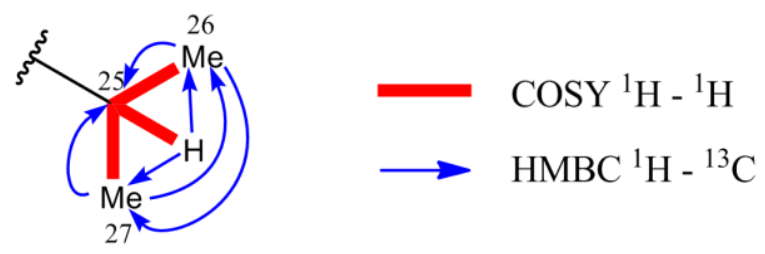

Figure 3.19 COSY and HMBC correlations establishing the connectivity of substructure five.

\section{Aglycon Substructure Connectivity}

Two methyl singlet carbons, one ketone carbonyl, one tri-substituted olefinic carbon and two quaternary carbon centres were unaccounted for after the elucidation of the five spin systems of the aglycon. In the HMBC experiment, correlations were observed from the olefinic methine $\mathrm{H}-6$ to the tri-substituted olefinic carbon $\mathrm{C}-5\left(\delta_{\mathrm{C}}\right.$ 141.4) establishing the $\mathrm{C} 5-\mathrm{C} 6$ double bond. The deshielded protons $\mathrm{H}-4 \mathrm{a}, \mathrm{b}$ revealed $\mathrm{HMBC}$ correlations to C-5 and C-6 which indicated a C-4 to C-5 bond, which established a connection between substructures one and two. This connection was further confirmed by an HMBC correlation from H-6 to C-4 and the appearance of H-6 in the 1D TOCSY experiments off $\mathrm{H}-4 \mathrm{a}, \mathrm{b}$. Selected $\mathrm{HMBC}$ correlations are shown in Figure 3.20. A methyl singlet $\mathrm{CH}_{3}-19\left(\delta_{C} 19.5, \delta_{H} 1.03\right)$ displayed $\mathrm{HMBC}$ correlations to $\mathrm{C}-1, \mathrm{C}-$ 5, C-9 and a quaternary centre $\mathrm{C}-10\left(\delta_{C} 37.5\right)$, as shown in Figure 3.20. The HMBC correlations from the methyl singlet established the connection of C-19 to the quaternary centre $\mathrm{C}-10$ and $\mathrm{C}-10$ to $\mathrm{C}-1, \mathrm{C}-5$ and $\mathrm{C}-9$. $\mathrm{HMBC}$ correlations were also observed from $\mathrm{H}-1$ a to $\mathrm{C}-10$ and $\mathrm{C}-19$, from $\mathrm{H}-1 \mathrm{~b}$ to $\mathrm{C}-9$ and $\mathrm{C}-10$ and also from $\mathrm{H}-9$ to C-19. This connectivity revealed the six-membered rings, A and B, fused at C-5 and C10, as shown in Figure 3.20.

A third connection point amongst the aglycon substructures was determined using COSY and $\mathrm{HMBC}$ correlations. A COSY correlation observed from $\mathrm{H}-8$ to $\mathrm{H}-14$ established a single bond linkage between C-8 and C-14 the methine terminus of substructure three. This linkage was confirmed by 1D TOCSY experiments with selective excitation of $\mathrm{H}-7 \mathrm{a}$ and $\mathrm{H}-9$, in separate experiments, affording the 
appearance of protons $\mathrm{H}-8$ and $\mathrm{H}-14$ as the mixing time was increased. $\mathrm{HMBC}$ correlations, illustrated in Figure 3.20, reaffirmed the bond between C-8 and C-14.

The second methyl singlet $\mathrm{CH}_{3}-18\left(\delta_{\mathrm{C}} 12.0, \delta_{\mathrm{H}} 0.72\right)$ correlated to carbons $\mathrm{C}-12, \mathrm{C}-14$, C-17 and the quaternary centre $\mathrm{C}-13\left(\delta_{\mathrm{C}} 43.2\right)$ in the $\mathrm{HMBC}$ experiment, shown in Figure 3.20. These correlations established the connection of C-18 to the quaternary centre $\mathrm{C}-13$ and $\mathrm{C}-13$ to $\mathrm{C}-12, \mathrm{C}-14$ and $\mathrm{C}-17$. $\mathrm{HMBC}$ correlations were also observed from $\mathrm{H}-12$ a to $\mathrm{C}-13$ and $\mathrm{C}-14, \mathrm{H}-12 \mathrm{~b}$ to $\mathrm{C}-13, \mathrm{C}-17$ and $\mathrm{C}-19$ and also from $\mathrm{H}-17$ to $\mathrm{C}-12$, C-13 and C-18, confirming this assignment. These bonds established two additional rings in the aglycon structure, ring $C$, a cyclohexane ring, and ring $D$, a cyclopentane ring, as shown in Figure 3.20.

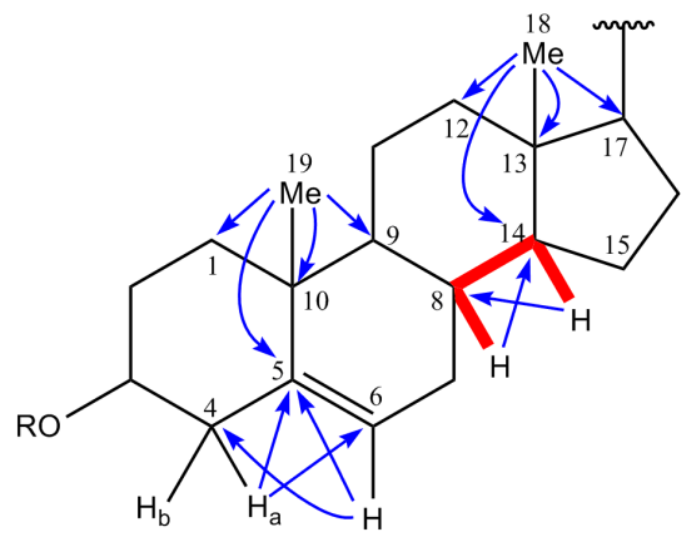

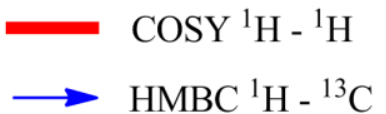

$\mathrm{R}=$ Oligosaccharide chain

Figure 3.20 Selected COSY and HMBC correlations establishing the connectivity of substructures one, two and three.

Substructures one, two and three connected to form a tetracyclic backbone accounting for five double bond equivalents. The remaining double bond equivalent was therefore a ketone present in the side chain. A COSY correlation was observed from $\mathrm{H}$ 20 to $\mathrm{H}-17$, which established a $\mathrm{C} 20-\mathrm{C} 17$ bond, the side chain attachment point. HMBC correlations revealed from $\mathrm{H}-17$ to $\mathrm{C}-20, \mathrm{C}-22, \mathrm{C}-21$, and from $\mathrm{H}-21$ to $\mathrm{C}-17$ confirmed the connectivity, shown in Figure 3.21. Additional 1D TOCSY data, with selective excitation of $\mathrm{H}-21$ revealed $\mathrm{H}-17$ appearing in the spectra upon the increasing of the spin lock mixing time.

The HMBC spectrum revealed the presence of a ketone carbonyl C-24 $\left(\delta_{C} 217.9\right)$ in the structure. $\mathrm{HMBC}$ correlations observed from $\mathrm{H}-25, \mathrm{H}-26, \mathrm{H}-27, \mathrm{H}-23 \mathrm{a}, \mathrm{b}$ and $\mathrm{H}-22 \mathrm{a}, \mathrm{b}$ to C-24, established the presence of the ketone between substructures four and five. Protons $\mathrm{H}-25$ and $\mathrm{H}-23 \mathrm{a}, \mathrm{b}$ were observed at higher shifts which were consistent with 
the deshielding effects of the ketone functional group. The data established connectivity between the substructures through $\mathrm{C} 23-\mathrm{C} 24$ and $\mathrm{C} 24-\mathrm{C} 25$ bonds. This connectivity is shown Figure 3.21.

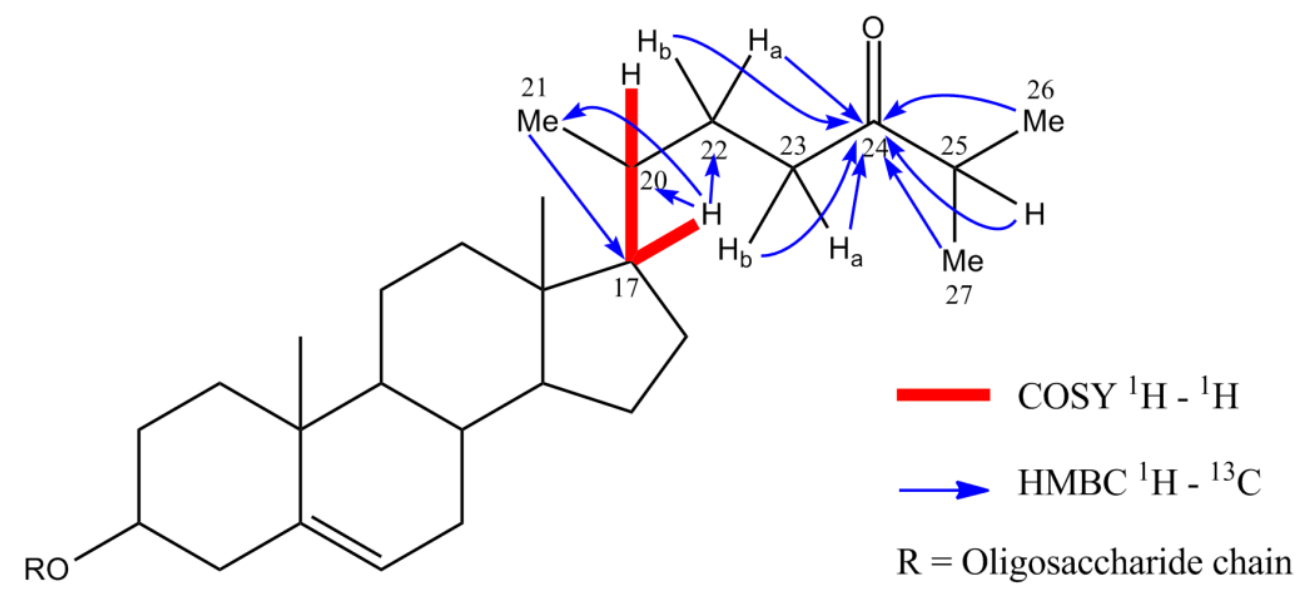

Figure 3.21 Selected COSY and HMBC correlations establishing the connectivity of the side chain (substructures four and five) to the tetracyclic ring system of the aglycon.

\section{Relative Stereochemistry of the Aglycon}

Full stereochemical assignment of the aglycon could not be achieved from correlations alone, however, portions of the aglycon moiety could be assigned using a combination of ${ }^{1} \mathrm{H}-{ }^{1} \mathrm{H}$ vicinal coupling constants and NOE correlations from 1D ROESY experiments. It was important to ascertain the relative stereochemistry of centres C-3, C-8, C-9, C$10, \mathrm{C}-13, \mathrm{C}-14$ and $\mathrm{C}-17$, as these positions had a large effect on whether the aglycon structure was planar in geometry or not, with Figure 3.22 illustrating the NOE correlations observed that aided in assigning these positions.

A 1D ROESY experiment, with selective irradiation of $\mathrm{H}-3$, showed NOE correlations from $\mathrm{H}-3$ to $\mathrm{S} 1-\mathrm{H} 1$ which indicated that the oligosaccharide chain was linked through the equatorial position on $\mathrm{C}-3$ and $\mathrm{H}-3$ was therefore bound in the axial position, as drawn in Figure 3.22. Protons $\mathrm{H}-4 \mathrm{a}, \mathrm{b}$ were each subjected to 1D ROESY experiments to determine the stereochemistry at $\mathrm{C}-10$. Proton $\mathrm{H}-4$ a showed NOE correlations to $\mathrm{H}-$ 3 and $\mathrm{S} 1-\mathrm{H} 1$, which indicated that $\mathrm{H}-4$ a was on the same face of the ring as $\mathrm{H}-3$, therefore equatorial (down). This was confirmed as $\mathrm{H}-4 \mathrm{~b}$ was observed in the 1D ROESY to be a broad triplet with a coupling constant of $12 \mathrm{~Hz}$ which indicated large geminal coupling with $\mathrm{H}-4 \mathrm{a}$ and large 1,2-diaxial coupling with $\mathrm{H}-3$ therefore $\mathrm{H}-4 \mathrm{~b}$ was 
assigned axially on the top face of ring $A$. An NOE correlation observed from $\mathrm{H}-4 \mathrm{~b}$ to $\mathrm{H}-19$ indicated that the methyl group at position $\mathrm{C}-10$ was axial on the top face of ring A, as drawn.

The stereochemistry of proton $\mathrm{CH}-9$ was determined by using a combination of $1 \mathrm{D}$ ROESY experiments at $\mathrm{H}-3$ and $\mathrm{H}-9$. An NOE correlation from $\mathrm{H}-3$ to proton $\mathrm{H}-1 \mathrm{~b}\left(\delta_{\mathrm{H}}\right.$ 1.07) indicated that $\mathrm{H}-1 \mathrm{~b}$ was axial to the ring on the bottom face as illustrated in Figure 3.22. An NOE correlation was also observed from $\mathrm{H}-9$ to $\mathrm{H}-1 \mathrm{~b}$ which confirmed that $\mathrm{H}-9$ was also axial on the bottom face of the aglycon structure.

The relative stereochemistry of $\mathrm{C}-13$ and $\mathrm{C}-17$ was determined by a 1D ROESY experiment irradiating the methyl at $\mathrm{C}-18$. An NOE correlation was observed from $\mathrm{H}$ 18 to $\mathrm{H}-20$, which indicated that methyl C-18 and side chain C-20 to C-27 were on the same face of the structure. A 1D ROESY experiment was performed irradiating a proton shift of $\delta_{H} 0.95$ which included $\mathrm{H}-9$ and the methyl group, $\mathrm{H}-21$. NOE correlations were observed from $\delta_{H} 0.95$ to $\mathrm{H}-12 \mathrm{a}, \mathrm{b}$ which afforded the possible stereochemical assignment of $\mathrm{H}-18$ and $\mathrm{H}-20$ either the top or bottom face (as drawn).

The axial and equatorial positions of $\mathrm{C}-12$ were assigned on the proton shifts of $\mathrm{H}-12 \mathrm{a}$ and $\mathrm{H}-12 \mathrm{~b}$ with the more deshielded signal $\mathrm{H}-12 \mathrm{a}\left(\delta_{\mathrm{H}} 2.04\right)$ designated equatorial on the top face and $\mathrm{H}-12 \mathrm{~b}\left(\delta_{\mathrm{H}}\right.$ 1.20) axial on the bottom face (as drawn). A strong NOE correlation from $\mathrm{H}-21$ to $\mathrm{H}-12$ a suggested that $\mathrm{H}-18$ and $\mathrm{H}-20$ were on the top face, as drawn. The methyl group C18 was assigned axial off C-13, and C-20 was therefore assigned to be in an equatorial-like position (there is no true equatorial position on a five-membered ring). This assignment was not unequivocal due to the signal overlap of $\mathrm{H}-9$ and $\mathrm{H}-21$, and the rotation that is possible with the side chain and $\mathrm{CH}_{3}-21$ group. A weak NOE correlation observed from $\mathrm{H}-18$ to $\mathrm{H}-12$ a provides support for this assignment.

A 1D ROESY experiment, irradiating the methyl $\mathrm{H}-18$, revealed correlations that afforded additional stereochemical assignment around ring C. An NOE correlation was observed from $\mathrm{H}-18$ to $\mathrm{H}-8$ which indicated that $\mathrm{H}-8$ was axial on the top face of the structure. This indicated that rings B and C were trans-fused. 


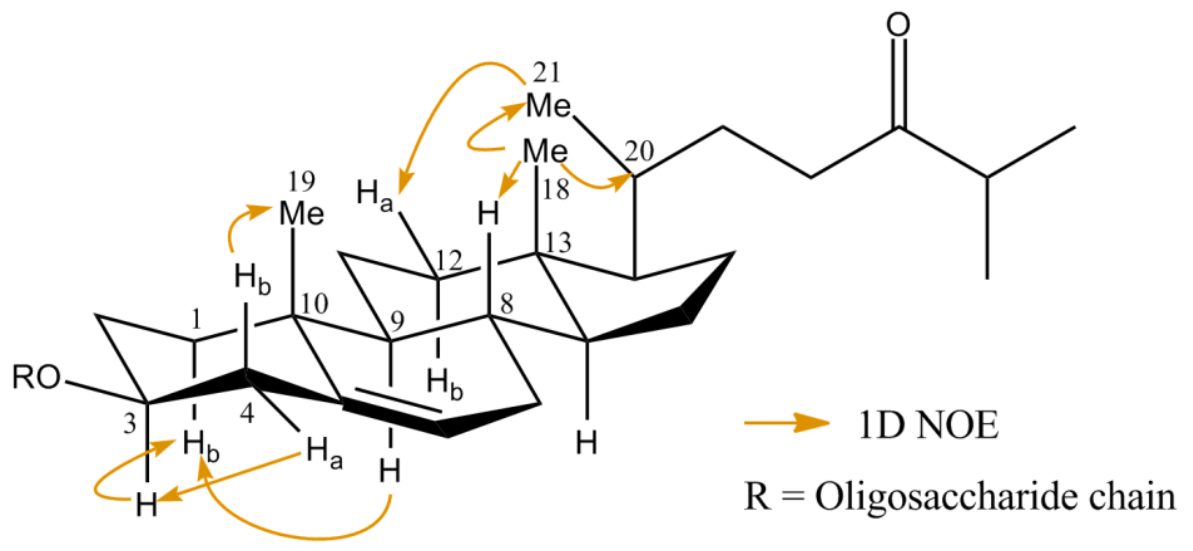

Figure 3.22 Selected NOE correlations establishing the relative stereochemistry of the aglycon moiety in $\mathbf{1 3 5}$.

The relative stereochemistry of C-14 could not be accurately determined from 1D ROESY experiments, with signal overlap from $\mathrm{H}-19$ and $\mathrm{H}-1 \mathrm{~b}$ meaning that NOE correlations observed could not be definitively attributed to H-14. Given the NOE correlations observed, the fusion of the rings and the side chain stereochemistry, position C-14 was assigned axial on the bottom face. This assignment was consistent with the well known stereochemistry of a standard cholesterol structure. This was further reaffirmed by the shifts of protons around the five-membered ring system which are comparable to the shifts of a trans-fused ring D system. ${ }^{122}$ While the complete relative stereochemistry could not be unequivocally assigned on the basis of NMR correlations alone, the portions that were fully established are consistent with the common steroid configuration. The contentious stereochemical assignments and remaining unassigned centres showed strong chemical shift similarities to known planar steroid structures and it was therefore strongly suggested that raspailoside $A$ (135) contained a conventional planar steroid configuration as drawn in Figure 3.22. 
Raspailoside A

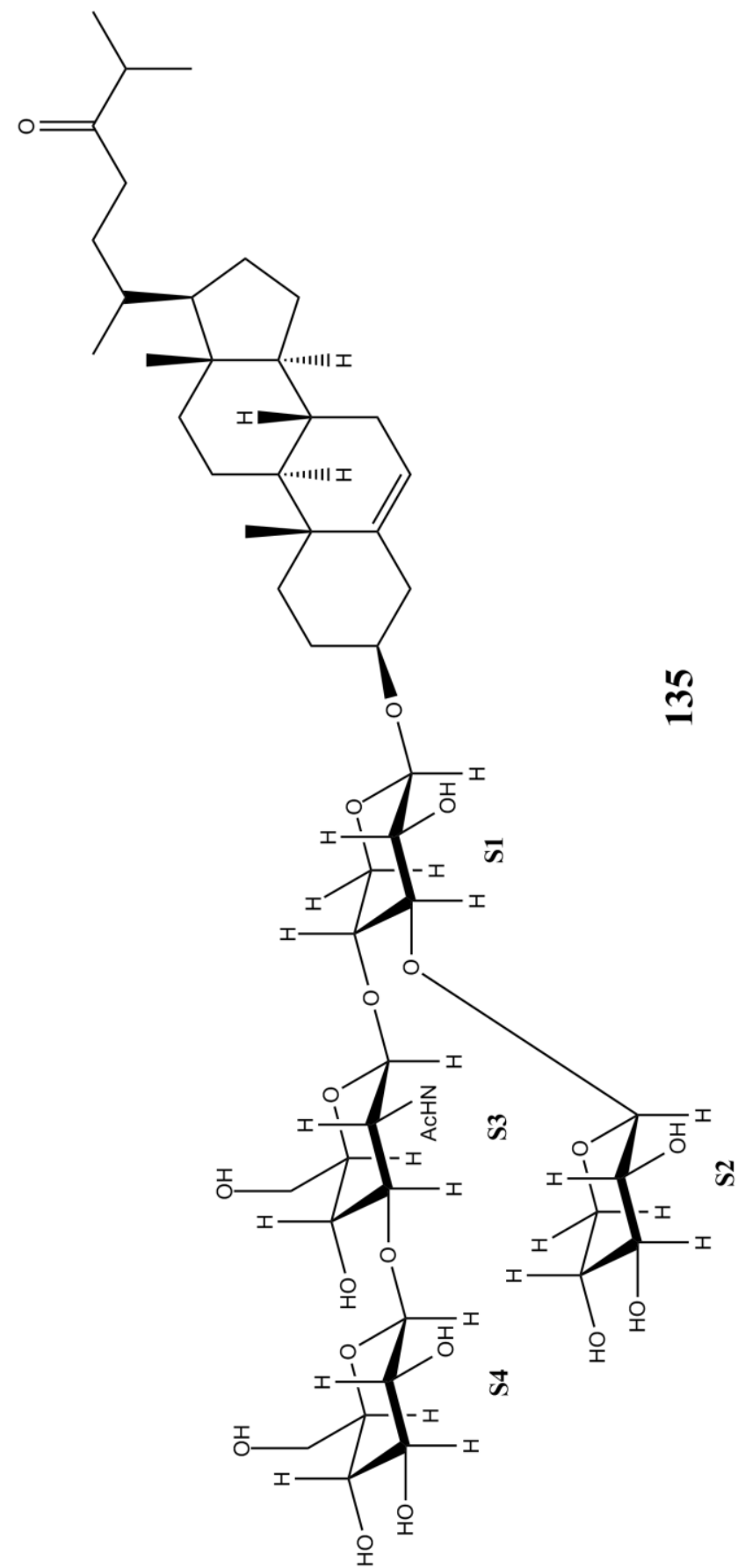


Table 3.3 ${ }^{13} \mathrm{C}(150 \mathrm{MHz})$ and ${ }^{1} \mathrm{H}(600 \mathrm{MHz})$ NMR data $\left(\mathrm{CD}_{3} \mathrm{OD}\right)$ for the oligosaccharide chain of raspailoside $\mathrm{A}(\mathbf{1 3 5})$.

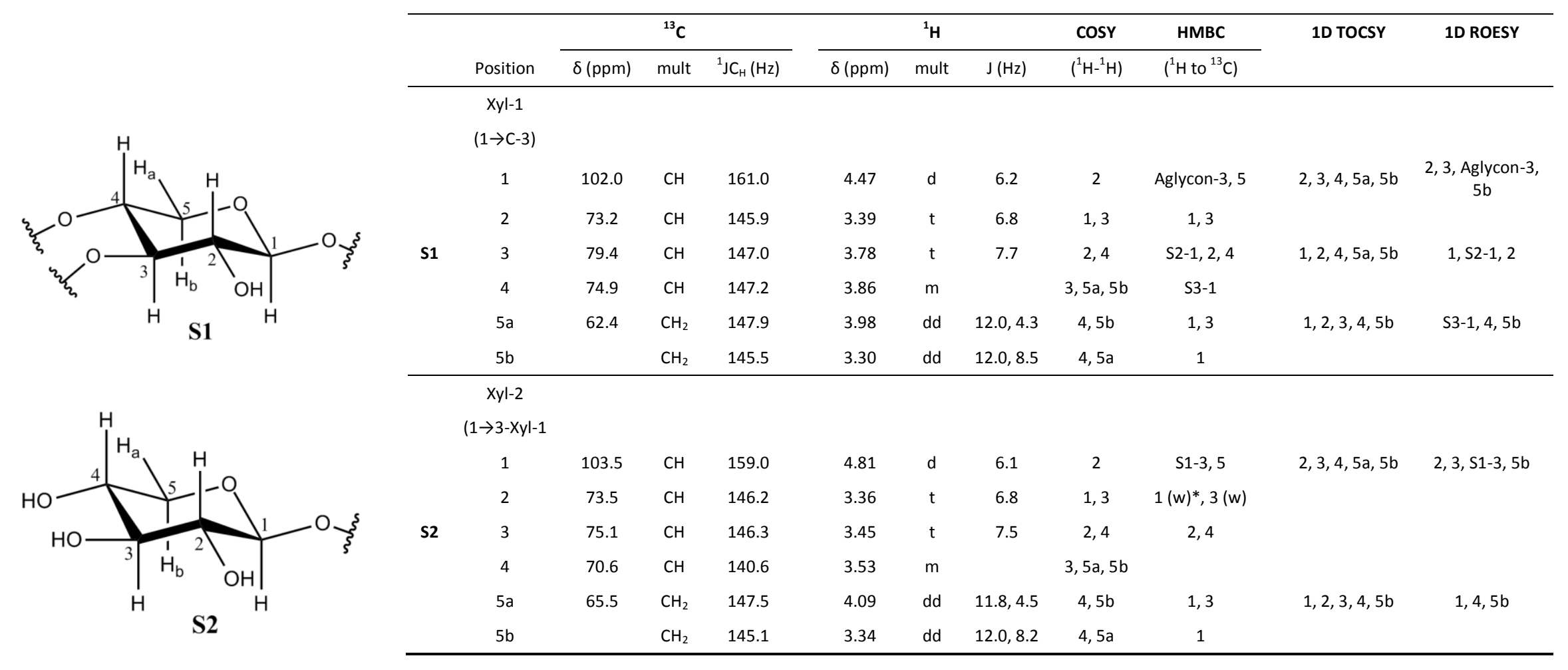

* (w) indicates weak signals 
Table $\mathbf{3 . 3}$ - continued from previous page

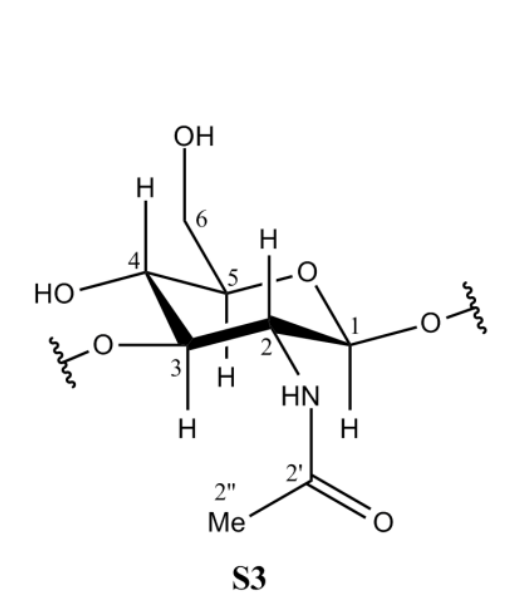

\begin{tabular}{|c|c|c|c|c|c|c|c|c|c|c|c|}
\hline & \multirow[b]{2}{*}{ Position } & \multicolumn{3}{|c|}{${ }^{13} \mathrm{C}$} & \multicolumn{3}{|c|}{${ }^{1} \mathrm{H}$} & \multirow{2}{*}{$\frac{\cos Y}{\left({ }^{1} \mathrm{H}-{ }^{1} \mathrm{H}\right)}$} & \multirow{2}{*}{$\frac{\text { HMBC }}{\left({ }^{1} \mathrm{H} \text { to }{ }^{13} \mathrm{C}\right)}$} & \multirow[t]{2}{*}{ 1D TOCSY } & \multirow[t]{2}{*}{ 1D ROESY } \\
\hline & & $\delta(\mathrm{ppm})$ & mult & ${ }^{1} \mathrm{JC}_{\mathrm{H}}(\mathrm{Hz})$ & $\delta(\mathrm{ppm})$ & mult & $J(H z)$ & & & & \\
\hline & \multicolumn{11}{|l|}{ 2-NHAC-GIC-1 } \\
\hline & \multicolumn{11}{|l|}{$(1 \rightarrow 4-x y \mid-1)$} \\
\hline & 1 & 100.0 & $\mathrm{CH}$ & 160.3 & 4.63 & $d$ & 7.8 & 2 & S1-4 & $\begin{array}{c}2,3,4,5 \\
6 a, 6 b\end{array}$ & $\begin{array}{c}2(w)^{*}, 3(w), \text { S1-4 } \\
\text { S1-5a (w) }\end{array}$ \\
\hline & 2 & 56.1 & $\mathrm{CH}$ & 141.8 & 3.71 & $\mathrm{t}$ & 9.5 & 1,3 & $1,2^{\prime}, 3$ & & \\
\hline & $2^{\prime}$ & 174.2 & c & & & & & & & & \\
\hline & $2^{\prime \prime}$ & 22.8 & $\mathrm{CH}_{3}$ & 127.8 & 1.98 & s & & & $2^{\prime}$ & & \\
\hline \multirow[t]{5}{*}{ S3 } & 3 & 84.5 & $\mathrm{CH}$ & 144.4 & 3.67 & $\mathrm{t}$ & 9.2 & 2,4 & $S 4-1,2,4,5$ & & \\
\hline & 4 & 69.8 & $\mathrm{CH}$ & 145.8 & 3.45 & $\mathrm{t}$ & 8.9 & 3,5 & $3(w), 5$ & & \\
\hline & 5 & 77.4 & $\mathrm{CH}$ & & 3.32 & $\mathrm{~m}$ & & $4,6 a, 6 b$ & $6(w)$ & & \\
\hline & $6 a$ & 62.1 & $\mathrm{CH}_{2}$ & 141.9 & 3.87 & $\mathrm{dd}$ & $11.7,2.1$ & $5,6 b$ & 4 & & \\
\hline & $6 b$ & & $\mathrm{CH}_{2}$ & 142.0 & 3.71 & & & $5,6 a$ & 5 & & \\
\hline
\end{tabular}

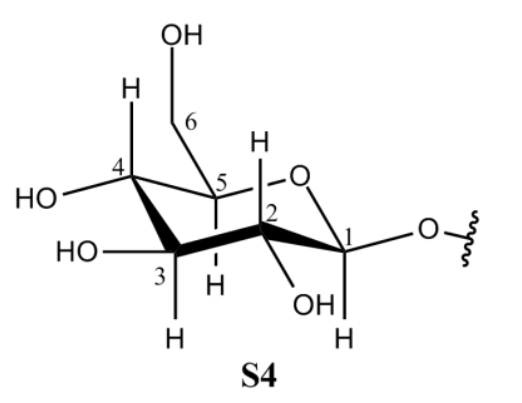

$(1 \rightarrow 3-G I c N H A c)$

\begin{tabular}{|c|c|c|c|c|c|c|c|c|c|c|c|}
\hline & 1 & 104.7 & $\mathrm{CH}$ & 160.1 & 4.32 & d & 7.8 & 2 & $2,3,53-3$ & $\begin{array}{c}2,3,4,5 \\
6 a, 6 b\end{array}$ & $2, \mathrm{~S} 3-2,3, \mathrm{~S} 3-3,5$ \\
\hline & 2 & 74.5 & $\mathrm{CH}$ & 144.5 & 3.22 & $\mathrm{t}$ & 8.5 & 1,3 & 1,3 & & \\
\hline \multirow[t]{5}{*}{ S4 } & 3 & 77.4 & $\mathrm{CH}$ & & 3.34 & $\mathrm{t}$ & 8.6 & 2 & & & \\
\hline & 4 & 71.1 & $\mathrm{CH}$ & 144.8 & 3.29 & & & & 5 & & \\
\hline & 5 & 77.9 & $\mathrm{CH}$ & 142.2 & 3.30 & & & & & & \\
\hline & $6 a$ & 62.2 & $\mathrm{CH}_{2}$ & 141.9 & 3.87 & dd & $11.9,1.9$ & $6 b$ & & & \\
\hline & $6 b$ & & $\mathrm{CH}_{2}$ & 140.7 & 3.63 & $\mathrm{dd}$ & $11.9,5.9$ & $6 a$ & & & \\
\hline
\end{tabular}

* (w) indicates weak signals 
Table 3.4 ${ }^{13} \mathrm{C}(150 \mathrm{MHz})$ and ${ }^{1} \mathrm{H}(600 \mathrm{MHz}) \mathrm{NMR}$ data $\left(\mathrm{CD}_{3} \mathrm{OD}\right)$ for the aglycon moiety of Raspailoside $\mathrm{A}$ (135)

\begin{tabular}{|c|c|c|c|c|c|c|c|}
\hline \multirow[b]{2}{*}{ Position } & \multicolumn{2}{|c|}{${ }^{13} \mathrm{C}$} & \multirow{2}{*}{$\frac{{ }^{1} \mathbf{H}}{\delta(\mathrm{ppm})}$} & \multirow{2}{*}{$\frac{\cos Y}{\left({ }^{1} \mathrm{H}-{ }^{1} \mathrm{H}\right)}$} & \multirow{2}{*}{$\begin{array}{c}\text { HMBC } \\
\left({ }^{1} \mathrm{H} \text { to }{ }^{13} \mathrm{C}\right) \\
\end{array}$} & \multirow[t]{2}{*}{ 1D TOCSY } & \multirow[t]{2}{*}{ 1D ROESY } \\
\hline & $\delta(\mathrm{ppm})$ & mult & & & & & \\
\hline $1 \mathrm{a}$ & 38.3 & $\mathrm{CH}_{2}$ & 1.88 & $1 b, 2 a, 2 b$ & $2,5,10,19$ & & \\
\hline $1 \mathrm{~b}$ & & $\mathrm{CH}_{2}$ & 1.07 & $1 \mathrm{a}, 2 \mathrm{a}, 2 \mathrm{~b}$ & $2,9,10$ & & $2 b, 3(w), 9$ \\
\hline $2 a$ & 30.5 & $\mathrm{CH}_{2}$ & 1.87 & $1 a, 1 b, 2 b 3$ & 5,10 & & \\
\hline $2 b$ & & $\mathrm{CH}_{2}$ & 1.60 & $1 a, 1 b, 2 a, 3$ & & & \\
\hline 3 & 79.6 & $\mathrm{CH}$ & 3.49 & $2 a, 2 b, 4 a, 4 b$ & & $1 a, 1 b, 2 a, 2 b, 4 a, 4 b$ & S1-1, 1b, 2a, 4a, \\
\hline $4 a$ & 39.3 & $\mathrm{CH}_{2}$ & 2.40 & $3,4 b$ & $2,3,5,6,10$ & $1 a, 1 b, 2 a, 2 b, 3,4 b, 6,9$ & S1-1, 3, 4b, 6 \\
\hline $4 b$ & & $\mathrm{CH}_{2}$ & 2.24 & $3,4 a$ & & $1 a, 1 b, 2 a, 2 b, 3,4 a, 6$ & $2 b(w), 4 a, 19$ \\
\hline 5 & 141.4 & c & & & & & \\
\hline 6 & 122.5 & $\mathrm{CH}$ & 5.38 & $7 a, 7 b(w)^{*}$ & $4,8,10$ & $7 a, 7 b, 8,9(w), 14(w)$ & $4 a, 7 a, 7 b(w)$ \\
\hline $7 a$ & 32.7 & $\mathrm{CH}_{2}$ & 1.99 & $6,7 b, 8$ & 6 & $6,8,9,14$ & $6,7 b, 8$ \\
\hline $7 \mathrm{~b}$ & & $\mathrm{CH}_{2}$ & 1.53 & $6,7 a, 8(w)$ & $5,6,8$ & & \\
\hline 8 & 32.9 & $\mathrm{CH}$ & 1.49 & $7 a, 9,14$ & $7,9,10,14$ & & \\
\hline 9 & 51.4 & $\mathrm{CH}$ & 0.95 & 8,11 & $8,11,12,19$ & $\begin{array}{c}6,7 a, 7 b, 8,11 a, 11 b, 12 a, 12 b, 14 \\
15 a, 15 b, 16 a, 16 b, 17,20,22 a, 22 b \\
23 a, 23 b\end{array}$ & $1 b, 11 b, 12 b$ (all w) \\
\hline 10 & 37.5 & C & & & & & \\
\hline $11 a$ & 21.8 & $\mathrm{CH}_{2}$ & 1.54 & $9,11 a, 11 b$ & $8,9,12,13$ & & \\
\hline $11 \mathrm{~b}$ & & $\mathrm{CH}_{2}$ & 1.54 & $9,11 a, 11 a$ & $8,9,12,13$ & & \\
\hline $12 a$ & 40.8 & $\mathrm{CH}_{2}$ & 2.04 & $11 a, 11 b, 12 b$ & $9,11,13,14$ & & \\
\hline $12 \mathrm{~b}$ & & $\mathrm{CH}_{2}$ & 1.20 & $11 a, 11 b, 12 a$ & $11,13,17,18$ & & \\
\hline 13 & 43.2 & C & & & & & \\
\hline 14 & 57.8 & $\mathrm{CH}$ & 1.04 & $8,15 a, 15 b$ & $8,13,15,18$ & & $7 b, 11 b, 15 a$ \\
\hline$\ldots$ & $\ldots$ & $\ldots$ & $\ldots$ & $\ldots$. & $\ldots$. & $\ldots$. & $\ldots$. \\
\hline
\end{tabular}

* $(w)$ indicates weak signals 
Table $\mathbf{3 . 4}$ - continued from previous page

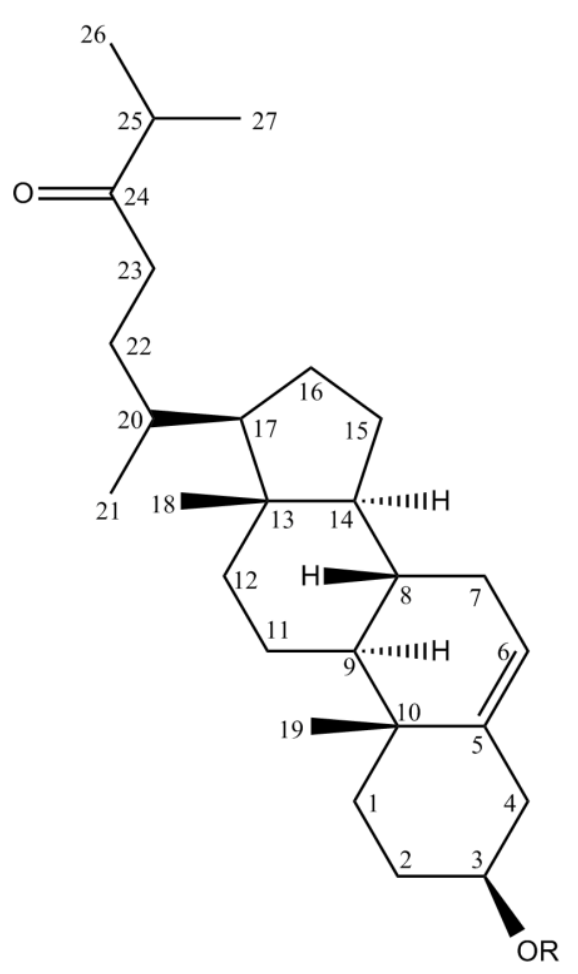

\begin{tabular}{|c|c|c|c|c|c|c|c|}
\hline \multirow[b]{2}{*}{ Position } & \multicolumn{2}{|c|}{${ }^{13} \mathrm{C}$} & \multirow{2}{*}{$\frac{{ }^{1} \mathbf{H}}{\delta(\mathrm{ppm})}$} & \multirow{2}{*}{$\frac{\cos Y}{\left({ }^{1} \mathrm{H}-{ }^{1} \mathrm{H}\right)}$} & \multirow{2}{*}{$\frac{\text { HMBC }}{\left({ }^{1} \mathrm{H} \text { to }{ }^{13} \mathrm{C}\right)}$} & \multirow[t]{2}{*}{ 1D TOCSY } & \multirow[t]{2}{*}{ 1D ROESY } \\
\hline & $\delta(p p m)$ & mult & & & & & \\
\hline $15 a$ & 25.0 & $\mathrm{CH}_{2}$ & 1.63 & $\begin{array}{c}14,15 b, 16 a \\
16 b\end{array}$ & $13,14(w)^{*}$ & & \\
\hline $15 b$ & & $\mathrm{CH}_{2}$ & 1.12 & $\begin{array}{c}14,15 a, 16 a \\
16 b\end{array}$ & $8,13,14,16$ & & \\
\hline $16 b$ & & $\mathrm{CH}_{2}$ & 1.34 & $\begin{array}{c}15 a, 15 b, 16 a \\
17\end{array}$ & & & \\
\hline 17 & 57.1 & $\mathrm{CH}$ & 1.13 & $16 a, 16 b, 20$ & $\begin{array}{c}12,13,16,18 \\
20,21,22\end{array}$ & & \\
\hline 18 & 12.0 & $\mathrm{CH}_{3}$ & 0.72 & & $12,13,14,17$ & & $12 \mathrm{a}(\mathrm{w}), 14,17,20,21$ \\
\hline 19 & 19.5 & $\mathrm{CH}_{3}$ & 1.03 & & $1,5,9,10$ & & $1 a, 4 b, 11 a$ \\
\hline 20 & 36.4 & $\mathrm{CH}$ & 1.42 & $17,21,22 b$ & & & \\
\hline 21 & 18.7 & $\mathrm{CH}_{3}$ & 0.95 & 20 & $17,20,22$ & $\begin{array}{c}6,7 a, 7 b, 8,11 a, 11 b, 12 a, 12 b, 14 \\
15 a, 15 b, 16 a, 16 b, 17,20,22 a, 22 b \\
23 a, 23 b\end{array}$ & $12 a, 20,23 a, 23 b$ \\
\hline $22 a$ & 30.7 & $\mathrm{CH}_{2}$ & 1.73 & $22 b, 23 a, 23 b$ & $20,21,23,24$ & & \\
\hline $22 b$ & & $\mathrm{CH}_{2}$ & 1.23 & $22 a, 23 a, 23 b$ & $20,21,23,24$ & & \\
\hline $23 a$ & 38.0 & $\mathrm{CH}_{2}$ & 2.54 & $22 a, 22 b, 23 b$ & $20,22,24$ & $17(w), 20,21,22 a, 22 b, 23 b$ & 21 \\
\hline $23 b$ & & $\mathrm{CH}_{2}$ & 2.46 & $22 a, 22 b, 23 a$ & $20,22,24$ & & \\
\hline 24 & 217.9 & c & & & & & \\
\hline 25 & 41.6 & $\mathrm{CH}$ & 2.68 & 26,27 & $24(w), 26,27$ & 26,27 & 26,27 \\
\hline 26 & 18.4 & $\mathrm{CH}_{3}$ & 1.07 & 27 & $24,25,27$ & & 25 \\
\hline 27 & 18.4 & $\mathrm{CH}_{3}$ & 1.07 & 26 & $24,25,26$ & & 25 \\
\hline
\end{tabular}

* $(w)$ indicates weak signal

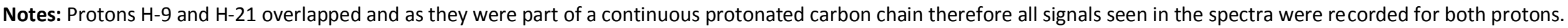

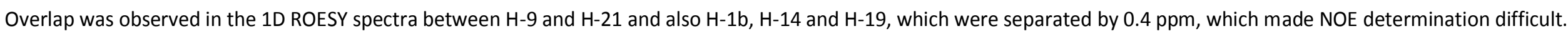




\subsection{Steroidall Grlycosides from Sponges}

Steroidal glycosides are a wide spread class of natural products that have been prevalent in terrestrial and marine sources. Initially, steroid glycosides were considered to be typical metabolites of higher plants and it was not until the 1960s that they were isolated from echinoderms. It was then, not until the 1980s that this class of natural product was reported from marine sponges.

The term steroidal glycoside has been used to classify both steroidal glycosides with a cholesterol-like aglycon and triterpene glycosides which differ with the presence of a gem-dimethyl group at C-4 of the aglycon (lanosterol aglycon framework). Numerous triterpene glycosides have been reported from marine sponges since the 1980s, however, there have been fewer steroidal glycosides (cholesterol aglycon framework) isolated over the same time frame.

The first compounds isolated from a marine sponge under the class steroidal glycosides were the sarasinosides A1, B1 and C1 (136-138), isolated from the Palauan sponge Asteropus sarasinosum. ${ }^{123-124}$ The sarasinosides were revealed to contain a lanosterol-like aglycon with the characteristic gem-dimethyl at C-4. In separate studies, the sarasinosides isolated only showed mild micromolar cytotoxicity towards lymphocytic leukaemia. ${ }^{123-124}$

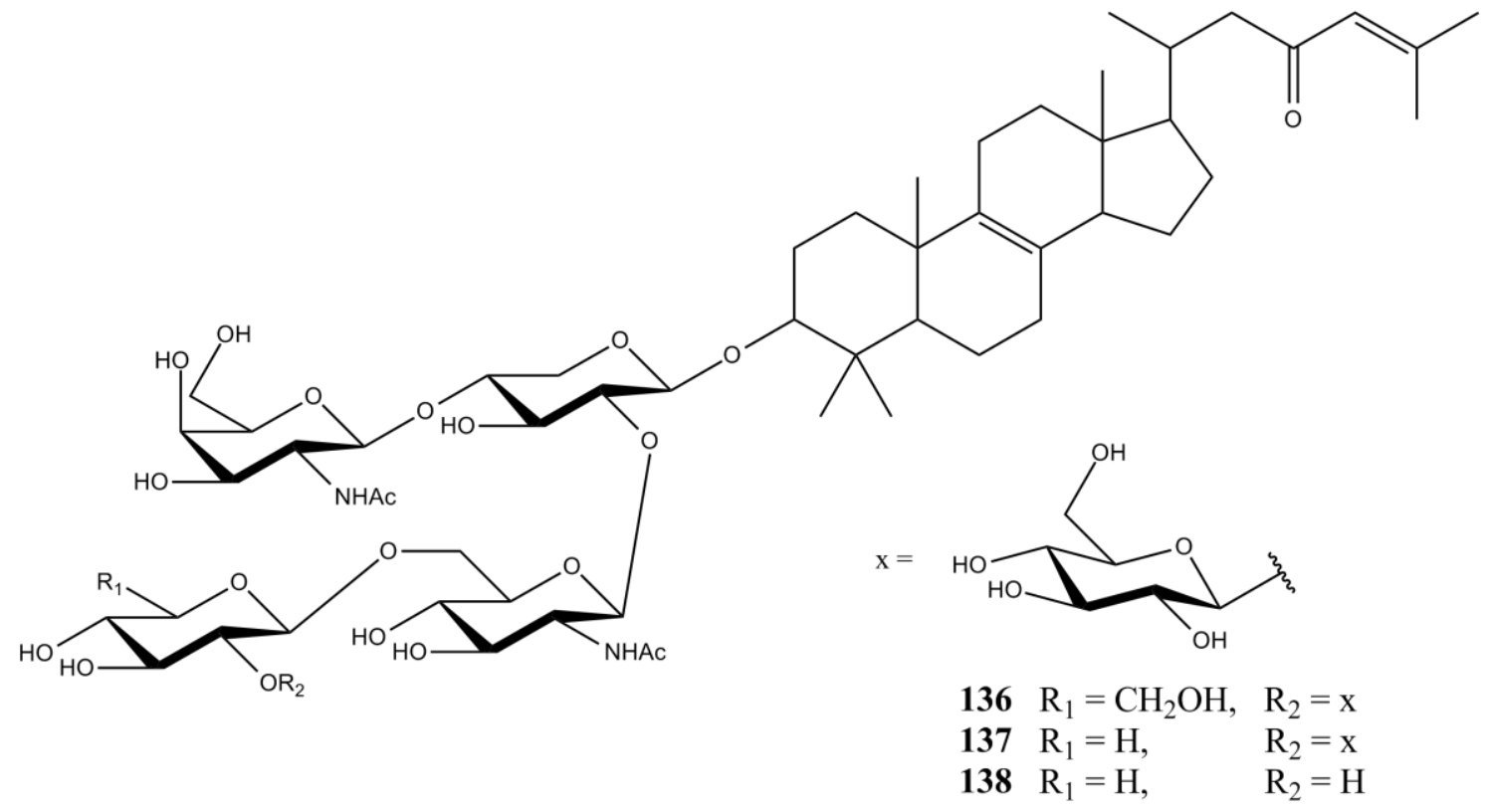


The first steroidal glycoside that showed demethylation at C-4 was eryloside A (139) which was reported from the Red Sea sponge Erylus lendenfeldi in $1989 .{ }^{125}$ Eryloside A was revealed to have mild micromolar anti-tumor and antifungal activity. ${ }^{125}$ The compounds pachastrelloside A (140), reported from the Japanese sponge Pachastrella in 1990, and wondosterols A-C (141-143), isolated from a two sponge association in Korea in 1999, observed complete demethylation at C-4, replaced by a glycosidic linkage. ${ }^{126-127}$ Most steroidal glycosides contain a single glycosidic linkage at C-3, however, 140-143 observed a glycosidic linkage at C-4 while 140 observed a second glycosidic linkage at C-7. Pachastrelloside A was found to have mild micromolar inhibition against cell division of fertilised starfish eggs while wondosterols A-C exhibited micromolar cytotoxicity towards murine leukaemia cells. ${ }^{126-127}$ Wondosterols $\mathrm{A}$ and $\mathrm{C}$ also showed mild anti-bacterial activity against Pseudomonas aeruginosa and Escherichia coli. ${ }^{127}$ This indicated that multiple glycosidic linkages off the aglycon did not necessarily enhance the biological activity of a steroidal glycoside.
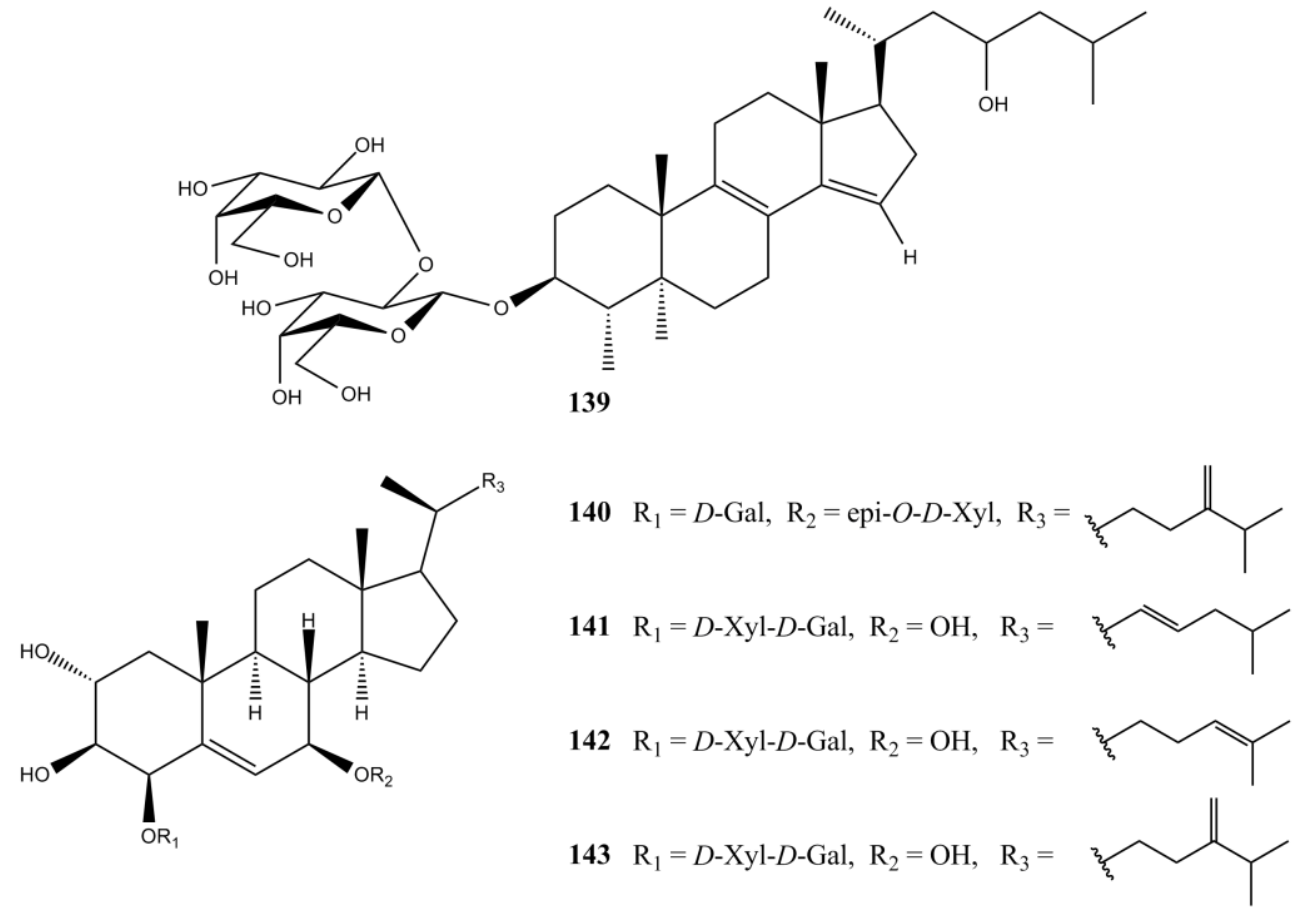

More recently, pandarosides A-M (144-156) and their methyl esters (157-168) have been reported from the Caribbean sponge Pandorus acanthifolium. ${ }^{128-130}$ The pandarosides contain a common glycosidic linkage at $\mathrm{C}-3$ and are among the first marine sponge steroidal glycosides recorded to contain a C-4 methylene. The pandarosides and their methyl esters showed antiprotozoal activity in the micromolar range. 


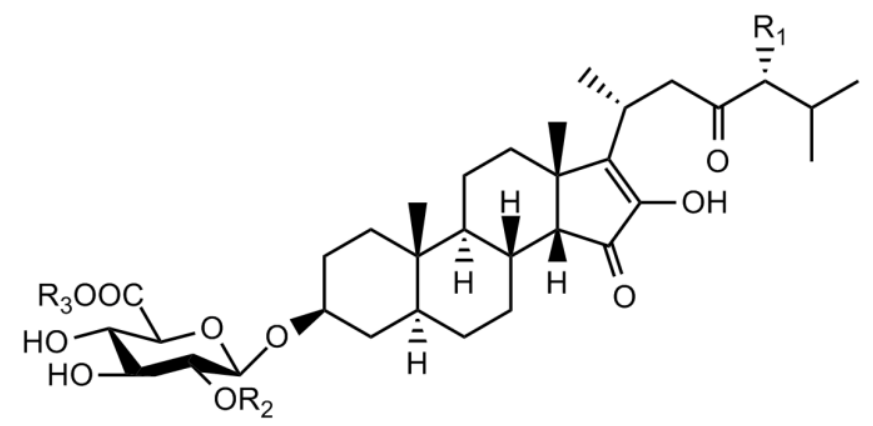

$144 \mathrm{R}_{1}=\mathrm{Et}, \quad \mathrm{R}_{2}=\beta$-Glc, $\mathrm{R}_{3}=\mathrm{H}$

$145 \mathrm{R}_{1}=\mathrm{Et}, \quad \mathrm{R}_{2}=\mathrm{H}, \quad \mathrm{R}_{3}=\mathrm{H}$

$146 \mathrm{R}_{1}=\mathrm{H}, \quad \mathrm{R}_{2}=\beta$-Glc, $\mathrm{R}_{3}=\mathrm{H}$

$147 \mathrm{R}_{1}=\mathrm{H}, \quad \mathrm{R}_{2}=\mathrm{H}, \quad \mathrm{R}_{3}=\mathrm{H}$

$154 \mathrm{R}_{1}=\mathrm{Me}, \mathrm{R}_{2}=\beta$-Glc, $\mathrm{R}_{3}=\mathrm{H}$

$157 \mathrm{R}_{1}=\mathrm{Et}, \quad \mathrm{R}_{2}=\beta$-Glc, $\mathrm{R}_{3}=\mathrm{Me}$

$158 \mathrm{R}_{1}=\mathrm{H}, \quad \mathrm{R}_{2}=\beta$-Glc, $\mathrm{R}_{3}=\mathrm{Me}$

$159 \mathrm{R}_{1}=\mathrm{H}, \quad \mathrm{R}_{2}=\mathrm{H}, \quad \mathrm{R}_{3}=\mathrm{Me}$

$166 \mathrm{R}_{1}=\mathrm{Me}, \mathrm{R}_{2}=\beta$-Glc, $\mathrm{R}_{3}=\mathrm{Me}$

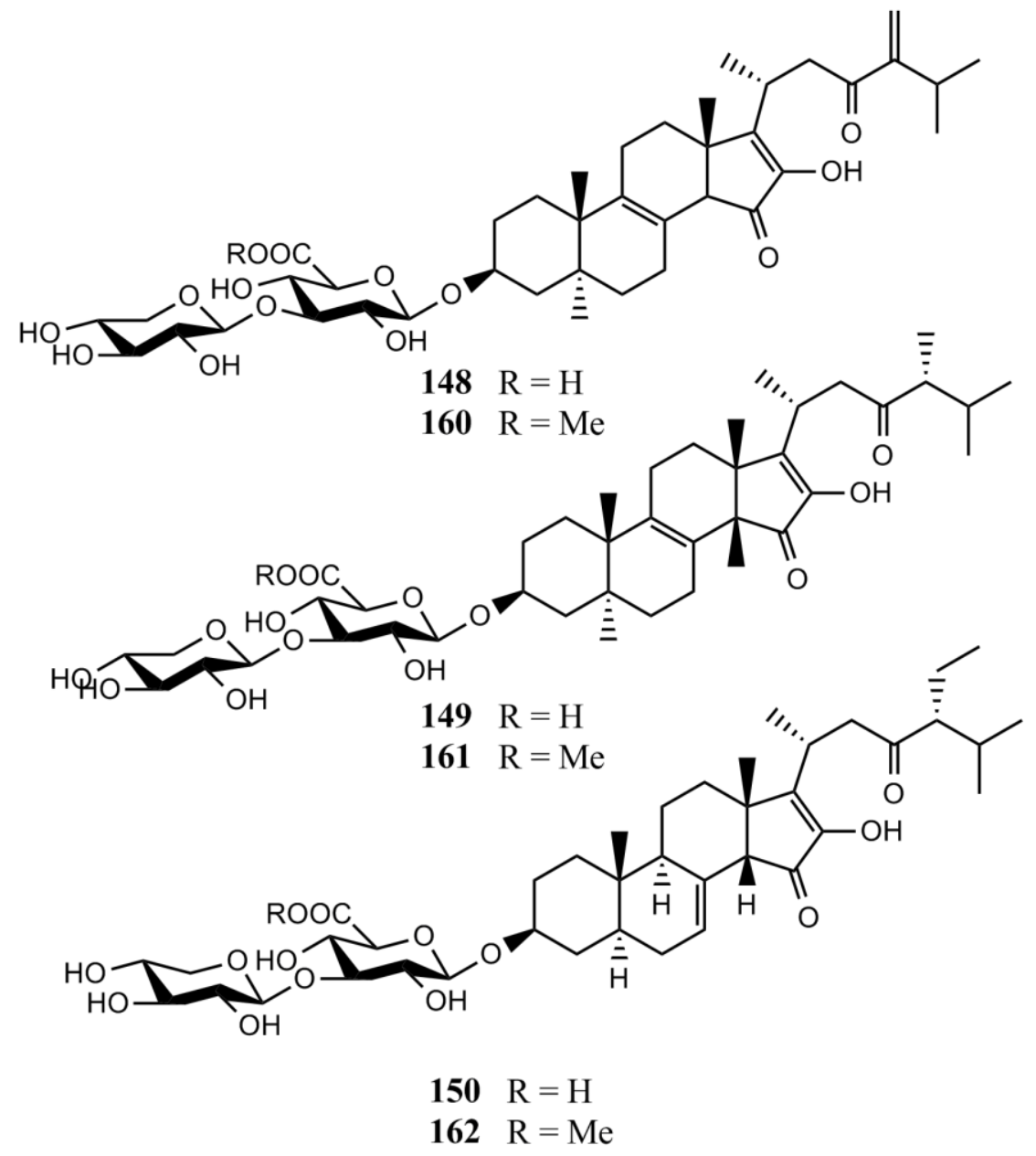




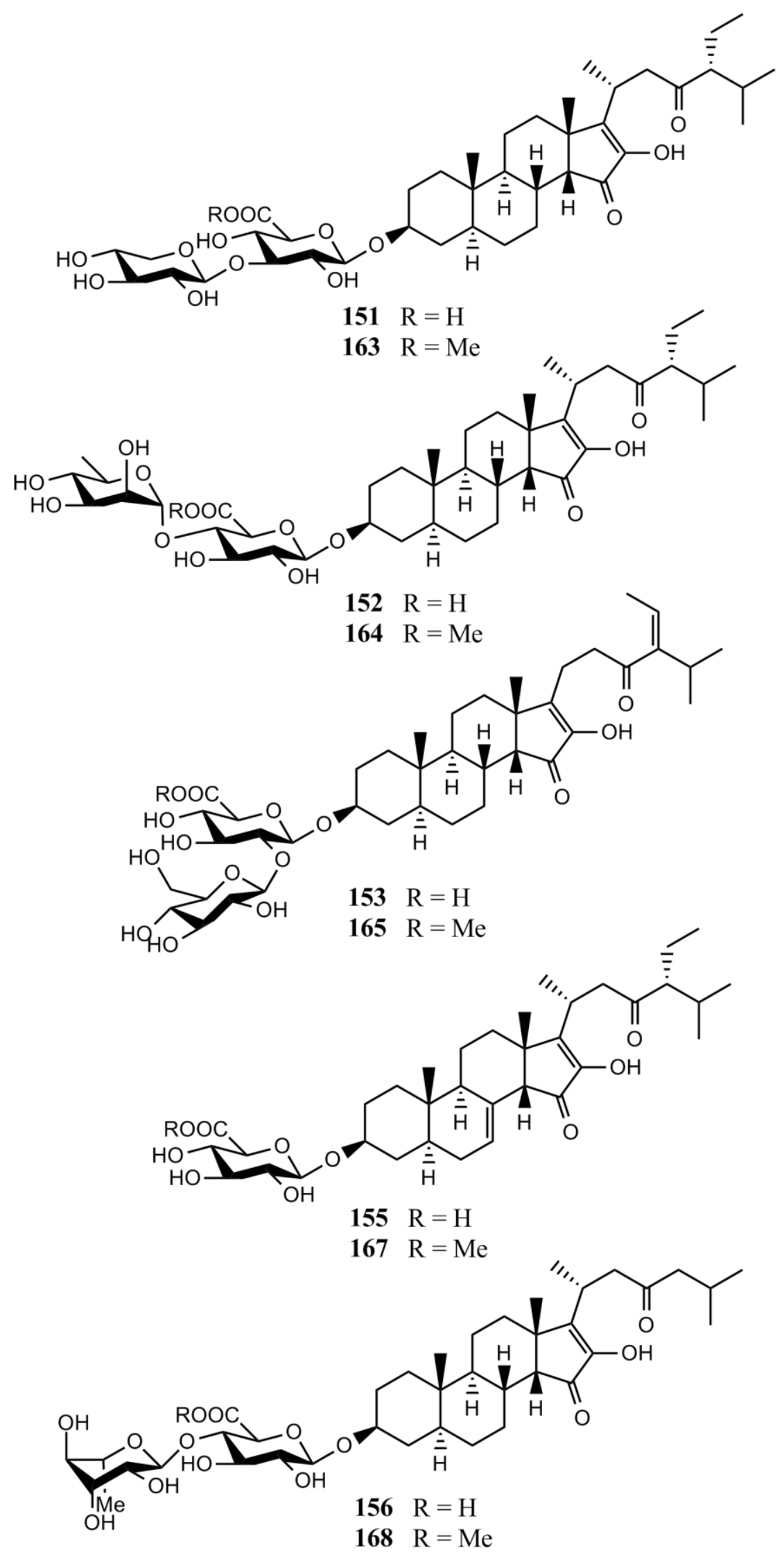




\subsection{Biologicall Activity}

The biological activity of raspailoside A was investigated by researchers in the School of Biological Sciences, VUW. A sample was submitted to the chemical genetics program whereby it was tested for high-level inhibition (100 $\mu \mathrm{M})$ against two haploid yeast strains of Saccharomyces cerevisiae, a wild type and a drug-sensitive mutant $(\Delta p d r)$. In the yeast, a complex pleiotropic drug resistance (PDR) network of membrane-bound pumps is responsible for ejecting xenobiotics before they can reach inhibitory levels within the cell. The PDR network is controlled by the transcription factor genes $p d r 1$ and $p d r 3$. Deletion of $p d r 1$ and $p d r 3$ produces a viable doubledeletion mutant strain, which is sensitised to most xenobiotics in comparison to the wild type. The drug-sensitive mutant is typically 30 -fold more susceptible than the wild type, however, as not all xenobiotics are substrates for the PDR network testing in the drug-sensitive mutant strain will not necessarily improve the $I C_{50}$ value. ${ }^{131}$

Bioassay results of raspailoside A showed inactivity in either strain at $100 \mu \mathrm{M}$. This suggested that either it is not a PDR substrate or, that a higher dose (not performed) was needed to achieve activity in the assay. Raspailoside A was also subjected to an MTT assay against a human promyelocytic leukaemia cell line. Concentrations ranging from $0.01 \mu \mathrm{M}$ to $50 \mu \mathrm{M}$ were used in this study, however, the compound displayed no activity at any concentration. 


\subsection{Summary}

Steroidal glycoside metabolite isolation is frequently reported from the marine environment, through echinoderms, in particular starfish and sea cucumbers, which are well known to produce a wide variety of steroidal glycosides. However, there have been very few reports of these metabolites being isolated from sponge specimens. Initial studies of PTN2_45D were conducted looking at the isolation of novel clerodanes, however, the early identification of anomeric sugar protons and non-lipid aglycon functionality, in the screening of PTN2_45D prompted further purification and eventual isolation of raspailoside A. A variety of NMR experiments were used to elucidate the full structure and assigned relative stereochemistry. Raspailoside A was found to exhibit limited biological activity in the HL-60 and yeast assays to which it was subjected. 


\section{Chapter 4}

\section{Conclusion}

Over the course of this study, 11 Tongan marine algae and one New Zealand sponge were investigated for the presence of novel secondary metabolites. One novel compound was isolated from the sponge, however, the algae specimens studied were found to only contain known compounds. Utilisation of the updated in-house HMBC screening protocol, along with a number of modern NMR techniques, facilitated partial, if not full structural elucidation of these compounds.

A previous study of New Zealand red algae found a large number of novel and diverse secondary metabolites however this study of red, green and brown Tongan algae was unable to yield any such structural novelty or diversity across the samples. Many of the species showed the strong presence of the isolated and semi-purified primary metabolite 76, while the brown algae specimens showed the presence substructure 83, previously reported in known fulvellic acid analogues. In each case full elucidation of the fatty acid chains was not performed due to a lack of novelty and inconclusive mass spectrometry results. During this study fistularin-3 (86) was unintentionally elucidated through the presence of a sponge impurity during extraction.

The results of this study suggested that the opposite effect was seen in algae compared to sponges in terms of the concentrations and structural diversity of secondary metabolites from temperate and tropical sources. The strong presence of the primary metabolite $\mathbf{7 6}$ in tropical algae, compared to the temperate New Zealand algae studied indicates that the compound might play a role in the algae that is affected by external conditions. Fistularin-3 was isolated from a small sponge contaminant in an algal extraction. Subsequent re-extraction of a clean sample of the same algae exhibited no such resonances. This discovery reaffirmed the idea that tropical algae produce far less secondary metabolites than tropical sponges. This may suggest that environmental factors in tropical regions have an effect on secondary metabolite production in marine macro-algae. Although the algae sample size was relatively small, the information that this study garnered provided an interesting 
comparison between tropical and temperate algae and sponges. The study suggested that even though current and future studies of marine sponges have made their way to the more diverse tropical environment, the study of algae in future may be better conducted in the temperate environment.

The isolation of a novel steroidal glycoside from a Raspailia sponge specimen previously deemed 'uninteresting', morphologically and when analysed using the HSQC screening protocol, indirectly proved the validity of the HMBC screening protocol. Raspailoside A (135) proved difficult to isolate and purify with several different procedures utilised in an effort to separate it from a very similar minor compound. Structural elucidation presented many challenges that required the use of less common experiments, including the HSQC-TOCSY. The biological activity of 135 was studied across HL-60 and yeast assays, with limited activity observed. Since the 1980s, reported instances of the isolation of steroidal glycosides from marine sponges have primarily been triterpene glycosides. Over the same period, there have been very few reported instances of steroidal glycosides isolated from marine sponges that contained the lanosterol-like aglycon moiety present in raspailoside $A$. 


\section{Chapter 5}

\section{Experimental}

\subsection{General}

All NMR spectra collected, were recorded using a Varian DirectDrive 600 (operating at $600 \mathrm{MHz}$ for ${ }^{1} \mathrm{H}$ nuclei and $150 \mathrm{MHz}$ for ${ }^{13} \mathrm{C}$ nuclei) spectrometer. The NMR instrument was equipped with an inverse-detected triple resonance $\mathrm{HCN}$ cryogenic probe operating at $25 \mathrm{~K}$. The chemical shifts observed $\delta(\mathrm{ppm})$ were referenced to the residual solvent peak. ${ }^{132}$ Mass spectrometry data was collected using an Agilent 6530 Q/TOF Icms (liquid chromatography-mass spectrometry) instrument.

Thin layer chromatography (TLC) analysis was performed using Macherey-Nagel plastic Polygram SIL G/UV 254 plates. The TLC plates were visualised under UV light $(\lambda=254$ $\mathrm{nm}$ ) then dipped in a $0.1 \%$ vanillin/EtOH solution followed by a $5 \%$ conc $\mathrm{H}_{2} \mathrm{SO}_{4} / \mathrm{MeOH}$ solution then heated to visualise spots. Reversed-phase chromatography on PSDVB was performed using Supelco Diaion HP2O and HP20ss. Normal-phase chromatography was performed using 2,3-dihydroxypropoxy-propyl-derivatised silica (DIOL), from YMC Co. Ltd. Size exclusion column chromatography was also performed, utilising Sigma Aldrich Sephadex LH20. The solvents used in normal- and reversedphase column chromatography were of HPLC or analytical grade quality. All other solvents were purified by distillation before use. Solvent mixtures are reported as $\% \mathrm{vol} / \mathrm{vol}$ unless otherwise stated. High-performance liquid chromatography (HPLC) was performed using a Rainin Dynamax SD-200 solvent delivery system with $25 \mathrm{~mL}$ pump heads. The system was equipped with a Varian ProStar 335 photodiode array detector, for UV/vis detection. All HPLC was performed using a reversed-phase C18 column support (both in analytical and semi-prep column sizes) with solvents of HPLC grade with additional purification using a Millipore filtration system.

The algae screened were collected from different locations around the islands of Vava'u and Tongatapu, Kingdom of Tonga, between the 19/11/2009 and 27/11/2009. The unknown sponge species of the genus Raspailia that was analysed in this study 
was collected by SCUBA from Elizabeth Reef, Tutukaka, New Zealand on 23/4/2003. All samples were frozen upon collection and stored in freezers at $-20^{\circ} \mathrm{C}$ until required.

\subsection{Isolation of Algal Natural Products}

\section{Sample PTN4_17G}

The green algae PTN4_17G (39 g wet weight, Houma blowholes, Tongatapu) was twice extracted over $24 \mathrm{~h}$ in $350 \mathrm{~mL}$ of $\mathrm{MeOH}$. The filtered second and first extracts were passed through a $40 \mathrm{~mL}$ column of HP20 beads. The resulting eluent was diluted with $700 \mathrm{~mL}$ of distilled $\mathrm{H}_{2} \mathrm{O}$ (now a $50 \% \mathrm{MeOH}$ in $\mathrm{H}_{2} \mathrm{O}$ solution) and passed back through the HP20 column. The eluent was diluted again with $1.4 \mathrm{~L}$ of distilled $\mathrm{H}_{2} \mathrm{O}$ (now a $25 \%$ $\mathrm{MeOH}$ in $\mathrm{H}_{2} \mathrm{O}$ solution) with the resulting $2.8 \mathrm{~L}$ eluent passed back through the column. The column was then eluted with $120 \mathrm{~mL}$ of distilled $\mathrm{H}_{2} \mathrm{O}$ followed by sequential 120 $\mathrm{mL}$ portions of $30 \%$, and $70 \% \mathrm{Me}_{2} \mathrm{CO}$ in $\mathrm{H}_{2} \mathrm{O}$ and $100 \% \mathrm{Me}_{2} \mathrm{CO}$. The $70 \% \mathrm{Me}_{2} \mathrm{CO}$ in $\mathrm{H}_{2} \mathrm{O}$ fraction was backloaded onto a $10 \mathrm{~mL}$ HP20 column, diluted to $25 \%$, and then eluted with $120 \mathrm{~mL}$ of $\mathrm{Me}_{2} \mathrm{CO}$. The $\mathrm{Me}_{2} \mathrm{CO}$ eluent was concentrated under reduced pressure.

The resulting dry material was sub-sampled and put through a secondary protocol using a $2 \mathrm{~mL}$ column of HP20ss. The sample was loaded onto the column and then eluted sequentially with $6 \mathrm{~mL}$ fractions of solvent. The elutions were $40 \%, 50 \%, 60 \%$, $70 \%, 80 \%$ and $90 \% \mathrm{MeOH}$ in $\mathrm{H}_{2} \mathrm{O}$ (fractions a-f) and $100 \% \mathrm{MeOH}$ (fractions g-i). Fractions g-i were combined and passed through a normal-phase $1 \mathrm{~cm}$ DIOL column, eluting with $5 \mathrm{~mL}$ volumes of $\mathrm{CH}_{2} \mathrm{Cl}_{2}, 10 \%, 25 \%, 50 \%$, and $75 \% \mathrm{EtOAc}$ in $\mathrm{CH}_{2} \mathrm{Cl}_{2}$, EtOAc, $\mathrm{MeOH}$ and finally $\mathrm{Me}_{2} \mathrm{CO}$ (fractions a-g, 50\% and 75\% were collected in the same fraction $d$ ). Full NMR spectral data of fraction $f$ revealed the avrainvilloside substructure 76 (2.4 $\mathrm{mg})$.

\section{Sample BJN1_92Ff}

White powder; NMR data see Table $2.2\left(\mathrm{CD}_{3} \mathrm{OD}\right) ;[\alpha]_{D}^{24.2}+13.6^{\circ}(\mathrm{EtOH}, \mathrm{c}=0.147)$. 


\section{Sample PTN4_18E}

The brown algae PTN4_18E (24 g wet weight, collected from Houma blowholes, Tongatapu) was twice extracted over $24 \mathrm{~h}$ in $200 \mathrm{~mL}$ of $\mathrm{MeOH}$. The filtered second and first extracts were passed through a $20 \mathrm{~mL}$ column of HP20 beads. The resulting eluent was diluted with $400 \mathrm{~mL}$ of distilled $\mathrm{H}_{2} \mathrm{O}$ (now a $50 \% \mathrm{MeOH}$ in $\mathrm{H}_{2} \mathrm{O}$ solution) and passed back through the HP20 column. The eluent was diluted again with $800 \mathrm{~mL}$ of distilled $\mathrm{H}_{2} \mathrm{O}$ (now a $25 \% \mathrm{MeOH}$ in $\mathrm{H}_{2} \mathrm{O}$ solution) with the resulting $1.6 \mathrm{~L}$ eluent passed back through the column. The column was then eluted with $60 \mathrm{~mL}$ of distilled $\mathrm{H}_{2} \mathrm{O}$ followed by sequential $60 \mathrm{~mL}$ portions of $30 \%$, and $75 \% \mathrm{Me}_{2} \mathrm{CO}$ in $\mathrm{H}_{2} \mathrm{O}$ and $100 \%$ $\mathrm{Me}_{2} \mathrm{CO}$. The $75 \% \mathrm{Me}_{2} \mathrm{CO}$ in $\mathrm{H}_{2} \mathrm{O}$ fraction was backloaded onto a $10 \mathrm{~mL} \mathrm{HP20}$ column, diluted to $25 \%$, and then eluted with $100 \mathrm{~mL}$ of $\mathrm{Me}_{2} \mathrm{CO}$. The $\mathrm{Me}_{2} \mathrm{CO}$ eluent was concentrated under reduced pressure.

The dry sample was then dissolved in a minimum of $\mathrm{CH}_{2} \mathrm{Cl}_{2}$, loaded onto a $10 \mathrm{~mL} \mathrm{DIOL}$ column and eluted with $60 \mathrm{~mL}$ volumes of $\mathrm{CH}_{2} \mathrm{Cl}_{2}, 10 \%$, and $50 \%$ EtOAc in $\mathrm{CH}_{2} \mathrm{Cl}_{2}$, EtOAc, 50\% $\mathrm{MeOH}$ in EtOAc and $\mathrm{MeOH}$ (fractions a-f). Fraction a was concentrated under reduced pressure and re-dissolved in $10 \% \mathrm{CH}_{2} \mathrm{Cl}_{2}$ in hexanes. The sample was loaded onto a $2 \mathrm{~mL}$ DIOL column and eluted with $10 \mathrm{~mL}$ volumes of hexanes, $25 \%$, $50 \%$, and $75 \% \mathrm{CH}_{2} \mathrm{Cl}_{2}$ in hexanes, $\mathrm{CH}_{2} \mathrm{Cl}_{2}$ and $\mathrm{MeOH}$ (fractions 1-6). Full $\mathrm{NMR}$ spectral data of fraction 3 revealed substructure $83(2.9 \mathrm{mg})$.

\section{Sample BJN2_35Fb3}

White powder; NMR data see Table $2.3\left(\mathrm{CD}_{3} \mathrm{OD}\right) ;[\alpha]_{D}^{25.8}+23.0^{\circ}(\mathrm{EtOH}, \mathrm{c}=0.187)$.

\section{Sample PTN3_38C}

The red algae PTN3_38C (25 g wet weight, collected from Split rock, Vava'u) was twice extracted over $24 \mathrm{~h}$ in $200 \mathrm{~mL}$ of $\mathrm{MeOH}$. The filtered second and first extracts were passed through a $20 \mathrm{~mL}$ column of HP20 beads. The resulting eluent was diluted with $400 \mathrm{~mL}$ of distilled $\mathrm{H}_{2} \mathrm{O}$ (now a $50 \% \mathrm{MeOH}$ in $\mathrm{H}_{2} \mathrm{O}$ solution) and passed back through the HP20 column. The eluent was diluted again with $800 \mathrm{~mL}$ of distilled $\mathrm{H}_{2} \mathrm{O}$ (now a $25 \% \mathrm{MeOH}$ in $\mathrm{H}_{2} \mathrm{O}$ solution) with the resulting $1.6 \mathrm{~L}$ eluent passed back through the column. The column was then eluted with $60 \mathrm{~mL}$ of distilled $\mathrm{H}_{2} \mathrm{O}$ followed by 
sequential $60 \mathrm{~mL}$ portions of $30 \%$, and $75 \% \mathrm{Me}_{2} \mathrm{CO}$ in $\mathrm{H}_{2} \mathrm{O}$ and $100 \% \mathrm{Me}_{2} \mathrm{CO}$. A further two $60 \mathrm{~mL} \mathrm{Me}{ }_{2} \mathrm{CO}$ elutions were performed to strip the column of the crude sample. The $75 \% \mathrm{Me}_{2} \mathrm{CO}$ in $\mathrm{H}_{2} \mathrm{O}$ fraction was backloaded onto a $10 \mathrm{~mL} \mathrm{HP20}$ column, diluted to $25 \%$, and then eluted with $100 \mathrm{~mL}$ of $\mathrm{Me}_{2} \mathrm{CO}$. The $\mathrm{Me}_{2} \mathrm{CO}$ eluent was concentrated under reduced pressure.

The $75 \% \mathrm{Me}_{2} \mathrm{CO}$ sample was dissolved in $10 \% \mathrm{MeOH}$ in $\mathrm{CH}_{2} \mathrm{Cl}_{2}$, loaded onto a $10 \mathrm{~mL}$ DIOL column, and subsequently eluted with $60 \mathrm{~mL}$ volumes of $\mathrm{CH}_{2} \mathrm{Cl}_{2}, 10 \%$, and $50 \%$ EtOAc in $\mathrm{CH}_{2} \mathrm{Cl}_{2}$, EtOAc, $50 \% \mathrm{MeOH}$ in EtOAc, $\mathrm{MeOH}$ and $50 \% \mathrm{H}_{2} \mathrm{O}$ in $\mathrm{MeOH}$ (fractions 1-7). Fraction 3 was concentrated under reduced pressure and the resulting NMR full data set showed the presence of the known compound fistularin-3 $(86,10.4 \mathrm{mg})$.

\section{Sample BJN2_37Hb3}

Colourless solid; NMR data see Table 2.4; HRESIMS observed $m / z 1130.6895[\mathrm{M}+\mathrm{Na}]^{+}$, $\mathrm{C}_{31} \mathrm{H}_{30} \mathrm{O}_{11} \mathrm{~N}_{4} \mathrm{Br}_{6} \mathrm{Na}^{+}$requires $1130.6909, \Delta-1.2 \mathrm{ppm} ;[\alpha]_{D}^{25.1}+93.9^{\circ}(\mathrm{EtOH}, \mathrm{c}=0.713)$. 


\subsection{Isolation of Naturall Products from Raspailia sp.}

The Raspailia sponge species PTN2_45D (107.7 g wet weight, collected from Elizabeth reef, Tutukaka) was twice extracted over $24 \mathrm{~h}$ in $350 \mathrm{~mL}$ of $\mathrm{MeOH}$. The filtered second and first extracts were passed through an $80 \mathrm{~mL}$ column of HP20 beads. The resulting eluent was diluted with $700 \mathrm{~mL}$ of distilled $\mathrm{H}_{2} \mathrm{O}$ (now a $50 \% \mathrm{MeOH}$ in $\mathrm{H}_{2} \mathrm{O}$ solution) and passed back through the HP20 column. The eluent was diluted again with $1.4 \mathrm{~L}$ of distilled $\mathrm{H}_{2} \mathrm{O}$ (now a $25 \% \mathrm{MeOH}$ in $\mathrm{H}_{2} \mathrm{O}$ solution) with the resulting $2.8 \mathrm{~L}$ eluent passed back through the column. The column was then eluted with $250 \mathrm{~mL}$ of distilled $\mathrm{H}_{2} \mathrm{O}$ followed by sequential $250 \mathrm{~mL}$ portions of $20 \%, 40 \%, 60 \%$, and $80 \% \mathrm{Me}_{2} \mathrm{CO}$ in $\mathrm{H}_{2} \mathrm{O}$ and $100 \% \mathrm{Me}_{2} \mathrm{CO}$. The column was eluted with a further $250 \mathrm{~mL}$ of $\mathrm{Me}_{2} \mathrm{CO}$ to strip the column of remaining crude sample. The first four elutions were backloaded onto separate $25 \mathrm{~mL} \mathrm{HP} 20$ columns, by dilution to $25 \%$, and then eluted using $100 \mathrm{~mL}$ of $\mathrm{Me}_{2} \mathrm{CO}$ in each case. All five samples were then concentrated under reduced pressure, leaving dry material.

\section{Raspailodane A (126)}

The $80 \% \mathrm{Me}_{2} \mathrm{CO}$ in $\mathrm{H}_{2} \mathrm{O}$ fraction was sub-sampled (initially two separate samples) with one sample being purified using DIOL. The sample was dissolved in a minimum of $\mathrm{CH}_{2} \mathrm{Cl}_{2}$, loaded onto a $10 \mathrm{ml}$ DIOL column and subsequently eluted with $60 \mathrm{ml}$ portions of $\mathrm{CH}_{2} \mathrm{Cl}_{2}, 10 \%$ and $50 \% \mathrm{CH}_{2} \mathrm{Cl}_{2}$ in EtOAc, EtOAc, $50 \% \mathrm{MeOH}$ in EtOAc and $\mathrm{MeOH}$ (fractions a-f). Analysis of fraction a, led to the elucidation of the known clerodane raspailodane $A(126,10.7 \mathrm{mg})$.

\section{Sample BJN3_56Ba}

Pale yellow solid; HRESIMS observed $\mathrm{m} / z \quad 315.1946[\mathrm{M}+\mathrm{H}]^{+}, \quad \mathrm{C}_{20} \mathrm{H}_{27} \mathrm{O}_{3}$ requires 315.1955, $\Delta-2.92 \mathrm{ppm} ;[\alpha]_{D}^{26.4}+32.0^{\circ}(\mathrm{EtOH}, \mathrm{c}=0.707)$; NMR data consistent with West's data. ${ }^{36}$ 


\section{Raspailoside A}

The $60 \% \mathrm{Me}_{2} \mathrm{CO}$ in $\mathrm{H}_{2} \mathrm{O}$ fraction was sub-sampled, with one sample dissolved in $50 \%$ $\mathrm{MeOH}$ in $\mathrm{CH}_{2} \mathrm{Cl}_{2}$ and loaded onto an $\mathrm{LH} 20$ column (prepared in $50 \% \mathrm{MeOH}$ in $\mathrm{CH}_{2} \mathrm{Cl}_{2}$ ). The column was run in $50 \% \mathrm{MeOH}$ in $\mathrm{CH}_{2} \mathrm{Cl}_{2}$, at approximately one drop per $20 \mathrm{~s}$, with fractions collecting for $1370 \mathrm{~s}$, until 78 tubes had been collected. Tubes 25-33 were found to contain the compound of interest and were combined and concentrated under reduced pressure (sample A). A second LH2O column was run on the remaining sub-sample using the same conditions, flow rate and fraction collection time. Seventy one fractions were collected with the fractions 38-59 combined and concentrated under reduced pressure (sample B).

The second $80 \% \mathrm{Me}_{2} \mathrm{CO}$ in $\mathrm{H}_{2} \mathrm{O}$ sample was further sub-sampled (two separate samples) with both samples chromatogrammed on separate $\mathrm{LH} 20$ columns. The first sample was dissolved in $66 \% \mathrm{MeOH}$ in $\mathrm{CH}_{2} \mathrm{Cl}_{2}$ and loaded onto an $\mathrm{LH} 20$ column prepared in $50 \% \mathrm{MeOH}$ in $\mathrm{CH}_{2} \mathrm{Cl}_{2}$. The column was run in $50 \% \mathrm{MeOH}$ in $\mathrm{CH}_{2} \mathrm{Cl}_{2}$ at a flow rate of approximately one drop per six seconds with each fraction collecting for 600 s. Eighty two fractions were collected with fractions $38-50,51,52-56$ and $57-64$ collected and concentrated under reduced pressure separately (samples C-F). The second sample was put through an LH2O column utilising the same parameters as the first sub-sample (of the original $80 \% \mathrm{Me}_{2} \mathrm{CO}$ in $\mathrm{H}_{2} \mathrm{O}$ sample) with 71 fractions collected, of which fractions 33-43 were combined and concentrated under reduced pressure (sample G).

The seven samples (A-G), collected from the four LH2O columns run across the two original $60 \%$ and $80 \% \mathrm{Me}_{2} \mathrm{CO}$ in $\mathrm{H}_{2} \mathrm{O}$ samples, were dissolved in $50 \% \mathrm{MeOH}$ in $\mathrm{CH}_{2} \mathrm{Cl}_{2}$, combined and loaded onto another $\mathrm{LH} 20$ column and run in a mobile phase of $50 \%$ $\mathrm{MeOH}$ in $\mathrm{CH}_{2} \mathrm{Cl}_{2}$. The column was run at a flow rate of approximately one drop per 15 seconds with each fraction being collected for $1380 \mathrm{~s}$. Fractions $34-39$ of a total 70 were combined and concentrated under reduced pressure.

The concentrated sample was dissolved in 1:1:1 MeOH:EtOAc: $\mathrm{CH}_{2} \mathrm{Cl}_{2}$, loaded onto a 10 $\mathrm{mL}$ DIOL column and eluted sequentially with $60 \mathrm{~mL}$ volumes of $50 \% \mathrm{EtOAc}$ in $\mathrm{CH}_{2} \mathrm{Cl}_{2}$, EtOAc, $10 \%$, and $25 \% \mathrm{MeOH}$ in EtOAc and $\mathrm{MeOH}$ (fractions 1-6). Fraction 5 was 
concentrated under reduced pressure and sub-sampled (fraction 5a (11.9 mg), fraction $5 b(5.3 \mathrm{mg}))$.

\section{HPLC Purification}

Fraction 5a was chromatographed on a semi-preparative C18 reversed-phase HPLC column, with $80 \% \mathrm{MeOH}$ in $\mathrm{H}_{2} \mathrm{O}$ as the mobile phase, at a flow rate of $5 \mathrm{~mL} / \mathrm{min}$. The compound of interest had a retention time of approximately $1560 \mathrm{~s}$ and was the fourth fraction collected. A full NMR data set revealed purification of the aglycon, from the compound of interest. The fraction was dissolved in a 2:2:1 hexanes:DCM:MeOH solvent system and loaded onto an LH2O column, utilising the same running solvent as what it was dissolved in. The column had a flow rate of approximately 7 seconds per drop and each fraction was collected for $1380 \mathrm{~s}$. No further purification was observed with a mass of $2.3 \mathrm{mg}$ recovered.

\section{Sample BJN3_84Fe4}

White solid; NMR data consistent with Tables 4.1 and 4.2.

\section{LH20 Purification}

Fraction $5 b$ (centrifuged off as a solid) was purified using predominantly LH20 columns with different mobile phases. The sample was dissolved in a minimum of $50 \% \mathrm{MeOH}$ in $\mathrm{CH}_{2} \mathrm{Cl}_{2}$, using a centrifuge to separate off any remaining un-dissolved sample, and then loaded onto an $\mathrm{LH} 20$ column and run in $50 \% \mathrm{MeOH}$ in $\mathrm{CH}_{2} \mathrm{Cl}_{2}$. The column was run at a flow rate of approximately one drop per 10 seconds with each fraction collecting for $1380 \mathrm{~s}$, until 62 total fractions had been collected. Fractions 45-53 were combined, concentrated under reduced pressure and then re-dissolved in $20 \% \mathrm{MeOH}$ in $\mathrm{CH}_{2} \mathrm{Cl}_{2}$ and loaded back onto the $\mathrm{LH} 20$ column containing a $20 \% \mathrm{MeOH}$ in $\mathrm{CH}_{2} \mathrm{Cl}_{2}$ running solvent. Seventy seven total fractions were collected off the column at a flow rate of approximately one drop per 10 seconds with each fraction collected for $1380 \mathrm{~s}$. Fractions $61-67,68-71$ and 73-77 were collected separately. A MeOH strip of the LH20 column was performed to ensure no sample remained on the column. 
Fractions 68-71 were concentrated under reduced pressure and re-dissolved, together with the remaining un-dissolved solid in a solvent system of $20 \% \mathrm{MeOH}$ in $\mathrm{CH}_{2} \mathrm{Cl}_{2}$, and loaded onto the column. The column was run with a $20 \% \mathrm{MeOH}$ in $\mathrm{CH}_{2} \mathrm{Cl}_{2}$ mobile phase at a flow rate of one drop per 10 seconds with each fraction collected for $1380 \mathrm{~s}$. A total of 133 fractions were collected with fractions 83-123 combined and concentrated under reduced pressure. Again, the LH2O column was stripped using $\mathrm{MeOH}$, with the collected eluent combined with the previous column strip and concentrated under reduced pressure. Fractions 83-123 and the column strips were dissolved in 2:2:1 hexanes: $\mathrm{CH}_{2} \mathrm{Cl}_{2}: \mathrm{MeOH}$ and loaded onto an $\mathrm{LH} 20$ column, with the mobile phase being the same 2:2:1 hexanes: $\mathrm{CH}_{2} \mathrm{Cl}_{2}: \mathrm{MeOH}$ solvent system. The column was run at a flow rate of approximately six seconds per drop with each fraction collecting for $1380 \mathrm{~s}$ until 90 fractions were collected. Fractions 50-72 were combined and concentrated under reduced pressure.

The concentrated fraction 50-72 was dissolved in a $20 \% \mathrm{MeOH}$ in EtOAc solution and loaded onto a $5 \mathrm{~mL} \mathrm{DIOL} \mathrm{column.} \mathrm{The} \mathrm{column} \mathrm{was} \mathrm{run} \mathrm{isocratically} \mathrm{in} \mathrm{the} \mathrm{same} 20 \%$ $\mathrm{MeOH}$ in EtOAc solution with a flow rate of six seconds per drop with approximately two $\mathrm{mL}$ per fraction collected. Fifty-five fractions were collected with the final five fractions being collected using $100 \% \mathrm{MeOH}$ as the solvent. Fractions 6 and 7 were combined, concentrated under reduced pressure and submitted for a full data set.

\section{Sample BJN4_8Fb}

White solid; NMR data see Tables 4.1 and 4.2; HRESIMS observed $\mathrm{m} / \mathrm{z} 1029.5499$ $[\mathrm{M}+\mathrm{H}]^{+}, \mathrm{C}_{51} \mathrm{H}_{83} \mathrm{NO}_{20}$ requires $1029.5508, \Delta-0.91 \mathrm{ppm} ;[\alpha]_{D}^{26.6}+42.9^{\circ}(\mathrm{EtOH}, \mathrm{c}=0.023)$. 


\section{Appendix A}

\section{Sponge Screening and Cyclic Loading Protocol}

\section{Cyclic Loading and Backloading Process}

The process of cyclic loading (shown schematically on page 100) avoids the need to pre-concentrate the extract allowing the crude sample to be loaded immediately onto a PSDVB column. The method follows an iterative dilution phase where the eluent is passed through the column, diluted with water, and then passed through the column again. Under most circumstances, dilution of a crude extract with water (a polar solvent) would result in the precipitation of non-polar compounds. This is avoided with cyclic loading since the first pass through the column removes the non-polar compounds in the crude extract and therefore, they will not be present in the eluent when it is diluted. Further dilution with water increases the polarity of the eluent and leads to the slightly more polar compounds having a greater affinity for the stationary phase, therefore forcing their adsorption onto the stationary phase. Subsequent runs through the reversed-phase column are performed to remove all the polar compounds from the diluted crude extract. This process is typically run until a four-fold dilution of the original solvent is achieved.

Once the cyclic loading process is completed, the next step involves elution of the column, which is carried out in a stepped system of increasing organic solvent (normally methanol or acetone) in water. The resulting fractions collected from the cyclic loading procedure will contain varying amounts of water which is problematic, if the fraction needs to be concentrated under reduced pressure, as 'bumping' of organic solvent/water mixtures can occur under vacuum. The cyclic loading method was modified to account for this with the addition of a 'backloading' procedure. A water containing fraction collected off the cyclic loading column is diluted and cyclic loaded onto a smaller column of PSDVB. The column is then eluted with organic solvent leaving a fraction that is now largely devoid of water which makes it easier to concentrate under reduced pressure. 


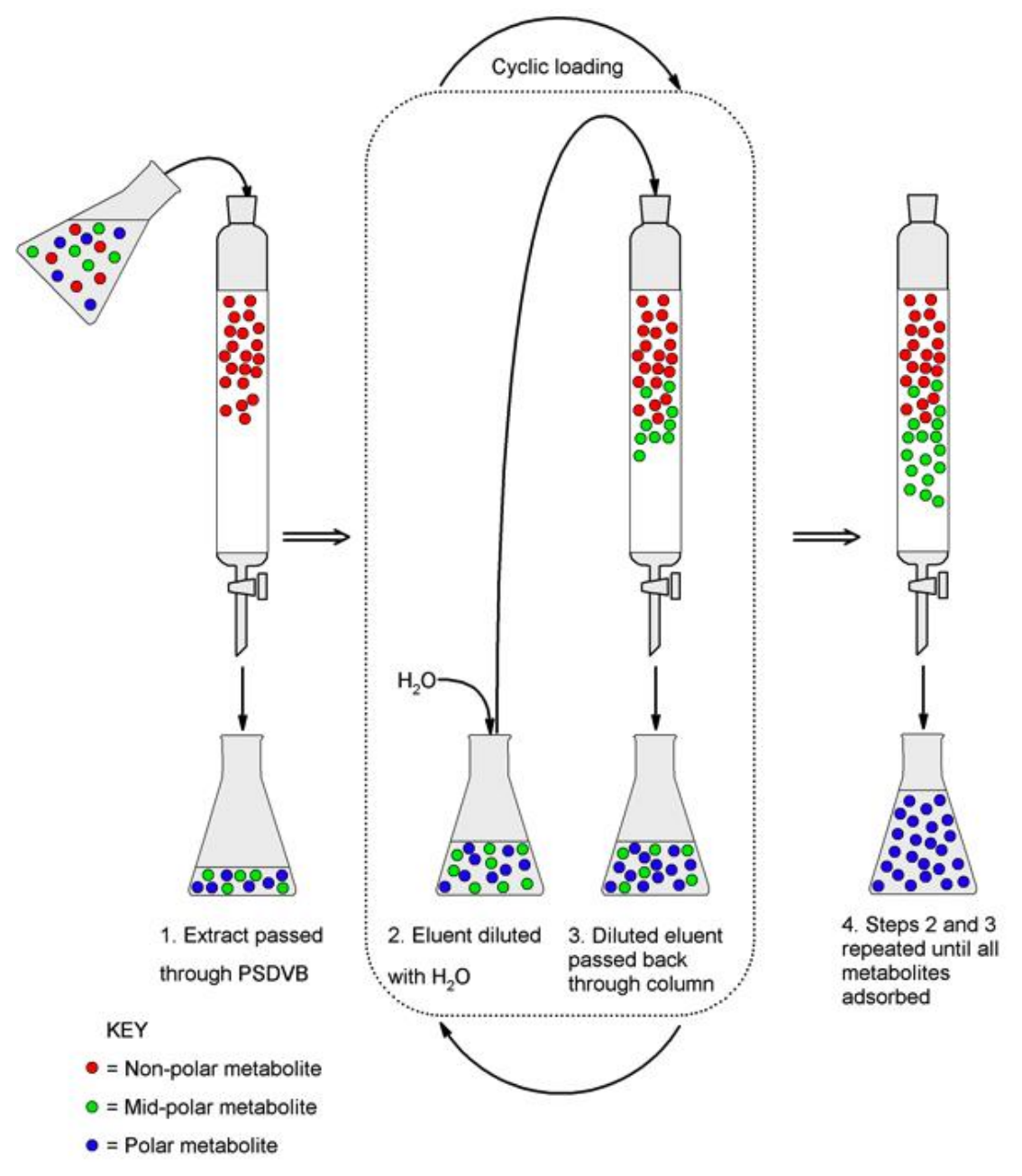

The cyclic loading process 


\section{Screening Protocol}

The protocol used to screen the algal specimens utilised the existing sponge screening protocol with some slight changes in the amounts used.

\section{Equipment needed (per screen)}

1x Screen column loaded with $20 \mathrm{~cm}^{3}$ of HP20 equilibrated in methanol

1x Backloading column loaded with $10 \mathrm{~cm}^{3}$ of HP20 equilibrated in methanol

\section{Procedure}

\section{Voucher Sample Preparation}

- Take a voucher specimen of approximately $10 \mathrm{~g}$ of the crude sponge material ensuring that both the ectoderm and the endoderm are represented.

- Leave in the freezer for future classification.

\section{Extraction}

- Extract approximately $20 \mathrm{~g}$ of crude sponge material in approximately $200 \mathrm{~cm}^{3}$ of methanol overnight.

- Filter the first extract and set aside. Re-extract the sponge material (and any filter paper/celite as necessary) in approximately $200 \mathrm{~cm}^{3}$ of methanol overnight.

- Filter the second extract.

- Keep all sponge material (and any filter paper/celite as necessary) until the screen is complete at which time it may be discarded.

\section{Cyclic Loading}

- Pass the second extract through the screen column with a flow rate of approximately $10 \mathrm{~cm}^{3} / \mathrm{min}$.

- Pass the first extract through the screen column with a flow rate of approximately $10 \mathrm{~cm}^{3} / \mathrm{min}$. Combine the eluent with that of the second extract.

- Dilute the combined eluents to a $50 \%$ vol/vol solution with distilled water. Pass the diluted eluents back through the screen column at a flow rate of approximately $10 \mathrm{~cm}^{3} / \mathrm{min}$.

- Dilute the eluent to a $25 \%$ vol/vol solution with distilled water. Pass the diluted eluent back through the screen column at a flow rate of approximately $10 \mathrm{~cm}^{3} / \mathrm{min}$. 
- The eluent should be kept until the screen is complete at which time it may be discarded.

\section{Elution}

- Elute the screen column with $60 \mathrm{~cm}^{3}$ of distilled water at a flow rate of approximately $10 \mathrm{~cm}^{3} / \mathrm{min}$. The water eluent can be discarded immediately.

- Elute the screen column with $60 \mathrm{~cm}^{3}$ of $30 \%$ acetone in distilled water at a flow rate of approximately $10 \mathrm{~cm}^{3} / \mathrm{min}$.

- Elute the screen column with $60 \mathrm{~cm}^{3}$ of $75 \%$ acetone in distilled water at a flow rate of approximately $10 \mathrm{~cm}^{3} / \mathrm{min}$.

- Elute the screen column with $60 \mathrm{~cm}^{3}$ of acetone at a flow rate of approximately $10 \mathrm{~cm}^{3} / \mathrm{min}$.

\section{Backloading the 75\% Acetone Fraction}

- Dilute the $75 \%$ acetone fraction with $60 \mathrm{~cm}^{3}$ of distilled water. Pass the diluted eluent through the backloading column at a flow rate of approximately 8 $\mathrm{cm}^{3} / \mathrm{min}$.

- Dilute the eluent with $120 \mathrm{~cm}^{3}$ of distilled water. Pass the diluted eluent back through the backloading column at a flow rate of approximately $8 \mathrm{~cm}^{3} / \mathrm{min}$.

- The eluent should be kept until the screen is complete at which time it may be discarded.

- Elute the backloading column with $100 \mathrm{~cm}^{3}$ of acetone.

\section{Processing the $75 \%$ Fraction}

- Rotary-evaporate the acetone eluent of the backloading column to dryness and transfer to a pre-weighed sample vial. Evaporate to dryness and the record mass.

- Prepare an NMR sample of the sample in $500 \mu \mathrm{l}$ of $\mathrm{CD}_{3} \mathrm{OD}$ in a $5 \mathrm{~mm}$ NMR tube.

\section{NMR Analysis of the 75\% Fraction}

- Run a ${ }^{1} \mathrm{H}$ spectrum of the sample using the standard ${ }^{1} \mathrm{H}$ experiment with 64 transients (ca. 4 mins)

- Run a COSY spectrum of the sample using the standard "ScreenCOSY" parameter set. (ca. 20 mins)

- Run an HSQC spectrum of the sample using the standard "ScreenHSQC" parameter set. (ca. $51 / 2 \mathrm{hrs}$ ) 
- Run an HMBC spectrum of the sample using the standard "ScreenHSQC" parameter set. (ca. $51 / 2 \mathrm{hrs}$ )

\section{Backloading the $30 \%$ Acetone Fraction}

- Dilute the $30 \%$ acetone fraction with $60 \mathrm{~cm}^{3}$ of distilled water. Pass the diluted eluent through the backloading column at a flow rate of approximately 8 $\mathrm{cm}^{3} / \mathrm{min}$.

- Dilute the eluent with $120 \mathrm{~cm}^{3}$ of distilled water. Pass the diluted eluent back through the backloading column at a flow rate of approximately $8 \mathrm{~cm}^{3} / \mathrm{min}$.

- The eluent should be kept until the screen is complete at which time it may be discarded.

- Elute the backloading column with $100 \mathrm{~cm}^{3}$ of acetone.

\section{Processing the $30 \%$ Fraction}

- Rotary-evaporate the methanol eluent of the backloading column to dryness and transfer to a pre-weighed sample vial. Evaporate to dryness and the record mass.

- Prepare an NMR sample of the sample in $500 \mu \mathrm{L}$ of $\mathrm{CD}_{3} \mathrm{OD}$ in a $5 \mathrm{~mm} \mathrm{NMR}$ tube.

NMR Analysis of the $30 \%$ Fraction

- Run a ${ }^{1} \mathrm{H}$ spectrum of the sample using the standard ${ }^{1} \mathrm{H}$ experiment with 64 transients (ca. 4 mins)

- Run further spectra if interesting signals are observed.

\section{Processing the $100 \%$ Fraction}

- Rotary-evaporate the acetone eluent of the screen column to dryness and transfer to a pre-weighed sample vial. Evaporate to dryness and the record mass.

- Prepare an NMR sample of the sample in $700 \mu \mathrm{L}$ of $\mathrm{CDCl}_{3}$ in a $5 \mathrm{~mm} \mathrm{NMR}$ tube.

\section{NMR Analysis of the $100 \%$ Fraction}

- Run a ${ }^{1} \mathrm{H}$ spectrum of the sample using the standard ${ }^{1} \mathrm{H}$ experiment with 64 transients. (ca. 4 mins)

- Run further spectra if interesting signals are observed. 


\section{Appendix B}

\section{Algae Spectra}

(Semi-Purified Samples) 


\section{Avrainvilloside Substructure}

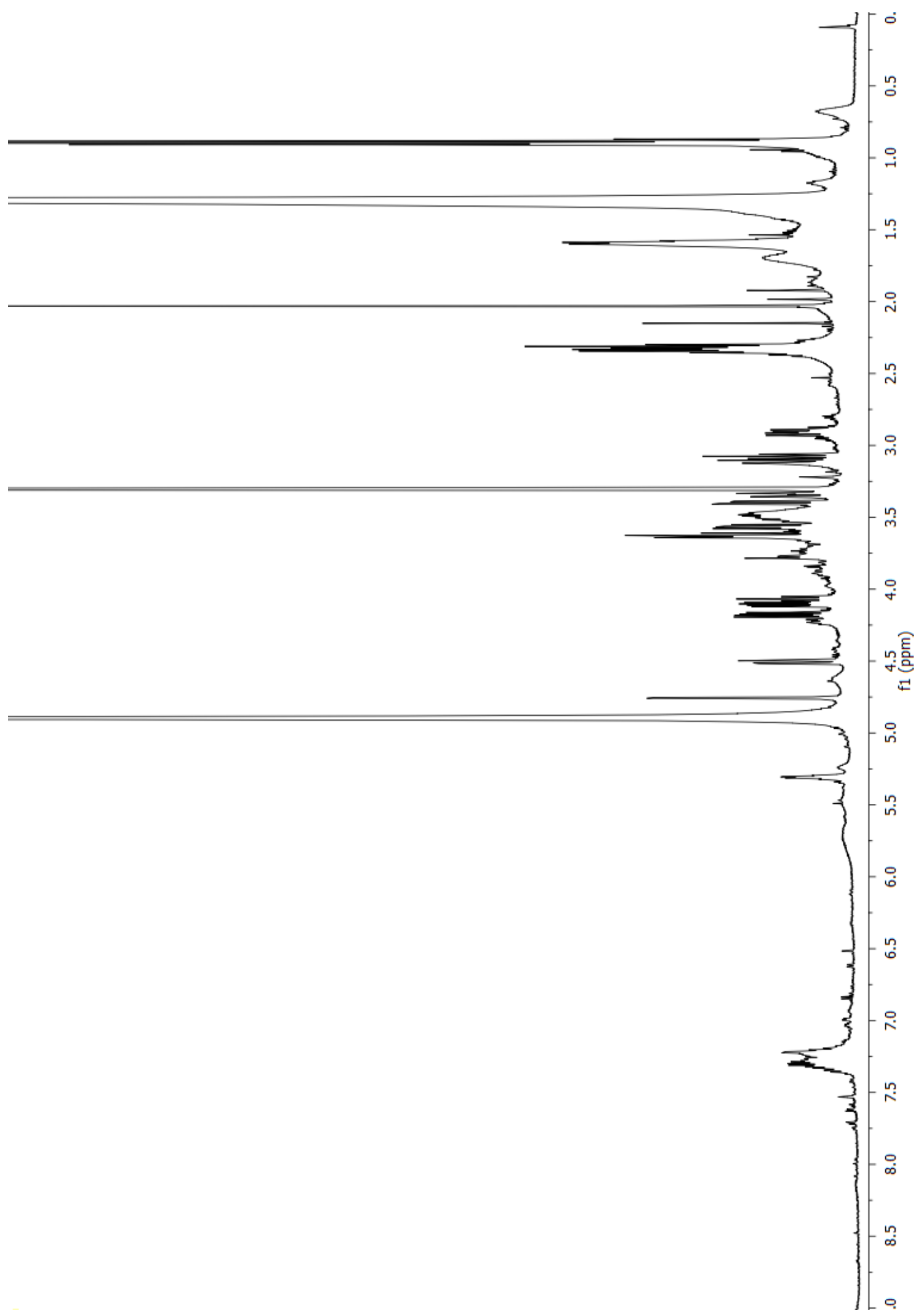

${ }^{1} \mathrm{H}$ NMR spectrum of known avrainvilloside substructure (76) $\left(600 \mathrm{MHz}, \mathrm{CD}_{3} \mathrm{OD}\right)$ 


\section{Avrainvilloside Substructure}

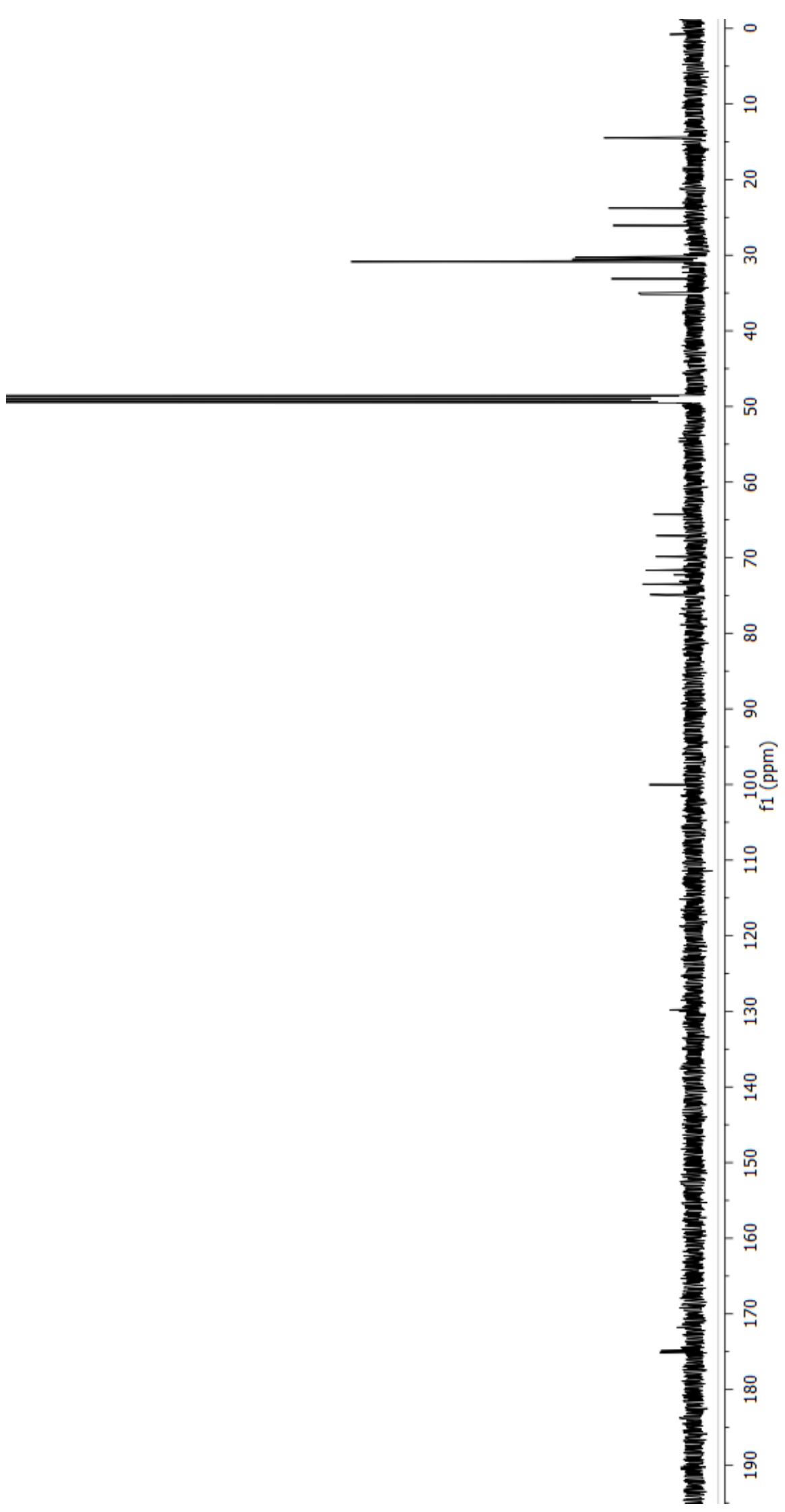

${ }^{13} \mathrm{C}$ NMR spectrum of known avrainvilloside substructure (76) $\left(150 \mathrm{MHz}, \mathrm{CD}_{3} \mathrm{OD}\right)$ 


\section{Avrainvilloside Substructure}

(udd) it

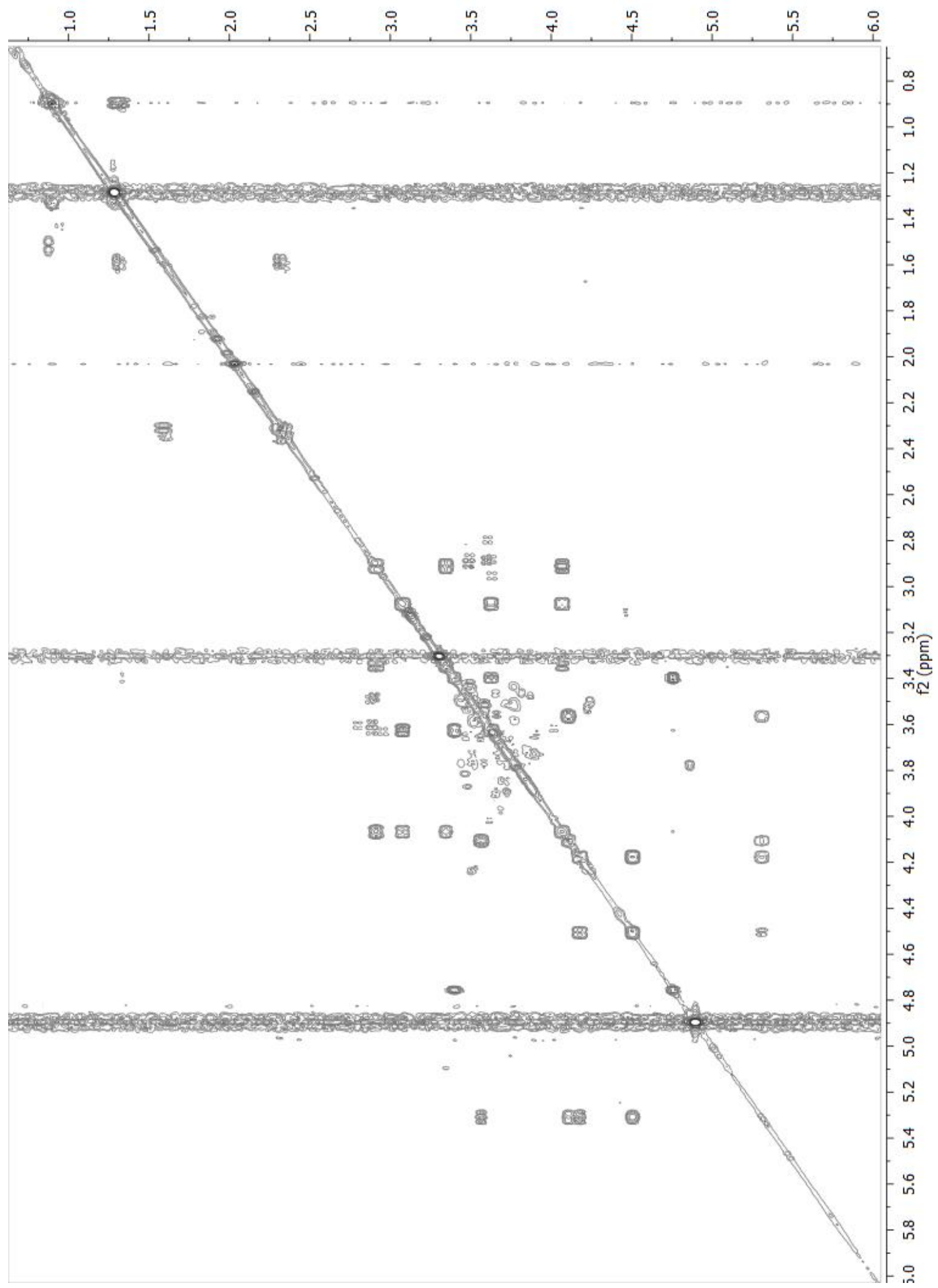

COSY NMR spectrum of known avrainvilloside substructure (76) $\left(600 \mathrm{MHz}, \mathrm{CD}_{3} \mathrm{OD}\right)$ 


\section{Avrainvilloside Substructure}

(udd) it

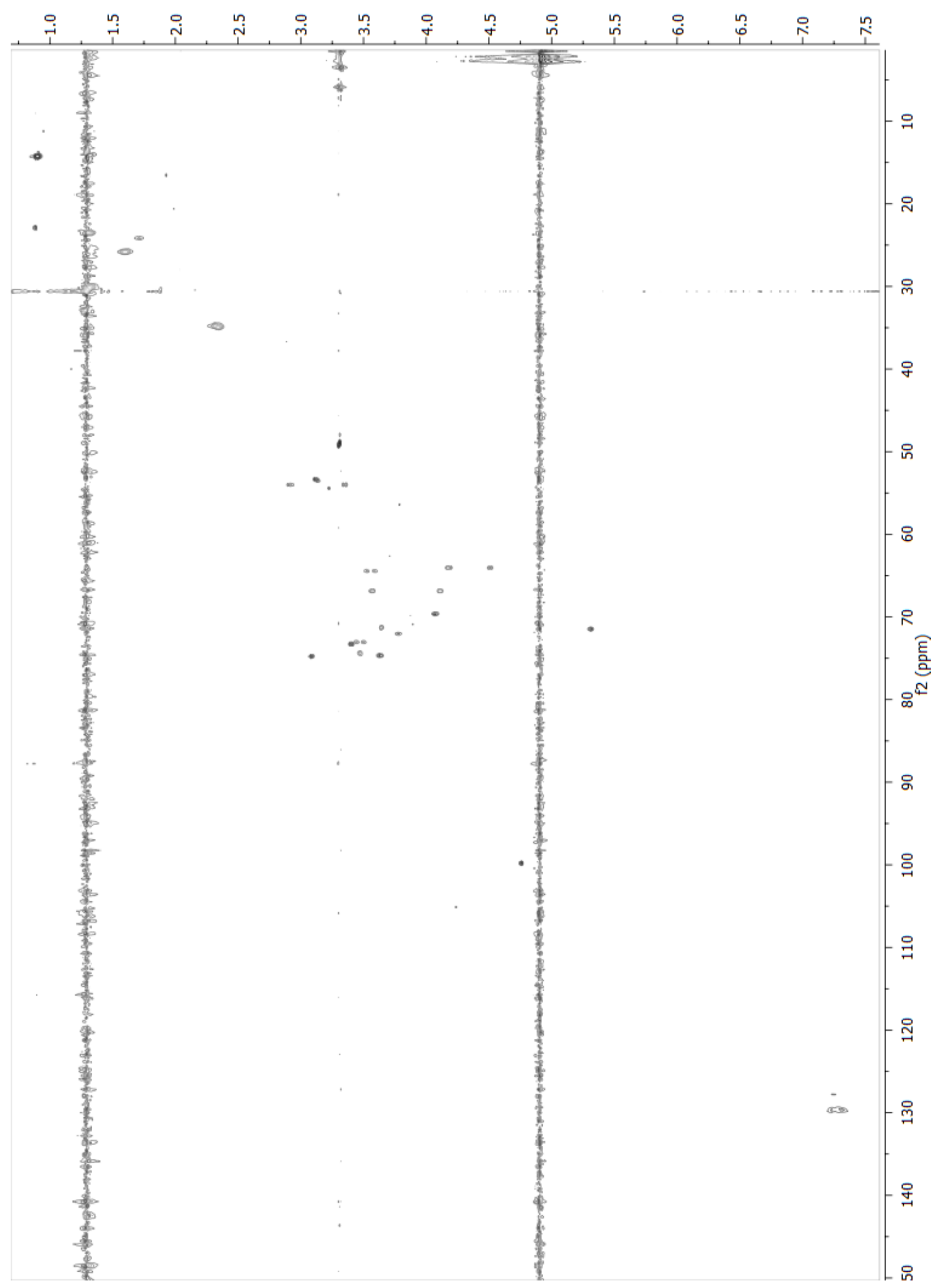

HSQC NMR spectrum of known avrainvilloside substructure (76) $\left(600 \mathrm{MHz}, \mathrm{CD}_{3} \mathrm{OD}\right)$ 


\section{Avrainvilloside Substructure}

(udd) it

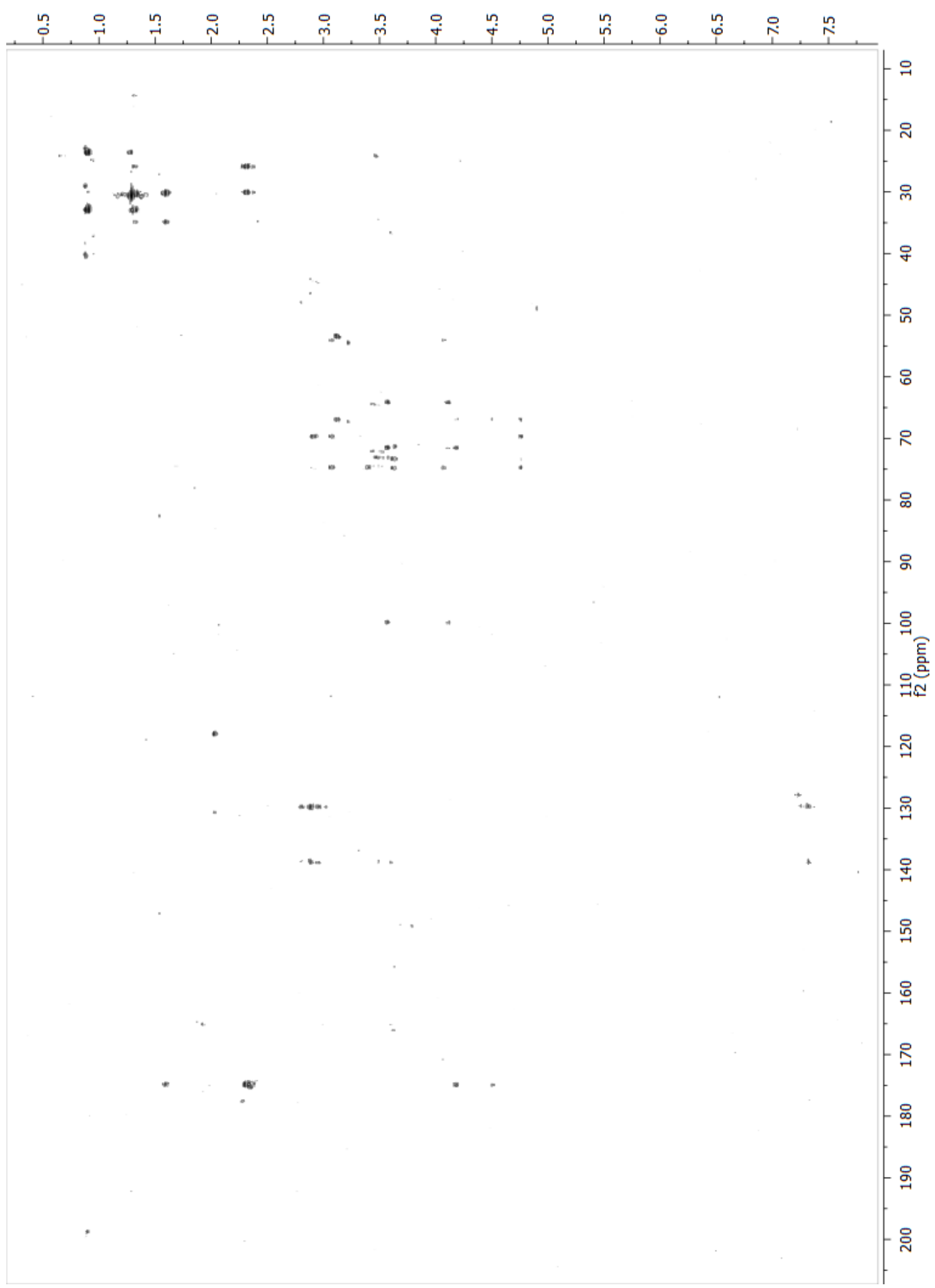

$\mathrm{HMBC}$ NMR spectrum of known avrainvilloside substructure (76) (600 MHz, CD ${ }_{3} \mathrm{OD}$ ) 


\section{Methacrylic Acid Substructure}

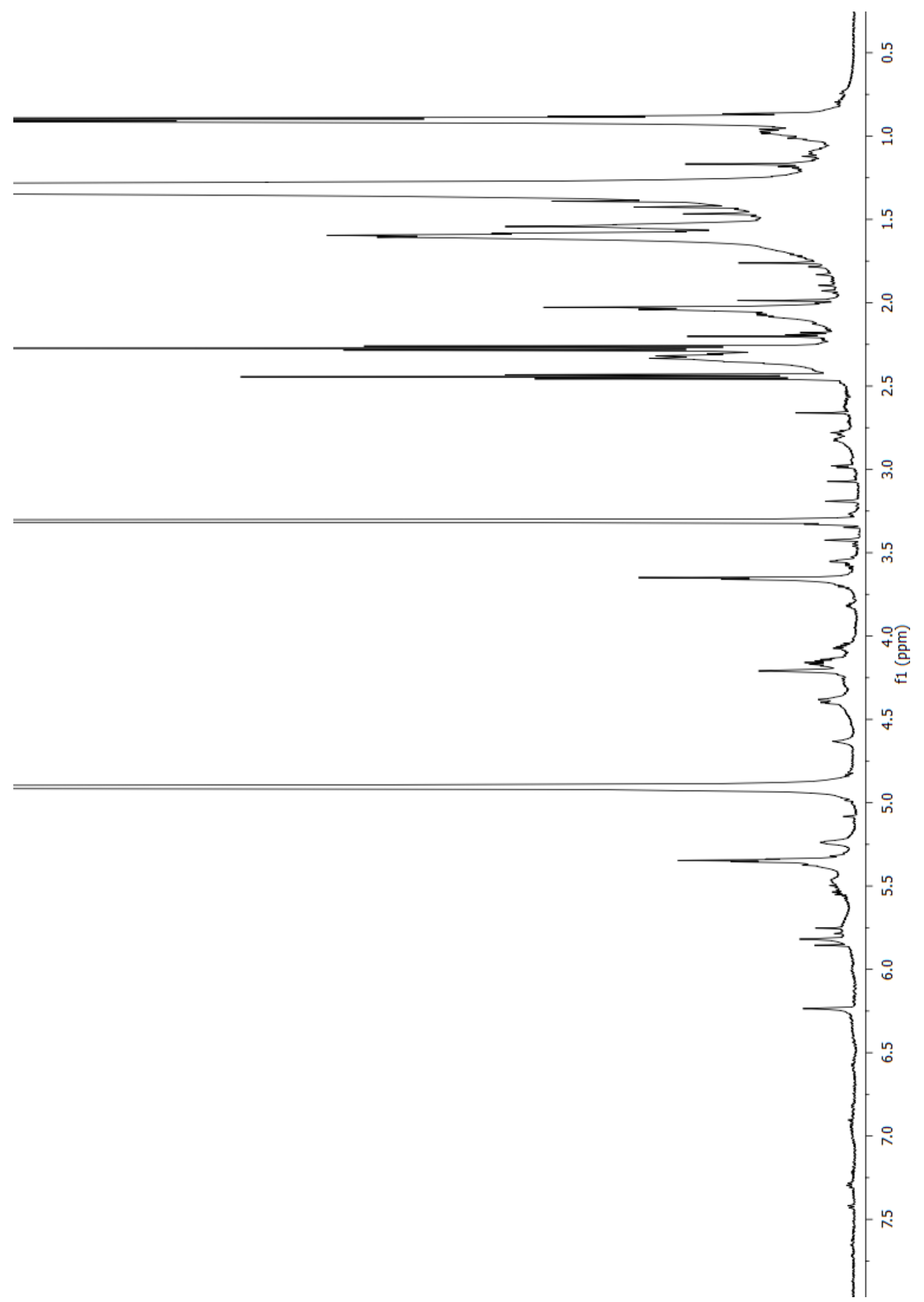

${ }^{1} \mathrm{H}$ NMR spectrum of known methacrylic acid substructure $(83)\left(600 \mathrm{MHz}, \mathrm{CD}_{3} \mathrm{OD}\right)$ 
Methacrylic Acid Substructure

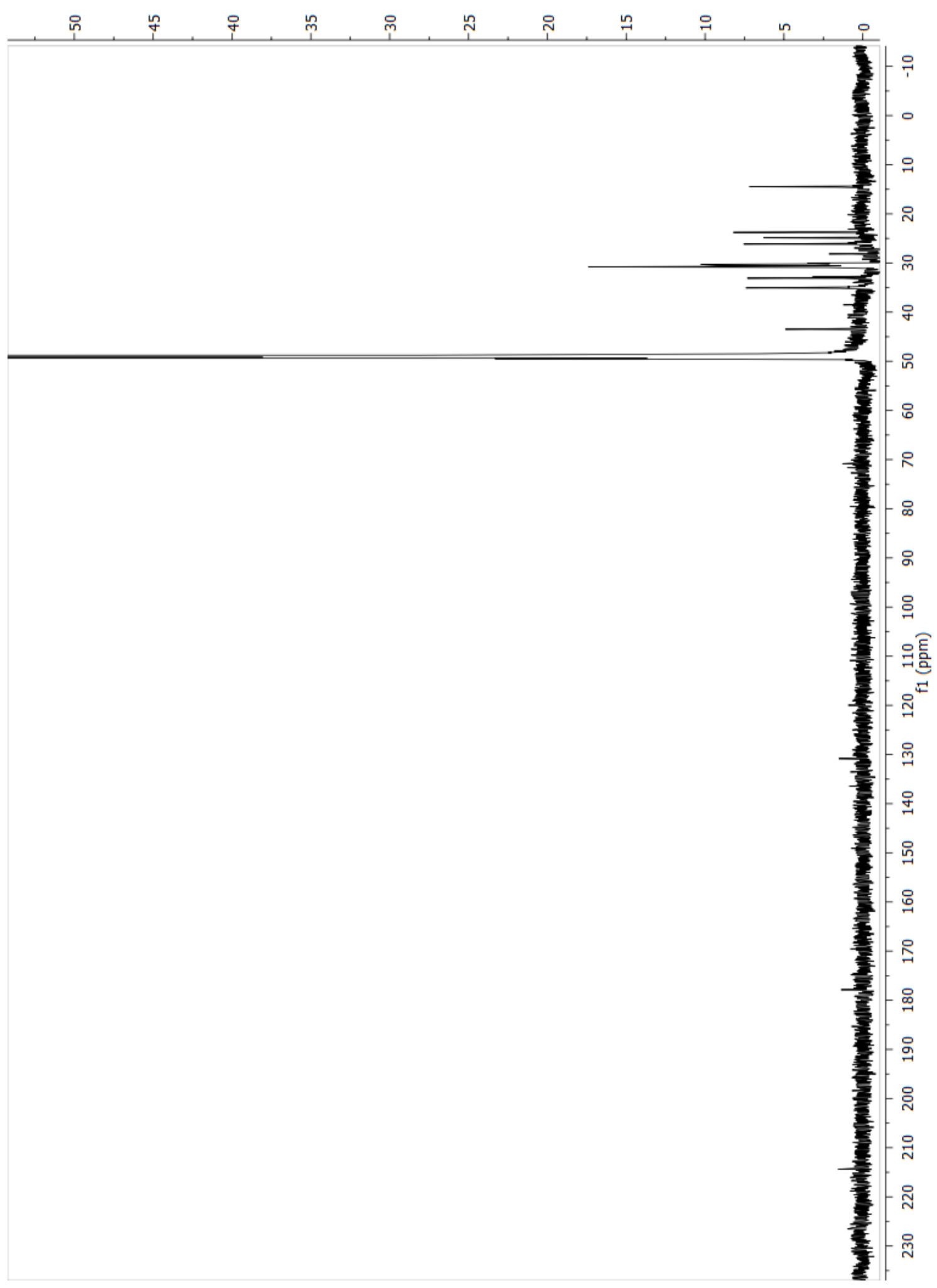

${ }^{13} \mathrm{C}$ NMR spectrum of known methacrylic acid substructure (83) $\left(150 \mathrm{MHz}, \mathrm{CD}_{3} \mathrm{OD}\right.$ ) 


\section{Methacrylic Acid Substructure}

(udd) it

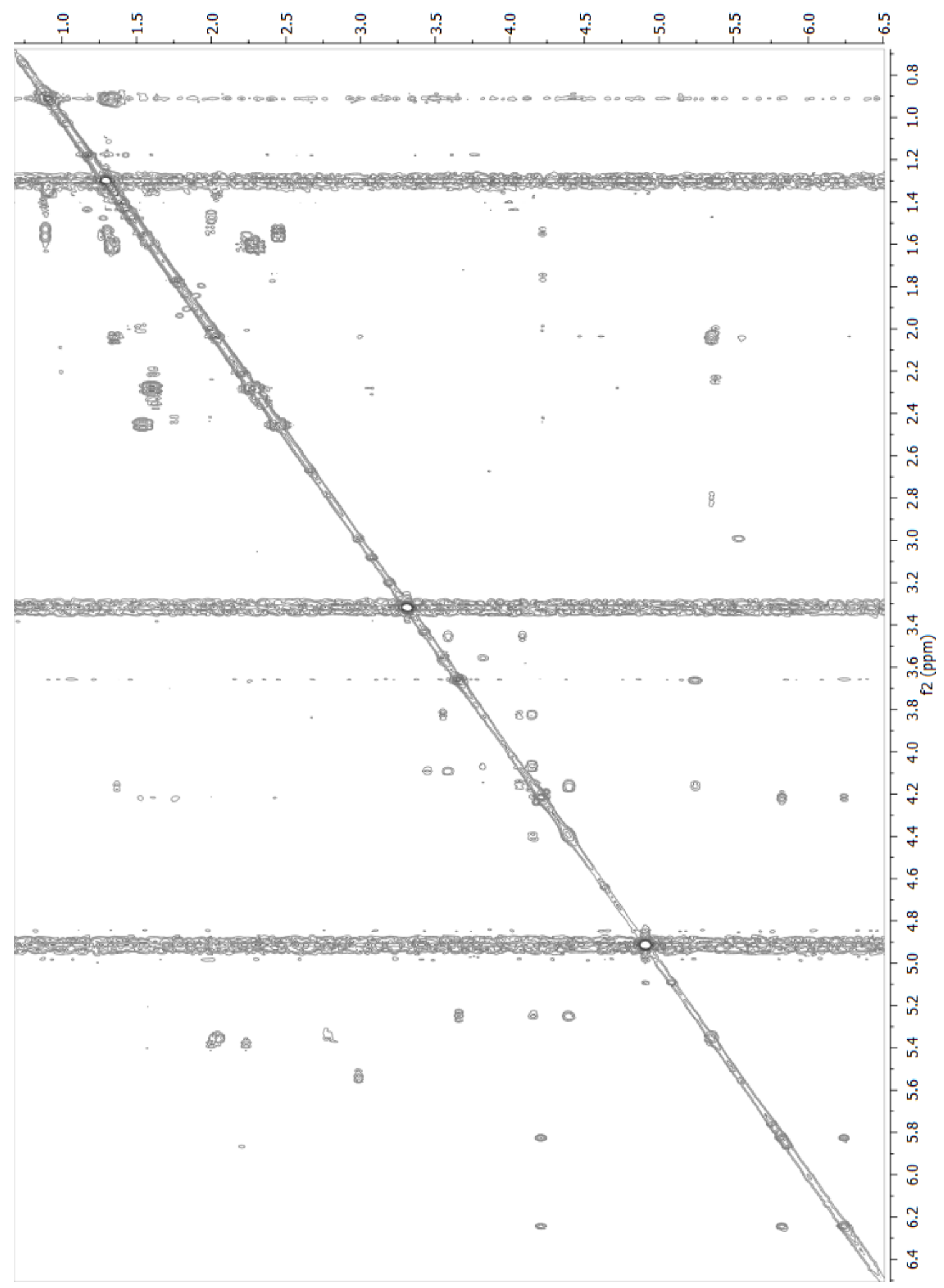

COSY NMR spectrum of known methacrylic acid substructure (83) $\left(600 \mathrm{MHz}, \mathrm{CD}_{3} \mathrm{OD}\right)$ 


\section{Methacrylic Acid Substructure}

(udd) it

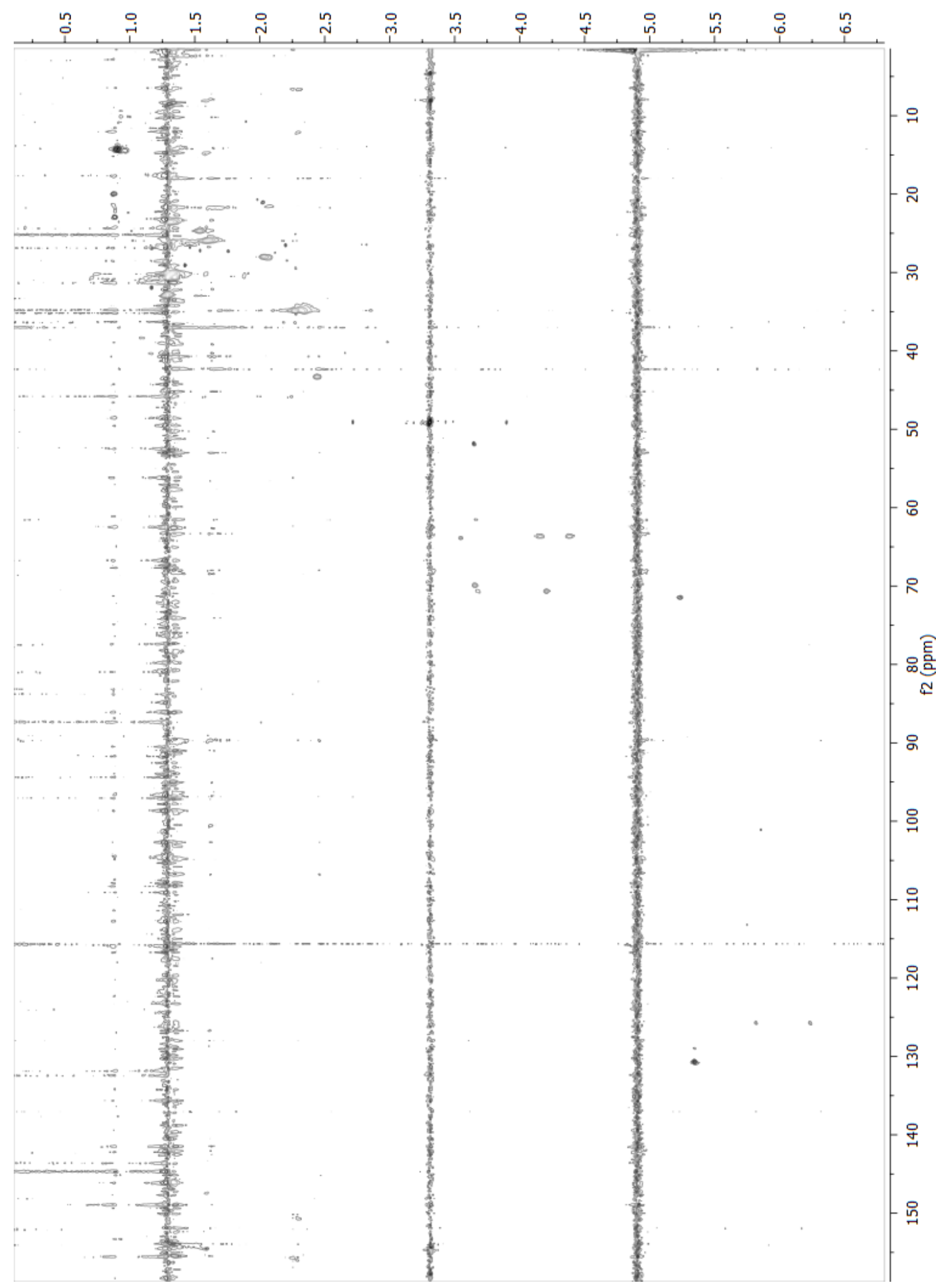

HSQC spectrum of known methacrylic acid substructure $(83)\left(\mathrm{CD}_{3} \mathrm{OD}\right)$ 


\section{Methacrylic Acid Substructure}

(udd) it

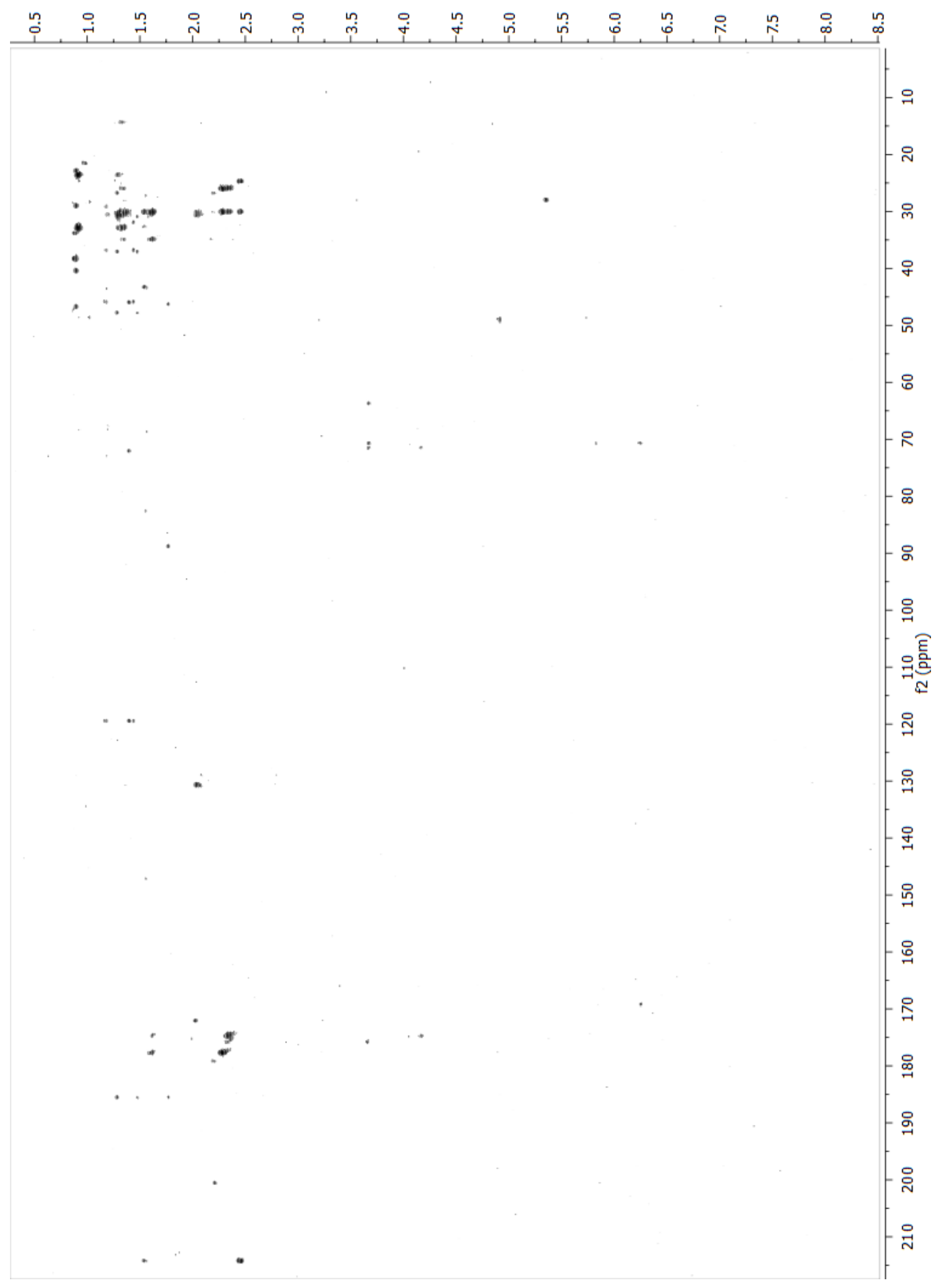

$\mathrm{HMBC}$ spectrum of known methacrylic acid substructure $(83)\left(\mathrm{CD}_{3} \mathrm{OD}\right)$ 


\section{Fistularin-3}

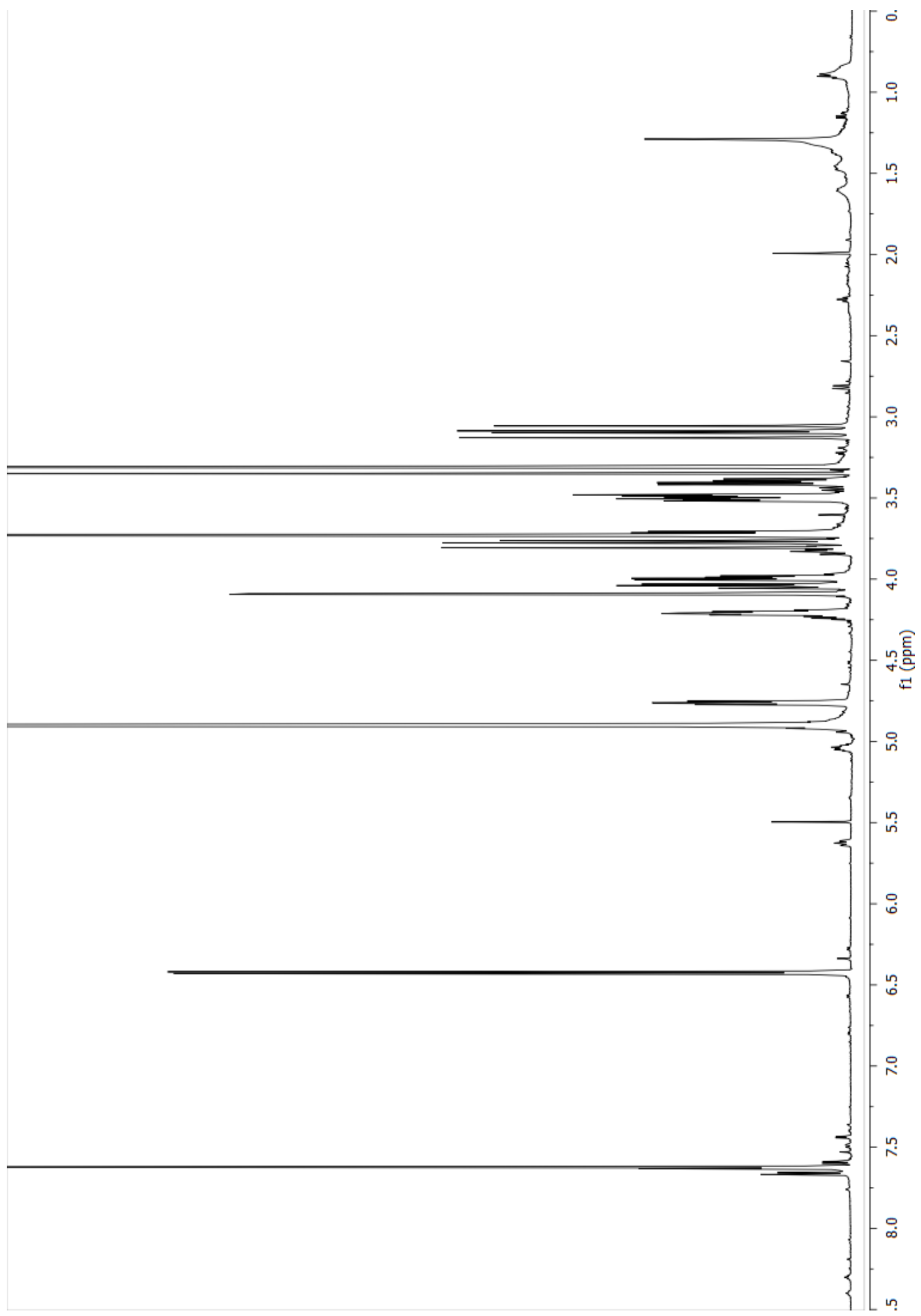

${ }^{1} \mathrm{H}$ NMR spectrum of known compound fistularin-3 (86) $\left(600 \mathrm{MHz}, \mathrm{CD}_{3} \mathrm{OD}\right)$ 
Fistularin-3

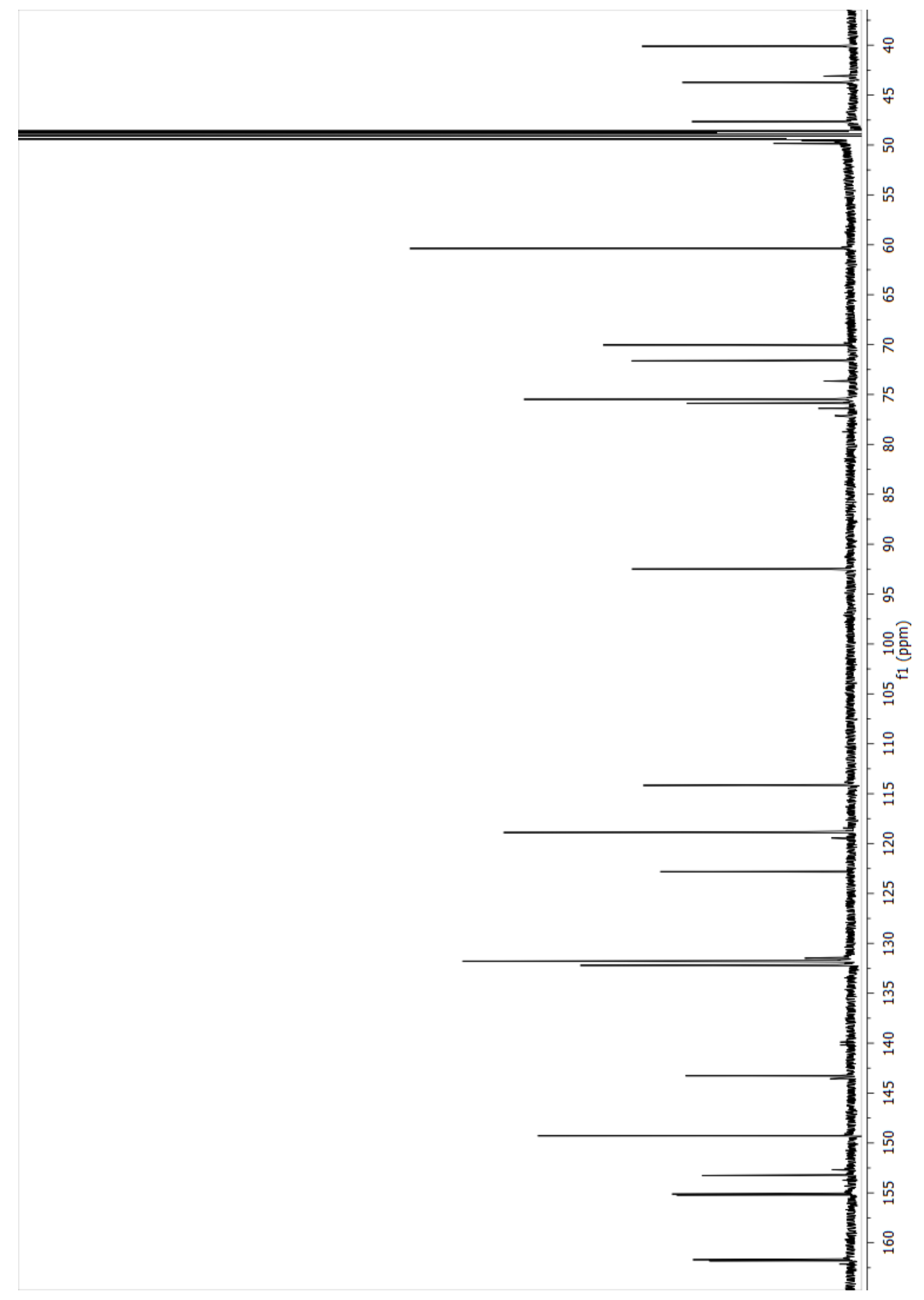

${ }^{13} \mathrm{C}$ NMR spectrum of known compound fistularin-3 (86) $\left(150 \mathrm{MHz}, \mathrm{CD}_{3} \mathrm{OD}\right)$ 
Fistularin-3

(udd) it

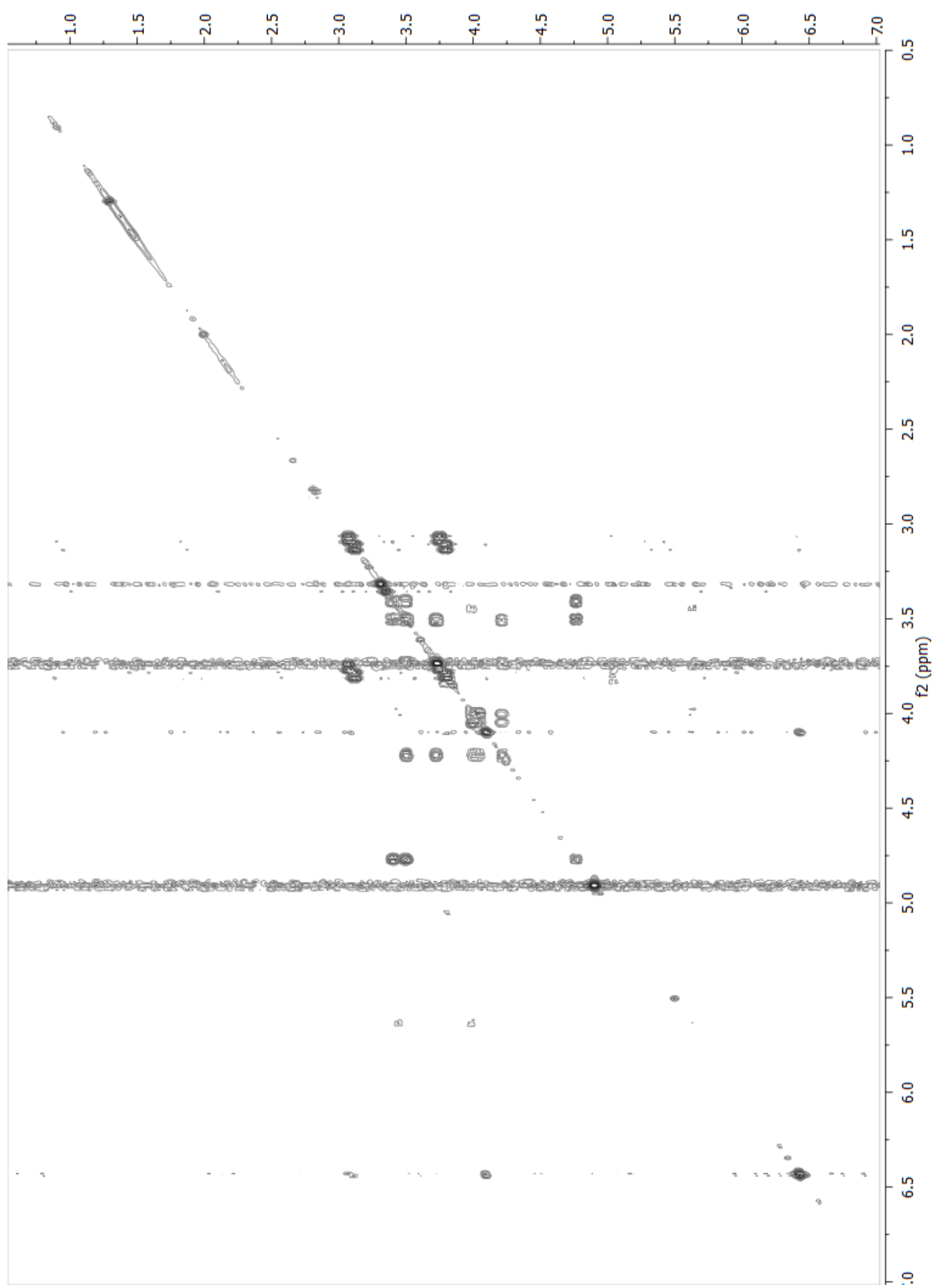

COSY spectrum of known compound fistularin-3 (86) (600 MHz, $\left.\mathrm{CD}_{3} \mathrm{OD}\right)$ 
Fistularin-3

(udd) It

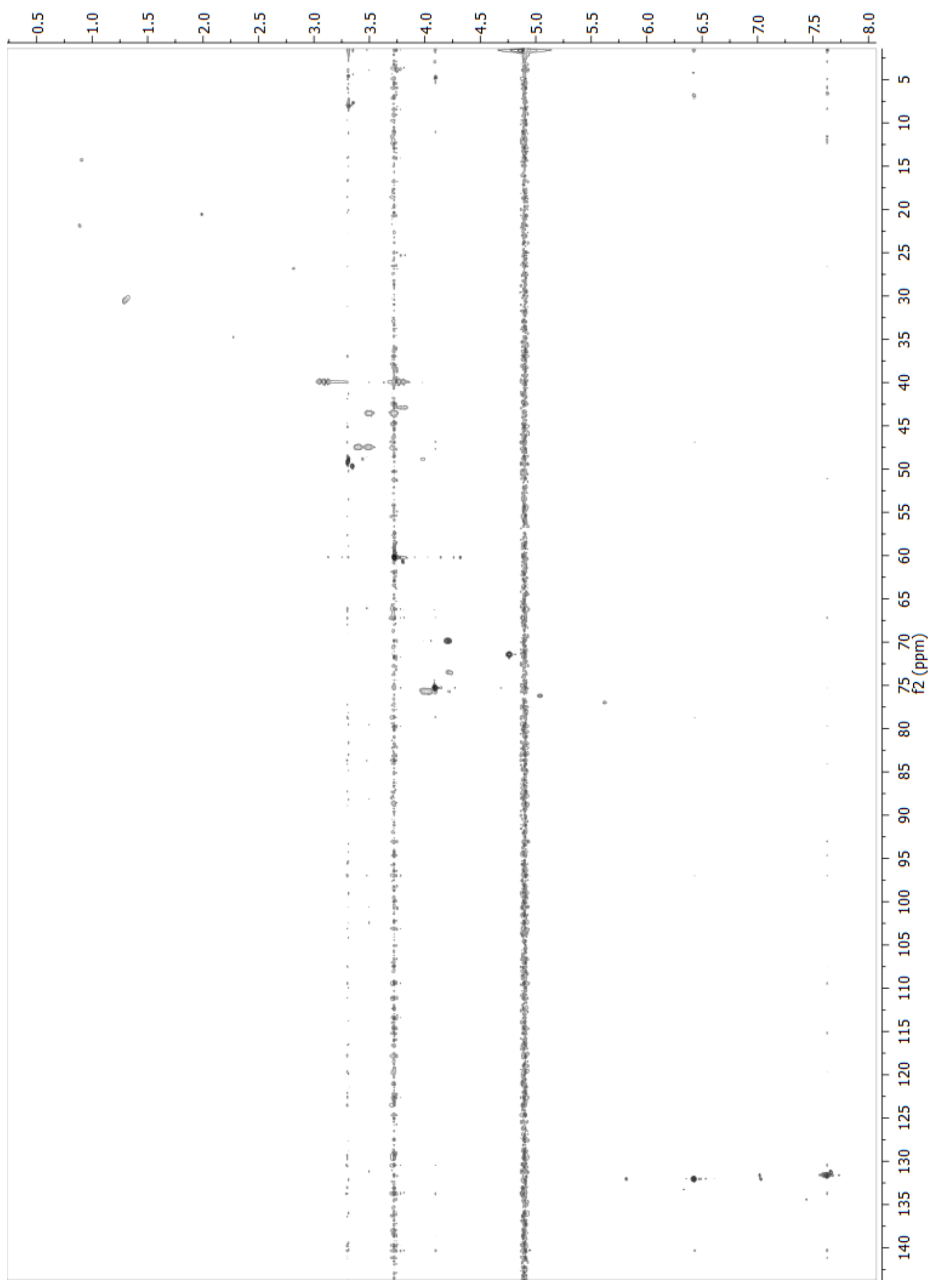

HSQC spectrum of known compound fistularin-3 (86) (600 MHz, $\left.\mathrm{CD}_{3} \mathrm{OD}\right)$ 
Fistularin-3

(udd) it

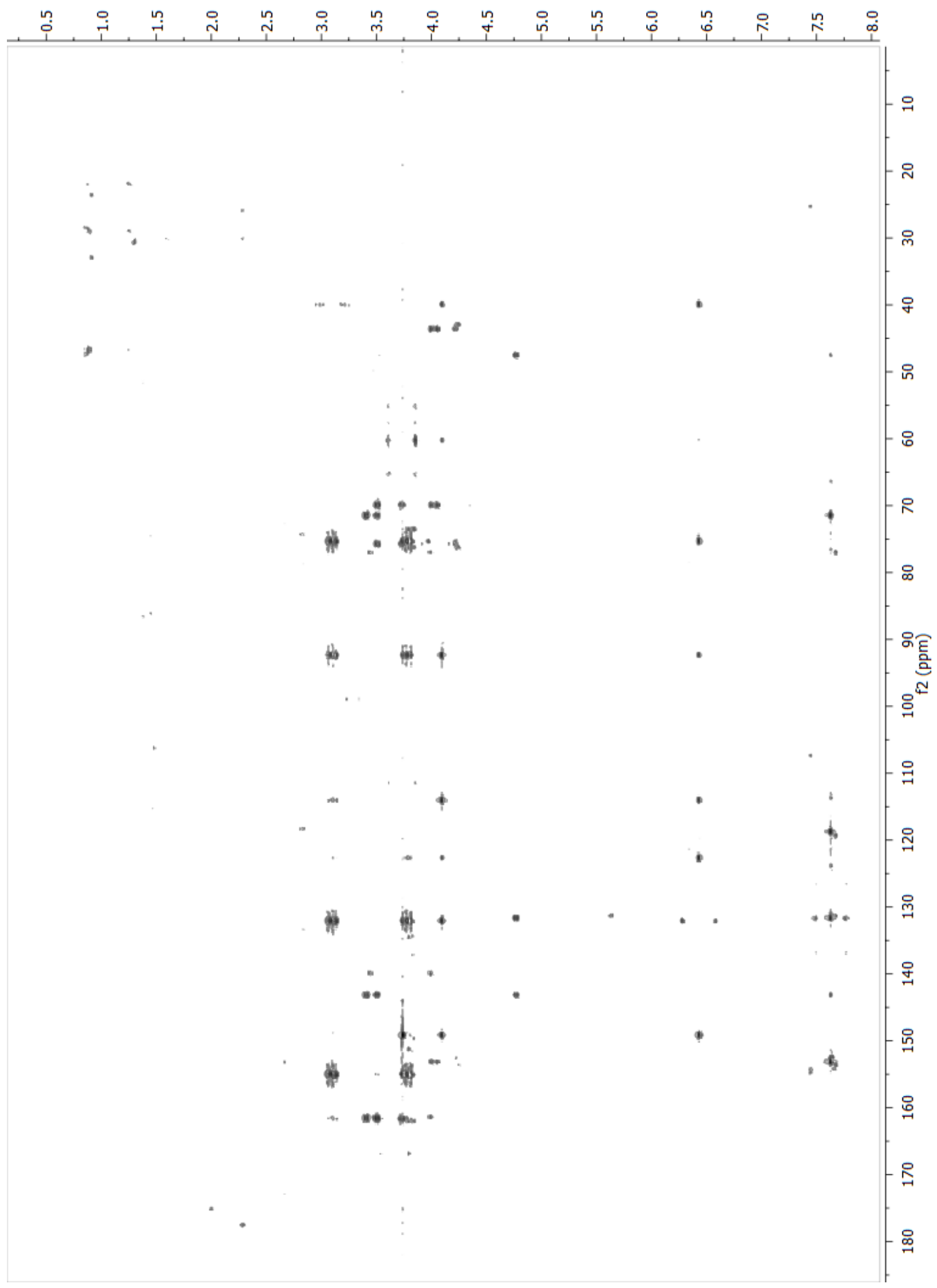

$\mathrm{HMBC}$ spectrum of known compound fistularin-3 (86) (600 MHz, CD $3 \mathrm{OD}$ ) 
Appendix C

\section{NMR Spectra of \\ Raspailoside A (135)}


Raspailoside A - HPLC Purification

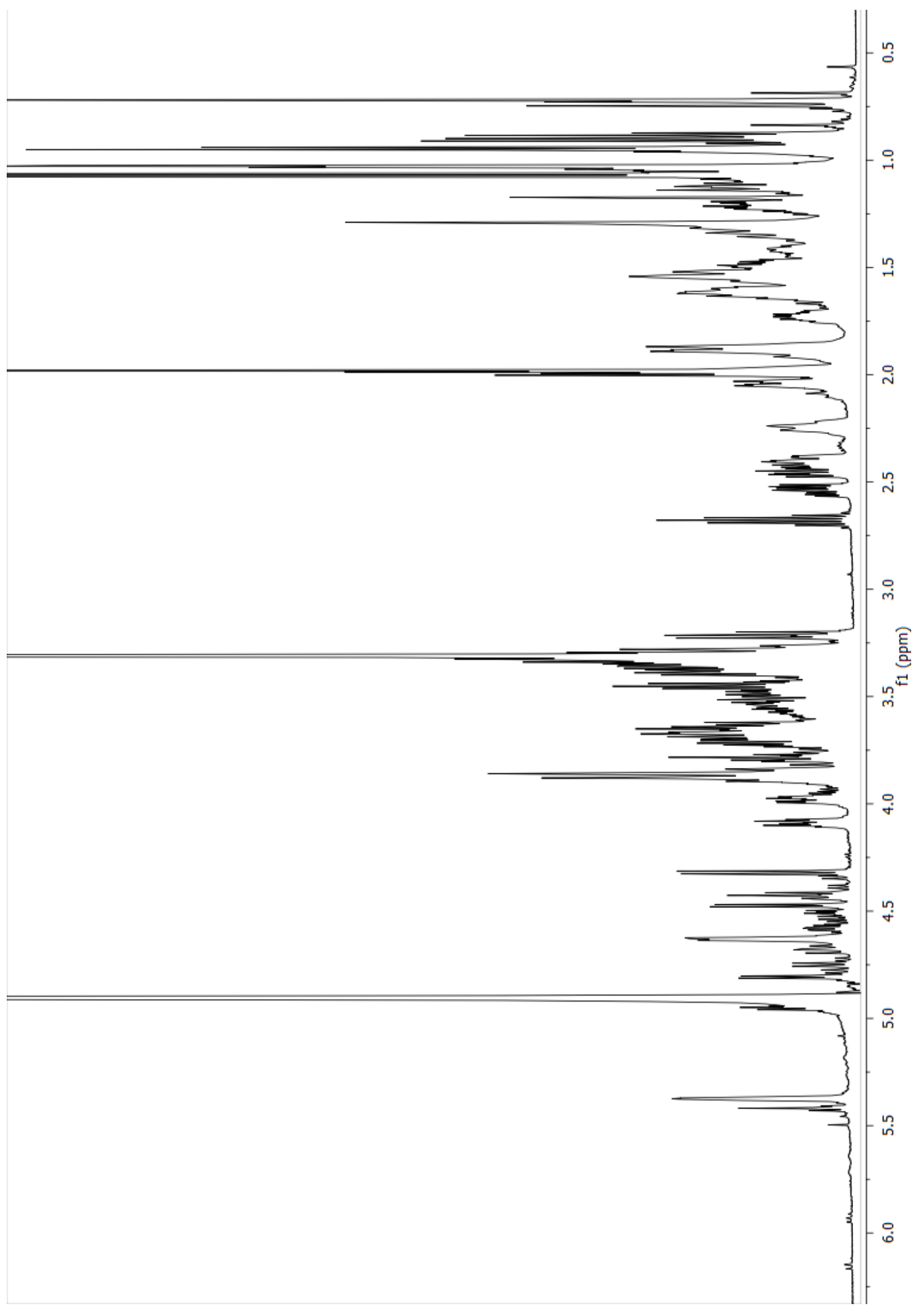

${ }^{1} \mathrm{H}$ NMR spectrum of raspailoside $\mathrm{A}(\mathbf{1 3 5})\left(600 \mathrm{MHz}, \mathrm{CD}_{3} \mathrm{OD}\right)$ 
Raspailoside A - HPLC Purification

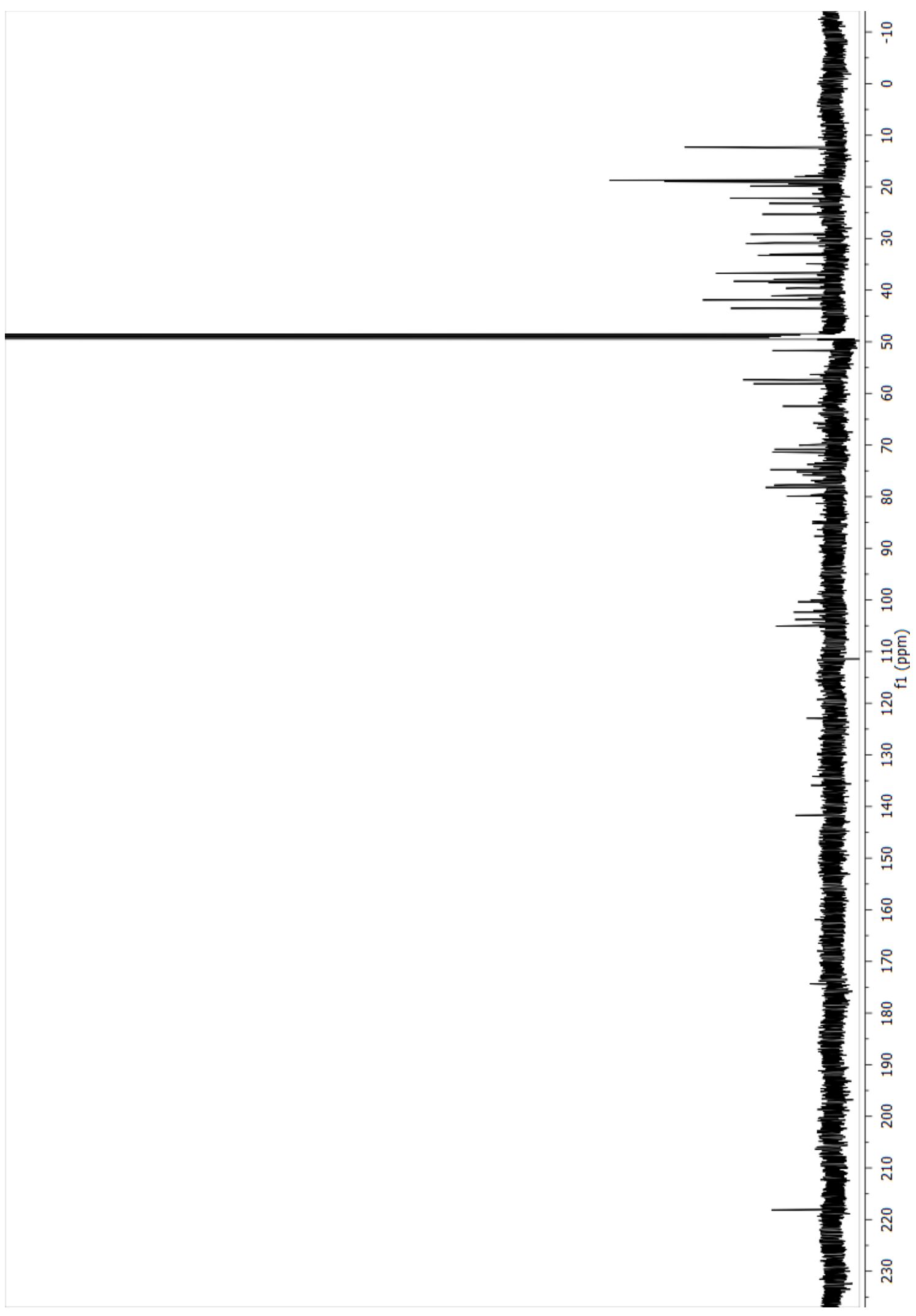

${ }^{13} \mathrm{C}$ NMR spectrum of raspailoside $\mathrm{A}(\mathbf{1 3 5})\left(150 \mathrm{MHz}, \mathrm{CD}_{3} \mathrm{OD}\right)$ 


\section{Raspailoside A - HPLC Purification}

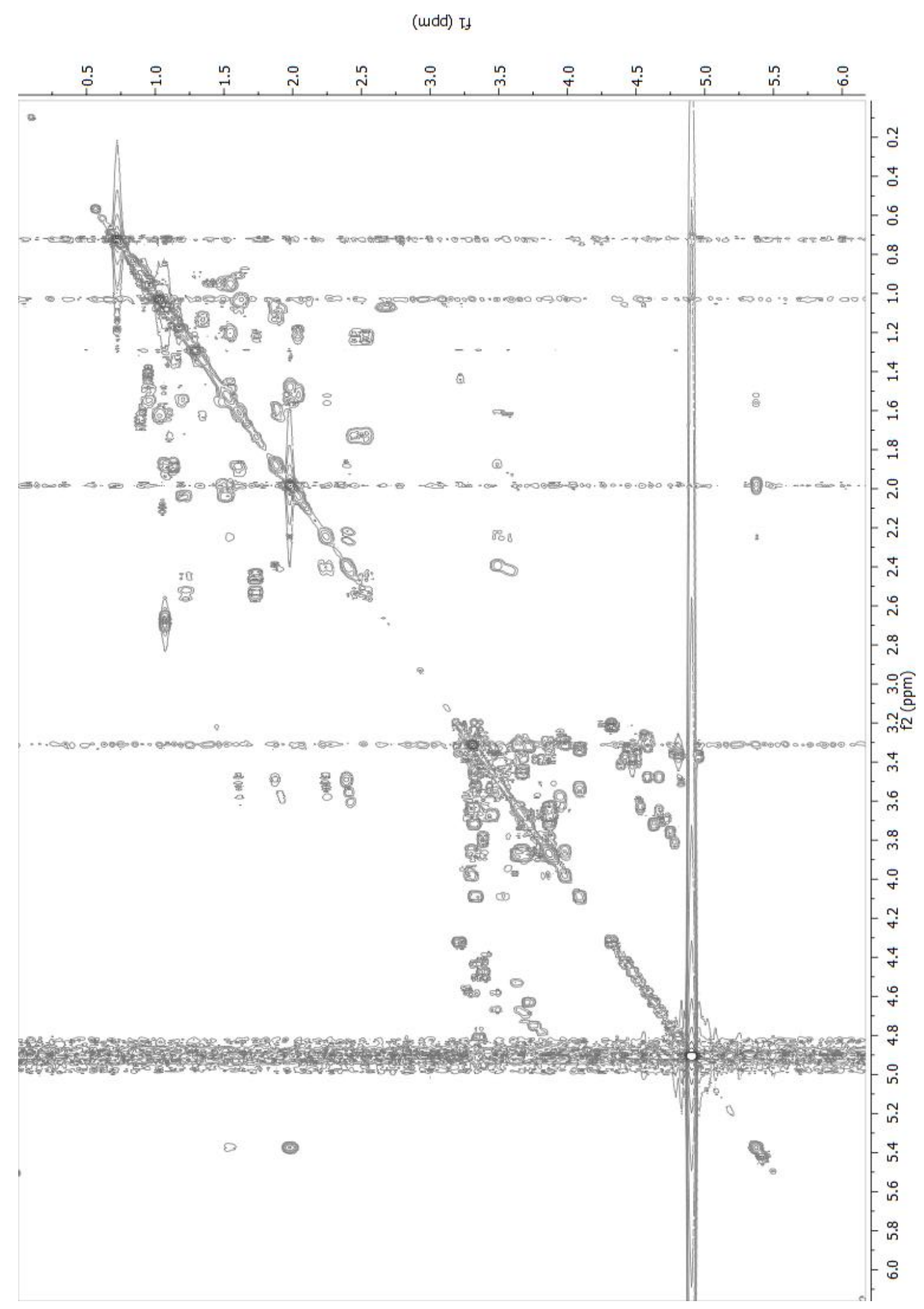

COSY NMR spectrum of raspailoside $A(135)\left(600 \mathrm{MHz}, \mathrm{CD}_{3} \mathrm{OD}\right)$ 
Raspailoside A - HPLC Purification

(udd) it

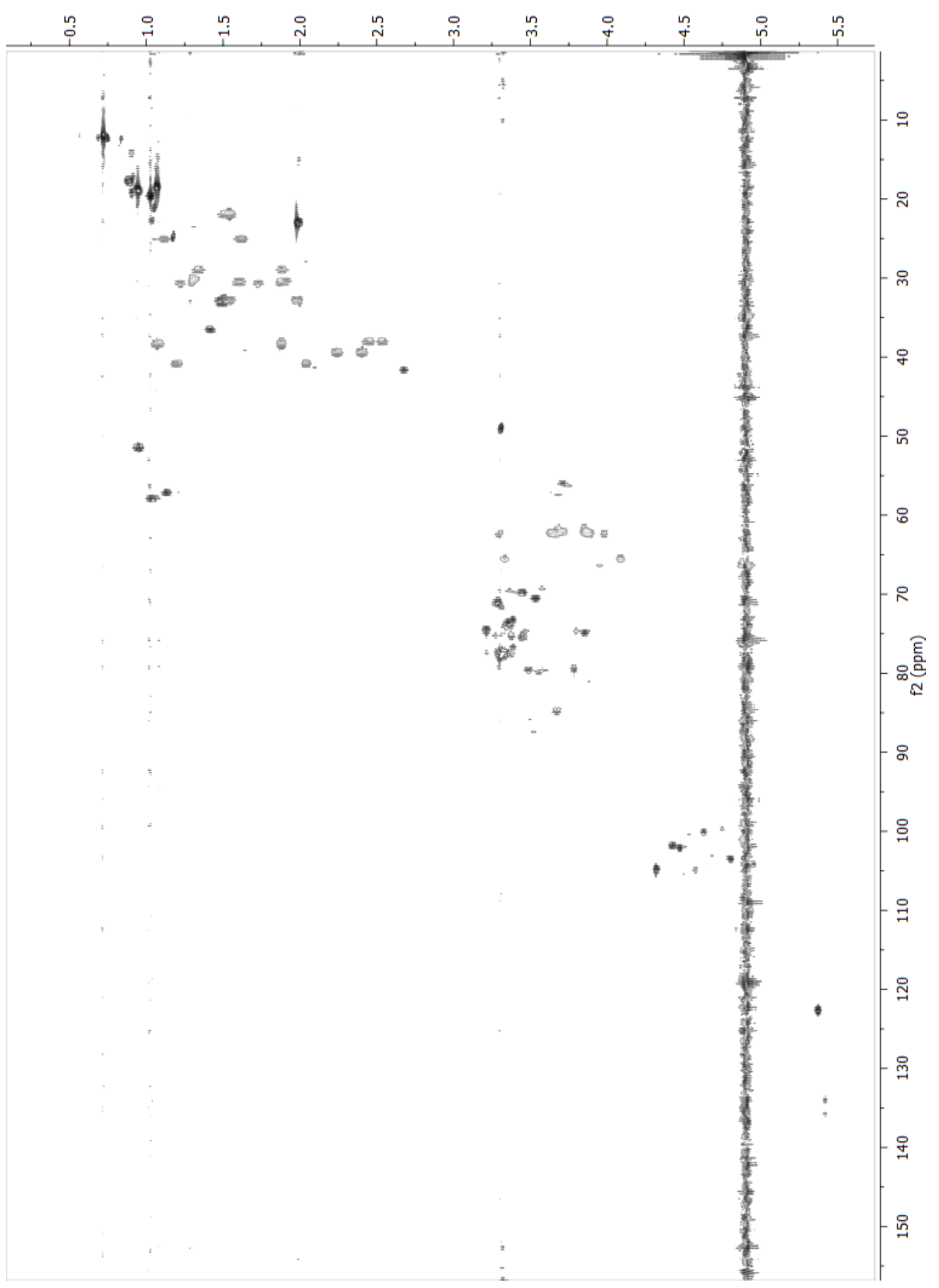

HSQC NMR spectrum of raspailoside $A(135)\left(600 \mathrm{MHz}, \mathrm{CD}_{3} \mathrm{OD}\right)$ 
Raspailoside A - HPLC Purification

(udd) if

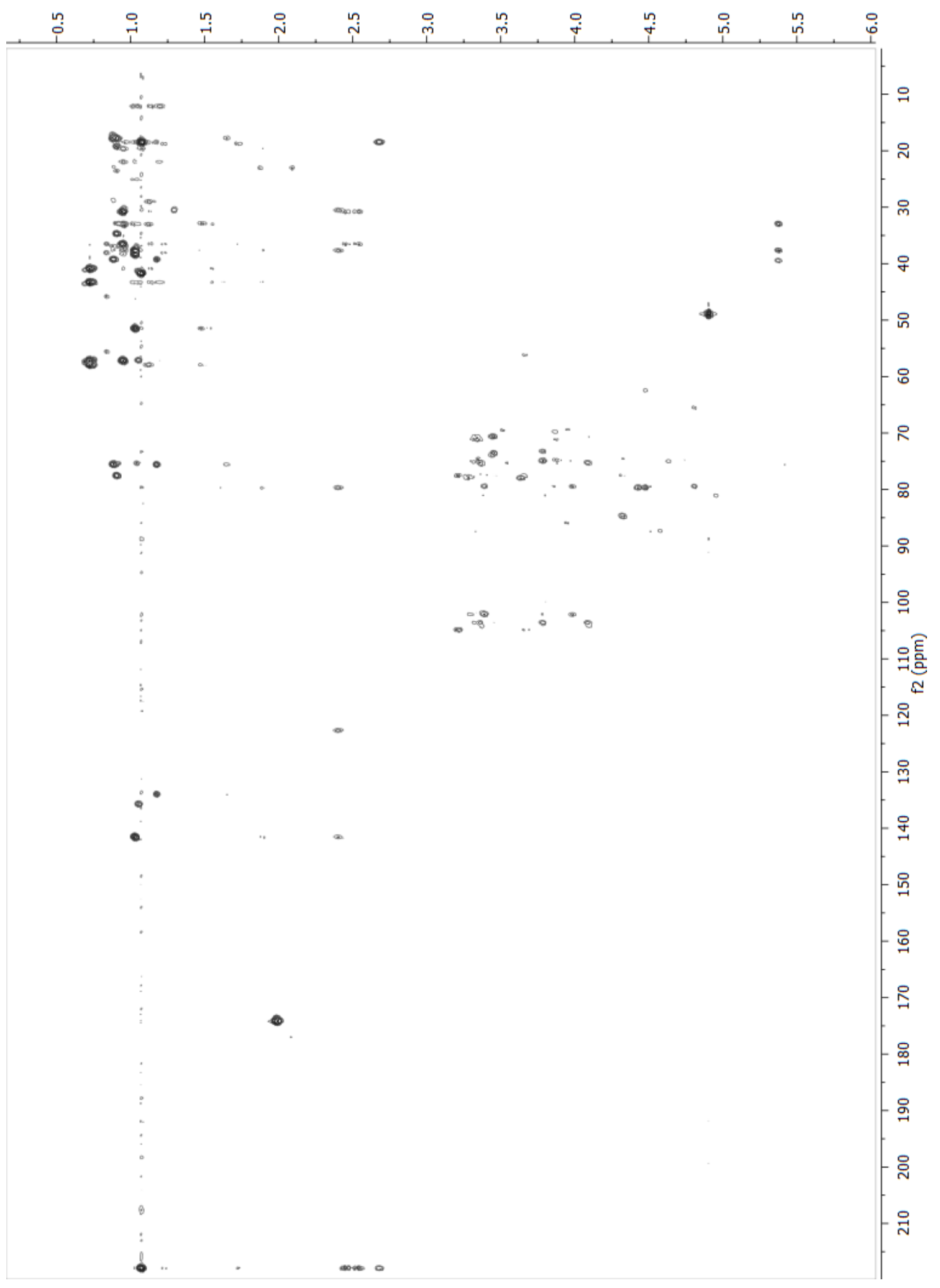

$\mathrm{HMBC}$ NMR spectrum of raspailoside $\mathrm{A}$ (135) (600 MHz, $\mathrm{CD}_{3} \mathrm{OD}$ ) 
Raspailoside A - LH20 Purification

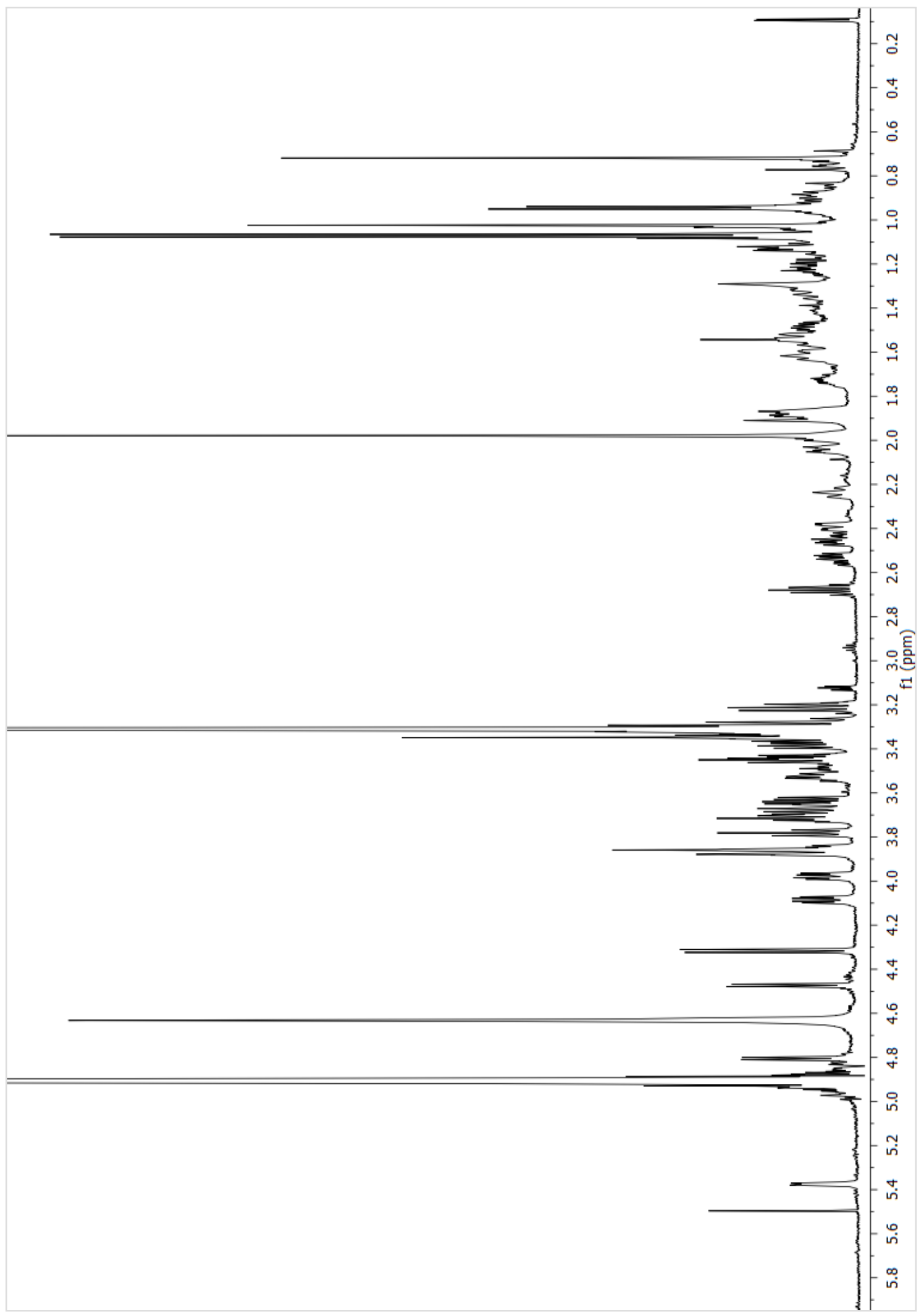

${ }^{1} \mathrm{H}$ NMR spectrum of raspailoside $\mathrm{A}(\mathbf{1 3 5})\left(600 \mathrm{MHz}, \mathrm{CD}_{3} \mathrm{OD}\right)$ 


\section{Raspailoside A - LH20 Purification}

(mdd) Tt

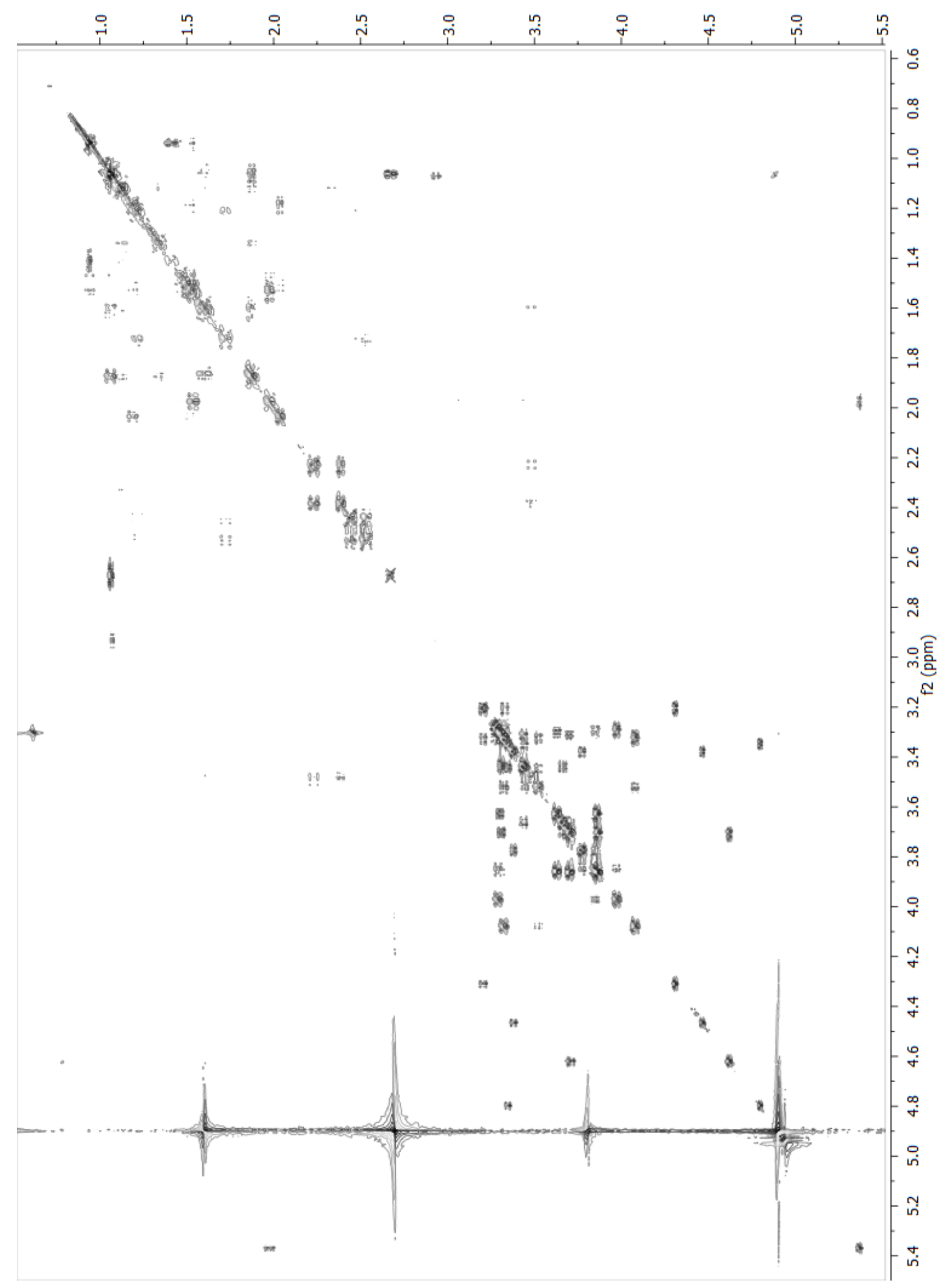

DQF COSY NMR spectrum of raspailoside $A(135)\left(600 \mathrm{MHz}, \mathrm{CD}_{3} \mathrm{OD}\right)$ 


\section{Raspailoside A - LH20 Purification}

(udd) it

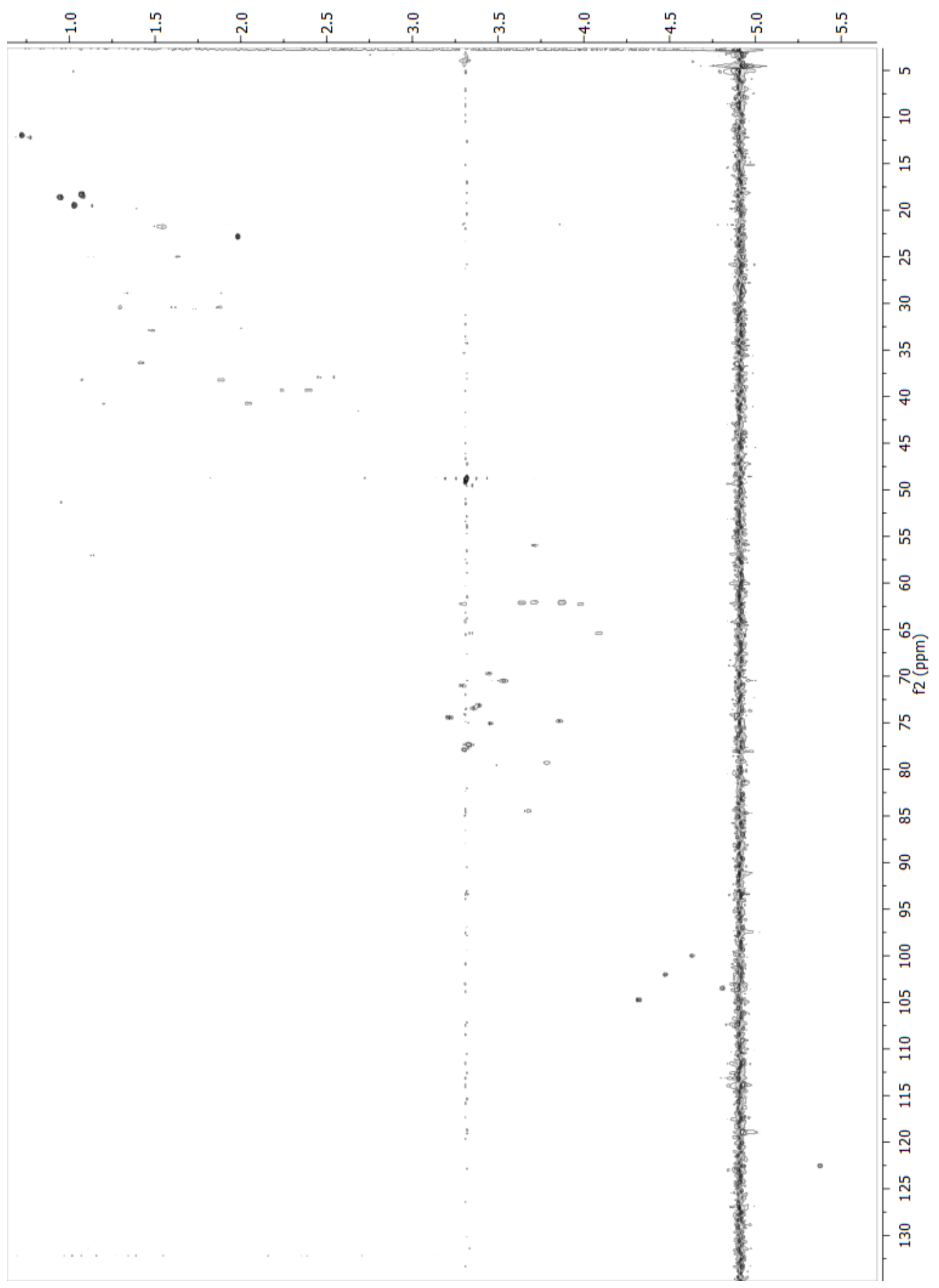

HSQC NMR spectrum of raspailoside $A(135)\left(600 \mathrm{MHz}, \mathrm{CD}_{3} \mathrm{OD}\right.$ ) 


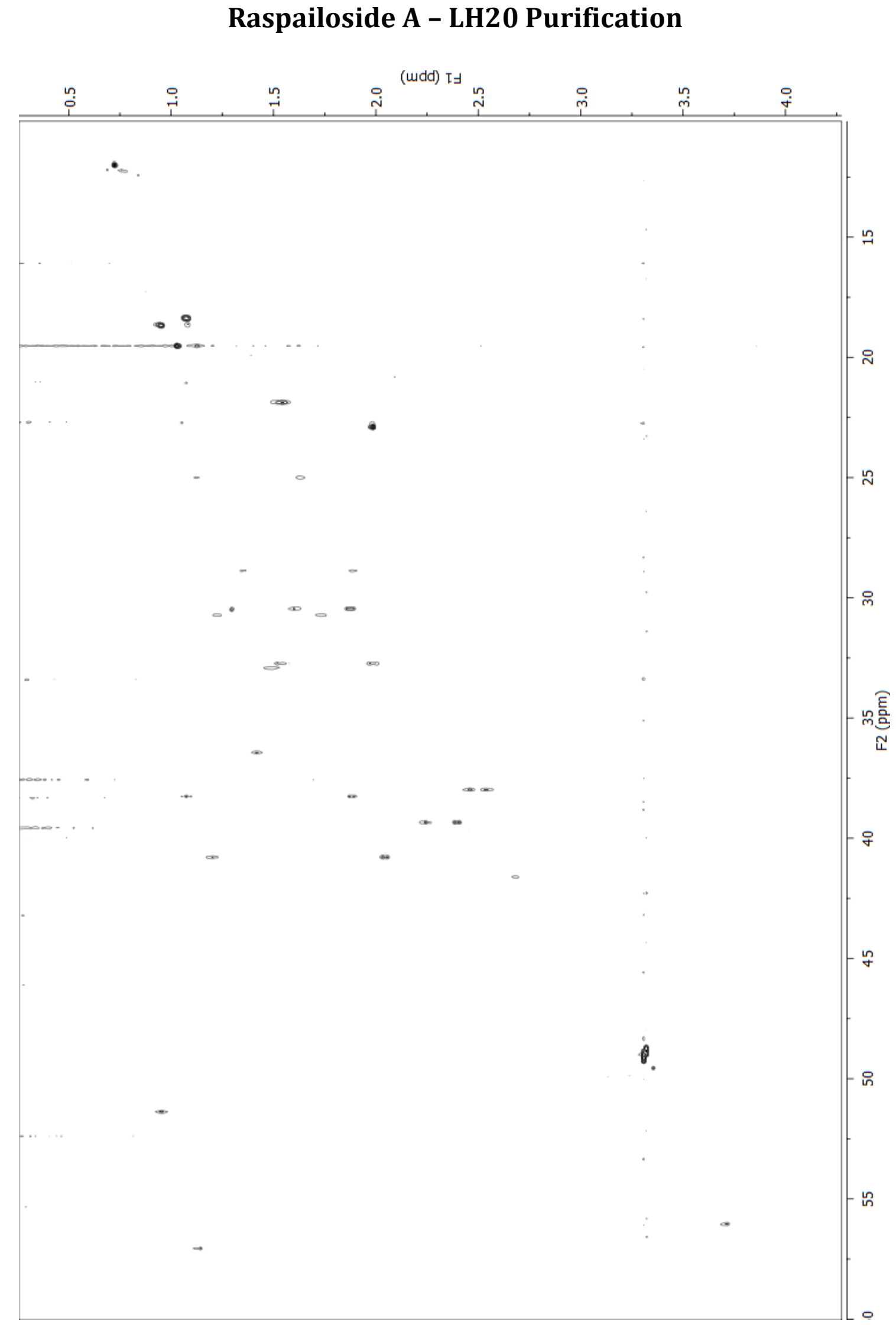

Band-selective HSQC NMR spectrum of raspailoside $A(135)\left(600 \mathrm{MHz}, \mathrm{CD}_{3} \mathrm{OD}\right)$ 
Raspailoside A - LH20 Purification

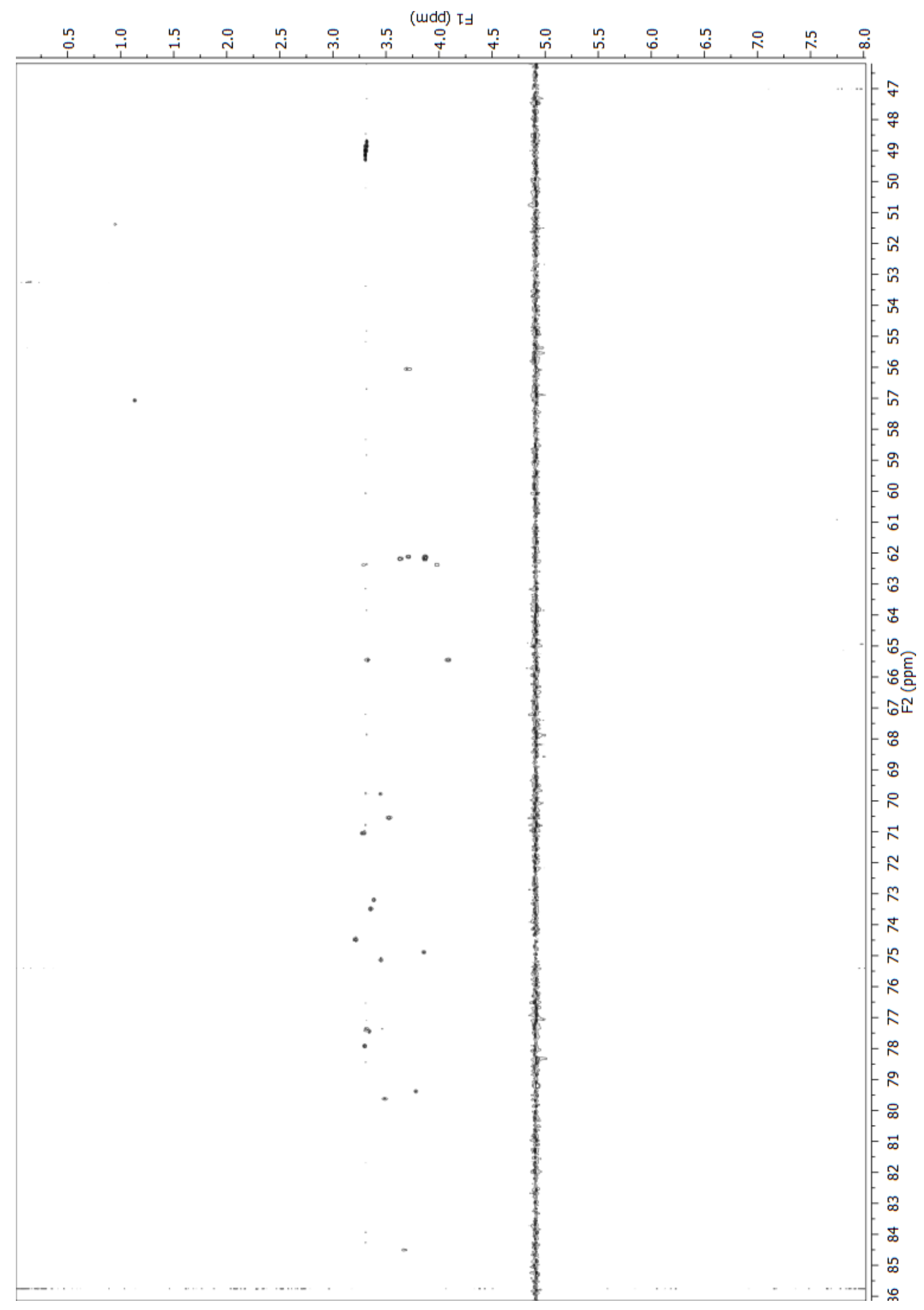

Band-selective HSQC NMR spectrum of raspailoside $A(135)\left(600 \mathrm{MHz}, \mathrm{CD}_{3} \mathrm{OD}\right)$ 
Raspailoside A - LH20 Purification

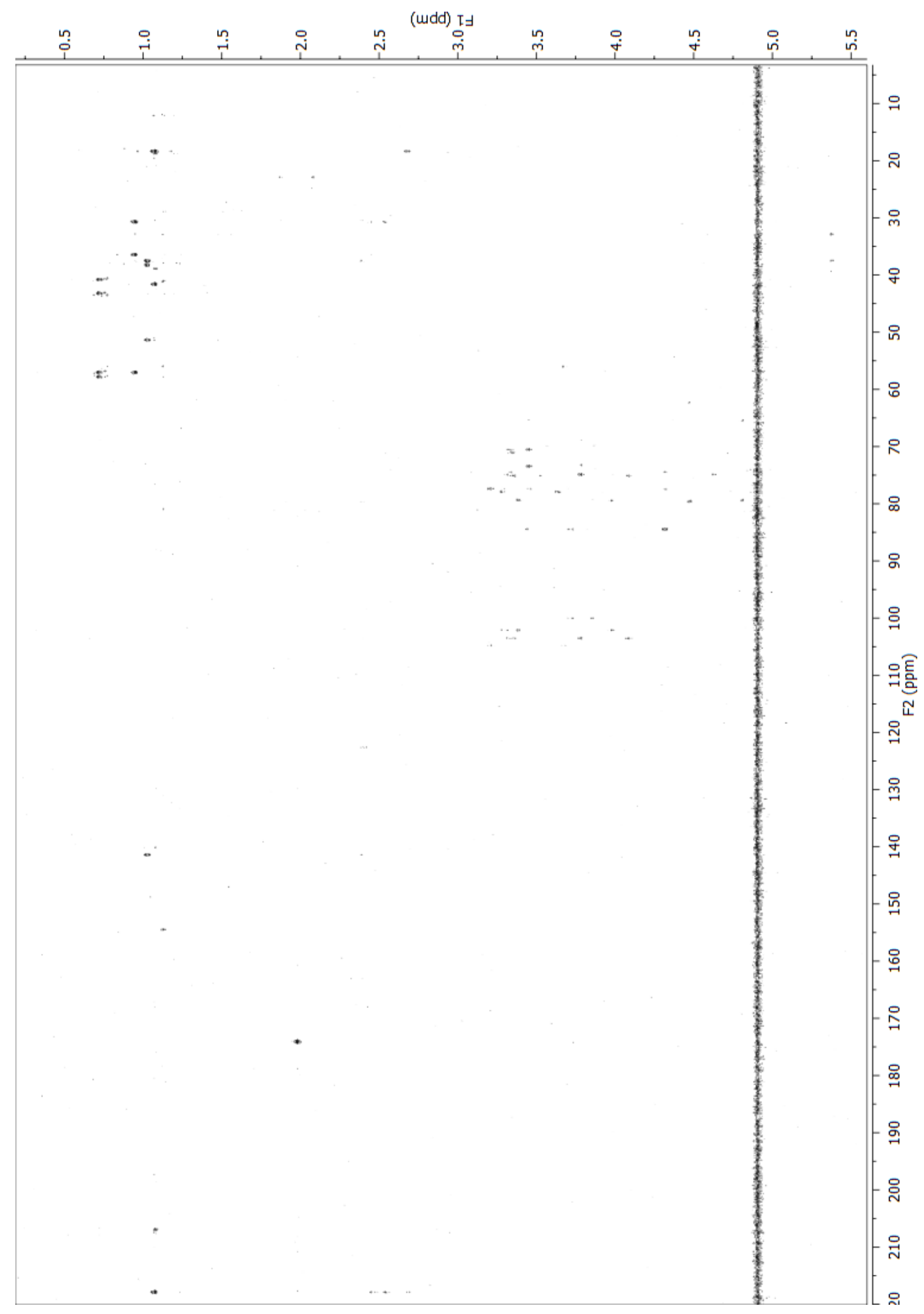

$\mathrm{HMBC}$ NMR spectrum of raspailoside $\mathrm{A}(135)\left(600 \mathrm{MHz}, \mathrm{CD}_{3} \mathrm{OD}\right)$ 


\section{References}

(1) Cragg, G. M.; Boyd, M. R.; Khanna, R.; Kneller, R.; Mays, T. D.; Mazan, K. D.; Newman, D. J.; Sausville, E. A. Pure and Applied Chemistry 1999, 71, 1619.

(2) Newman, D. J.; Cragg, G. M.; Snader, K. M. Natural Product Reports 2000, 17, 215.

(3) Li, J. W. H.; Vederas, J. C. Science 2009, 325, 161.

(4) Kupchan, S. M. In Advances in Chemistry 1971; Vol. 108, p 1

(5) Raynes, K. International Journal for Parasitology 1999, 29, 367.

(6) Grabley, S.; Thiericke, R.; Eds. Drug Discovery from Nature; Springer: Berlin, 1999.

(7) Fleming, A. British Journal of Experimental Pathology 1929, 60, 3.

(8) Baker, D. D.; Chu, M.; Oza, U.; Rajgarhia, V. Natural Product Reports 2007, 24, 1225.

(9) Haefner, B. Drug Discovery Today 2003, 8, 536.

(10) Newman, D. J.; Cragg, G. M. Journal of Natural Products 2004, 67, 1216.

(11) Bergmann, W.; Burke, D. C. Journal of Organic Chemistry 1955, 20, 1501.

(12) Bergmann, W.; Feeney, R. J. Journal of the American Chemical Society 1950, 72, 2809.

(13) Bergmann, W.; Feeney, R. J. Journal of Organic Chemistry 1951, 16, 981.

(14) Sipkema, D.; Franssen, M. C. R.; Osinga, R.; Tramper, J.; Wijffels, R. H. Marine Biotechnology 2005, 7, 142.

(15) Wright, K. Nature 1986, 323, 283.

(16) Marris, E. Nature 2006, 443, 904.

(17) Mayer, A. M. S.; Glaser, K. B.; Cuevas, C.; Jacobs, R. S.; Kem, W.; Little, R. D.; McIntosh, J. M.; Newman, D. J.; Potts, B. C.; Shuster, D. E. Trends in Pharmacological Sciences 2010, 31, 255.

(18) Blunt, J. W.; Munro, M. H. G. MarinLit, Marine Literature Database 2012

(19) Alonso, D.; Khalil, Z.; Satkunanthan, N.; Livett, B. G. Mini Reviews in Medicinal Chemistry 2003, 785.

(20) Miljanich, G. P. Current Medicinal Chemistry 2004, 11, 3029. 
(21) Thomas, T. R. A.; Kavlekar, D. P.; LokaBharathi, P. A. Marine Drugs 2010, 8, 1417.

(22) Althoff, K.; Schutt, C.; Steffen, R.; Batel, R.; Muller, W. E. G. Marine Biology 1998, 130, 529.

(23) Land Information New Zealand, www.linz.govt.nz

(24) Arnold, A.; WWF-New Zealand: Wellington, New Zealand, 2004, p 5.

(25) Perry, N. B.; Blunt, J. W.; Munro, M. H. G.; Pannell, L. K. Journal of the American Chemical Society 1988, 110, 4850.

(26) Perry, N. B.; Blunt, J. W.; Munro, M. H. G.; Thompson, A. M. Journal of Organic Chemistry 1990, 55, 223.

(27) Singh, A. J.; Xu, C.-X.; Xu, X.; West, L. M.; Wilmes, A.; Chan, A.; Hamel, E.; Miller, J. H.; Northcote, P. T.; Ghosh, A. K. Journal of Organic Chemistry 2010, 75, 2.

(28) West, L. M.; Northcote, P. T.; Battershill, C. N. Journal of Organic Chemistry 2000, 65, 445.

(29) West, L. M.; Northcote, P. T.; Hood, K. A.; Miller, J. H.; Page, M. J. Journal of Natural Products 2000, 63, 707.

(30) Konig, G. M.; Wright, A. D. Journal of Natural Products 1994, 57, 477.

(31) NationMaster, www.nationmaster.com

(32) Taufa, T. New Sesterterpenes from Marine Sponges from the Tropical Waters of the Kingdom of Tonga, MSc thesis, Victoria University of Wellington, 2010.

(33) Barber, J. M. Chemical and Biological Aspects of Secondary Metabolites from Tongan Marine Sponges, PhD thesis, Victoria University of Wellington, 2012.

(34) Blunt, J. W.; Calder, V. L.; Fenwick, G. D.; Lake, R. J.; McCombs, J. D.; Munro, M. H. G.; Perry, N. B. Journal of Natural Products 1987, 50, 290.

(35) Keyzers, R. A. Biologically Active Secondary Metabolites from New Zealand Marine Organisms, PhD thesis, Victoria University of Wellington, 2003.

(36) West, L. M. Biologically Active Secondary Metabolites from New Zealand Marine Organisms Ph.D thesis, Victoria University of Wellington, 2001.

(37) Koehn, F. E.; Carter, G. T. Nature Reviews Drug Discovery 2005, 4, 206. 
(38) Ryan, J. M. Novel Secondary Metabolites from New Zealand Marine Sponges, PhD thesis, Victoria University of Wellington, 2007.

(39) Ryan, J. M.; Northcote, P. T. Unpublished work, 2008

(40) Popplewell, W. L. Isolation and Structure Elucidation of New Secondary Metabolites from New Zealand Marine Red Algae, PhD thesis, Victoria University of Wellington, 2008.

(41) Singh, A. J. The Structure-Directed Isolation of New Secondary Metabolites from South Pacific Marine Sponges, PhD thesis, Victoria University of Wellington, 2012.

(42) Wojnar, J. Isolation of New Secondary Metabolites from New Zealand Marine Invertebrates, PhD thesis, Victoria University of Wellington, 2008.

(43) Bax, A.; Summers, M. F. Journal of the American Chemical Society 1986, 108, 2093.

(44) Smit, A. J. Journal of Applied Phycology 2004, 16, 245.

(45) Bold, H. C.; Wynne, M. J. INTRODUCTION TO THE ALGAE; 2nd ed.; Prentice Hall, Inc: New Jersey, 1985.

(46) Ireland, C. M.; Copp, B. R.; Foster, M. P.; McDonald, L. A.; Radisky, D. C.; Swersey, J. C. Marine Biotechnology 1993, 1, 1.

(47) Faulkner, D. J. Natural Product Reports 1984, 1, 251.

(48) Blackman, A. J.; Wells, R. J. Tetrahedron Letters 1978, 3063.

(49) Amico, V.; Oriente, G.; Piattelli, M.; Tringali, C.; Fattorusso, E.; Magno, S.; Mayol, L. Tetrahedron Letters 1978, 3593.

(50) Sun, H. H.; Fenical, W. Tetrahedron Letters 1979, 685.

(51) Capon, R. J.; Ghisalberti, E. L.; Jefferies, P. R. Australian Journal of Chemistry 1981, 34, 1775.

(52) Capon, R. J.; Ghisalberti, E. L.; Jefferies, P. R. Phytochemistry 1983, 22, 1465 .

(53) Paul, V. J.; Fenical, W. Tetrahedron Letters 1982, 23, 5017.

(54) Paul, V. J.; Sun, H. H.; Fenical, W. Phytochemistry 1982, 21, 468.

(55) Paul, V. J.; Fenical, W. Science 1983, 221, 747.

(56) Paul, V. J.; Fenical, W. Tetrahedron 1984, 40, 3053. 
(57) De Napoli, L.; Fattorusso, E.; Magno, S.; Mayol, L. Phytochemistry 1982, $21,782$.

(58) Hogberg, H. E.; Thomson, R. H.; King, T. J. Journal of the Chemical Society-Perkin Transactions 1 1976, 1696.

(59) McConnell, O. J.; Hughes, P. A.; Targett, N. M. Phytochemistry 1982, 21, 2139.

(60) Glombitza, K. W.; Forster, M.; Eckhardt, G. Phytochemistry 1978, 17, 579.

(61) Glombitza, K. W.; Geisler, C.; Eckhardt, G. Botanica Marina 1980, 23, 735.

(62) Glombitza, K. W.; Wiedenfeld, G.; Eckhardt, G. Archiv Der Pharmazie 1978, 311, 393.

(63) Koch, M.; Glombitza, K. W.; Eckhardt, G. Phytochemistry 1980, 19, 1821.

(64) Koch, M.; Glombitza, K. W.; Rosener, H. U. Phytochemistry 1981, 20, 1373.

(65) Glombitza, K. W.; Forster, M.; Farnham, W. F. Botanica Marina 1982, 25, 449.

(66) Glombitza, K. W.; Schnabel, C.; Koch, M. Archiv Der Pharmazie 1981, $314,602$.

(67) Gerwick, W. H.; Fenical, W. Journal of Organic Chemistry 1981, 46, 22.

(68) Gerwick, W. H.; Fenical, W.; Fritsch, N.; Clardy, J. Tetrahedron Letters 1979, 145.

(69) Gerwick, W. H.; Fenical, W.; Vanengen, D.; Clardy, J. Journal of the American Chemical Society 1980, 102, 7991.

(70) Bates, P.; Blunt, J. W.; Hartshorn, M. P.; Jones, A. J.; Munro, M. H. G.; Robinson, W. T.; Yorke, S. C. Australian Journal of Chemistry 1979, 32, 2545 .

(71) Blunt, J. W.; Hartshorn, M. P.; Munro, M. H. G.; Yorke, S. C. Tetrahedron Letters 1978, 4417.

(72) Suzuki, M.; Furusaki, A.; Kurosawa, E. Tetrahedron 1979, 35, 823.

(73) Suzuki, M.; Kurosawa, E.; Irie, T. Tetrahedron Letters 1974, 1807.

(74) Rose, A. F.; Sims, J. J.; Wing, R. M. Tetrahedron Letters 1978, 2533. 
(75) Blunt, J. W.; Hartshorn, M. P.; McLennan, T. J.; Munro, M. H. G.; Robinson, W. T.; Yorke, S. C. Tetrahedron Letters 1978, 69.

(76) Mahdi, F.; Falkenberg, M.; loannou, E.; Roussis, V.; Zhou, Y.-D.; Nagle, D. G. Phytochemistry Letters 2011, 4, 75.

(77) Kazlauskas, R.; Murphy, P. T.; Wells, R. J.; Blackman, A. J. Australian Journal of Chemistry 1982, 35, 113.

(78) Ankisetty, S.; Nandiraju, S.; Win, H.; Park, Y. C.; Amsler, C. D.; McClintock, J. B.; Baker, J. A.; Diyabalanage, T. K.; Pasaribu, A.; Singh, M. P.; Maiese, W. M.; Walsh, R. D.; Zaworotko, M. J.; Baker, B. J. Journal of Natural Products 2004, 67, 1295.

(79) Blunt, J. W.; Copp, B. R.; Keyzers, R. A.; Munro, M. H. G.; Prinsep, M. R. Natural Product Reports 2012, 29, 144.

(80) Blunt, J. W.; Copp, B. R.; Munro, M. H. G.; Northcote, P. T.; Prinsep, M. R. Natural Product Reports 2011, 28, 196.

(81) Gao, J.; Caballero-George, C.; Wang, B.; Rao, K. V.; Shilabin, A. G.; Hamann, M. T. Journal of Natural Products 2009, 72, 2172.

(82) Heo, S. J.; Hwang, J.-Y.; Choi, J.-I.; Han, J.-S.; Kim, H.-J.; Jeon, Y. J. European Journal of Pharmacology 2009, 615, 252.

(83) Jiang, Z. D.; Ketchum, S. O.; Gerwick, W. H. Phytochemistry 2000, 53, 129.

(84) Grechkin, A. Progress in Lipid Research 1998, 37, 317.

(85) Drazen, J. M.; Israel, E.; O'Byrne, P. M. New England Journal of Medicine 1999, 340, 197.

(86) Wang, W.; Okada, Y.; Shi, H. B.; Wang, Y. Q.; Okuyama, T. Journal of Natural Products 2005, 68, 620.

(87) Popplewell, W. L.; Northcote, P. T. Tetrahedron Letters 2009, 50, 6814.

(88) Dai, J. Q.; Zhu, Q. X.; Zhao, C. Y.; Yang, L.; Li, Y. Phytochemistry 2001, 58, 1305.

(89) Andersen, R. J.; Taglialatela-Scafati, O. Journal of Natural Products 2005, $68,1428$.

(90) Mishra, P. K.; Singh, N.; Ahmad, G.; Dube, A.; Maurya, R. Bioorganic \& Medicinal Chemistry Letters 2005, 15, 4543. 
(91) Gupta, P.; Yadav, D. K.; Siripurapu, K. B.; Palit, G.; Maurya, R. Journal of Natural Products 2007, 70, 1410.

(92) Zou, Y.; Li, Y.; Kim, M.-M.; Lee, S.-H.; Kim, S.-K. Biotechnology and Bioprocess Engineering 2009, 14, 20.

(93) Kusumi, T.; Ishitsuka, M.; Iwashita, T.; Naoki, H.; Konno, T.; Kakisawa, H. Chemistry Letters 1981, 1393.

(94) Gopichand, Y.; Schmitz, F. J. Tetrahedron Letters 1979, 3921.

(95) Gunasekera, S. P.; Cross, S. S. Journal of Natural Products 1992, 55, 509.

(96) Li, C. W.; Chen, J. Y.; Hua, T. E. Science 1998, 279, 879.

(97) Bergquist, P. R. Sponges; Hutchinson \& Co., 1978.

(98) World Porifera Database, www.marinespecies.org

(99) Hooper, J. N. A.; Van Soest, R. W. M. Systema Porifera: a guide to the classification of sponges. Volume 1; 1st ed.; Kluwer Academic/Plenum: New York, 2002.

(100) Van Soest, R. W. M.; Boury-Esnault, N.; Vacelet, J.; Dohrmann, M.; Erpenbeck, D.; De Voogd, N. J.; Santodomingo, N.; Vanhoorne, B.; Kelly, M.; Hooper, J. N. A. PloS one 2012, 7, e35105.

(101) Guella, G.; Mancini, I.; Pietra, F. Chemical Communications 1986, 77.

(102) Guella, G.; Mancini, I.; Pietra, F. Helvetica Chimica Acta 1987, 70, 1050.

(103) Cerda-garcia-rojas, C. M.; Faulkner, D. J. Tetrahedron 1995, 51, 1087.

(104) Czuba, I. R.; Zammit, S.; Rizzacasa, M. A. Organic \& Biomolecular Chemistry 2003, 1, 2044.

(105) Yosief, T.; Rudi, A.; Kashman, Y. Journal of Natural Products 2000, 63, 299.

(106) Yosief, T.; Rudi, A.; Stein, Z.; Goldberg, I.; Gravalos, G. M. D.; Schleyer, M.; Kashman, Y. Tetrahedron Letters 1998, 39, 3323.

(107) Rudi, A.; Shalom, H.; Schleyer, M.; Benayahu, Y.; Kashman, Y. Journal of Natural Products 2004, 67, 106.

(108) Rudi, A.; Aknin, M.; Gaydou, E.; Kashman, Y. Journal of Natural Products 2004, 67, 1932.

(109) Capon, R. J.; Skene, C.; Liu, E. H.; Lacey, E.; Gill, J. H.; Heiland, K.; Friedel, T. Natural Product Research 2004, 18, 305. 
(110) Saludes, J. P.; Lievens, S. C.; Molinski, T. F. Journal of Natural Products 2007, 70, 436.

(111) Wojnar, J. M.; Northcote, P. T. Journal of Natural Products 2011, 74, 69.

(112) Dendy, A. British Antarctic Terra Nova Expedition 1910 Zoology 1924, 6, 269.

(113) West, L. M.; Northcote, P. T.; Battershill, C. N. Australian Journal of Chemistry 1998, 51, 1097.

(114) Moraes, G. The Isolation and Structure Elucidation of Novel, Antiinflammatory Secondary Metabolites from New Zealand Marine Invertebrates, PhD thesis, Victoria University of Wellington, 2006.

(115) Dowle, K. O. New Nitrogenous Spongian Diterpenes from the New Zealand Marine Sponge Darwinella Oxeata, Honours thesis, Victoria University of Wellington, 2008.

(116) Claridge, T. D. W. High-Resolution NMR Techniques in Organic Chemistry; 2nd ed.; Elsevier: Oxford, 2009.

(117) Altunkeyik, H.; Gulcemal, D.; Masullo, M.; Alankus-Caliskan, O.; Piacente, S.; Karayildirim, T. Phytochemistry 2012, 73, 127.

(118) Bedir, E.; Kirmizipekmez, H.; Sticher, O.; Calis, I. Phytochemistry 2000, $53,905$.

(119) Colson, P.; King, R. R. Carbohydrate research 1976, 47, 1.

(120) Roslund, M. U.; Tahtinen, P.; Niemitz, M.; Sjoholm, R. Carbohydrate research 2008, 343, 101.

(121) Podlasek, C. A.; Wu, J.; Stripe, W. A.; Bondo, P. B.; Serianni, A. S. Journal of the American Chemical Society 1995, 117, 8635.

(122) Zhang, H.-J.; Sun, J.-B.; Lin, H.-W.; Wang, Z.-L.; Tang, H.; Cheng, P.; Chen, W.-S.; Yi, Y.-H. Natural Product Research 2007, 21, 953.

(123) Schmitz, F. J.; Ksebati, M. B.; Gunasekera, S. P.; Agarwal, S. Journal of Organic Chemistry 1988, 53, 5941.

(124) Kitagawa, I.; Kobayashi, M.; Okamoto, Y.; Yoshikawa, M.; Hamamoto, Y. Chemical \& Pharmaceutical Bulletin 1987, 35, 5036.

(125) Carmely, S.; Roll, M.; Loya, Y.; Kashman, Y. Journal of Natural Products 1989, 52, 167. 
(126) Hirota, H.; Takayama, S.; Miyashiro, S.; Ozaki, Y.; Ikegami, S. Tetrahedron Letters 1990, 31, 3321.

(127) Ryu, G.; Choi, B. W.; Lee, B. H.; Hwang, K. H.; Lee, U. C.; Jeong, D. S.; Lee, N. H. Tetrahedron 1999, 55, 13171.

(128) Cachet, N.; Regalado, E. L.; Genta-Jouve, G.; Mehiri, M.; Amade, P.; Thomas, O. P. Steroids 2009, 74, 746.

(129) Regalado, E. L.; Tasdemir, D.; Kaiser, M.; Cachet, N.; Amade, P.; Thomas, O. P. Journal of Natural Products 2010, 73, 1404.

(130) Regalado, E. L.; Turk, T.; Tasdemir, D.; Gorjanc, M.; Kaiser, M.; Thomas, O. P.; Fernandez, R.; Amade, P. Steroids 2011, 76, 1389.

(131) Barber, J. M., Personal Communication, 2012.

(132) Gottlieb, H. E.; Kotlyar, V.; Nudelman, A. Journal of Organic Chemistry $1997,62,7512$. 